\title{
Molecular Rhenium and Molybdenum-based (pre)catalysts for the deoxydehydration of vicinal diols and biomass-derived polyols
}

\author{
Moleculaire Rhenium- en Molybdeen-(pre)katalysatoren \\ voor de deoxydehydratatie van \\ vicinale diolen en, van biomassa-afgeleide, polyolen
}

(met een samenvatting in het Nederlands)

Proefschrift

ter verkrijging van de graad van doctor aan de Universiteit Utrecht op gezag van de rector magnificus, prof.dr. H.R.B.M. Kummeling ingevolge het besluit van het college voor promoties in het openbaar te verdedigen op woensdag 8 juli 2020 des middags te 2.30 uur

door

Jing Li

geboren op 12 oktober 1989 te Jiangsu, China 
Promotor: Prof. dr. R.J.M. Klein Gebbink

The work described in this Ph.D. thesis was financially supported by the China Scholarship Council (CSC). 
Molecular Rhenium and Molybdenum-based (pre)catalysts for the deoxydehydration of vicinal diols and biomass-derived polyols 
Li, Jing

Molecular Rhenium and Molybdenum-based (pre)catalysts for the deoxydehydration of vicinal diols and biomass-derived polyols

ISBN: 978-94-6375-957-1

The work described in this $\mathrm{PhD}$ thesis was carried out at:

Organic Chemistry and Catalysis, Debye Institute for Nanomaterials Science,

Faculty of Science, Utrecht University, Utrecht, The Netherlands

Print: Ridderprint $\mid$ www.ridderprint.nl.

Cover designer: 大吉设平面设计 


\section{Table of Contents}

Chapter 1 Homogeneous Transition Metal-Catalyzed Deoxydehydration of Biomass Derived Diols and Polyols

Chapter 2 A C $p^{\text {tt }}$-based Trioxo-Rhenium Catalyst for the Deoxydehydration of Diols and Polyols

Chapter 3 N-Donor Ligand Supported " $\mathrm{ReO}_{2}{ }^{+"}$ :

A Pre-Catalyst for the Deoxydehydration of Diols and Polyols

Chapter 4 A Cp-based Molybdenum Catalyst fort the Deoxydehydration of Biomass-derived Diols

Chapter 5 N,N,O-supported Tricarbonylrhenium Pre-catalysts for the Aerobic Deoxydehydration of Diols and Polyols

Summary

Samenvatting 



\title{
Chapter 1
}

\section{Homogeneous Transition Metal-Catalyzed Deoxydehydration of Biomass-Derived Diols and Polyols}

\begin{abstract}
Nowadays the depletion of fossil feedstocks asks for the development of alternative and more sustainable resources. Biomass is a quite attractive candidate. One of the big challenges in biomass conversion is the defunctionalization of the oxygen-rich platform molecules that are obtained after depolymerization of cellulosic biomass. Reactions such as dehydration, deoxygenation, and deoxydehydration (DODH) are well known methods to obtain less functionalized biomass derivatives. This chapter aims to provide the reader with a general overview of deoxydehydration reactions of vicinal diols and biomass derived polyols catalyzed by transition metal complexes, in terms of reported catalysts, their mechanism of operation, and their substrate scope. First of all, rhenium-catalyzed DODH is described, which includes systems using Cp-based trioxorhenium complexes $(\mathrm{Cp}=$ cyclopentadienyl $)$, methyltrioxorhenium, perrhenate, perrhenic acid and $\mathrm{Re}_{2} \mathrm{O}_{7}$ as catalysts. Additionally, DODH reactions initiated by low valent rhenium complexes are covered. Second, molecular molybdenum-based DODH catalysts are described. Commercial molybdate and a few dioxomolybdenum complexes are reported as active catalyst for deoxydehydration reactions. Last but not the least, a small number of vanadium-catalyzed DODH reactions are summarized in this chapter. Metavanadates and $\mathrm{N}, \mathrm{N}, \mathrm{O}$-tridentate ligand supported dioxovanadium complexes are the only reported vanadium catalysts for the DODH of diols and polyols.
\end{abstract}




\subsection{Introduction}

The anticipated depletion of fossil hydrocarbon resources, along with a gradual increase in cost, calls for the development of new supply chains for the chemical industry that rely on renewable feedstocks, such as biomass. ${ }^{[1,2]}$ The small molecules obtained from the degradation of lignin and cellulosic biomass are typically of high-oxygen content and over-functionalized, e.g. sugars contain approximately one oxygen atom per carbon atom. In this case, the direct substitution of the traditional under-functionalized hydrocarbon feedstocks with biomass-derived resources gives rise to several challenges. While traditional synthetic routes often involve the introduction of functionalities on carbon backbones, we now need to defunctionalize oxygen-rich molecules. ${ }^{[3]}$ Formal deoxygenation reactions are required to realize the conversion of, e.g., non-edible, low-value sugars and sugar-derived compounds into low-volume, high-value chemicals.

To address this problem, a range of reductive deoxygenation methods via heterogeneous or homogeneous catalysis, e.g., hydrodeoxygenation, ${ }^{[4]}$ hydrogenolysis, ${ }^{[5]}$ decarbonylation, ${ }^{[6]}$ decarboxylation $^{[7]}$ or direct deoxygenation, ${ }^{[8-10]}$ are currently investigated. Remarkably, the combination of deoxygenation and dehydraton reactions offers a formal deoxydehydration (DODH), efficiently converting a vicinal diol into an olefin with release of one oxygen atom and one water molecule. ${ }^{[1-14]}$ In order to realize the deoxydehydration of oxygen-rich molecules, an oxophilic metal catalyst is required. Late transition elements are normally not oxophilic enough to abstract oxygen atoms, while early transition elements prefer to form strong metal-oxygen bonds which are difficult to be cleaved through reduction, that is the catalyst cannot be regenerated. For this reason, the elements in the middle of the transition series, e. g., V, Mo, W, Re, are a good choice for the development of catalysts suitable for the DODH of biobased polyols. Among these, rhenium is the most explored metal, probably due to its large number of accessible oxidation states, as well as its ability to form strong bonds to ligands which will then allow tuning of catalytic performance by ligand modification. ${ }^{[11,12]}$ However, the scarcity and high cost of rhenium asks for the availability of alternative catalysts based on less expensive metals, such as Mo and V. ${ }^{[13]}$

This chapter is aimed at providing the reader with a background on the organometallic oxidecatalyzed deoxydehydration of biomass-derived diols and polyols. It starts with the description of rhenium-based catalysts/pre-catalysts. Accordingly, Cp-based trioxo-rhenium complexes, methyltrioxorhenium (MTO), perrhenate (perrhenic acid), as well as other rhenium-based 
catalyst/pre-catalyst are descibed in some detail, together with corresponding mechanistic studies. The chapter then continues with a description of molybdenum-based catalysts for deoxydehydration of diols and polyols and with a section that describes the different mechanisms involved in the Mo-catalyzed DODH systems. Finally, a selection of examples of vanadium-catalyzed DODH is presented, followed by an outline of the aim and scope of this thesis.

\subsection{Rhenium-Based Catalysts/Pre-Catalysts for DODH}

\subsubsection{Cp-based Trioxo-Rhenium Complexes}

High-valent trioxo-rhenium complexes are well known catalysts for the deoxydehydration of diols and polyols. In 1996, the first catalytic deoxydehydration was reported by Cook and Andrews. ${ }^{[15]} \mathrm{Cp}^{*} \mathrm{ReO}_{3}\left(\mathrm{Cp}^{*}=1,2,3,4,5\right.$-pentamethylcyclopentadienyl) was used as catalyst for the deoxydehydration of 1-phenyl-1,2-ethanediol and biomass-based erythritol, as well as, 1,2:5,6-diisopropylidene-D-mannitol with quite good olefin product yield, while $\mathrm{PPh}_{3}$ was applied as sacrificial reductant (Scheme1).

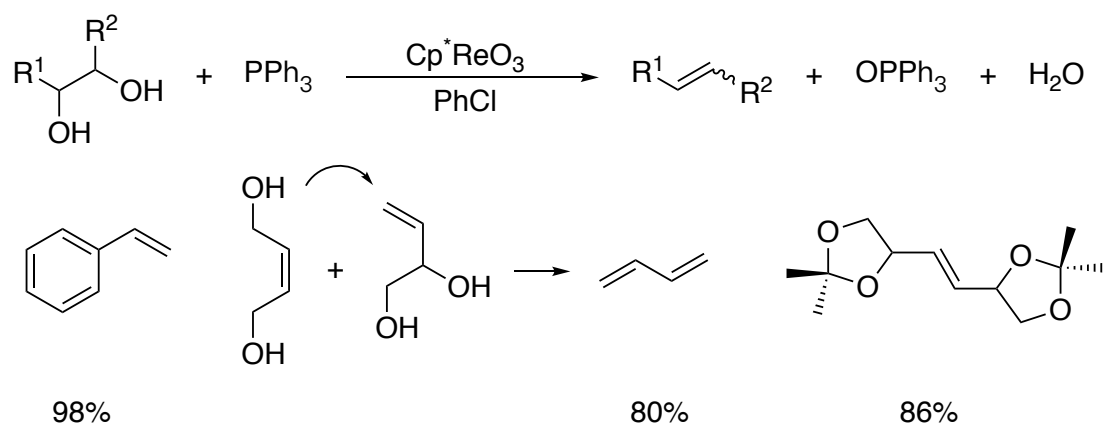

Scheme 1. $\mathrm{Cp}^{*} \mathrm{ReO}_{3}$-catalyzed deoxydehydration. ${ }^{[15]}$

A catalytic cycle was proposed based on stoichiometric studies by Gable (Scheme 2). ${ }^{[16,17]}$ In the first step, $\mathrm{Cp}^{*} \mathrm{ReO}_{3}$ is reduced by $\mathrm{PPh}_{3}$ to form the active dioxo complex $\mathrm{Cp}^{*} \mathrm{ReO}_{2}$, which is in equilibrium with its $\mu$-oxo-bridged dimer $\left[\mathrm{Cp}^{*} \mathrm{Re}^{\mathrm{V}}(\mathrm{O})(\mu-\mathrm{O})\right]_{2} \cdot \mathrm{Cp}^{*} \mathrm{ReO}_{2}$ then condensates with a diol substrate to generate the $\mathrm{Cp}^{*} \mathrm{ReO}$ (diolate), followed by olefin extrusion to regenerate $\mathrm{Cp}^{*} \mathrm{ReO}_{3}$. Besides, an over-reduced $\mathrm{Re}^{\mathrm{III}}$ complex was proposed as a catalytically inactive species formed during the catalytic cycle on basis of experimental data obtained by Cook and Andrews. The over-reducing of $\mathrm{Cp}^{*} \mathrm{ReO}_{2}$ was then proposed as the deactivation of the catalyst. The use of $p$-toluenesulfonic acid to accelerate the formation of the diolate or of the less reducing $\mathrm{P}\left(\mathrm{C}_{6} \mathrm{~F}_{5}\right)_{3}$ could inhibit the deactivation of catalyst in this reaction system. 


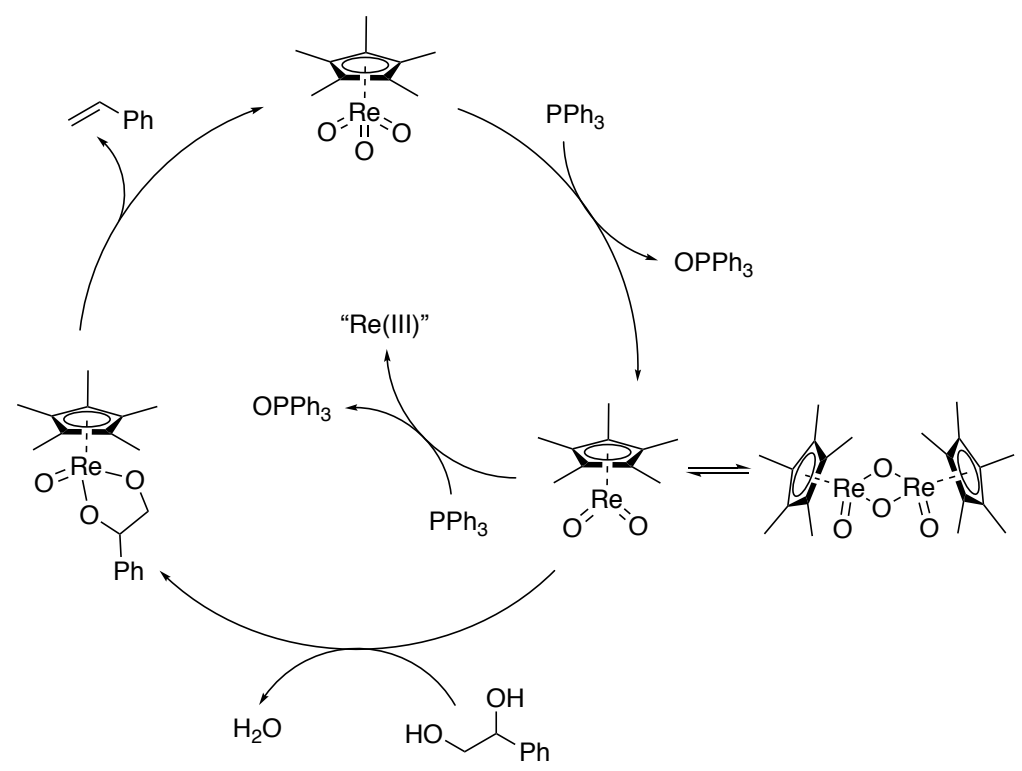

Scheme 2. Proposed catalytic cycle of $\mathrm{Cp}^{*} \mathrm{ReO}_{3}$-catalyzed deoxydehydration. ${ }^{[15]}$

Later on, an ionic tetranuclear cluster (1) was reported by Gable's group (Scheme 3). ${ }^{[18]} \mathbf{1}$ was formed via comproportionation of $\mathrm{Cp}^{*} \mathrm{ReO}_{3}$ and $\mathrm{Cp}^{*} \mathrm{ReO}_{2}$ (or $\left[\mathrm{Cp}^{*} \mathrm{Re}^{\mathrm{V}}(\mathrm{O})(\mu-\mathrm{O})\right]_{2}$ ). In the presence of oxygen transfer reagents $\left(\mathrm{Cp}^{*} \mathrm{ReO}_{3}\right.$ or DMSO), 1 would be further oxidized to form a dicationic trinuclear cluster (2), which was also observed by Herrmann. ${ }^{[19]}$ The formation of these tetranuclear/trinuclear clusters was proposed as an alternative catalyst decomposition pathway. Gable claimed that further ligand development could realize inhibition of cluster formation, in which way a long-lived catalyst could be discovered. ${ }^{[18]}$

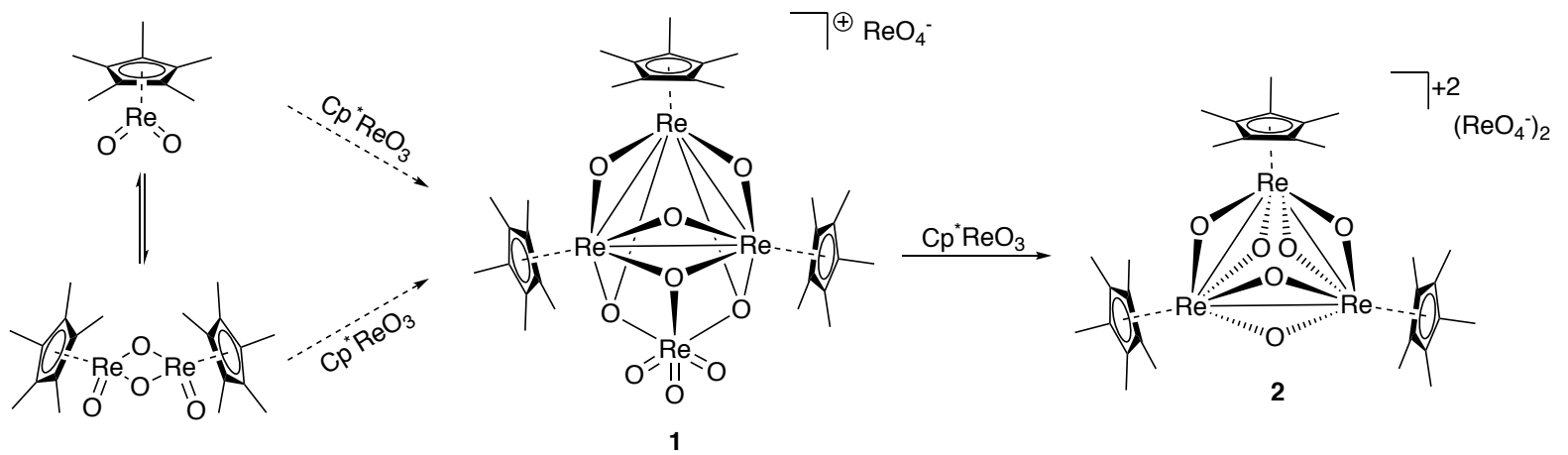

Scheme 3. Catalyst decomposition pathway of $\mathrm{Cp}^{*} \mathrm{ReO}_{3}$-catalyzed deoxydehydration system. ${ }^{[18]}$

In 2013, a new Cp-based trioxo-rhenium complex, 1,2,4-tri(tert-butyl)cyclopentadienyl trioxorhenium $\left(\mathrm{Cp}^{\mathrm{ttt}} \mathrm{ReO}_{3}\right)$, was reported by Klein Gebbink as a DODH catalyst. ${ }^{[20]}$ The aim of the use of the bulky $\mathrm{Cp}^{\text {ttt }}$ ligand was to avoid the formation of clusters during catalysis to achieve a long life time of the catalyst. This reaction system was optimized using $2 \mathrm{~mol} \%$ of $\mathrm{Cp}^{\mathrm{ttt}} \mathrm{ReO}_{3}$ as catalyst, 1.1 equiv. of $\mathrm{PPh}_{3}$ as reductant, and $\mathrm{PhCl}$ as solvent. Both aromatic and alphatic vicinal diols could be converted into the corresponding olefins in good to excellent 
yields. Remarkably, a high turnover number (TON) of 1400 per Re was achieved for the deoxydehydration of 1,2-octanediol. Comparing with the initial 55 TON per Re of the $\mathrm{Cp}^{*} \mathrm{ReO}_{3}$-catalyzed deoxydehydration system, ${ }^{[15]}$ the very high TON obtained with $\mathrm{Cp}^{\mathrm{ttt}} \mathrm{ReO}_{3}$ indicated that the use of a bulky ligand improved catalyst stability. By treating $\mathrm{Cp}^{\mathrm{ttt}} \mathrm{ReO}_{3}$ with equivalent amounts of $\mathrm{PPh}_{3}$, the dinuclear $\left[\mathrm{Cp}^{\text {ttt }} \mathrm{Re}(\mathrm{O})(\mu-\mathrm{O})\right]_{2}(4)$ was synthesized (Scheme 4). A variable temperature ${ }^{1} \mathrm{H}$ NMR study of $\left[\mathrm{Cp}^{\mathrm{ttt}} \mathrm{Re}(\mathrm{O})(\mu-\mathrm{O})\right]_{2}(4)$ showed that the use of the bulky ligand shifted the equilibium between $\mathrm{Cp}^{\mathrm{ttt}} \mathrm{ReO} \mathrm{O}_{2}$ and $\left[\mathrm{Cp} \mathrm{p}^{\mathrm{ttt}} \mathrm{Re}(\mathrm{O})(\mu-\mathrm{O})\right]_{2}$ to the mononuclear side (Scheme 4), that is, lowering the fraction of the metal present in the inactive dimeric form under catalytic conditions. ${ }^{[21]}$ In this way, catalyst decompositon via rhenium cluster formation was slowed down.

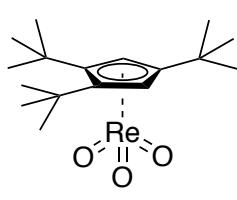

$\mathrm{Cp}^{\mathrm{ttt}} \mathrm{ReO}_{3}$

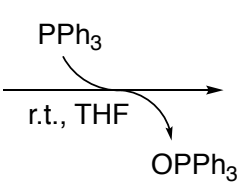

$\mathrm{OPPh}_{3}$

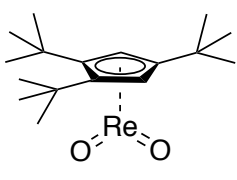

3

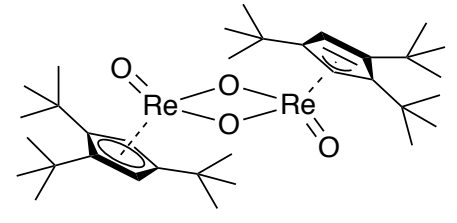

4

Scheme 4. Synthesis of $\left[\mathrm{Cp}{ }^{\text {ttt }} \operatorname{Re}(\mathrm{O})(\mu-\mathrm{O})\right]_{2}{ }^{[21]}$

Encouraged by the excellent catalytic performance of $\mathrm{Cp}^{\text {ttt }} \mathrm{ReO}_{3}$ towards deoxydehydration of diols and polyols, a series of $\mathrm{Cp}$-based trioxo-rhenium complexes were then synthesized by Klein Gebbink et al. aiming to realize further catalyst optimization (Figure 1). ${ }^{[22]}$ These Cpbased trioxo-rhenium complexes were synthesized via oxidative decarbonylation of the corresponding tricarbonyl precursor by using aqueous $\mathrm{H}_{2} \mathrm{O}_{2}$ or $t \mathrm{BuOOH}$ as the oxidant. The formation of trioxo-rhenium complexes was followed by in situ ${ }^{1} \mathrm{H}$ NMR experiments while heating the tricarbonyl precursor with $t \mathrm{BuOOH}$ in deuterated benzene at $50{ }^{\circ} \mathrm{C}$. The decomposition of the $\mathrm{Cp}^{\prime} \mathrm{ReO}_{3}$ complex ( $\mathrm{Cp}^{\prime}=$ substituted cyclopentadienyl) was observed while keeping the mixtures for an extended reaction time. The per-alkylated $\mathrm{Cp}^{*} \mathrm{ReO}_{3}$ and $\left(\mathrm{CpEtMe}_{4}\right) \mathrm{ReO}_{3}$ complexes were exceptionally stable under these conditions, no decomposition was observed. The reaction time of oxidative decarbonylation was optimized to be $c a .30 \mathrm{~min}$. Under this optimized condition, the synthesis of $\left(\mathrm{CptBu}_{2} \mathrm{H}_{3}\right) \mathrm{ReO}_{3}(18 \%)$, $\left(\mathrm{Cp} i \mathrm{Pr}_{3} \mathrm{H}_{2}\right) \mathrm{ReO}_{3}(4 \%),\left(1,2,3-\mathrm{Me}_{3}\right.$ (tetrahydroindenyl)) $\mathrm{ReO}_{3}(36 \%)$, and $\left(\mathrm{CpMe}_{4} \mathrm{H}\right) \mathrm{ReO}_{3}(33 \%)$ was achieved.

All these Cp-based trioxo-rhenium complexes were found active in catalytic DODH of 1,2octanediol with excellent 1 -octene yield. The modification of both the electronic and steric properties of the ligand have an effect on catalysis: upon increase of electron density of Cp', that is from $\mathrm{Cp}^{*} \mathrm{ReO}_{3}$ to $(\mathrm{CpEtMe}) \mathrm{ReO}_{3}$ and $\left(1,2,3-\mathrm{Me}_{3}\right.$ (tetrahydroindenyl)) $\mathrm{ReO}_{3}$, catalyst 
stability decreased, while catalytic activity increased. In case of using a less bulky $\mathrm{Cp}^{\text {tt }}$ ligand instead of the $\mathrm{Cp}^{\text {ttt }}$ ligand, $\mathrm{Cp}^{\mathrm{tt}} \mathrm{ReO}_{3}$ was much less stable than $\mathrm{Cp}^{\mathrm{ttt}} \mathrm{ReO}_{3}$, although they had quite similar catalytic activity. Besides, the modifications of the $\mathrm{Cp}$ ' ligand also affected product distribution. The use of per-alkylated $\mathrm{Cp}$-ligated catalysts gave more 2-octene isomers than their less substituted counterparts at a higher reaction temperature $\left(180{ }^{\circ} \mathrm{C}\right)$. At a lower reaction temperature $\left(135{ }^{\circ} \mathrm{C}\right)$, no isomers were obtained while $\mathrm{Cp}^{\mathrm{tt}} \mathrm{ReO}_{3},\left(\mathrm{Cp} \mathrm{Pr}_{3} \mathrm{H}_{2}\right) \mathrm{ReO}_{3}$, $\left(1,2,3-\mathrm{Me}_{3}\right.$ (tetrahydroindenyl) $\mathrm{ReO}_{3}$, and $\left(\mathrm{CpMe}_{4} \mathrm{H}\right) \mathrm{ReO}_{3}$ was used as catalyst.
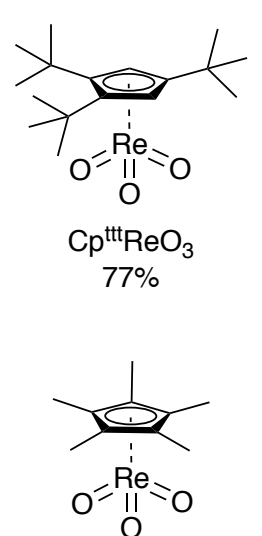

$\mathrm{Cp}^{\star} \mathrm{ReO}_{3}$ $70 \%$

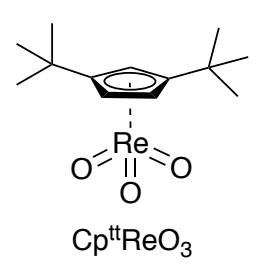

$18 \%$

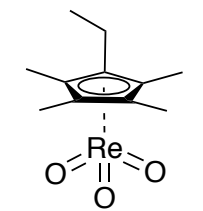

$\left.(\mathrm{CpEtMe})_{4}\right) \mathrm{ReO}_{3}$

$44 \%$

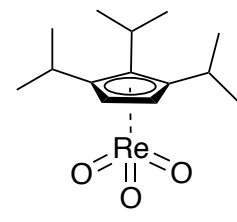

$\left(\mathrm{Cp} / \mathrm{Pr}_{3} \mathrm{H}_{2}\right) \mathrm{ReO}_{3}$
$4 \%$

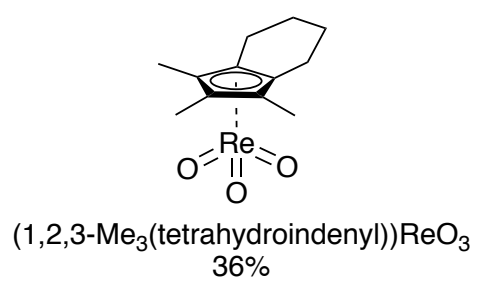

$\left(1,2,3-\mathrm{Me}_{3}\right.$ (tetrahydroindenyl)) $\mathrm{ReO}_{3}$ $36 \%$

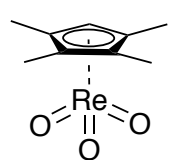

$\left(\mathrm{CpMe}_{4} \mathrm{H}\right) \mathrm{ReO}_{3}$ $33 \%$

Figure 1. Cp-based trioxo-rhenium complexes. ${ }^{[22]}$

By following the deoxydehydration of 1,2-octanediol via an ${ }^{1} \mathrm{H}$ NMR experiment, the timecourse profiles of $\mathrm{Cp}^{\prime} \mathrm{ReO}_{3}$-catalyzed deoxydehydration were recorded. Zero-order kinetics in substrate was observed in all cases. No induction period was observed when $\mathrm{Cp}^{\text {tt }} \mathrm{ReO}_{3}$ or $(1,2,3-$ $\mathrm{Me}_{3}$ (tetrahydroindenyl)) $\mathrm{ReO}_{3}$ were used as catalyst. In case of using $\mathrm{Cp}^{\mathrm{ttt}} \mathrm{ReO}_{3}$ or $\mathrm{Cp}^{*} \mathrm{ReO}_{3}$ as catalyst, an induction period was observed. Last but not the least, the former two Cp-based trioxo-rhenium complexes catalyzed the DODH of 1,2-octanediol was much faster than the latter two.

\subsubsection{Methyltrioxorhenium (MTO)}

Next to the Cp-based trioxo-rhenium complexes, methyltrioxorhenium (MTO) is another wellknown catalyst for the deoxydehydration of diols and biomass-based polyols. Its air and moisture stability makes MTO quite attractive for catalytic deoxydehydration. Several reductants, such as $\mathrm{H}_{2}$, (secondary) alcohols, sulfite, and hydroaromatic reductants have been investigated for MTO-catalyzed deoxydehydration reactions. In this section, not only are the 
different MTO-catalyzed deoxydehydration procedures described, reported mechanistic studies are also summarized.

\section{$\mathrm{MTO} / \mathrm{H}_{2}$ System}

In 2009, Abu-Omar et al. reported the MTO-catalyzed deoxydehydration of diols using $\mathrm{H}_{2}$ as the reductant. ${ }^{[24]}$ 1,2-hexanediol was converted to hexane (50\%) under high $\mathrm{H}_{2}$ pressure (300 psi), while hexene (18\%) was formed under low $\mathrm{H}_{2}$ pressure ( 80 psi) with significant charring. In contrast, cis-1,2-cyclohexanediol was converted into cyclohexene $(60 \%)$ with only $3 \%$ of cyclohexane as by-product, even under high $\mathrm{H}_{2}$ pressure (300 psi). The authors found that trans1,2-cyclohexanediol was not converted under these conditions (Scheme 5). They therefore claimed that even though trans-1,2-cyclohexanediol might coordinate to rhenium to form a metal diolate, it cannot form a cis-epoxide and, hence, cannot react further to form the olefin.

A color change from colorless to red was observed under the reaction conditions, which is consistent with the formation of methyldioxorhenium (MDO). ${ }^{[25,26]}$ Exposure of the reaction mixture to air after completion of the reaction regenerated MTO. Combining these observations with the results that trans-1,2-cyclohexanediol was not converted and cis-stilbene oxide was isomerized, these authors proposed the reaction mechanism depicted in Scheme 6. In this mechanism, MTO is first reduced by $\mathrm{H}_{2}$ to form MDO, which reacts with a diol via diol condensation. The resulting mono-oxo-diolate intermediate is in equilibrium with an dioxoepoxide adduct (5). This epoxide-rhenium adduct (5) can undergo epoxide release to regenerate MDO or extrudes an olefin, most likely via a metallaoxetane to regenerate MTO, closing the catalytic cycle.

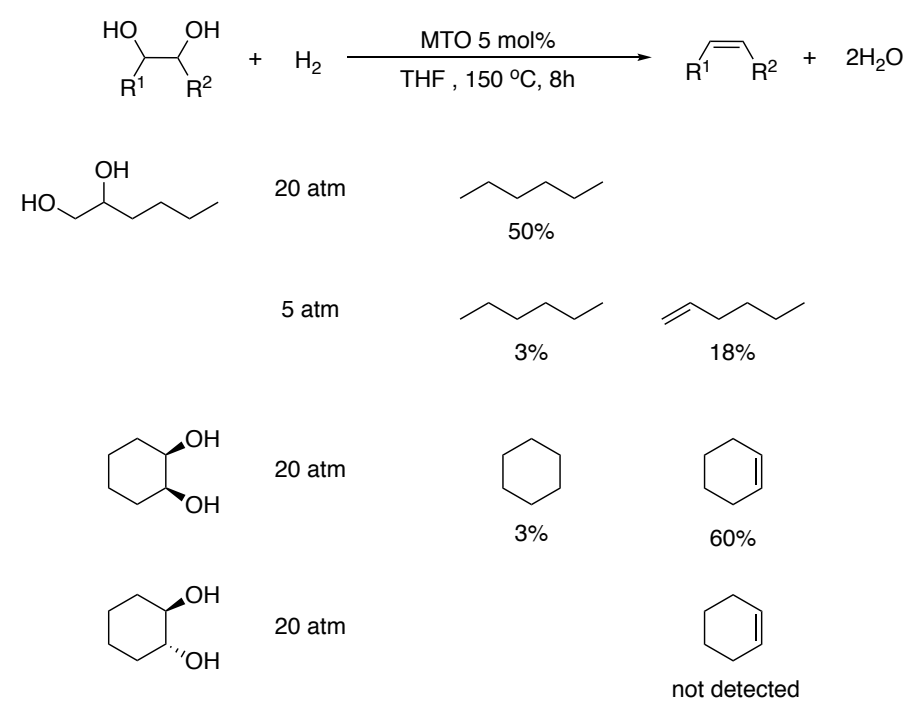

Scheme 5. MTO-catalyzed deoxydehydration with $\mathrm{H}_{2}$ as reductant. ${ }^{[24]}$ 


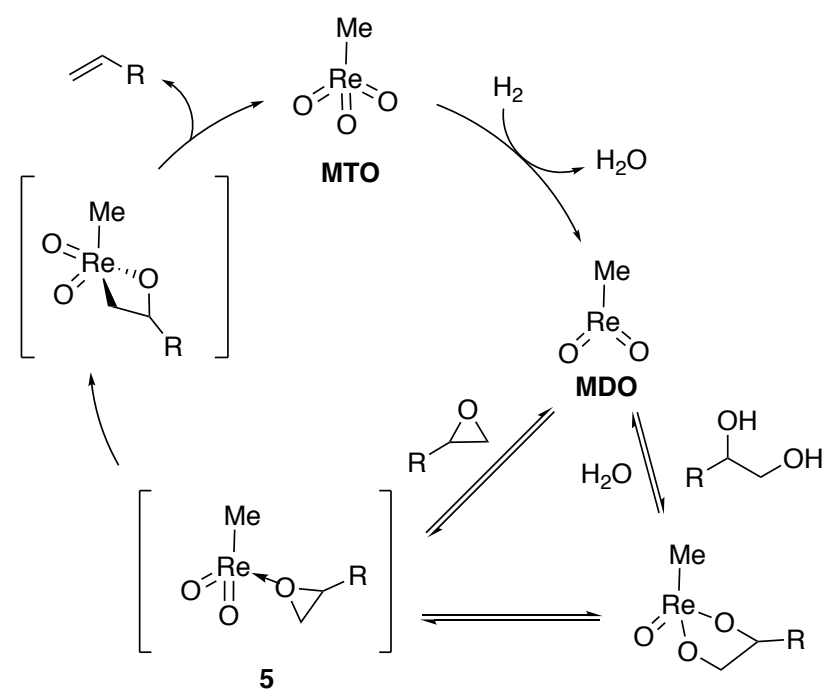

Scheme 6. Proposed mechanism of MTO-catalyzed deoxygenation of epoxides/diols using $\mathrm{H}_{2}$ as reductant $^{[24]}$

However, based on density functional theory (DFT) calculations of the MTO-catalyzed epoxide deoxygenation from $\mathrm{Bi}$ and Lin's group, the catalytic cycle starts with a $[2 \sigma+2 \pi]$ addition of epoxide to MTO to give a dioxo-diolate intermediate, followed by $\mathrm{H}_{2}$ addition, proton transfer, and olefin extrusion to regenerate the catalyst (Scheme 7). ${ }^{[27]} \mathrm{Bi}$ and Lin claimed that addition of $\mathrm{H}_{2}$ to MTO via the [2+3] mechanism is significantly endothermic and the barrier inaccessibly high, which rules out the mechanism starting with reduction of MTO to MDO as proposed by Abu-Omar.

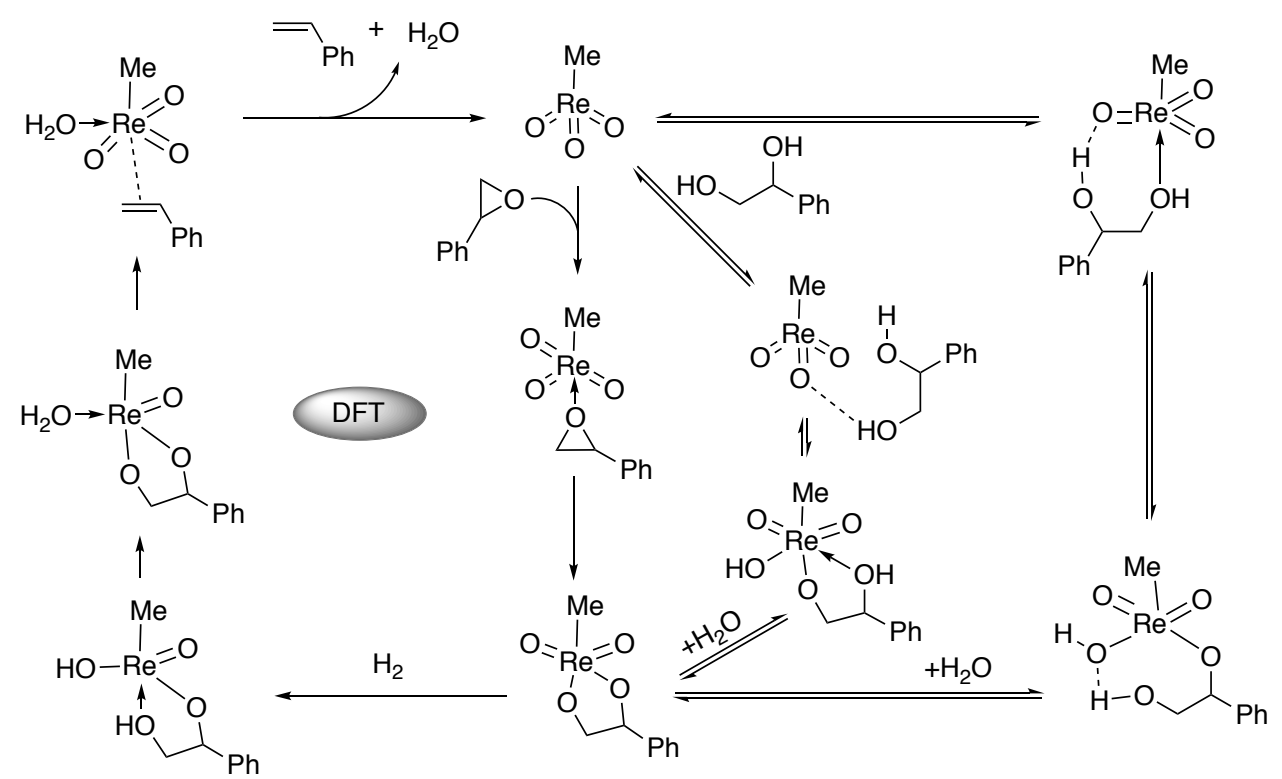

Scheme 7. DFT-calculated mechanism of the MTO-catalyzed deoxygenation of epoxide/diol driven by $\mathrm{H}_{2}{ }^{[27]}$ 


\section{MTO/Sulfite System}

Sulfite, which is a cheap, non-toxic, and recyclable reductant, is quite an attractive reducing agent for DODH reactions. In 2010, Nicholas et al. reported the first examples of MTOcatalyzed DODH driven by sulfite. ${ }^{[28]}$ Initially, by using MTO as catalyst, $\mathrm{Na}_{2} \mathrm{SO}_{3}$ as reductant, and benzene as solvent, $90 \%$ of 1-phenyl-1,2-ethanediol was converted into $44 \%$ of styrene after heating at $150{ }^{\circ} \mathrm{C}$ for $40 \mathrm{~h}$ (Table 1, entry 1). Likewise, $95 \%$ of 1,2-octanediol converted into $34 \%$ of 1 -octene after $168 \mathrm{~h}$ (Table 1 , entry 2). Considering the poor solubility of $\mathrm{Na}_{2} \mathrm{SO}_{3}$ in nonpolar organic solvents, more polar ones, e.g., THF, $\mathrm{CH}_{3} \mathrm{CN}$, and water, were investigated aiming to accelerate the reaction rate. Likely due to the coordination of THF or $\mathrm{CH}_{3} \mathrm{CN}$ to the metal center of MTO, which would reduce the Lewis acidity of MTO, the deoxydehydration of 1-phenyl-1,2-ethanediol using THF or $\mathrm{CH}_{3} \mathrm{CN}$ as solvent was much slower. The use of the sodium-complexing agent 15-crown-5, enhancing sulfite solubility, significantly shortened the reaction time (21 h) in case of 1,2-octanediol as the substrate (Table 1, entry 3 ).

Two possible pathways were proposed for this DODH system on the basis of experimental observations (Scheme 8, A and B). In path A, MTO condenses with the diol to form a Re $\mathrm{VII}_{-}$ diolate, which is reduced by sulfite to generate a $\mathrm{Re}^{\mathrm{V}}$-diolate. In path $\mathrm{B}, \mathrm{MTO}$ is first reduced by sulfite to generate MDO, which then condensed with the diol to form the $\mathrm{Re}^{\mathrm{V}}$-diolate. In both cases, the olefin product is formed and MTO is regenerated by olefin extrusion from the $\mathrm{Re}^{\mathrm{V}}$-diolate. Mixing MTO and 1-phenyl-1,2-ethanediol (1:1) in benzene at room temperature gave a 3:1 mixture of MTO: $\mathrm{Re}^{\mathrm{VII}}$-diolate. Heating this mixture or only the $\mathrm{Re}^{\mathrm{VII}}$-diolate with $\mathrm{Na}_{2} \mathrm{SO}_{3}\left(150{ }^{\circ} \mathrm{C}, 2-3 \mathrm{~h}\right)$ produced styrene, lending credit to pathway A. On the other hand, heating MTO and $\mathrm{Na}_{2} \mathrm{SO}_{3}$ in benzene at $150{ }^{\circ} \mathrm{C}$ for $2 \mathrm{~h}$ gave a dark precipitate. After adding 1phenyl-1,2-ethanediol to the dark precipitate and continued heating of the mixture gave $c a .60 \%$ of styrene was generated, suggesting that pathway B is operative.

Table 1. MTO-catalyzed DODH of diols using sulfite as reductant. ${ }^{[28]}$

\begin{tabular}{|c|c|c|c|c|c|c|}
\hline entry & substrate & solvent/additive & product & time $(\mathrm{h})$ & conversion $(\%)$ & yield $(\%)$ \\
\hline 1 & & benzene & $\mathrm{Ph} \curvearrowright$ & 40 & 90 & 44 \\
\hline 2 & & benzene & $\mathrm{C}_{6} \mathrm{H}_{13} \curvearrowright$ & 168 & 95 & 34 \\
\hline 3 & $\mathrm{C}_{6} \mathrm{H}_{13}$ & $\begin{array}{c}\mathrm{PhCl} \\
\text { 15-crown-5 }\end{array}$ & $\mathrm{C}_{6} \mathrm{H}_{13} \curvearrowright$ & 21 & 98 & 43 \\
\hline
\end{tabular}




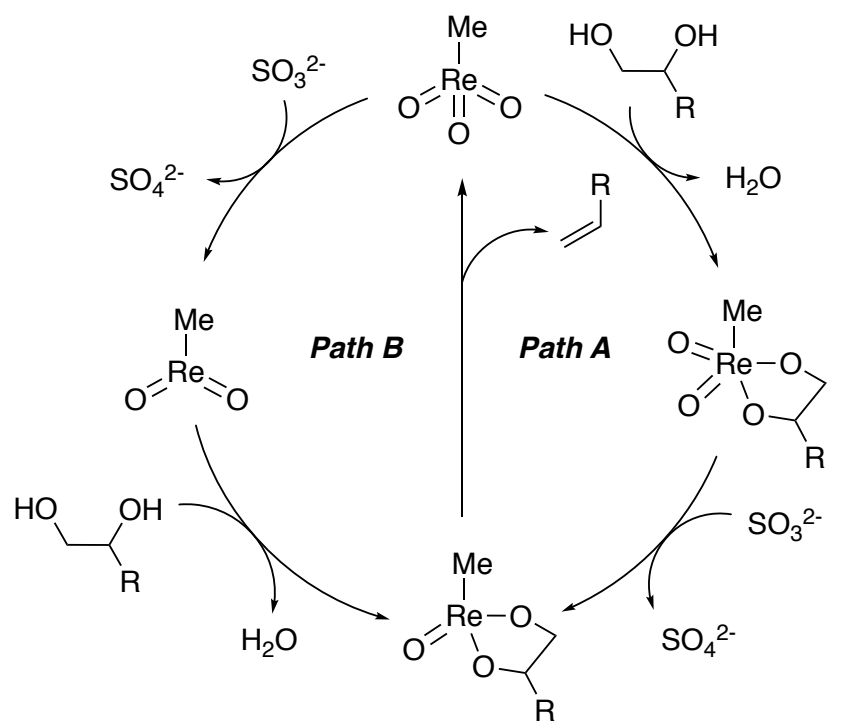

Scheme 8. Proposed catalytic cycle of MTO-catalyzed DODH using sulfite as reductant. ${ }^{[28]}$

Later on, stochiometric reaction studies provided a more detailed picture of pathway A, involving a. diol condensation with MTO to form a MeRe $\mathrm{VII}_{2}$ (diolate); b. O-transfer reduction of $\mathrm{MeRe}{ }^{\mathrm{VII}} \mathrm{O}_{2}$ (diolate) by $\mathrm{PPh}_{3}$ or sulfite $\left(\mathrm{Na}_{2} \mathrm{SO}_{3}\right.$ or $\left.\left(\mathrm{Bu}_{4} \mathrm{~N}\right)_{2} \mathrm{SO}_{3}\right)$ to form a $\left[\mathrm{MeRe}^{\mathrm{V}} \mathrm{O} \text { (diolate) }\right]_{2}$ dimer, which is in equilibrium with its $\mathrm{O}=\mathrm{PPh}_{3}$ or sulfate-coordinated monomer; and c. thermal fragmentation of the reduced Re-diolate to produce olefin and regenerate MTO (Scheme 9). ${ }^{[29]}$ The condensation of diol and MTO to form a $\mathrm{MeRe}^{\mathrm{VII}} \mathrm{O}_{2}$ (diolate) was performed at room temperature. Treatment of $\mathrm{MeRe}^{\mathrm{VII}} \mathrm{O}_{2}$ (diolate) with $\mathrm{PPh}_{3}$ at room temperature resulted in a rapid disappearance of $\mathrm{MeRe}^{\mathrm{VII}} \mathrm{O}_{2}$ (diolate). O-transfer from $\mathrm{MeRe}^{\mathrm{VII}} \mathrm{O}_{2}$ (diolate) to $\mathrm{PPh}_{3}$ was confirmed by ${ }^{31} \mathrm{P}$ NMR and IR. After addition of $\mathrm{PPh}_{3}$, the ${ }^{31} \mathrm{P}$ NMR spectrum showed the full consumption of $\mathrm{PPh}_{3}$, as well as a clean formation of $\mathrm{OPPh}_{3}$. The IR spectrum of the reaction mixture showed the existence of strong, new peaks in the Re-O and C-O region at 1026, 992, and $930 \mathrm{~cm}^{-1}$, which indicated O-atom removal from the metallodiolate. Besides, Nicholas claimed that two or more structurally related species were formed because they observed a complex ${ }^{1} \mathrm{H}$ NMR spectrum after addition of $\mathrm{PPh}_{3}$. They suggested that a mixture of stereoisomeric, dinuclear $\mathrm{Re}^{\mathrm{V}}$-diolates 6' was formed from the coordinatively unsaturated $\mathrm{Re}^{\mathrm{V}}$ diolate 6. Treatment of $\mathrm{MeRe}^{\mathrm{VII}} \mathrm{O}_{2}$ (diolate) with $\mathrm{Na}_{2} \mathrm{SO}_{3}$ in benzene at room temperature only caused little change in the NMR spectrum. By switching to more soluble $(\mathrm{Bu} 4 \mathrm{~N})_{2} \mathrm{SO}_{3}$ at higher reaction temperature $\left(60^{\circ} \mathrm{C}\right)$, a mixture of mononuclear $\mathrm{Re}^{\mathrm{V}}$-diolate 6 and dinuclear $\mathrm{Re}^{\mathrm{V}}$-diolate 6' was generated on the basis of IR and ${ }^{1} \mathrm{H}$ NMR analysis. Heating dinuclear $\mathrm{Re}^{\mathrm{V}}$-diolate 6' at $60-80{ }^{\circ} \mathrm{C}$ led to the formation of styrene and reappearance of MTO, while $\mathrm{Re}^{\mathrm{V}}$-diolate $\mathbf{6}^{\text {' was }}$ gradually disappeared. Besides, Nicholas mentioned that the olefin extrusion was the ratelimiting step, because the condensation and reduction steps were performed at room temperature while the olefin extrusion only occurred at $\geq 60{ }^{\circ} \mathrm{C}$. 


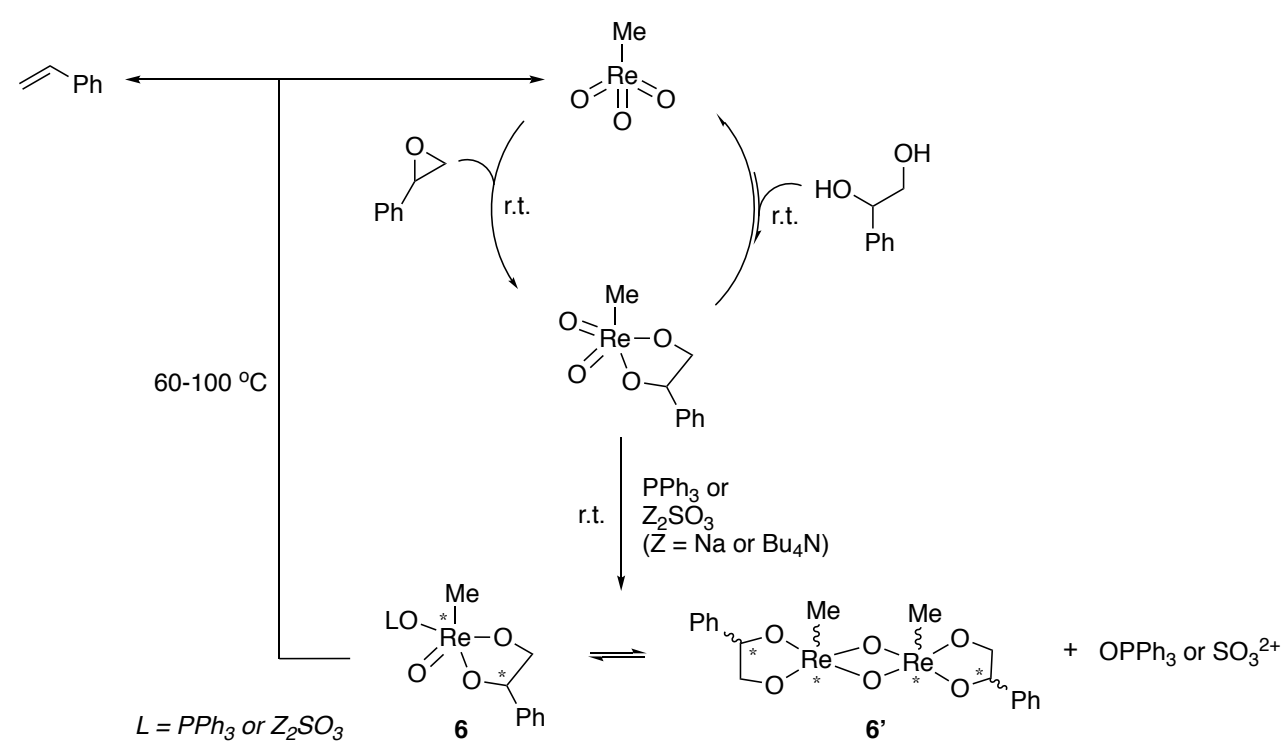

Scheme 9. Proposed mechanism of MTO-catalyzed DODH based on stochiometric studies ${ }^{[29]}$

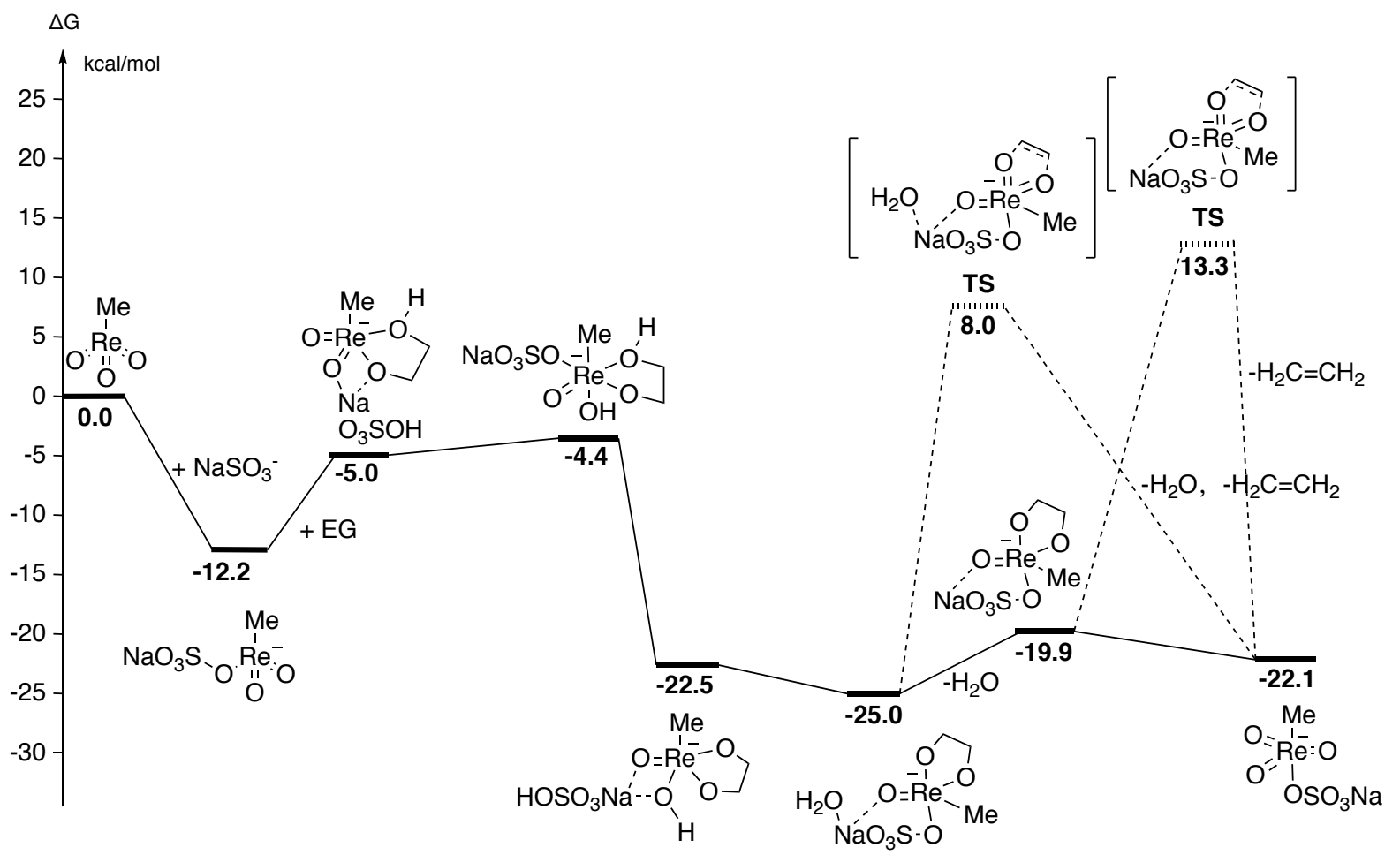

Scheme 10. DFT calculated free energy profile of MTO/sulfite mediated DODH. ${ }^{[30]}$

To answer the question whether the diol condensation step happens before or after the reduction step in the catalytic cycle (Scheme 8, path A and path B), Nicholas et al. studied the mechanism of the MTO-catalyzed deoxydehydration of diols to olefins with sulfite through DFT calculations. ${ }^{[30]}$ These showed that the lowest energy pathway involves the rhenium sulfate species, i.e. $\mathrm{NaSO}_{3}{ }^{-}$attacks on an oxo ligand of $\mathrm{MTO}$ to generate $\mathrm{MeRe}^{\mathrm{V}} \mathrm{O}_{2}\left(\mathrm{SO}_{3} \mathrm{Na}\right)^{-}$, followed 
by diol coordination to form $\mathrm{MeRe}^{\mathrm{V}} \mathrm{O}_{2}\left(\mathrm{SO}_{3} \mathrm{Na}\right)^{-}$, and intramolecular H-transfer steps to $\mathrm{Re}=\mathrm{O}$ and/or Re-OSO${ }_{3} \mathrm{Na}^{-}$to generate $\left[\mathrm{MeRe}^{\mathrm{V}} \mathrm{O}(\text { diolate })\left(\mathrm{OSO}_{3} \mathrm{Na}\right)\left(\mathrm{H}_{2} \mathrm{O}\right)\right]^{-}$(Scheme 11) This anionic $\mathrm{Re}^{\mathrm{V}}$-diolate then regenerates MTO via olefin extrusion, and $\mathrm{H}_{2} \mathrm{O}$ and $\mathrm{NaSO}_{4}{ }^{-}$dissociation. Olefin extrusion from the $\mathrm{Re}^{\mathrm{V}}$-diolate is the turnover-limiting step of the reaction sequence on basis of these DFT calculations. This result is in line with the previous experimental observations (vide supra). ${ }^{[29]}$

\section{MTO/Alcohol Systems}

In 2012, Abu-Omar reported the MTO-catalyzed transfer hydrogenation and deoxygenation of glycerol (Scheme 11). ${ }^{[31]}$ In this reaction, disproportionation of glycerol happens to obtain a 1:0.22:0.15 mixture of allyl alcohol: propionaldehyde: acrylaldehyde (74\%). The dihydroxyacetone (DHA) byproduct could be easily removed under distillation conditions, because of the polymerization of DHA at high temperatures. Except glycerol, another two biomass-derived polyols, erythritol and DL-threitol, were also investigated by using MTO as catalyst and 1-heptanol as solvent. A total of $58 \%$ of volatile products (2,5-dihydrofuran and (E)-2-butenal) were formed from erythritol. However, this MTO-catalyzed deoxydehydration of polyols via disproportionation was not quite efficient in case of DL-threitol; only $7 \%$ of volatile products ((E)-2-butenal) were obtained, while the major, non-volatile product was 1,2anhydroethreitol (Scheme 12). A way to increase the volatile product yield is adding another alcohol into the system as sacrificial reductant.

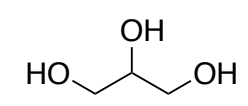
glycerol

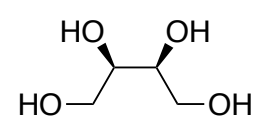

Erythritol

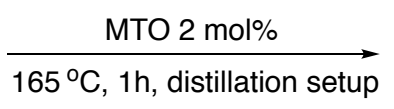

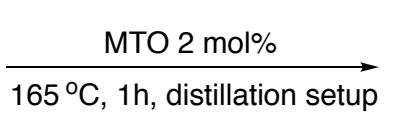

$\overrightarrow{165^{\circ} \mathrm{C}, 1 \mathrm{~h} \text {, distillation setup }}$

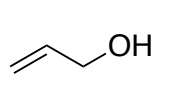

1

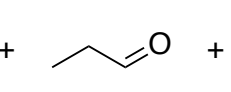

0.22
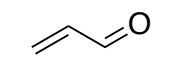

0.15

volatile products yield $74 \%$

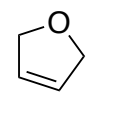

1<smiles>OC[C@H](O)[C@H](O)CO</smiles>

DL-Threitol

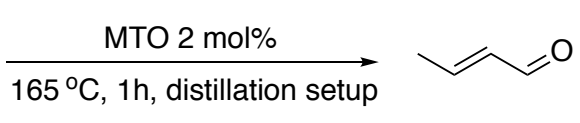

volatile products yield $7 \%$

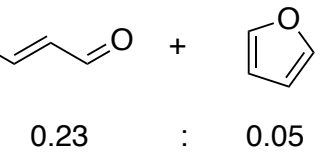

0.05

volatile products yield $58 \%$

$+$

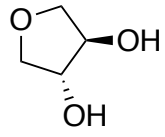

in residue

Scheme 11. MTO-catalyzed deoxydehydration of biomass-derived polyols via polyol disproportionation. ${ }^{[31]}$ 
Around the same time, the MTO-catalyzed DODH of biomass-derived sugars and sugar alcohols using secondary alcohols as the reductant was reported by Toste. ${ }^{[32]}$ Initially, 1,4anhydroerythritol was chosen as model substrate. Several rhenium resources, for example MTO, $\mathrm{Re}_{2}(\mathrm{CO})_{10}, \mathrm{ReO}\left(\mathrm{PPh}_{3}\right)_{2} \mathrm{Cl}_{3}, \mathrm{NH}_{4} \mathrm{ReO}_{3}, \mathrm{ReIO}_{2}\left(\mathrm{PPh}_{3}\right)_{2}$, and perrhenic acid, were investigated. MTO was selected to be further investigated because of its simple, ligand-free structure and its ease of handling. In terms of sacrificial alcohol reductant, secondary alcohols were found to be more favorable than primary alcohols. The reaction conditions were then optimized to be: 2.5 mol\% of MTO as catalyst, 3-octanol $(0.3 \mathrm{M})$ as both reductant and solvent, and $170{ }^{\circ} \mathrm{C}$. Under these optimized reaction conditions, $90 \%$ of allyl alcohol was formed from glycerol (Table 2 , entry 1). 1,3-butadiene, an industrially important rubber precursor, was obtained in $89 \%$ yield from erythritol, and in 81\% yield from DL-threitol (Table 2, entry 2 and 3). 2,5-dihydrofuran (11\%) and 1,2-anhydroethreitol (13\%) were formed as by-product, respectively. Except from these $\mathrm{C}_{3}$ and $\mathrm{C}_{4}$ polyols, these studies were extended to more complicated $\mathrm{C}_{5}$ and $\mathrm{C}_{6}$ sugar alcohols (Table 2, entries 4-8). 33\% to 61\% DODH product yields were obtained. Inositols, a class of natural carbohydrates, were also applied to this MTO-catalyzed DODH system. By three consecutive deoxydehydration of inositols, benzene was formed as final product. Besides, phenol was obtained as by-product of this reaction, likely formed from a cationic species generated after two DODH steps. The benzene yield varied from $17 \%$ to $64 \%$, probably due to inositol stereochemistry or fast isomerization (Table 2, entries 9-12).

Remarkably, Toste also investigated the application of this method to sugars (Table 2, entries 13-18). This is the first time that the most-direct feedstock from biomass was used as substrate for rhenium-catalyzed DODH. D-erythrose and L-threose afforded furan in $60 \%$ and $47 \%$ yield, respectively. 2-Vinylfuran and furan were obtained from DODH of hexoses (D-mannose, Dallose, D-glucose, D-galactose). In all cases, furan was the major product, the total volatile products varied between $25 \%$ to $40 \%$. 2-Vinylfuran and furan were also obtained from DODH of hexoses catalyzed by $\mathrm{Cp}^{\mathrm{tt}} \mathrm{ReO}_{3}$, but the products distribution was not the same as MTOcatalyzed DODH. ${ }^{[23]}$

In terms of the mechanism of these DODH reactions, a stable organorhenium(V) compound 7 was obtained by heating MTO with 3-pentanol (5 equiv.) and 3-hexyne (2 equiv.) at $155^{\circ} \mathrm{C}$ for $5 \mathrm{~h}$ (Scheme 13). The reactions between 7 and diols was dependent on the structure of the diol. No reaction was observed when trans-cyclohexanediol was applied, while full conversion was obtained at room temperature when 1,4-anhydroerythritol was used as substrate, forming organorhenium(VII) compound $\mathbf{8}$. The extrusion of olefin from $\mathbf{8}$ asked for a higher reaction temperature $\left(155^{\circ} \mathrm{C}\right) ; 91 \%$ of 2,5 -dihydrofuran was obtained. In terms of the reaction between 
Table 2. MTO-catalyzed DODH with secondary alcohol reductants of biomass-derived sugars and sugar alcohols. ${ }^{[32]}$

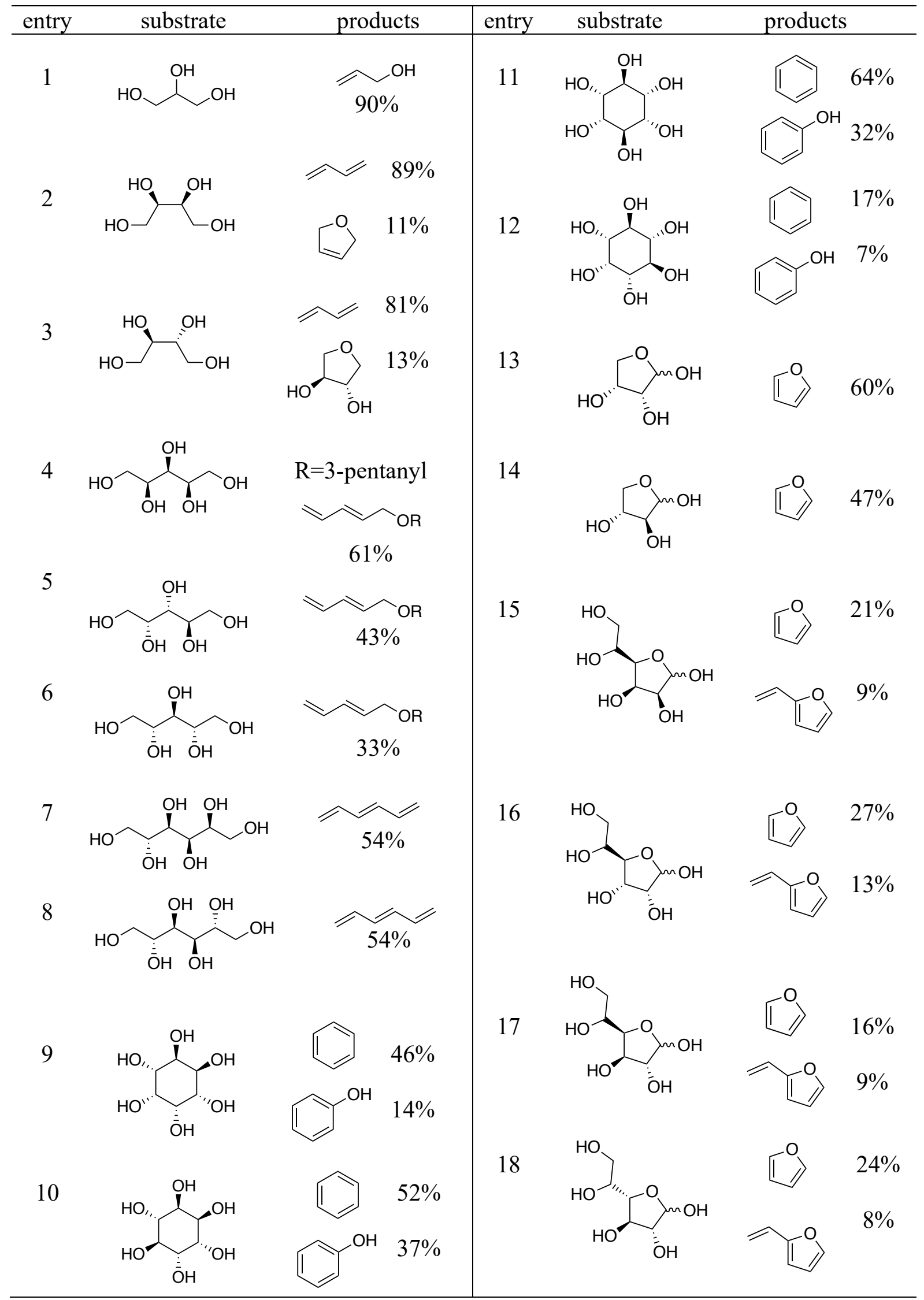


7 and meso-2,3-butanediol, only of 56\% conversion was obtained. By adding 1,4anhydroerythritol into this reaction mixture, the formation of 8 was observed, indicating that diol binding is reversible. Besides, 7 was also able to catalyze the deoxydehydration of 1,4anhydroerythritol; full substrate conversion and 90\% 2,5-dihydrofuran yield was achieved. On the basis of these results, Toste proposed a catalytic cycle in which MTO is initially reduced by a secondary alcohol to form MDO, the diol then condenses with MDO to generate a $\mathrm{Re}^{\mathrm{V}}$-diolate species, followed by olefin extrusion to regenerate MTO.

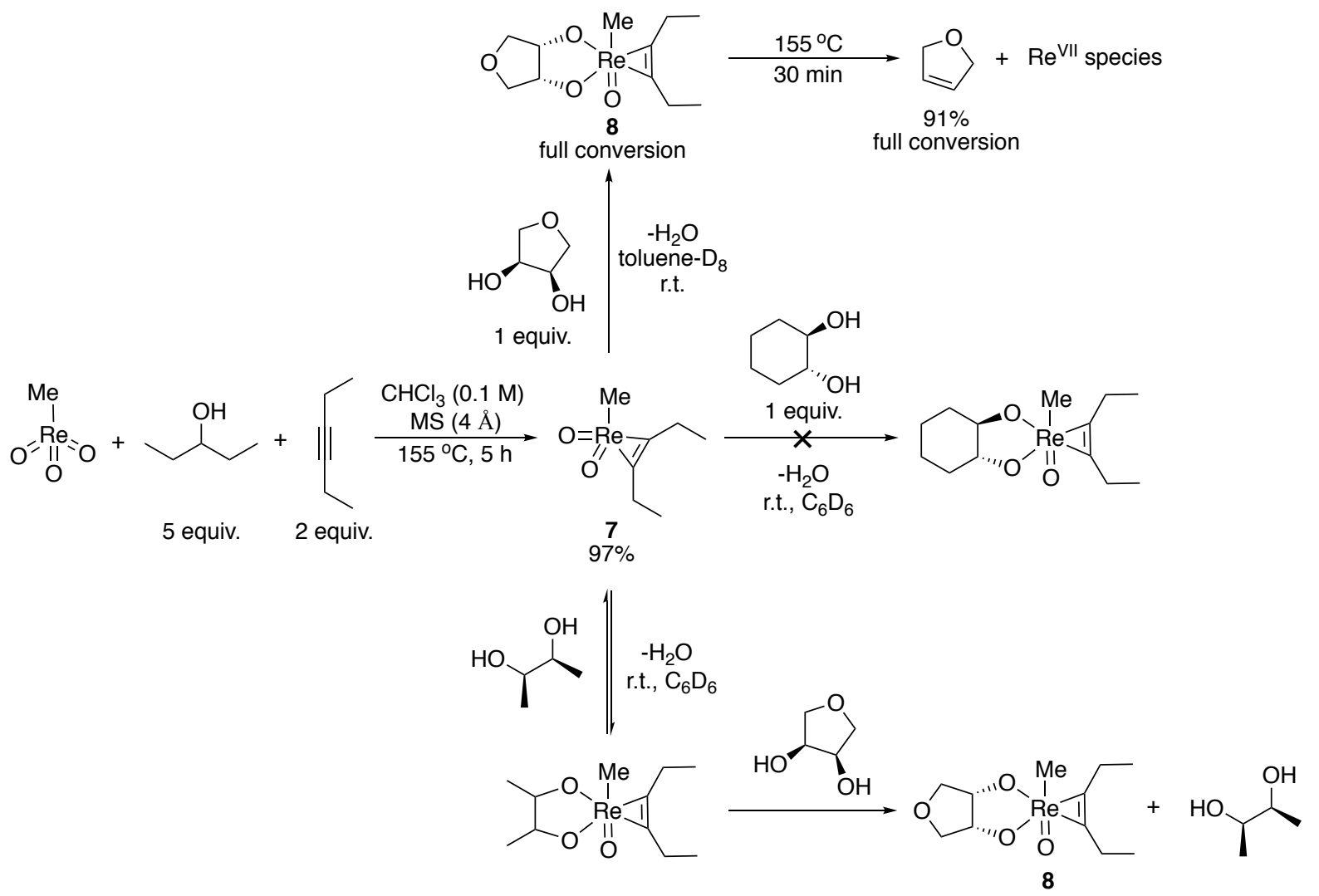

Scheme 12. Synthesis of organorhenium(V) compound 7 and its reactions with diols. ${ }^{[32]}$

This MTO/secondary alcohols system was later on applied to the DODH of 2-ene-1,4-diols and 2,4-diene-1,6-diols (1,4-DODH and 1,6-DODH, respectively), showing that the oxorhenium complexes do not only catalyze the deoxydehydration but also the [1,3]-OH shift of allyl alcohols (Scheme 13). ${ }^{[33]}$ Toste proposed an MTO-mediated [1,3]-OH shift mechanism including coordination of the alcohol to MTO to generate an alkoxy(hydroxy)rhenium species, $\mathrm{H}$-transfer via the Re-OH fragment, and concerted H-exchange to form but-3-ene-1,2-diol. But3-ene-1,2-diol then generates 1,3-butadiene through a normal deoxydehydration pathway, that is, MTO is reduced by a secondary alcohol through H-transfer to form MDO, MDO then condenses with but-3-ene-1,2-diol to generate a $\mathrm{MeRe}^{\mathrm{V}} \mathrm{O}$ (diolate), which regenerates MTO via olefin extrusion. This novel 1,4-DODH pathway suggested that rhenium-catalyzed DODH is 
particularly useful for the total deoxydehydration of polyols by merging different intermediates into one product, that is, to increase product selectivity.

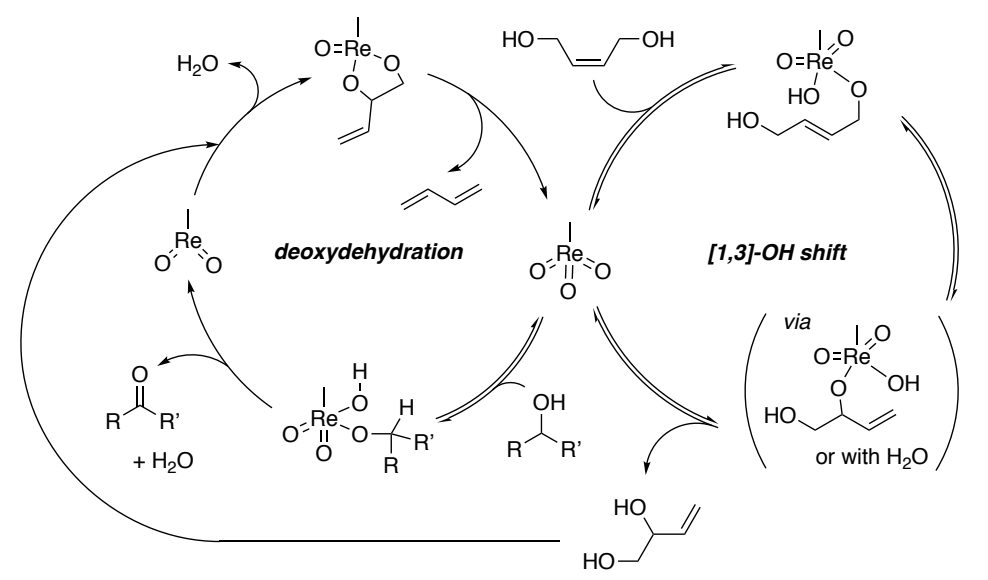

Scheme 13. MTO-catalyzed deoxydehydration of (Z)-but-2-ene-1,4-diol ${ }^{[33]}$

Besides, the DODH of mucic acid catalyzed by either MTO or $\mathrm{HReO}_{4}$ with a secondary alcohol as reductant was reported in the same work by Toste (Scheme 14). ${ }^{[33]}$ With 7 mol\% of $\mathrm{HReO}_{4}$ as catalyst, $n \mathrm{BuOH}$ as both reductant and solvent, $71 \%$ of trans,trans-dibutyl muconate was generated from mucic acid. In case of using mucic acid dibutyl ester as substrate, the yield of trans,trans-dibutyl muconate was as high as 94\%. A one-pot synthesis procedure of dibutyl adipate was discovered by combining the DODH of mucic acid and the hydrogenation of trans,trans-dibutyl muconate. After hydrolysis of dibutyl adipate, adipic acid, a building block of Nylon-66, was obtained.

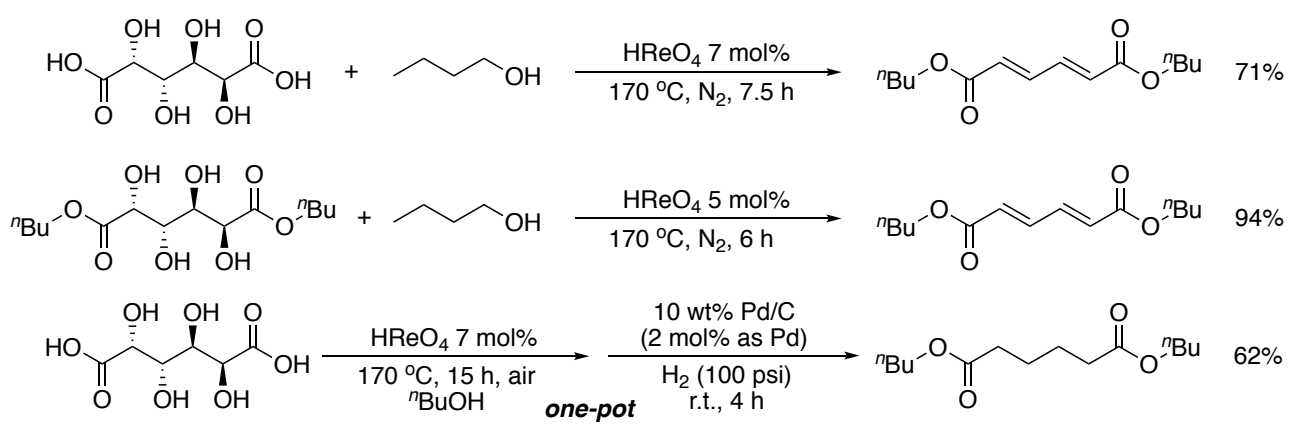

Scheme 14. $\mathrm{HReO}_{4}$-catalyzed deoxydehydration of mucic acid ${ }^{[33]}$

Since this MTO-catalyzed DODH of diols and polyols is quite useful for biomass conversion, its mechanistic study has attracted quite some attention. The mechanism of MTO-catalyzed deoxydehydration of 1,4-anhydroerythritol with secondary alcohols as reductant was investigated via DFT calculations by Wang. ${ }^{[34]}$ The calculated catalytic cycle goes through a reduction $\rightarrow$ condensation $\rightarrow$ extrusion pathway. On basis of their calculation, a lower free 
enthalpy of activation was calculated involving a hydrated- $\mathrm{Re}^{\mathrm{V}}$ species, $\mathrm{MeReO}(\mathrm{OH})_{2}$ 9, instead of MDO. Besides, the role of the secondary alcohol in the catalytic cycle proved interesting. It does not only act as reductant and solvent in the system, but also acts as a shuttle to facilitate H-transfer steps in the catalytic cycle. The calculated free energy profile for the DODH of 1,4-anhydroerythritol catalyzed by MTO with a secondary alcohol as reductant according to Wang's work is summarized in Scheme 15.

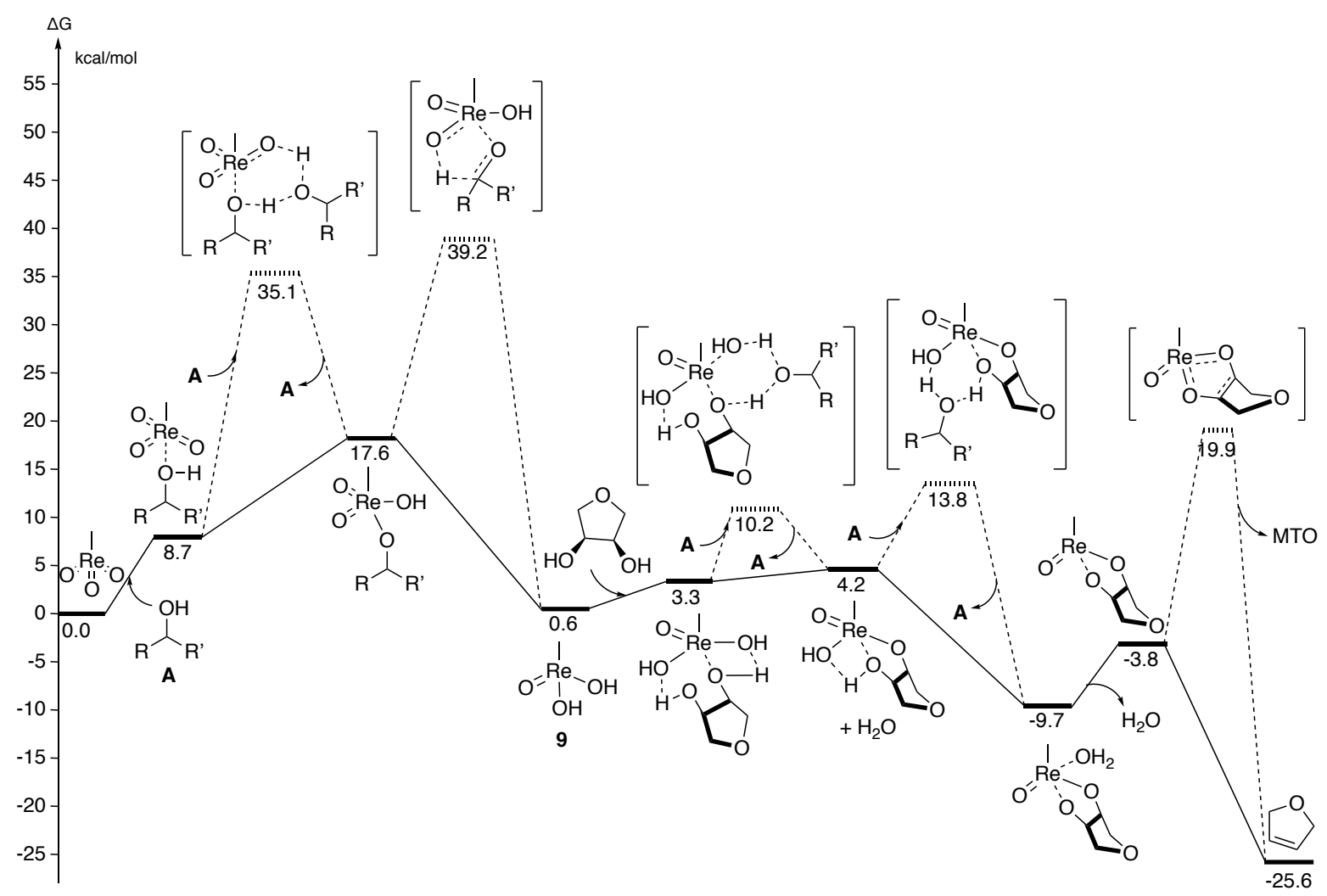

Scheme 15. DFT calculated free energy profile of the MTO-catalyzed DODH of 1,4-anhydroerythritol with secondary alcohols as reductant. ${ }^{[34]}$

The formation of the hydrated MDO species $\mathrm{MeReO}(\mathrm{OH})_{2}$ (9) was also demonstrated in Zhang and Su's work. ${ }^{[35]}$ In case of rhenium-catalyzed 1,4-DODH, they proposed an alternative reaction pathway, where instead of forming MDO after the reduction of $\mathrm{MTO}, \operatorname{MeReO}(\mathrm{OH})_{2} 9$ forms as the active species of the catalytic cycle. Besides, in previous work, a three-step pathway was proposed: a. reduction of MTO to form MDO; b. [1,3]-OH shift mediated by MTO to form but-3-ene-1,2-diol; and c. DODH of but-3-ene-1,2-diol to form 1,3-butadiene (Scheme 14). Instead, Zhang and Su proposed a two-step pathway, which includes the reduction of MTO to form $\mathrm{MeReO}(\mathrm{OH})_{2} \mathbf{9}$, and the $\mathrm{MeReO}(\mathrm{OH})_{2}$-catalyzed deoxydehydration of but-2-ene-1,4diol to form 1,3-butadiene. No [1,3]-OH shift of 2-ene-1,4-diols is involved in this alternative pathway. Based on DFT calculation, the two-step pathway has lower activation barriers than 
the three-step pathway. The rate-limiting step of the two-step catalytic cycle is the first hydrogen transfer in the reduction of MTO to form $\mathrm{MeReO}(\mathrm{OH})_{2}$ 9. The activation barrier of this step is $28.0 \mathrm{kcal} / \mathrm{mol}$. Similarly, the activation barrier of the reduction from MTO to MDO is $28.2 \mathrm{kcal} / \mathrm{mol}$. In the three-step pathway, the activation barriers of the rate-limiting steps are $28.0 \mathrm{kcal} / \mathrm{mol}, 28.2 \mathrm{kcal} / \mathrm{mol}$, and $15.9 \mathrm{kcal} / \mathrm{mol}$ for the consecutive reduction, [1,3]-OH shift, and 1,2-DODH steps, respectively. In the two-step pathway, the activation barriers are 28.0 $\mathrm{kcal} / \mathrm{mol}$, and $12.4 \mathrm{kcal} / \mathrm{mol}$ for the reduction and 1,4-DODH steps, respectively. The calculated free energy profile for the DODH of but-2-ene-1,4-diol through a two-step pathway according to Wang's work is summarized in Scheme 16.

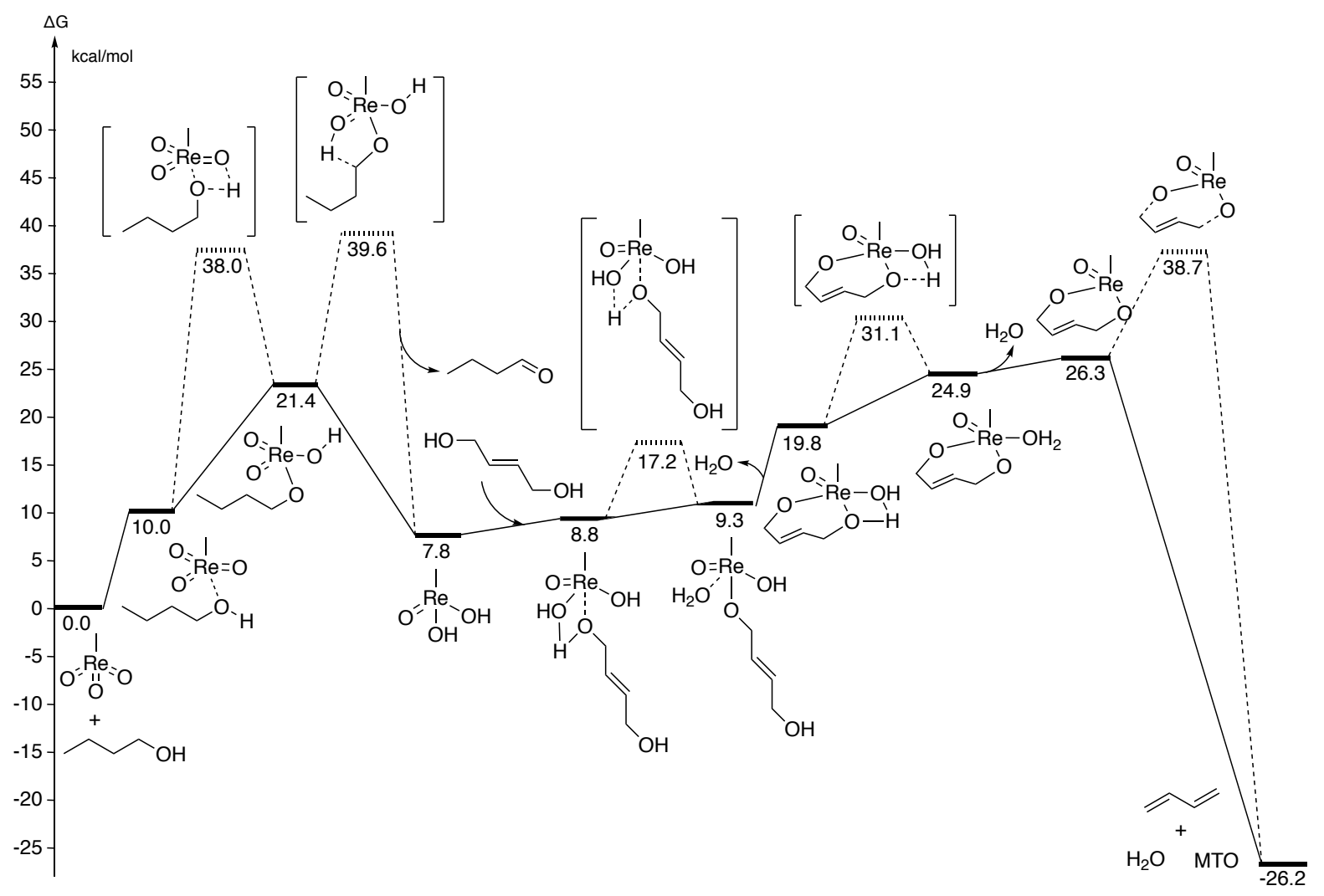

Scheme 16. DFT calculated free energy profile of the DODH of but-2-ene-1,4-diol through a two-step pathway. ${ }^{[35]}$

For this MTO-catalyzed deoxydehydration system, only the $\mathrm{Re}^{\mathrm{V}} \leftrightarrow \mathrm{Re}^{\mathrm{VII}}$ catalytic cycle has been considered above. In 2013, Abu-Omar proposed a catalytic cycle that involves a $\operatorname{Re}^{\mathrm{V}} \leftrightarrow \mathrm{Re}^{\mathrm{III}}$ pathway (Scheme 17). ${ }^{[36]}$ An induction period (10 min) was observed for MTO-catalyzed DODH of hydrobenzoin when 3-octanol was used as reductant and solvent. Upon addition of hydrobenzoin after pre-treating MTO with 3-octanol at $140{ }^{\circ} \mathrm{C}$ for $10 \mathrm{~min}$, no induction period was observed. Besides, by heating $\mathrm{MeRe}^{\mathrm{VII}} \mathrm{O}_{2}$ (diolate) 9 alone, no olefin was detected, but instead benzaldehyde formation was observed. These results indicate that the catalytic cycle 
might start with MDO and that MTO is just a pre-catalyst. MDO is formed through the reduction of MTO, either via oxygen transfer mediated by the secondary alcohol or via oxidative cleavage from the Re(VII)-diolate 9. Subsequently, MDO would then condense with a diol to form $\mathrm{MeRe}^{\mathrm{V}} \mathrm{O}$ (diolate), which would be further reduced by the secondary alcohol to generate $\mathrm{MeRe}^{\mathrm{III}}$ (diolate). After olefin extrusion from this low-valent rhenium diolate, MDO would be regenerated. In addition, kinetic data showed a zero-order in [hydrobenzoin] and a half-order in [Re]. By using 3-D-octanol, a kinetic isotope effect (KIE) of 1.4 was observed, suggesting that the reduction of $\mathrm{MeRe}^{\mathrm{V}} \mathrm{O}$ (diolate) to form $\mathrm{MeRe} \mathrm{e}^{\mathrm{III}}$ (diolate) is the rate-limiting step of the catalytic cycle.

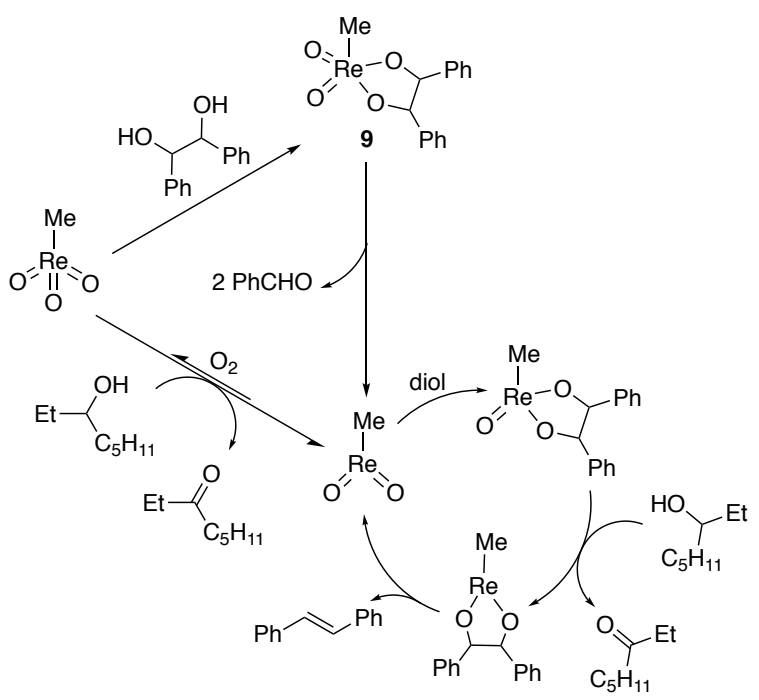

Scheme 17. Proposed mechanism of MTO-catalyzed DODH via a $\operatorname{Re}^{\mathrm{V}} \leftrightarrow \mathrm{Re}^{\mathrm{III}}$ cycle and a secondary alcohol reductant. ${ }^{[36]}$

In short, three different catalytic pathways for MTO-catalyzed DODH have been proposed. Two of them proceed through a $\mathrm{Re}^{\mathrm{V}} \leftrightarrow \mathrm{Re}^{\mathrm{VII}}$ cycle with a different active species, either methyldioxorhenium (MDO) or $\mathrm{MeRe}^{\mathrm{V}} \mathrm{O}(\mathrm{OH})_{2}$. The third pathway proceeds through a $\mathrm{Re}^{\mathrm{V}} \leftrightarrow \mathrm{Re}^{\mathrm{III}}$ cycle, with MTO acting as a pre-catalyst. Later on, another study related to the mechanism of MTO-catalyzed DODH with secondary alcohol reductants was reported by Fristrup and co-workers. ${ }^{[37]}$ An in situ IR spectrophotometer (a ReactIR instrument) equipped with an attenuated total reflection probe was employed for this study. By applying this set-up, spectra were recorded every few seconds, eliminating the need to take samples, and like other in situ techniques, reaction intermediates can be observed if they are present in significant amounts. The investigation was carried out using $2.5 \mathrm{mmol}$ 1,2-tetradecanediol as substrate, 2.5 equivalents of 3 -octanol as reductant, $2 \mathrm{~mol} \%$ of MTO as catalyst, and dodecane as solvent (a total volume of $\sim 6 \mathrm{~mL}$ ). An increased $\mathrm{C}=\mathrm{O}$ stretch at $1721 \mathrm{~cm}^{-1}$, decreased $\mathrm{O}-\mathrm{H}$ stretches around $3500 \mathrm{~cm}^{-1}$, and the appearance of a weak $\mathrm{C}=\mathrm{C}$ stretch at $1643 \mathrm{~cm}^{-1}$ was observed. 
Different reaction temperatures (approximately 140 to $\left.185^{\circ} \mathrm{C}\right)$, catalyst concentrations $(2.1 \mathrm{~mol} \%$ and $1.3 \mathrm{~mol} \%)$, and reductant concentrations (1.2, 2.4, and 3.7 equivalents of 3 -octanol) were then investigated.

The kinetics measured throughout the reaction showed a zero-order reaction initially, but the reaction rate accelerated towards the end. Based on this study, the authors proposed a mechanism which includes a deactivating pre-equilibrium (Scheme 18). A MeRe ${ }^{\mathrm{V}} \mathrm{O}$ (diolate) was considered as the pivotal intermediate of the catalytic cycle. This $\mathrm{MeRe}^{\mathrm{V}} \mathrm{O}$ (diolate) is proposed to form from $\mathrm{MDO}$ or $\mathrm{MeReO}(\mathrm{OH})_{2}$, instead of through reduction of $\mathrm{MeRe}^{\mathrm{V}} \mathrm{O}_{2}$ (diolate). To explain the acceleration at the end of the reaction, it was proposed that when most of the diol has been consumed at the end of the reaction, the deactivating preequilibrium shifts to the MTO site causing the observed acceleration. Besides, two separate KIE experiments were done using $\mathrm{C}_{5} \mathrm{H}_{11} \mathrm{CH}(\mathrm{OD}) \mathrm{C}_{2} \mathrm{H}_{5}$ and $\mathrm{C}_{5} \mathrm{H}_{11} \mathrm{CD}(\mathrm{OH}) \mathrm{C}_{2} \mathrm{H}_{5}$ (the $\mathrm{OD}$ and CD isotopomers of 3-octanol, respectively). The KIE for the OD and CD isotopomers was 1.1 and 2.1, respectively. The observation of a primary KIE for the $\mathrm{CD}$ isotopomer suggested that cleavage of the $\mathrm{C}-\mathrm{H}$ bond is involved in the rate-limiting step, that is, the reduction of MTO is the rate-limiting step.

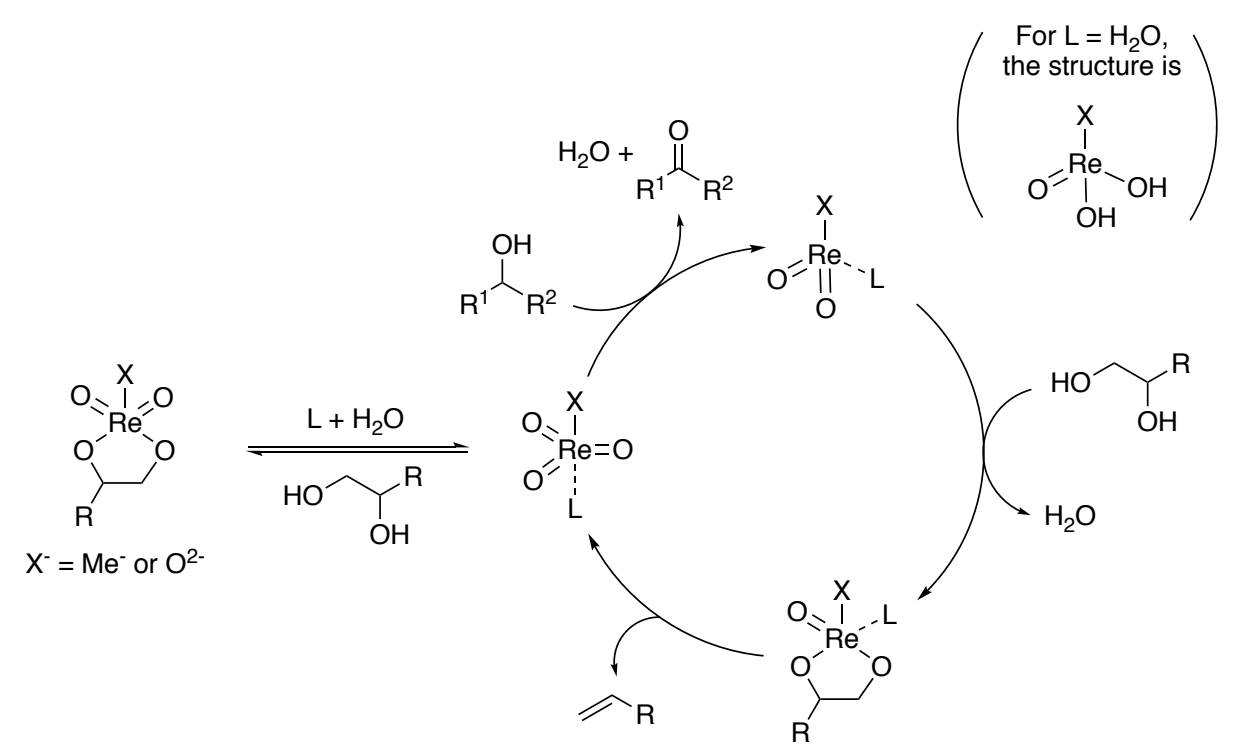

Scheme 18. Mechanism of MTO-catalyzed DODH with secondary alcohols as reductant involving a deactivating pre-equilibrium as proposed by Fristrup et al. ${ }^{[37]}$

In 2019, Marrone and d'Alessandro reported a study that mainly focussed on the performance of rhenium compounds in the DODH of glycerol, forming allyl alcohol. ${ }^{[38]}$ Eleven rhenium compounds were investigated. Except $\operatorname{Re}_{2}(\mathrm{CO})_{10}$, all of these rhenium compounds were active towards the deoxydehydration of glycerol. The allyl alcohol yield varied from $5 \%$ to approx. 
90\%. Time-course profiles of selected rhenium-catalysts (i.e., $\mathrm{ReO}_{3}, \mathrm{MTO}, \mathrm{Re}_{2} \mathrm{O}_{7}$, $\mathrm{IReO}_{2}\left(\mathrm{PPh}_{3}\right)_{2}, \mathrm{ReCl}_{5}$, and $\left.\mathrm{ReI}_{3}\right)$ in glycerol DODH showed an induction period for all catalysts (Figure 2, left). After removing all the volatile products and solvent, the residues of these reactions were recovered. Use of these recovered solids as catalyst showed no induction period in glycerol DODH. IR spectra of these solid residues showed intense and broad signals in the $1800-3750 \mathrm{~cm}^{-1}$ range, which were assigned to $\mathrm{C}-\mathrm{H}$ and $\mathrm{O}-\mathrm{H}$ stretching vibrations. In the $1000-$ $1750 \mathrm{~cm}^{-1}$ range multiple signals were detected. Since this range is where $\mathrm{C}-\mathrm{O}$ stretching and $\mathrm{C}-\mathrm{C}-\mathrm{H}, \mathrm{C}-\mathrm{O}-\mathrm{H}$ bending frequencies are located and most of the rhenium sources invested here didn't contain an organic component, these spectra indicated that rhenium species containing an organic ligand were formed. The most intense signal appeared at $920 \mathrm{~cm}^{-1}$ for all residues, independent of the rhenium source, and was assigned to $\mathrm{Re}=\mathrm{O}$ stretching. Besides, a less intense band around $700 \mathrm{~cm}^{-1}$ was observed, which was assigned either to the out-of-plane bending of $\mathrm{O}-\mathrm{H}$ bonds or to the stretching of oxo-bridges in Re-O-Re moieties. On the basis of the timecourse profile studies and the IR spectra of the solid residues (Figure 2, right), these recovered solid residues were then suggested to be the actual DODH catalyst.
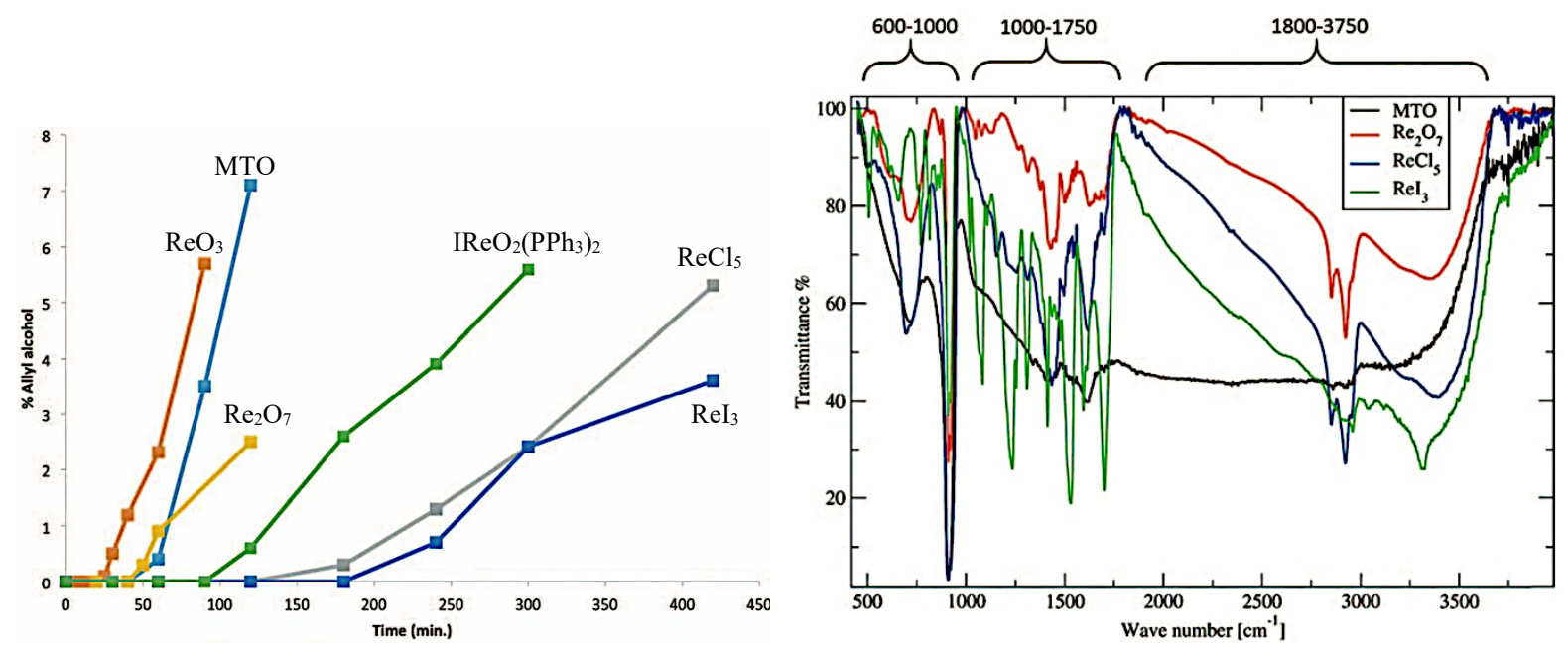

Figure 2. Left: time-course profile of rhenium-catalyzed DODH of glycerol to form allyl alcohol; Right: IR spectra of reaction residues from rhenium-catalyzed DODH of glycerol after removing volatile products, reductant, and solvent. (Reproduced by permission of The Royal Society of Chemistry). ${ }^{[38]}$

In case of the MTO-catalyzed DODH of glycerol, methane was detected in this study. On basis of DFT calculations, the substitution of $\mathrm{CH}_{3}{ }^{-}$with 2-propanol alkoxide (2- $\left.\mathrm{PrO}^{-}\right)$on the rhenium center, causing methane releasing, is thermodynamically feasible, the free energy of this reaction is $-18.5 \mathrm{kcal} / \mathrm{mol}$. When using deuterated 2,4-dimethyl-3-propanol as reductant and solvent for the MTO-catalyzed $\mathrm{DODH}, \mathrm{CH}_{3} \mathrm{D}$ was detected; lending further credit to this substitution reaction. Accordingly, a catalytic mechanism was proposed that starts with methane release from MTO via substitution of $\mathrm{CH}_{3}{ }^{-}$with $2-\mathrm{PrO}^{-}$to form a $\mathrm{Re}^{\mathrm{VII}}$ alkoxide, 
which subsequently aggregates to yield the observed precipitate. The aggregated $\mathrm{Re}^{\mathrm{VII}}$ alkoxide is then reduced to a $\mathrm{Re}^{\mathrm{V}}$ alkoxide by Jones-like reduction, followed by condensation of $\mathrm{Re}^{\mathrm{V}}$ alkoxide and glycerol to form the $\mathrm{Re}^{\mathrm{V}}$ (glycerolate), from which allyl alcohol is extruded to close the catalytic cycle (Scheme 19).

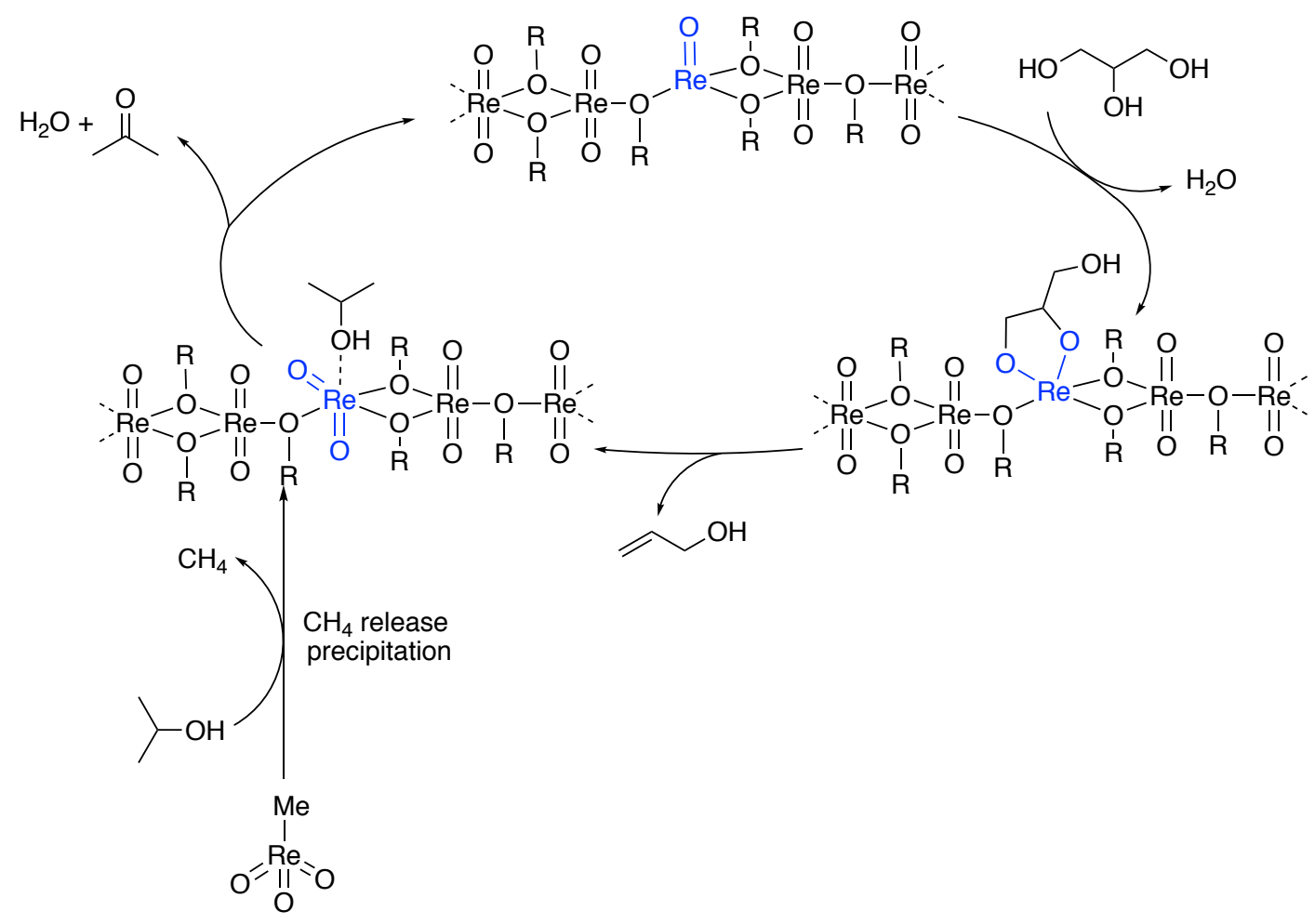

Scheme 19. Proposed catalytic cycle of MTO-catalyzed DODH of glycerol involving methane releasing and $\mathrm{Re}^{\mathrm{VII}}$ alkoxide formation. ${ }^{[38]}$

\section{MTO/Hydroaromatic Reductants Systems}

Hydroaromatics, several of which are abundant in fossil resources, have been used as hydrogen carriers for hydrogenation and for hydrogen storage. Several of these hydroaromatic reductants have also investigated in rhenium-catalyzed DODH systems. ${ }^{[39,40]}$ Nicholas started these investigation by testing several hydroaromatics, e.g. acenaphthene, 1,3-cyclohexadiene, indoline, 1-indanol, 1,2,3,4-tetrahydronaphthalene, 9,10-dihydroanthracene, and $9 \mathrm{H}$-fluorene, for the DODH of diethyl tartrate (DET) and 1,2-octanediol. Moderate to excellent yields (48\% to $99 \%$ ) of olefin were obtained. Among the hydroaromatics tested, indoline proved the most effective hydroaromatic hydrogen donor for DODH. Accordingly, indoline was applied to the deoxydehydration of a broader range of polyols. Moderate to high yields (35-99\%) of olefins were formed. They also mentioned that indoline was a superior H-transfer agent compared to primary and secondary alcohols. In the indoline-driven reaction with 1-butanol as solvent, no 
butanol or butanal/1-butanol acetal was detected. Competition experiments were done by using both indoline and secondary alcohol as reductant for the same DODH reaction. In case of glycerol DODH, the ratio of allyl alcohol:indole:2-butanone was 1.0:1.0:0 (Scheme 20). For the DODH of DET, the ratio of olefin:indole:3-pentanone was 1.0:0.8:0.1, showing that more indoline was converted than secondary alcohol.
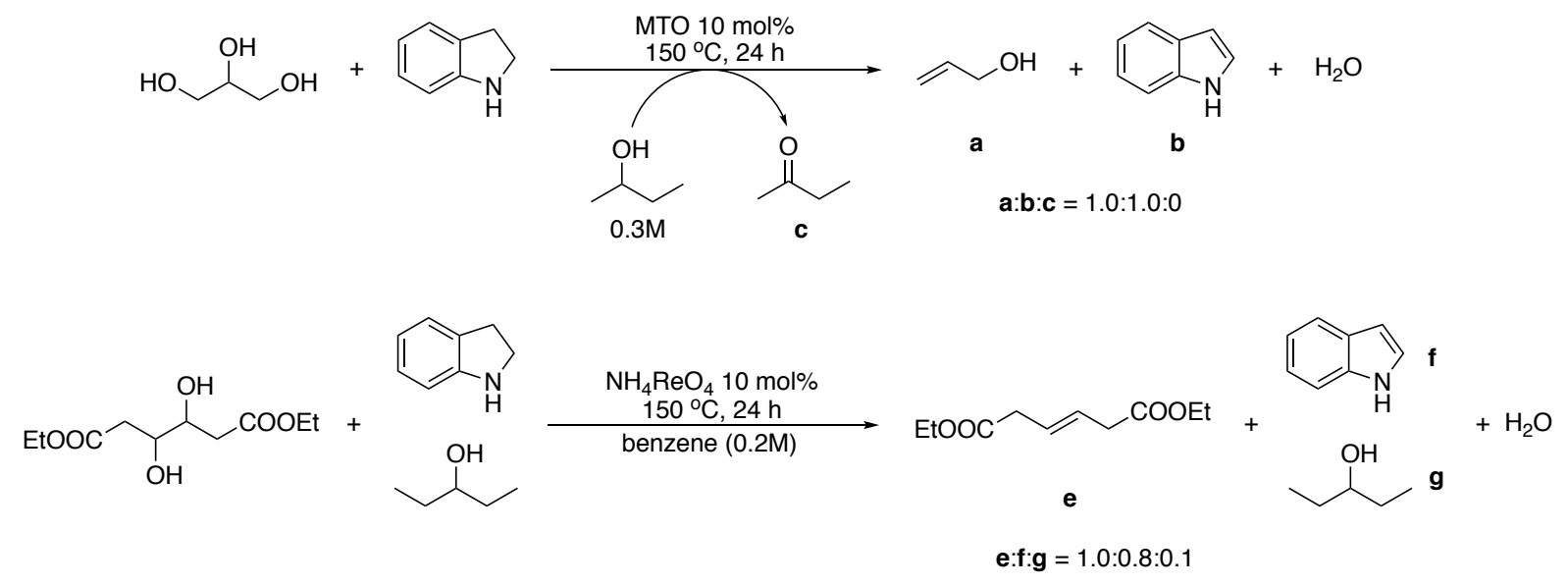

Scheme 20. Competition between indoline and secondary alcohol reductants. ${ }^{[40]}$

By adding stoichiometric amounts of indoline to an MTO solution at room temperature, a rapid color change was observed, from colorless to yellow or green depending on the concentration. From ${ }^{1} \mathrm{H}$ NMR analysis, a significant shifting of indoline and Me-Re signals was observed. The $\mathrm{Re}=\mathrm{O}$ IR vibration decreased by $33 \mathrm{~cm}^{-1}$. Accordingly, the formation of an MTO-indoline adduct was proposed, and the authors were able to isolate this adduct. On basis of the X-Ray diffraction of this adduct, it has a distorted trigonal bipyramidal Re center with the Ncoordinated indoline unit occupying an apical position and the Me-Re moiety in an equatorial position. After heating this MTO-indoline adduct at $150{ }^{\circ} \mathrm{C}$ for $1 \mathrm{~h}$, the formation of indole was observed by ${ }^{1} \mathrm{H}$ NMR (indoline:indole = 1.0:0.4). A full conversion was achieved after $4.5 \mathrm{~h}$. The less basic indole does not seem to coordinate to MTO, since there was no change of the ratio of MTO and indole after $20 \mathrm{~h}$ at room temperature. Heating the mixture of MTO, indoline (5 equiv.), and 3-hexyne (2 equiv.) at $100{ }^{\circ} \mathrm{C}$ for $19 \mathrm{~h}$, gave the stable organorhenium(V) compound 7 (Scheme 21, top). The proposed mechanism for the reduction of MTO by indoline includes coordination of indoline to MTO to form the MTO-indoline adduct, H-transfer of the acidified $\mathrm{N}-\mathrm{H}$ to a $\mathrm{Re}=\mathrm{O}$ unit, and $\alpha-\mathrm{C}-\mathrm{H}$ transfer with $\mathrm{H}_{2} \mathrm{O}$ loss to generate MDO. Isoindoline tautomerization is involved in this reaction to form indole (Scheme 21, bottom). 

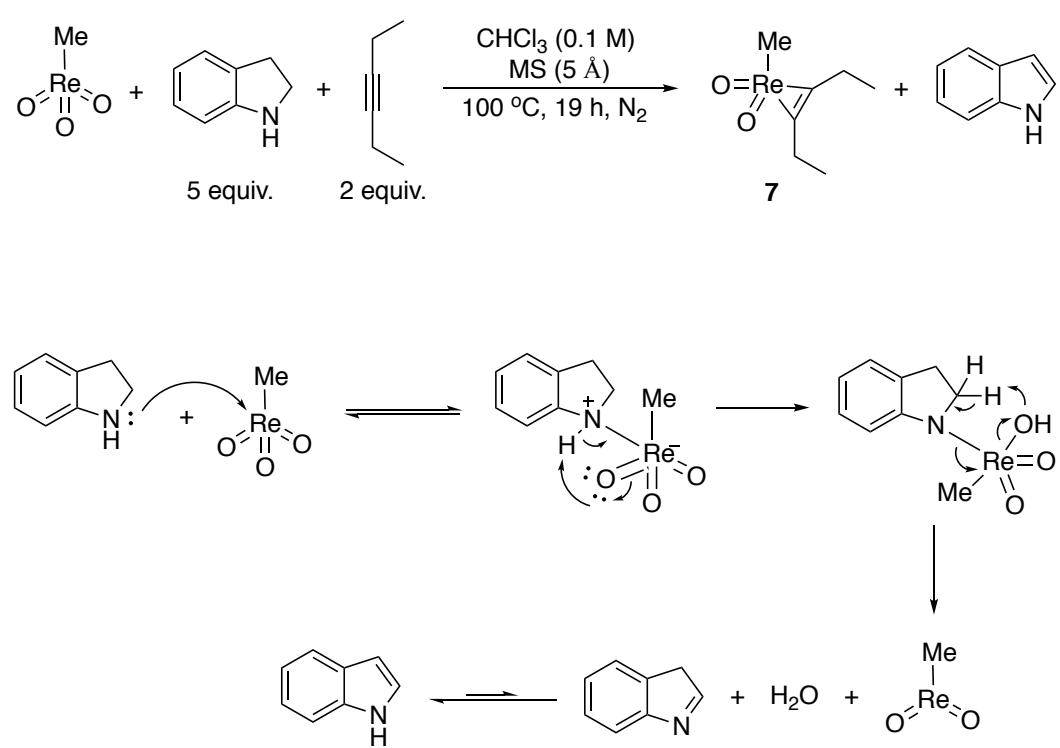

Scheme 21. Top: indoline-mediated synthesis of organorhenium(V) compound 7; Bottom: possible mechanism of MTO reduction by indoline. ${ }^{[40]}$

\subsubsection{Perrhenate $/ \operatorname{Re}_{2} \mathrm{O}_{7} /$ Perrhenic Acid}

Besides Cp-based trioxorhenium complexes and methyltrioxorhenium, another series of high valent rhenium compounds, including perrhenic acid, perrhenates, and hepta-oxo-dirhenium $\left(\mathrm{Re}_{2} \mathrm{O}_{7}\right)$, have also been investigated as catalysts for the DODH of diols and polyols. Considering that these compounds generate the same active species $\left(\mathrm{ReO}_{4}^{-}\right)$, the corresponding studies will be summarized in this section. Studies on perrhenic acid and perrhenates have in many cases been reported alongside with MTO studies, while extending the catalyst scope or in mechanistic studies. In this section, only selected studies closely related to perrhenates, perrhenic acid, and $\mathrm{Re}_{2} \mathrm{O}_{7}$ will be discussed in detail.

Sodium perrhenate $\left(\mathrm{NaReO}_{4}\right)$ was firstly investigated as catalyst for the DODH of diols and polyols by Nicholas in 2010. ${ }^{[28]}$ By using $10 \mathrm{~mol} \%$ of $\mathrm{NaReO}_{4}$ as catalyst, 1.0-1.5 equiv. of $\mathrm{Na}_{2} \mathrm{SO}_{3}$ as reductant, $\mathrm{PhCl}$ as solvent, $4 \%$ of 1-octene was formed from 1,2-octanediol (8\% conversion) after heating at $150^{\circ} \mathrm{C}$ for $88 \mathrm{~h}$. The catalytic activity was quite low compared to MTO in the same reaction system. Later on, ammonium perrhenate $\left(\mathrm{APR}, \mathrm{NH}_{4} \mathrm{ReO}_{4}\right)$ and tetrabutylammonium perrhenate $\left(\left[\left({ }^{n} \mathrm{Bu}\right)_{4} \mathrm{~N}\right] \mathrm{ReO}_{4}\right)$ was applied to the DODH of diols using sulfite as the reductant. ${ }^{[29]}$ A $68 \%$ yield of 1-octene could be achieved with full substrate conversion by using $10 \mathrm{~mol} \%$ of $\left[\left({ }^{n} \mathrm{Bu}\right)_{4} \mathrm{~N}\right] \mathrm{ReO}_{4}$ as catalyst, 1.5 equiv. of $\mathrm{Na}_{2} \mathrm{SO}_{3}$ as reductant, benzene as solvent, 15 -crown- 15 as additive, and heating at $150^{\circ} \mathrm{C}$ for $100 \mathrm{~h}$. 
In 2013, Nicholas reported a DODH reaction system using APR as catalyst and benzyl alcohol as reductant. ${ }^{[41]}$ Moderate to excellent olefin yields (23-95\%) were achieved in this DODH reaction system. The authors describe a number of advantages of this reaction system (Scheme 22). By cooling the reaction mixture to room temperature, APR could be easily recovered by filtration because of its low solubility in aromatic solvents. Also, the aryl aldehyde formed from the reaction could be removed by treating the reaction mixture with aqueous $\mathrm{NaHSO}_{3}$, forming a benzaldehyde bisulfite adduct as precipitate. The olefin product could then be separated by solvent evaporation or distillation and the benzaldehyde could be recovered in good yield by treating the adduct with $\mathrm{NaHCO}_{3}$ and extraction with ethyl acetate.

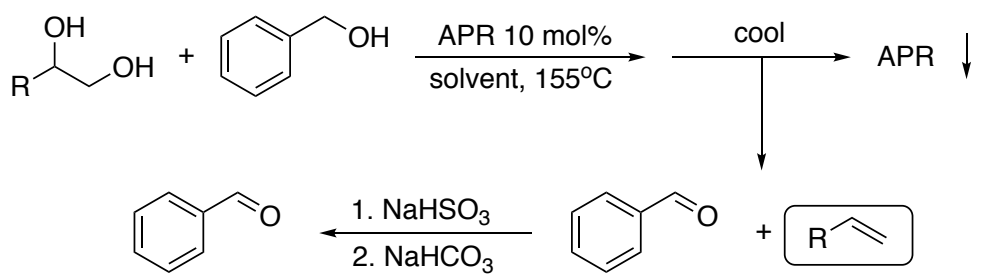

Scheme 22. Product separation and catalyst recovery of the $\mathrm{APR} / \mathrm{PhCH}_{2} \mathrm{OH}$ system. ${ }^{[41]}$

APR was almost quantitively recovered by precipitation from the reaction mixture at room temperature. By reusing the recovered catalyst for the DODH of (+)-diethyl tartrate, after an initial drop from $95 \%$ to $80 \%$ for the first and second cycle, the next five cycles provided almost constant olefin yield (approximately $80 \%$ to $85 \%$ ). Accordingly, this $\mathrm{APR} / \mathrm{PhCH}_{2} \mathrm{OH}$ system offers an efficient DODH of diols and allows for convenient product separation and catalyst recovery.

In 2014, a perrhenate-catalyzed DODH of diols with element reductants was reported by Nicholas. ${ }^{[42]}$ Zinc (Zn), iron (Fe), manganese (Mn), and carbon (C) were investigated with 10 mol $\%$ of APR as catalyst for the DODH of 1,2-decanediol at $150{ }^{\circ} \mathrm{C}$. Moderate 1-decene yield (62-69\%) was obtained with full substrate conversion. For other diols, including 1-phenyl-1,2ethanediol, diethyl tartrate (DET), and 3-(octadecyloxy)propane-1,2-diol, the DODH product yields ranged from 46 to $85 \%$. In case of the DODH of DET, considering the high boiling point of both DET and diethyl fumarate (DEF, DODH product of DET), solventless conditions were employed at $150{ }^{\circ} \mathrm{C}$ for $24 \mathrm{~h}$ combining DET, carbon, and APR under $\mathrm{N}_{2}$ to obtain $60 \%$ of DEF. A scale-up experiment with DET (3.9 mmol)/Zn/APR provided an $84 \%$ isolated yield of DEF.

In this study, trans $-\left[(\mathrm{Py})_{4} \mathrm{ReO}_{2}\right] \mathrm{Cl}$ and trans $-\left[(\mathrm{Py})_{4} \mathrm{ReO}_{2}\right] \mathrm{PF}_{6}$ was also investigated as catalysts for the DODH of 1,2-decanediol with 2.0 equivalent of $\mathrm{Zn}$ as reductant. With full substrate conversion, the 1 -decene yield was $90 \%$ and $67 \%$, respectively. The authors claimed that this 
trans-[(Py) $\left.{ }_{4} \mathrm{ReO}_{2}\right]^{+}$-catalyzed DODH operates through a $\mathrm{Re}(\mathrm{V}) \leftrightarrow \mathrm{Re}(\mathrm{VII})$ catalytic cycle. They performed a stochiometric reaction between 1,2-decanediol (1.6 eq.) and trans-[( $\left.\left.\mathrm{Py}_{4}\right) \mathrm{ReO}_{2}\right] \mathrm{Cl}$ ( 1.0 eq.), which yielded $98 \%$ of 1 -decene (with respect to $\mathrm{Re}$ ) while no oxidation products of the diol (aldehydes, ketones) were detected. This result indicates that the $\operatorname{Re}(\mathrm{V})$ complex is not reduced by the 1,2-decanediol substrate and that a $\left[(\mathrm{Py})_{n} \mathrm{Re}^{\mathrm{VII}} \mathrm{O}_{3}\right]^{+}$intermediate is probably involved in this reaction (Scheme 23).

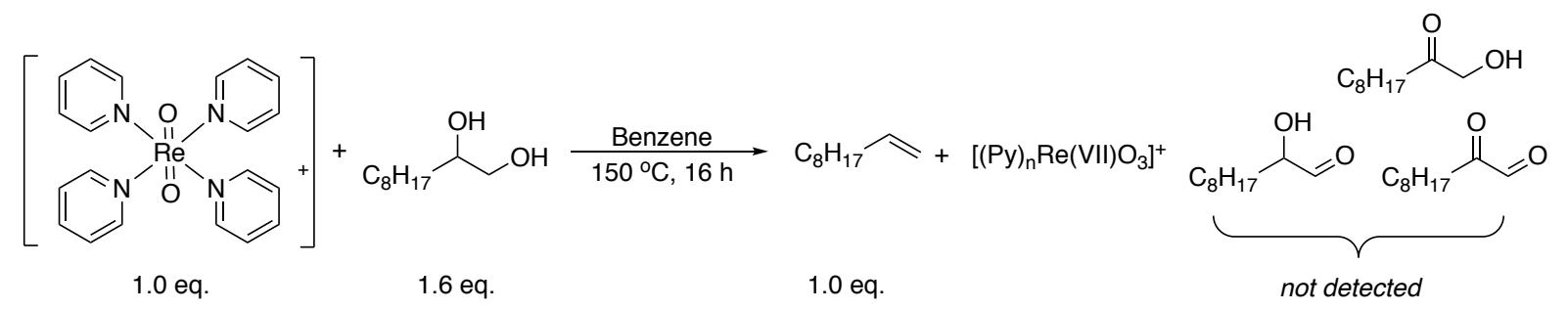

Scheme 23. Stochiometric reaction of 1,2-decanediol and trans-[(Py) $\left.{ }_{4} \mathrm{ReO}_{2}\right] \mathrm{Cl}^{[42]}$

In 2017, Toste reported on a catalyst system that directly provides adipates from glucose derivatives in a single operation using $\mathrm{H}_{2}$ as terminal reductant. ${ }^{[43]}$ This reaction system combines $\mathrm{KReO}_{4}$-catalyzed DODH of glucose derivatives and Pd-catalyzed hydrogenation of olefins to obtain adipates, remarkably only using $\mathrm{H}_{2}$ as reductant for both two steps. The optimized reaction conditions are $1 \mathrm{~mol} \% \mathrm{KReO}_{4}, 0.75 \mathrm{~mol} \% \mathrm{Pd} / \mathrm{C}, 3 \mathrm{~mol} \% \mathrm{H}_{3} \mathrm{PO}_{4}, 27 \mathrm{wt} \%$ activated $\mathrm{C}, 5$ bar $\mathrm{H}_{2}$, and $\mathrm{MeOH}(0.1 \mathrm{M})$ as solvent at $150{ }^{\circ} \mathrm{C}$ for $18 \mathrm{~h}$. A variety of polyhydroxylated esters and lactones have been applied with this reaction system (Scheme 24).

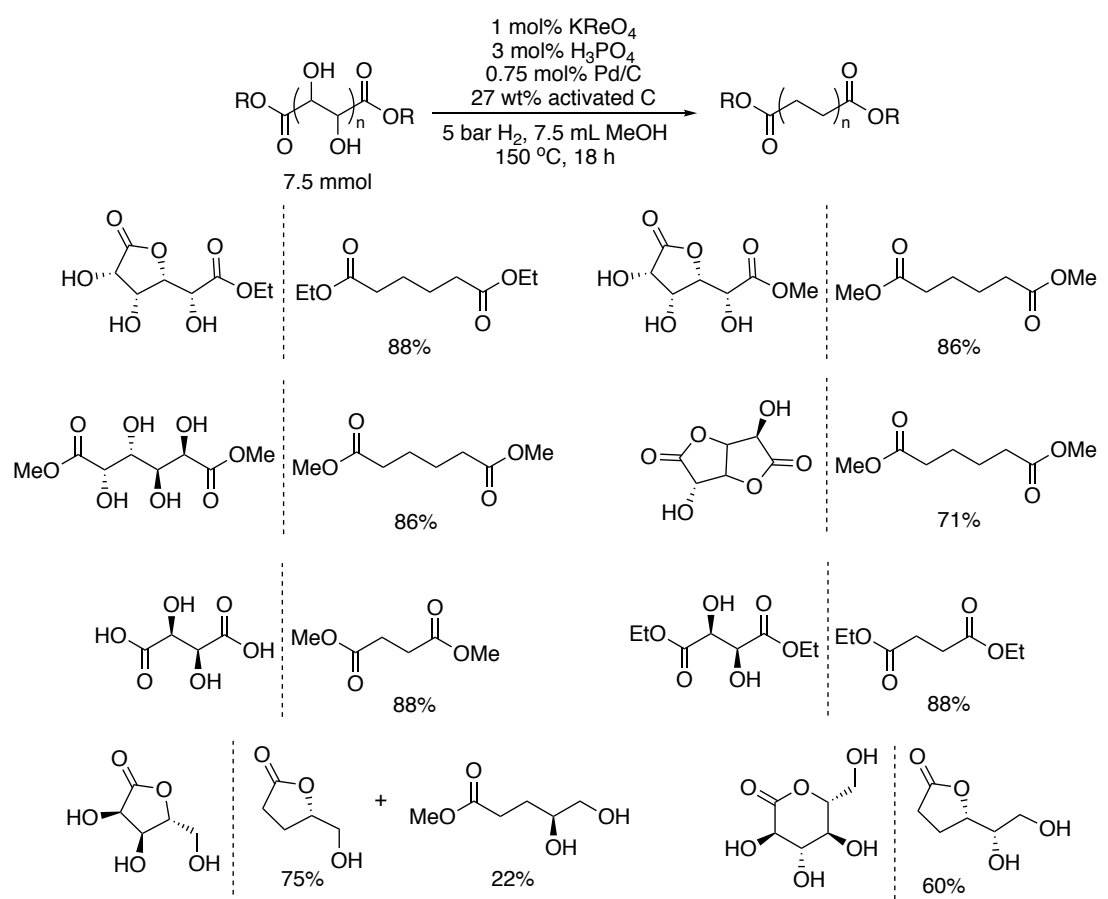

Scheme 24. Hydrogen gas-mediated deoxydehydration/hydrogenation of sugar acids. ${ }^{[43]}$ 
A competition experiment was also reported, using an equimolar mixture of DET and 1,2dodecanediol as substrate. Diethyl succinate was produced while no dodecane was detected, indicating that complete selectivity for the DODH of vicinal diols in the $\alpha, \beta$ positions of an carboxylic acid and ester can be achieved using these reaction conditions. As part of a mechanistic study, applying diethyl 2-oxopentanedioate and ethyl 3-oxobutanoate to this reaction systems provided no DODH/hydrogenation product in former case, while only trace amounts of DODH/hydrogenation product were detected in latter case (Scheme 25). These results indicate that no intermediacy of ketonic dehydration products is involved in this reaction system. The authors proposed that the ester group of the substrate might facilitate the DODH reaction either by serving as an electron-withdrawing group or by coordinating to the rhenium catalyst.

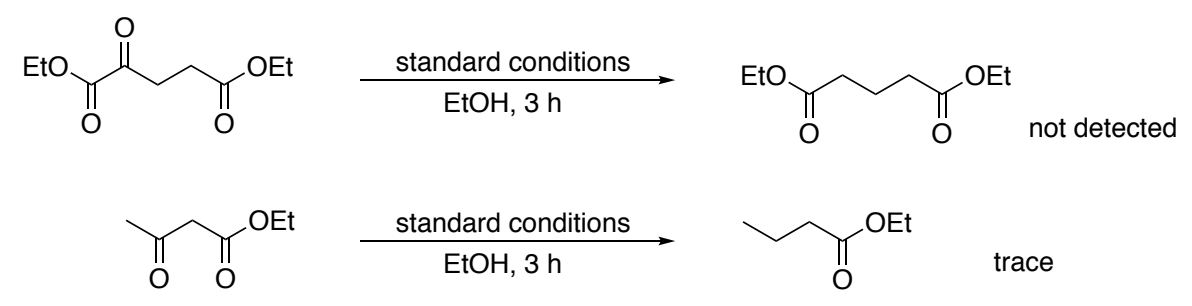

Scheme 25. Competence of diol dehydration products. ${ }^{[43]}$

Control reactions were carried out by investigating the DODH of 1-phenyl-1,2-ethanediol and ester-substituted 1-phenyl-1,2-ethanediol (Scheme 26). In case of ester-substituted 1-phenyl1,2-ethanediol, a higher yield was obtained compared to using 1-phenyl-1,2-ethanediol as substrate. An experiment using a 1:1 ratio of 1-phenyl-1,2-ethanediol and ester-substituted 1phenyl-1,2-ethanediol as substrates showed a complete selectivity for the DODH of the estersubstituted substrate under the standard reaction conditions. Based on these results, the authors claimed that the ester (or other electron-withdrawing groups) would benefit the reaction by accepting electron density from a vicinal carbon-oxygen $\sigma$ orbital into its $\pi^{*}$ orbital, lowering the energy of the transition state for $\mathrm{C}-\mathrm{O}$ bond cleavage.

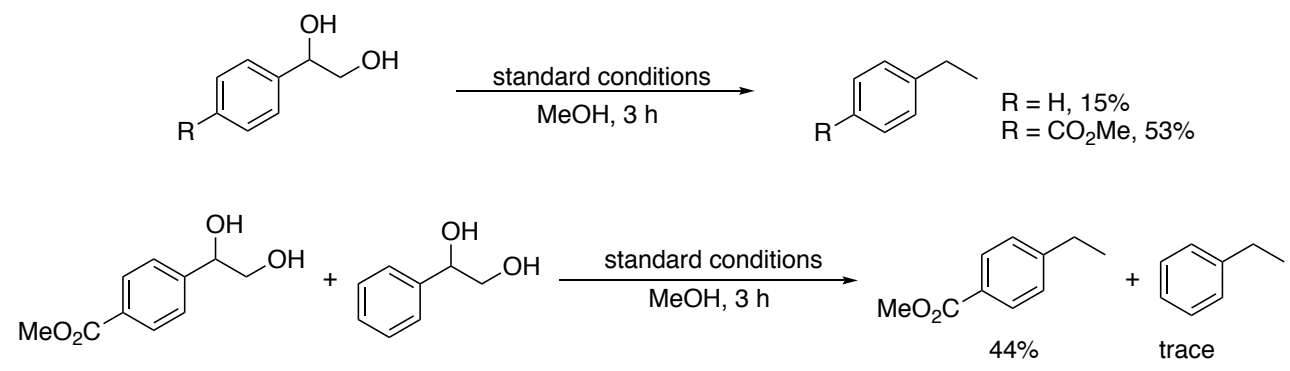

Scheme 26. Impact of electronic properties of diol substrates. ${ }^{[43]}$ 
In addition, when the solvent of this reaction system was switched to water; $19 \%$ of adipic acid was formed from glucarodilactone. By adding 4-dimethylaminopyridine (DMAP) to stabilize the rhenium catalyst, ${ }^{[44]}$ the adipic acid yield could be improved to $72 \%$ (scheme 27 ).

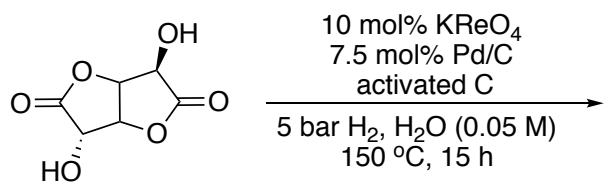<smiles>O=C(O)CCCCC(=O)O</smiles>

$70 \mathrm{wt} \% \mathrm{C}$, no ligand, $19 \%$ $120 \mathrm{wt} \%, 10 \mathrm{~mol} \%$ DMAP, $72 \%$

Scheme 27. Hydrogen gas-mediated deoxydehydration/hydrogenation of glucarodilactone. ${ }^{[43]}$

Except these commercially available perrhenates described above, Love reported a series of pyridinium perrhenates as catalysts for the DODH of diols and polyols. ${ }^{[45]}$ The pyridinium perrhenates and ammonium perrhenates $\left(\mathrm{ZReO}_{4}\right.$, cation of these perrhenates listed in Scheme 28) were prepared by liquid-liquid extraction of perrhenic acid into a solution of the base in toluene. The solid-state structures of several of these compounds were determined by singlecrystal X-ray crystallography. Except for 10 and 11, a H-bonding interaction was observed between the $\mathrm{N}-\mathrm{H}$ moiety in the pyridinium cation and the $\mathrm{ReO}_{4}{ }^{-}$anion. Due to the sterically hindering tert-butyl groups of $\mathbf{1 1}$, a $\mathrm{C}-\mathrm{H}-\mathrm{O}$ hydrogen-bond was seen in the case of $\mathbf{1 1}$. In case of 10, the diamido motif promoted diffuse $\mathrm{N}-\mathrm{H}$ and $\mathrm{C}-\mathrm{H}$ hydrogen bonding to $\mathrm{ReO}_{4}{ }^{-}$.<smiles>CCCCNC(=O)C(C(=O)Nc1ccccc1)c1cc(C(C)(C)C)cc(CCCC)n1</smiles>

10

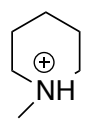

17<smiles>CN(C)c1ccccc1</smiles>

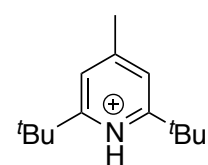

11

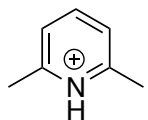

12

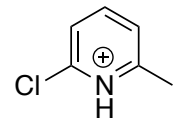

13

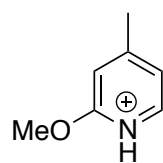

14

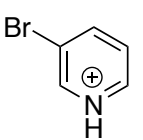

15<smiles></smiles>

16 $\stackrel{\oplus}{\mathrm{N}} \mathrm{H}_{3}\left(\mathrm{C}_{6} \mathrm{H}_{13}\right) \quad \stackrel{\oplus}{\mathrm{N}} \mathrm{H}_{2}\left(\mathrm{C}_{6} \mathrm{H}_{13}\right)_{2}$ $\stackrel{\oplus}{\mathrm{N}} \mathrm{H}\left(\mathrm{C}_{6} \mathrm{H}_{13}\right)_{3}$ $\stackrel{\oplus}{\mathrm{N}}\left(\mathrm{C}_{6} \mathrm{H}_{13}\right)_{4}$ $\stackrel{\oplus}{\mathrm{N}}\left(\mathrm{C}_{4} \mathrm{H}_{9}\right)_{4}$ $\stackrel{\oplus}{\mathrm{NH}_{4}}$

Scheme 28. Cations in perrhenate salts $\left(\mathrm{ZReO}_{4}, \mathrm{Z}=\right.$ cation $)$ reported by Love. ${ }^{[4]}$

The perrhenates listed in Scheme 28 were then investigated as catalysts for the DODH of 1phenyl-1,2-ethanediol in $\mathrm{CDCl}_{3}$ at $80{ }^{\circ} \mathrm{C}$. Quaternary ammonium salts, e.g., [( ${ }^{n}$ hexyl $\left.)_{4} \mathrm{~N}\right] \mathrm{ReO}_{4}$, $\left[\left({ }^{n} \mathrm{Bu}\right)_{4} \mathrm{~N}\right] \mathrm{ReO}_{4}$, and APR, were ineffective as catalyst under these reaction conditions, while the other ammonium perrhenates were much less effective than the pyridinium perrhenates. The highest conversion was obtained after $4 \mathrm{~h}$ at $80{ }^{\circ} \mathrm{C}$ using 11 as catalyst. Considering the poor dissolubility of 11 in $\mathrm{CDCl}_{3}$, the second efficient perrhenate $\mathbf{1 2}$ was then chosen as catalyst for further investigations. By screening solvents and reductants, the reaction conditions were optimized to be: $5 \mathrm{~mol} \%$ of 12 as catalyst, 1.1 equiv. of $\mathrm{PPh}_{3}$ as reductant, and $0.5 \mathrm{~mL} \mathrm{CDCl}_{3}$ 
as solvent. The temperature of this reaction was dependent on the substrates: $90{ }^{\circ} \mathrm{C}$ for activated vicinal diols and $140{ }^{\circ} \mathrm{C}$ for aliphatic vicinal diols. Both aromatic and aliphatic vicinal diols could be converted to the corresponding olefins with moderate to excellent yields $(21 \%$ to quantitative).

The reaction mechanism was studied by means of DFT calculations on lutidinium perrhenate. The favored catalytic cycle starts with the reduction of perrhenate, instead of the condensation of perrhenate and diol. After the reduction, $\mathrm{OPPh}_{3}$ dissociates from the Re center and a trigonal planar $\mathrm{Re}^{\mathrm{V}}$-intermediate $\mathbf{1 9}$ is generated, which further condenses with the diol to form tetracoordinated intermediate $\mathbf{2 0}$, followed by water elimination to generate $\mathrm{Re}^{\mathrm{V}}$-diolate 21 . The last step of the catalytic cycle is the olefin extrusion to regenerate the lutidinium perrhenate (Scheme 29). The rate-limiting step of this catalytic cycle is the reduction of the $\mathrm{Re}^{\mathrm{VII}}$ species to the $\operatorname{Re}^{\mathrm{V}}$ species.

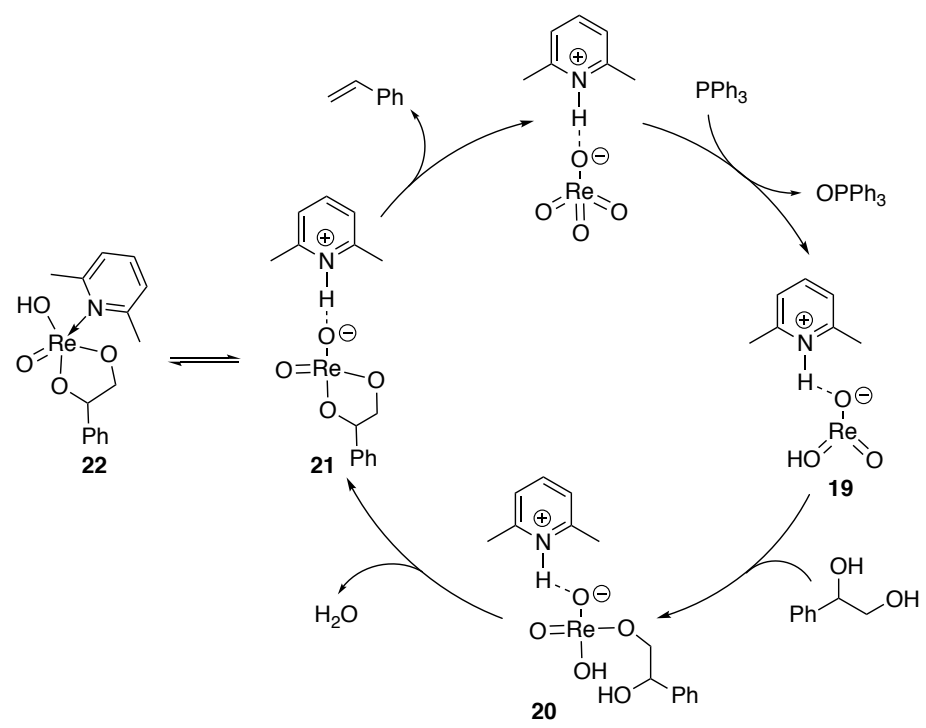

Scheme 29. Proposed mechanism of lutidinium perrhenate-catalyzed DODH. ${ }^{[4]}$

Related to $\mathrm{Re}^{\mathrm{V}}$-diolate 21, another neutral complex $\mathrm{Re}^{\mathrm{V}} \mathrm{O}(\mathrm{OH})$ (diolate)(2,6-lutidine) 22 was proposed, which could be formed from 21 via consecutive proton transfer. Although a different catalytic activity was observed for ammonium perrhenate and lutidinium perrhenate, similar energetics were observed based on DFT calculations. Love et al. then proposed the neutral intermediate 22. DFT calculation of the catalytic cycle involving this neutral intermediate showed that the elimination from cationic intermediate $\mathbf{2 1}$ was thermodynamically more favorable, which then indicated that the formation of $\mathbf{2 2}$ should be limited. On the other hand, the stability of this neutral intermediate highly depended on steric effects, i.e., the stability of $\mathrm{Re}^{\mathrm{V}} \mathrm{O}(\mathrm{OH})($ diolate $)(\mathrm{L})$ increased with a smaller steric bulk of $\mathrm{L}$. In this case the neutral 
intermediate in the ammonium perrhenate-catalyzed reaction was more stable than the one in the lutidinium perrhenate-catalyzed reaction. In another words, the former reaction had a more stable off-cycle species, which then explained why the former catalyst was less efficient.

Almost at the same time, a mechanistic study of the perrhenate-catalyzed DODH of vicinal diols was reported by Hadadzadeh and Farrokhpour. ${ }^{[46]}$ DFT calculations were applied to study three pathways that were proposed on the basis of previously reported studies (Scheme 30). ${ }^{[34-}$ ${ }^{36]}$ In pathway A, perrhenate condenses with the diol to form a Re ${ }^{\mathrm{VII}}$-diolate, $\mathrm{PPh}_{3}$ then reduces this $\mathrm{Re}^{\mathrm{VII}}$-diolate to a $\mathrm{Re}^{\mathrm{V}}$-diolate via $\mathrm{O}$-transfer, and olefin extrusion happens from the $\mathrm{Re}^{\mathrm{V}}$ diolate to regenerate $\mathrm{ReO}_{4}^{-}$. Pathways $\mathrm{B} 1$ and $\mathrm{B} 2$ both start with the reduction of $\mathrm{ReO}_{4}^{-}$to form $\mathrm{ReO}_{3}{ }^{-}$, followed by diol condensation to generate a $\mathrm{Re}^{\mathrm{V}}$-diolate intermediate. In pathway $\mathrm{B} 1$ the last step is the same as in pathway $\mathrm{A}$, i.e. olefin extrusion of $\mathrm{Re}^{\mathrm{V}}$-diolate to regenerate $\mathrm{ReO}_{4}{ }^{-}$. In pathway $\mathrm{B} 2$, a $\mathrm{Re}^{\mathrm{V}} \leftrightarrow \mathrm{Re}^{\mathrm{III}}$ cycle is involved, in line with Abu-Omar's work. ${ }^{[36]}$ The $\mathrm{Re}^{\mathrm{V}}$ diolate would be further reduced by $\mathrm{PPh}_{3}$ to generate a $\mathrm{Re}^{\mathrm{III}}$-diolate species, which then releases the olefin to regenerate $\mathrm{ReO}_{3}{ }^{-}$.In this case, perrhenate is only the pre-catalyst while $\mathrm{ReO}_{3}{ }^{-}$is the actual active species of the catalytic cycle.
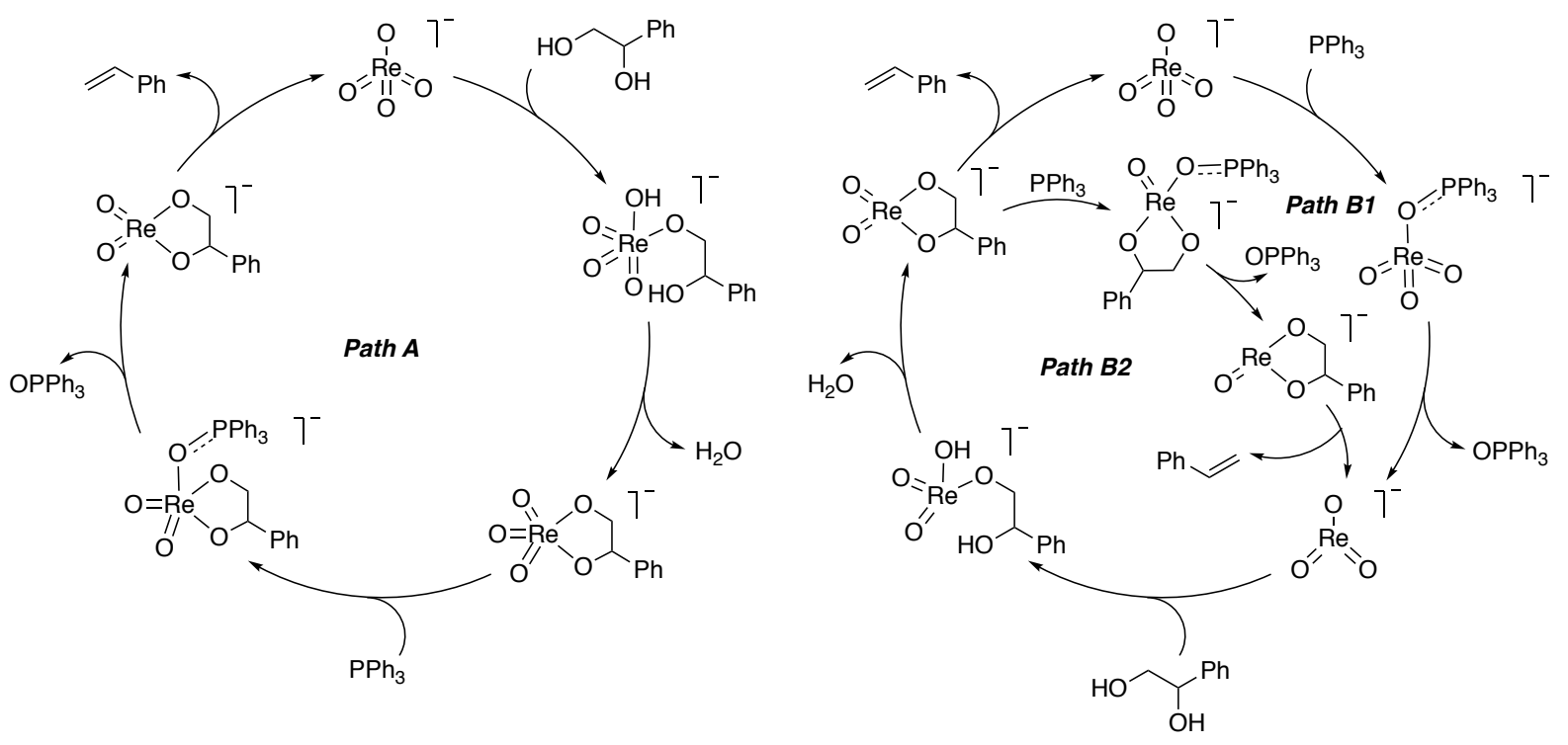

Scheme 30. Catalytic cycles of perrhenate-catalyzed DODH proposed by Hadadzadeh and Farrokhpour. ${ }^{[46]}$

DFT calculations on these three pathways indicated that the DODH reaction through all these three pathways in the gas and the chlorobenzene phase are thermodynamically feasible. Also, DODH seems thermodynamically viable in polar or hydroxyl solvents. The lowest overall energy barrier was obtained for pathway A. The free energy profile for the perrhenate-catalyzed DODH of 1-phenyl-1,2-ethanediol with $\mathrm{PPh}_{3}$ as reductant according to Hadadzadeh and 
Farrokhpour's work is summarized in Scheme 31. Interestingly, based on Love's study pathway B1 would be favored over pathway A. In Love's study, the involvement of the lutidinium cation might affect the overall energy barrier of pathway B1, and might make it more favorable.

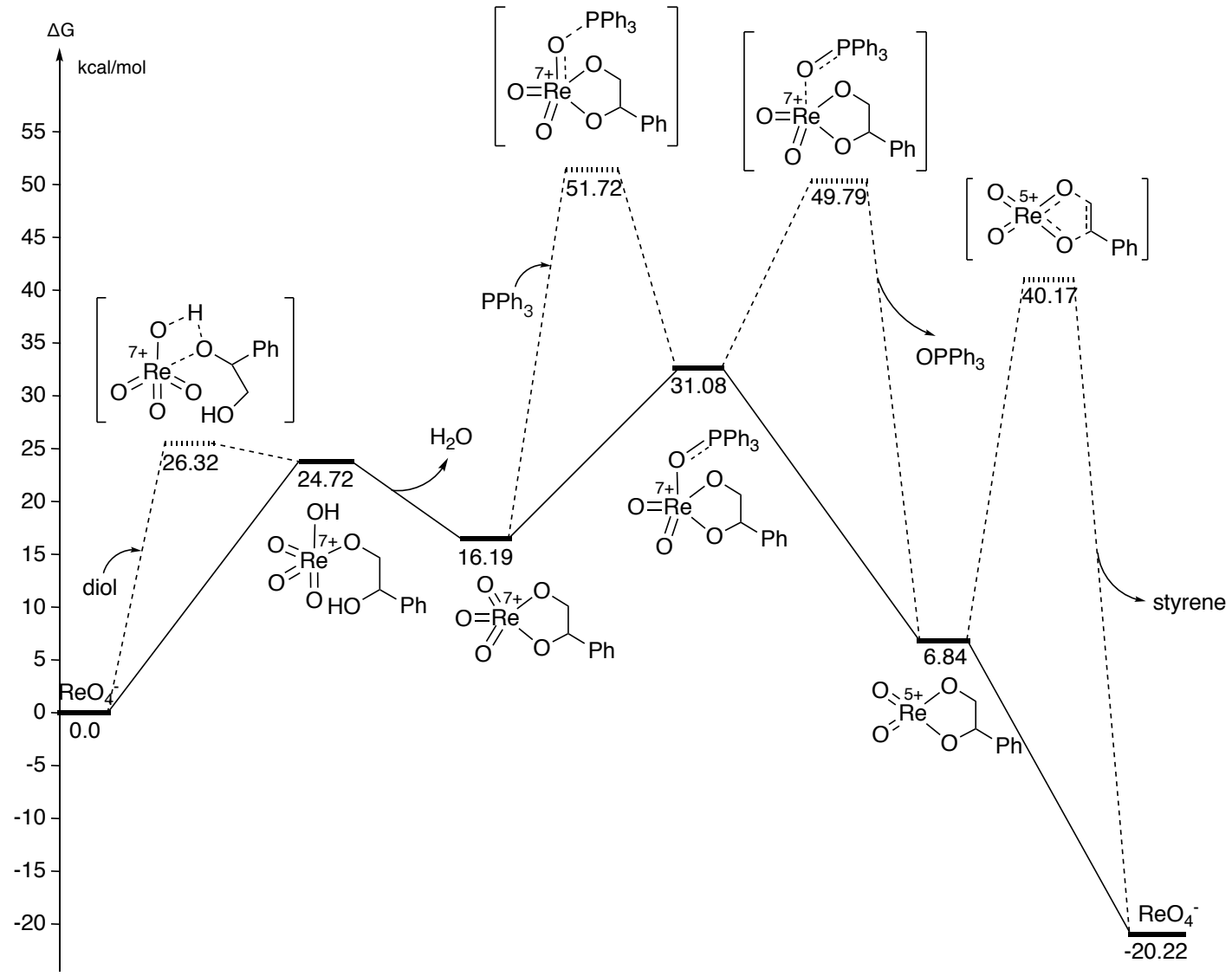

Scheme 31. Free energy profile for the perrhenate-catalyzed DODH of 1-phenyl-1,2ethanediol with $\mathrm{PPh}_{3}$ as reductant according to Hadadzadeh and Farrokhpour. ${ }^{[46]}$

Later, De Vries reported the DODH of sugar-derived triols catalyzed by $\mathrm{Re}_{2} \mathrm{O}_{7} \cdot{ }^{[47]}$ Initially, several rhenium sources like MTO, $\mathrm{Re}_{2} \mathrm{O}_{7}, \mathrm{APR}, \mathrm{Re}_{2}(\mathrm{CO})_{10}$, and 2,6-lutidinium perrhenate were investigated for the DODH of 1,2,6-hexanetriol (1,2,6-HT) using $\mathrm{PPh}_{3}$ as reductant to form hex-5-en-1-ol as the product. Among these rhenium sources only $\operatorname{Re}_{2}(\mathrm{CO})_{10}$ was inactive. Both MTO and $\mathrm{Re}_{2} \mathrm{O}_{7}$ showed full substrate conversion with $96 \%$ and $98 \%$ olefin yield, respectively. Since $\mathrm{Re}_{2} \mathrm{O}_{7}$ was more active and remarkably cheaper than $\mathrm{MTO}, \mathrm{Re}_{2} \mathrm{O}_{7}$ was selected as catalyst for further reaction condition optimization. By optimizing the reaction temperature, reducing agent, and catalyst loading, the final reaction conditions were $1 \mathrm{~mol} \%$ $\mathrm{Re}_{2} \mathrm{O}_{7}$ as catalyst and 1.1 equiv. $\mathrm{PPh}_{3}$ as reductant for $1 \mathrm{~h}$ at $165^{\circ} \mathrm{C}$ in air. Several triols were then investigated under these optimized conditions, providing moderate to excellent olefin yields (Scheme 32). 


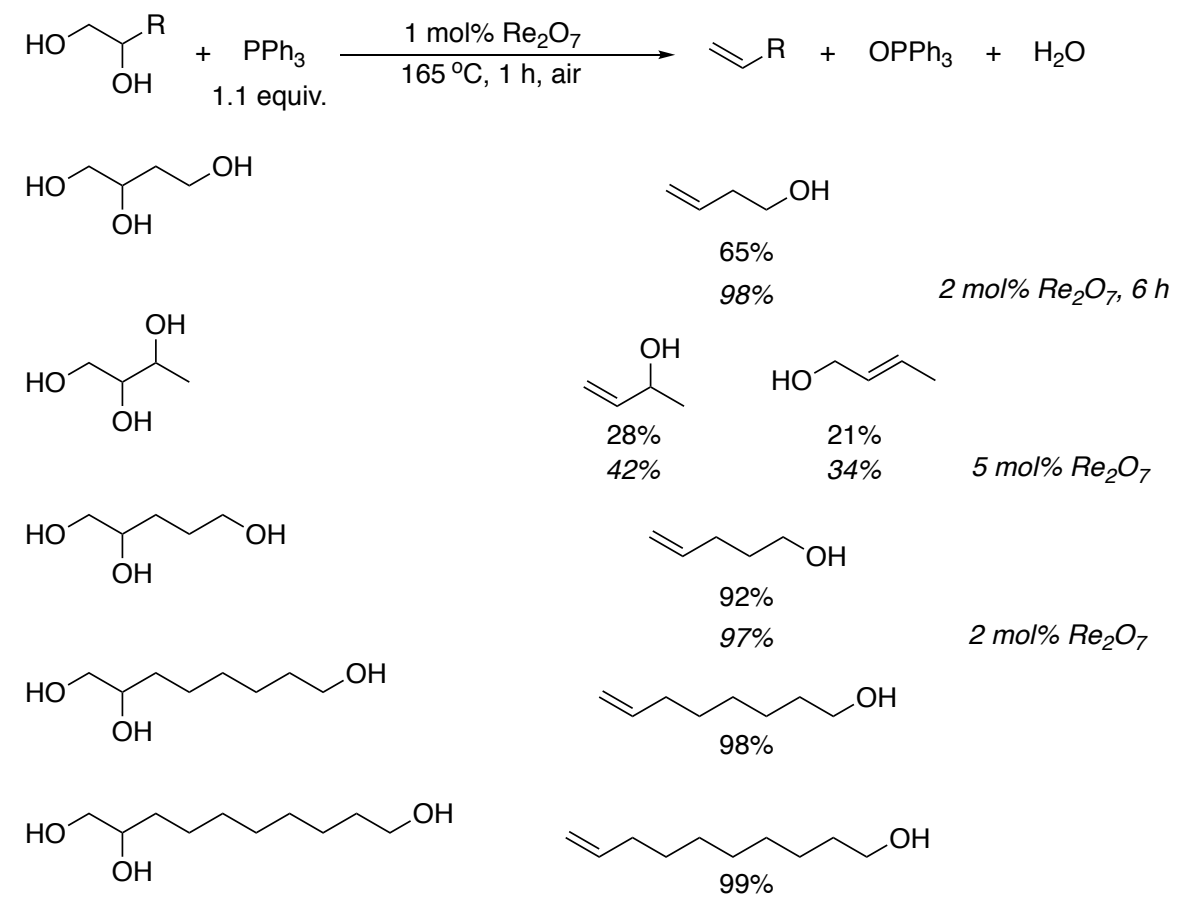

Scheme 32. $\mathrm{Re}_{2} \mathrm{O}_{7}$-catalyzed deoxydehydration of triols ${ }^{[47]}$

By adding co-catalysts to the reaction system described above, a one-pot deoxydehydrationhydrogenation reaction was obtained. $\mathrm{Pd} / \mathrm{C}, \mathrm{Pt} / \mathrm{C}$, and $\mathrm{Ru} / \mathrm{C}$ were investigated as co-catalyst for this one-pot reaction. The highest aliphatic alcohol product yield $(68 \%+12 \%)$ was achieved by using $\mathrm{Pd} / \mathrm{C}$ as co-catalyst (Scheme 33 ).

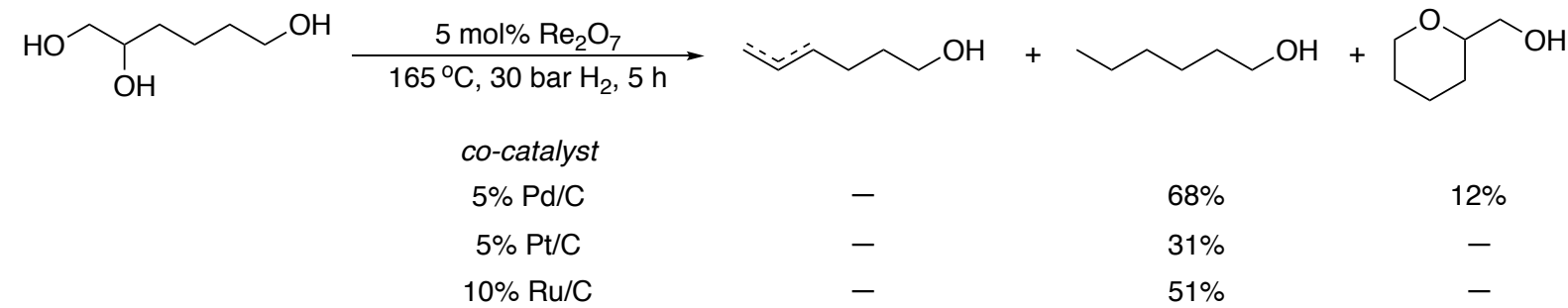

Scheme 33. One-pot deoxydehydration-hydrogenation of 1,2,6-HT ${ }^{[47]}$

\subsection{4 $\operatorname{Re}_{2}(\mathrm{CO})_{10}$ and $\mathrm{BrRe}(\mathrm{CO})_{5}$}

Last but not the least, the low valent compounds $\operatorname{Re}_{2}(\mathrm{CO})_{10}$ and $\operatorname{Br} \operatorname{Re}(\mathrm{CO})_{5}$ were also found to be active DODH catalysts in combination with secondary alcohols as reductant under aerobic conditions. ${ }^{[48]}$ An initial study by Ellman and Bergman in 2010 investigated the disproportionation of $(4 R, 5 R)$-octane-4,5-diol using $\operatorname{Re}_{2}(\mathrm{CO})_{10}$ as catalyst. $50 \%$ of $(E)$-oct-4ene was formed after heating at $180^{\circ} \mathrm{C}$ under air for $3.5 \mathrm{~h}$. Octane-4,5-dione was detected at the beginning of this reaction, along with the formation of $(E)$-oct-4-ene. Because of the instability 
of vicinal diketones under this reaction condition, the amount of vicinal diketone product eventually ceased.

In order to avoid the consumption of diol substrates via the formation of unstable vicinal diketones and to promote olefin formation, simple alcohols were added as reductant. 1,2Tetradecanediol was selected as model substrate, $\operatorname{Re}_{2}(\mathrm{CO})_{10}$ and $\operatorname{BrRe}(\mathrm{CO})_{5}$ were tested as rhenium sources, and 5-nonanol, 3-octanol, and 2-octanol were investigated as reductant. The presence of oxygen was necessary since no conversion was observed under $\mathrm{N}_{2}$ atmosphere. The highest 1-tetradecene yield (84\%) was achieved by using $\mathrm{BrRe}(\mathrm{CO})_{5}$ as catalyst, 3-octanol as reductant and solvent at $170{ }^{\circ} \mathrm{C}$ for $4 \mathrm{~h}$. Additionally, the addition of para-toluenesulfonic acid or sulfuric acid affected the DODH reaction. No conversion was observed when the reaction was performed at $155^{\circ} \mathrm{C}$ for $5 \mathrm{~h}$. By adding para-toluenesulfonic acid or sulfuric acid, good 1-tetradecene yields (74-87\%) were achieved with full substrate conversion and shorter reaction times. This significant effect of acid might be related to an assisted olefin extrusion, through protonation of a rhenium-diolate intermediate. At that time the report by Ellman and Bergman mentioned that the mechanism of the DODH reaction was still unknown. The dependence of the reaction on oxygen provides a strong indication that an oxidized rhenium species is formed as the active catalyst in this reaction.

\subsection{Molybdenum-Based DODH Catalysts/Pre-Catalysts}

As summarized in the previous section, rhenium complexes can efficiently catalyze the deoxydehydration of diols and biomass-based polyols with excellent substrate conversions and olefin product yields. However, the scarcity and high cost of rhenium asks for the availability of alternative catalysts based on less expensive metals, such as Mo and V. It is for this reason that there is a current interest in the development of homogeneous catalysts derived from these latter metals for the DODH of (biomass-derived) diols and polyols. In the next two sections, molybdenum- and vanadium-based catalysts for DODH reactions will be summarized. For the homogeneous molybdenum-catalyzed DODH of diols and polyols, a relatively limited number of examples have been reported, mainly including the use of molybdate salts ${ }^{[49-52]}$ and dioxo$\mathrm{Mo}(\mathrm{VI})$ complexes. ${ }^{[53-56]}$

\subsubsection{Ammonium Heptamolybdate (AHM, $\left.\left(\mathrm{NH}_{4}\right)_{6} \mathrm{Mo}_{7} \mathrm{O}_{24}\right)$}

Ammonium heptamolybdate (AHM), a commercially available molybdate salt, has been reported as a catalyst for the deoxydehydration of diols. The first example was reported by 
Fristrup and co-workers in 2014. ${ }^{[49]}$ Their investigations started with the $\mathrm{MoO}_{2}\left(\mathrm{CH}_{3}\right)_{2}$ (bipy) (bipy $=2,2$ '-bipyridine) catalyzed DODH of 1,2-tetradecanediol in dodecane using 3-octanol as reductant. By increasing the temperature from $175{ }^{\circ} \mathrm{C}$ to $195{ }^{\circ} \mathrm{C}$, the 1 -tetradecene yield increased from traces to $37 \%$. Screening different reductants did not increase the olefin yield and none of the reductants were oxidized to any considerable extent. Accordingly, the authors proposed to use the diol itself as the reductant in this reaction system. Different Mo sources, including $\mathrm{Mo}(\mathrm{CO})_{6}, \mathrm{Mo}(\mathrm{CO})_{4}$ (bipy), $\mathrm{MoO}_{2} \mathrm{Cl}_{2}$ (bipy), $\mathrm{MoO}_{2} \mathrm{Br}_{2}$ (bipy), $\mathrm{MoO}_{2}\left(\mathrm{CH}_{3}\right)_{2}$ (bipy), $\left(\mathrm{NH}_{4}\right)_{6} \mathrm{Mo}_{7} \mathrm{O}_{24}, \mathrm{Na}_{2} \mathrm{MoO}_{4}$, and $\mathrm{H}_{3} \mathrm{PMo}_{12} \mathrm{O}_{40}$, were tested for the DODH of 1,2-tetradecanediol. Remarkably, $\left(\mathrm{NH}_{4}\right)_{6} \mathrm{Mo}_{7} \mathrm{O}_{24}$, which is expected to be insoluble in dodecane, was active towards the deoxydehydration of 1,2-tetradecanediol. By using $5 \mathrm{~mol} \%$ of this cheap molybdate salt as catalyst, $43 \%$ of 1 -tetradecene was formed with full substrate conversion after heating at 195 ${ }^{\circ} \mathrm{C}$ for $1 \mathrm{~h}$. A lower catalyst loading did also lead to full conversion, but at a lower reaction rate.

In an attempt to identify the volatile products of this reaction system, 1,2-hexanediol was chosen as the substrate to ensure that the volatile products could be collected from the reaction mixture using a reactive distillation setup. In order to avoid the collection of solvent through the distillation setup, no additional solvent was applied. GC-MS analysis of the volatile products proved the formation of hexanal, 2-hexanone, pentanol, as well as the acetals formed by condensation of 1,2-hexanediol and pentanal or hexanal. In addition, 4-butyl-1,3-dioxolane, formed from the condensation of 1,2-hexanediol and formaldehyde, was found in the reaction residue. The observation of acetals and ketals in the reaction residue indicated that oxidative cleavage of the $\mathrm{C}-\mathrm{C}$ bond in the vicinal diol takes place during the reaction (Scheme 34 ).
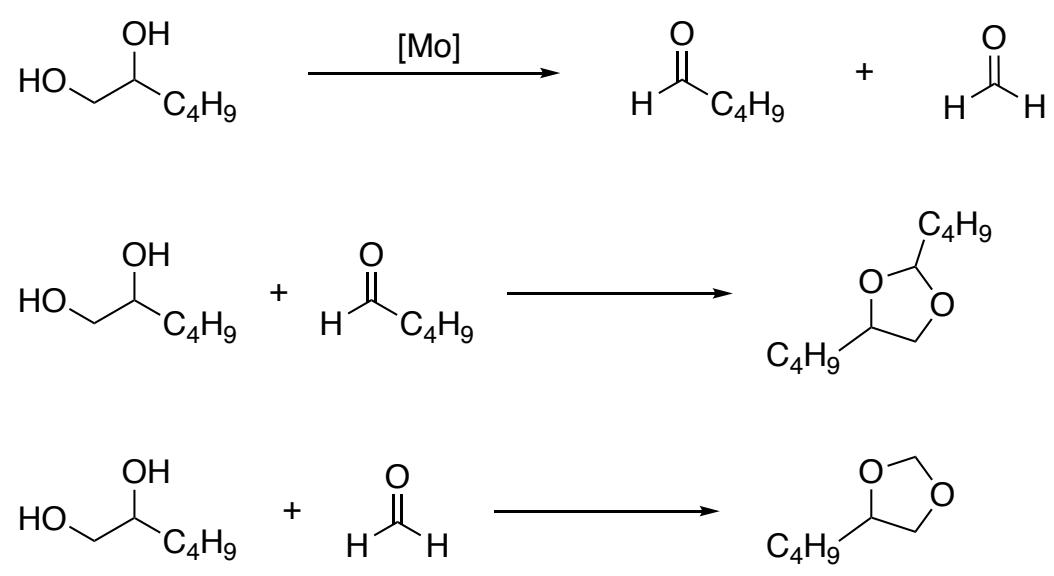

Scheme 34. Oxidative deformylation of 1,2-hexanediol during Mo-catalyzed DODH. ${ }^{[49]}$

Because the diol was used as the sacrificial reductant for the DODH reaction, the highest olefin yield of this Mo-catalyzed DODH system would be 50\%, and if the formation of acetals was 
complete, the olefin yield would then not be higher than $25 \%$. If the main objective of this reaction system was to convert diols into olefins, the formation of acetals should be limited. A solution was to add base to this reaction system. The addition of base was efficient, but instead of an increase in olefin yield, epoxide formation was observed, i.e., the use of base benefited the dehydration of diol to form corresponding epoxide. Using AHM and $\mathrm{NaOH}$ (or $\mathrm{Na}_{2} \mathrm{MoO}_{4}$, the basic version of heptamolybdate), $29 \%$ of epoxide formed. Surprisingly, the epoxide would not undergo deoxygenation to the olefin in this reaction system. By using 1,2epoxytetradecanediol as substrate and 1,2-decanediol as reductant, very low amounts $(<5 \%)$ of 1-tetradecene and 1-decene were detected. Diluting the reaction mixture by using 1,5pentanediol as solvent, $45 \%$ of 1 -hexene and $40 \%$ of allyl alcohol were obtained in this AHMcatalyzed DODH reaction. However, 95\% conversion of 1,5-pentanediol was observed when heating the neat diol to $200{ }^{\circ} \mathrm{C}$ with $0.4 \mathrm{~mol} \%$ of AHM, showing that it is not an inert solvent under these conditions. The observation of an olefin yield lower than $50 \%$ indicated that vicinal diol deformylation was the oxidation step during the catalytic cycle, and that the 1,5pentanediol solvent was not consumed as reductant in this reaction.

The mechanism of the AHM-catalyzed DODH reaction was then investigated by DFT calculations. ${ }^{[51]}$ Unlike the catalytic cycle of Re-catalyzed DODH, the reduction of $\mathrm{Mo}^{\mathrm{VI}}$ to $\mathrm{Mo}^{\mathrm{IV}}$ seems to proceed through oxidative C-C bond cleavage of the diol. DFT calculations therefore focused on the diolate cleavage and olefin extrusion steps. Based on the calculations, diolate cleavage from mononuclear Mo-dioxo monodiolate 23 is unfavorable (Scheme 35).

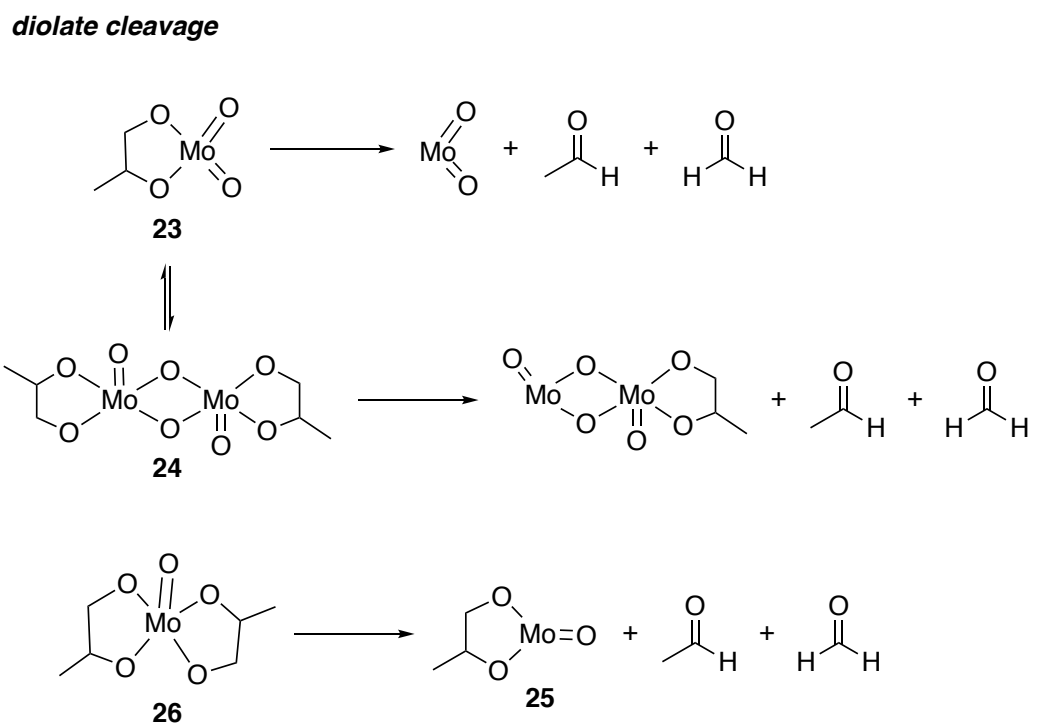

Scheme 35. Possible diolate cleavage pathways in AHM-catalyzed DODH considered by Fristrup. ${ }^{[51]}$ 
Comparing the thermodynamic stabilities of the mononuclear monodiolate $\mathbf{2 3}$ and its dimer $\mathbf{2 4}$ showed that the latter is more stable at room temperature, while its formation is only favored by $0.9 \mathrm{kacl} / \mathrm{mol}$ at $453 \mathrm{~K}$. Next diolate cleavage from $\mathbf{2 4}$ was compared to that from the Momono-oxo bisdiolate 26 (Scheme 35). Diolate cleavage from bisdiolate 26 was found to be 1.3 $\mathrm{kcal} / \mathrm{mol}$ more favorable than cleavage from dinuclear monodiolate $\mathbf{2 4}$. In addition, olefin extrusion is $11.5 \mathrm{kcal} / \mathrm{mol}$ more favorable from mononuclear $\mathbf{2 6}$ than from dinuclear 24.

For the olefin extrusion also the extrusion from mononuclear bisdiolate $\mathbf{2 7}$ and mononuclear monodiolate 25 were investigated (Scheme 36). The extrusion from 27 and 25 through both reverse [3+2] cycloaddition and reverse [2+2] cycloaddition was calculated, showing that olefin extrusion through a reverse [3+2] cycloaddition mechanism from 25 is most favorable.

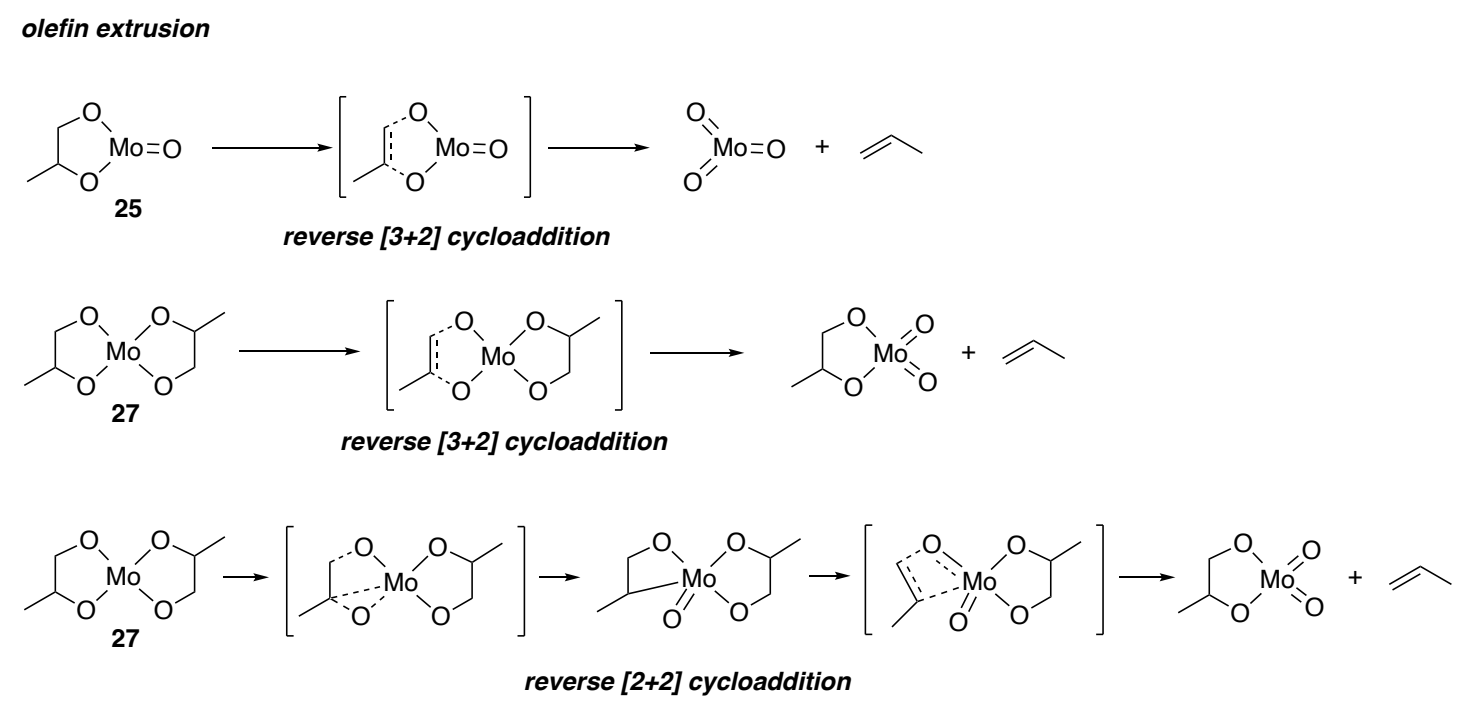

Scheme 36. Possible olefin extrusion pathways from reduced Mo-species considered by Fristrup. ${ }^{[51]}$

Based on these combination theoretical studies, the authors proposed a catalytic cycle for AHM-catalyzed DODH that starts with a twofold condensation reaction of a " $\mathrm{MoO}_{3}$ " moiety and the diol substrate to form $\mathrm{Mo}^{\mathrm{VI}}$-bisdiolate 26. $\mathrm{C}-\mathrm{C}$ bond oxidative cleavage of one of the diolate ligands in $\mathbf{2 6}$ forms formaldehyde and acetaldehyde, and generates the reduced $\mathrm{Mo}^{\mathrm{V}}$ diolate 25. Olefin extrusion from $\mathbf{2 5}$ then yields the olefin product and regenerates the starting " $\mathrm{MoO}_{3}$ " moiety (Scheme 37). The free energy profile for the AHM-catalyzed deoxydehydration of 1,2-propanediol with the diol itself as reductant at both $298 \mathrm{~K}$ and $453 \mathrm{~K}$ according to Fristrup's study is depicted in Scheme 38 and Scheme 39. The most significant differences between these two energy profiles are the diolate cleavage and the olefin extrusion steps. These two steps are the most energy-demanding steps at both $298 \mathrm{~K}$ and $453 \mathrm{~K}$. According to Fristrup the larger contribution of entropy to the overall free energy at higher temperature causes the difference between these two energy profiles. At $298 \mathrm{~K}$, an energy span 
of $33.9 \mathrm{kcal} / \mathrm{mol}$ was found for the diolate to olefin extrusion step. At $453 \mathrm{~K}$, the corresponding energy span is only $20.4 \mathrm{kacl} / \mathrm{mol}$.

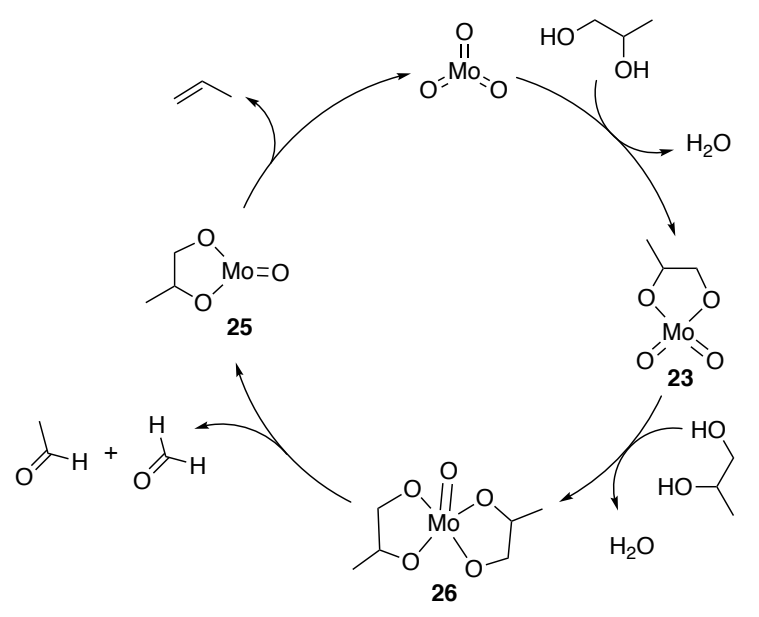

Scheme 37. Proposed catalytic cycle of AHM-catalyzed DODH using the diol itself as reductant. ${ }^{[51]}$

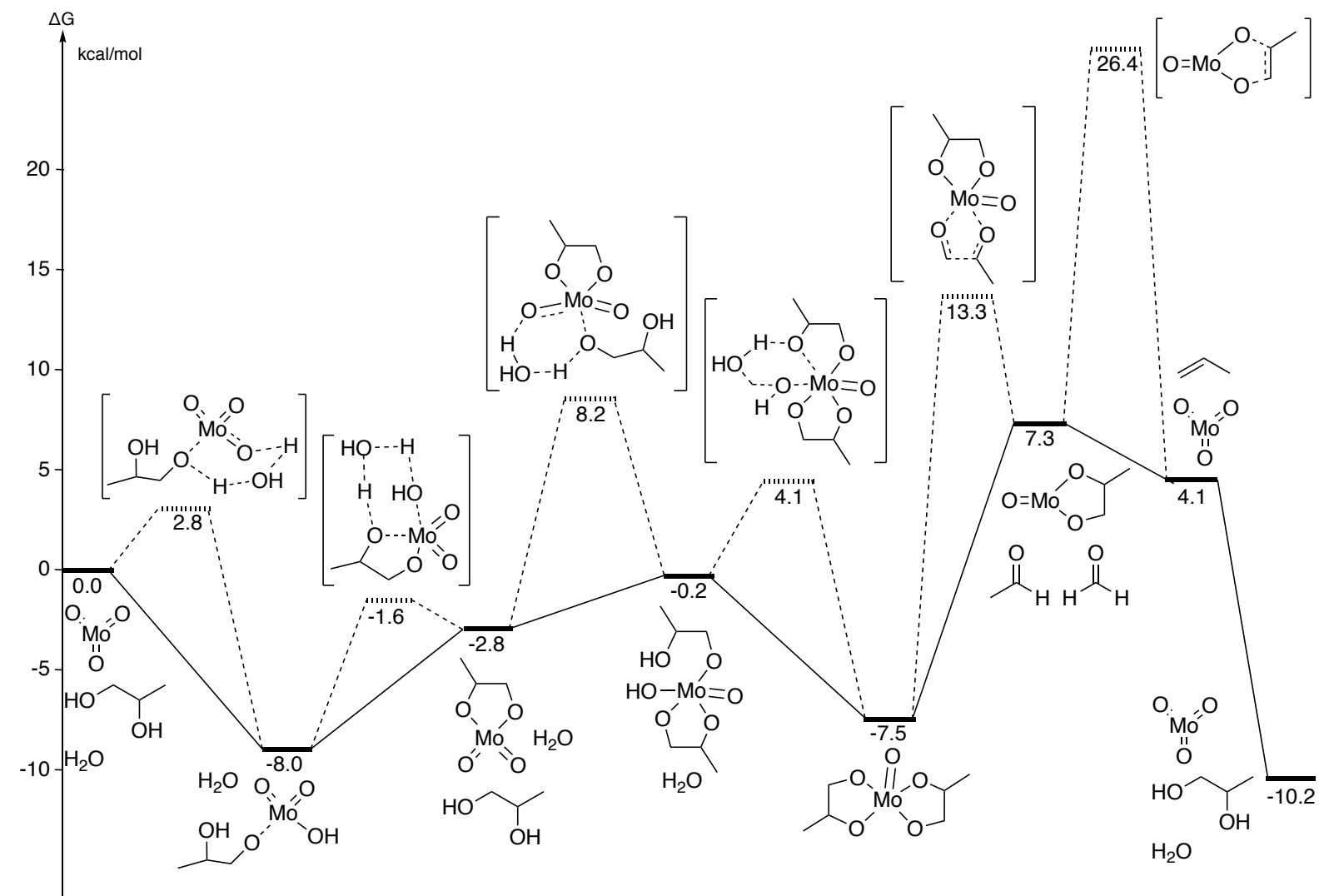

Scheme 38. Free energy profile for AHM-catalyzed DODH of 1,2-propanediol with the diol itself as reductant at $298 \mathrm{~K}^{[51]}$ 


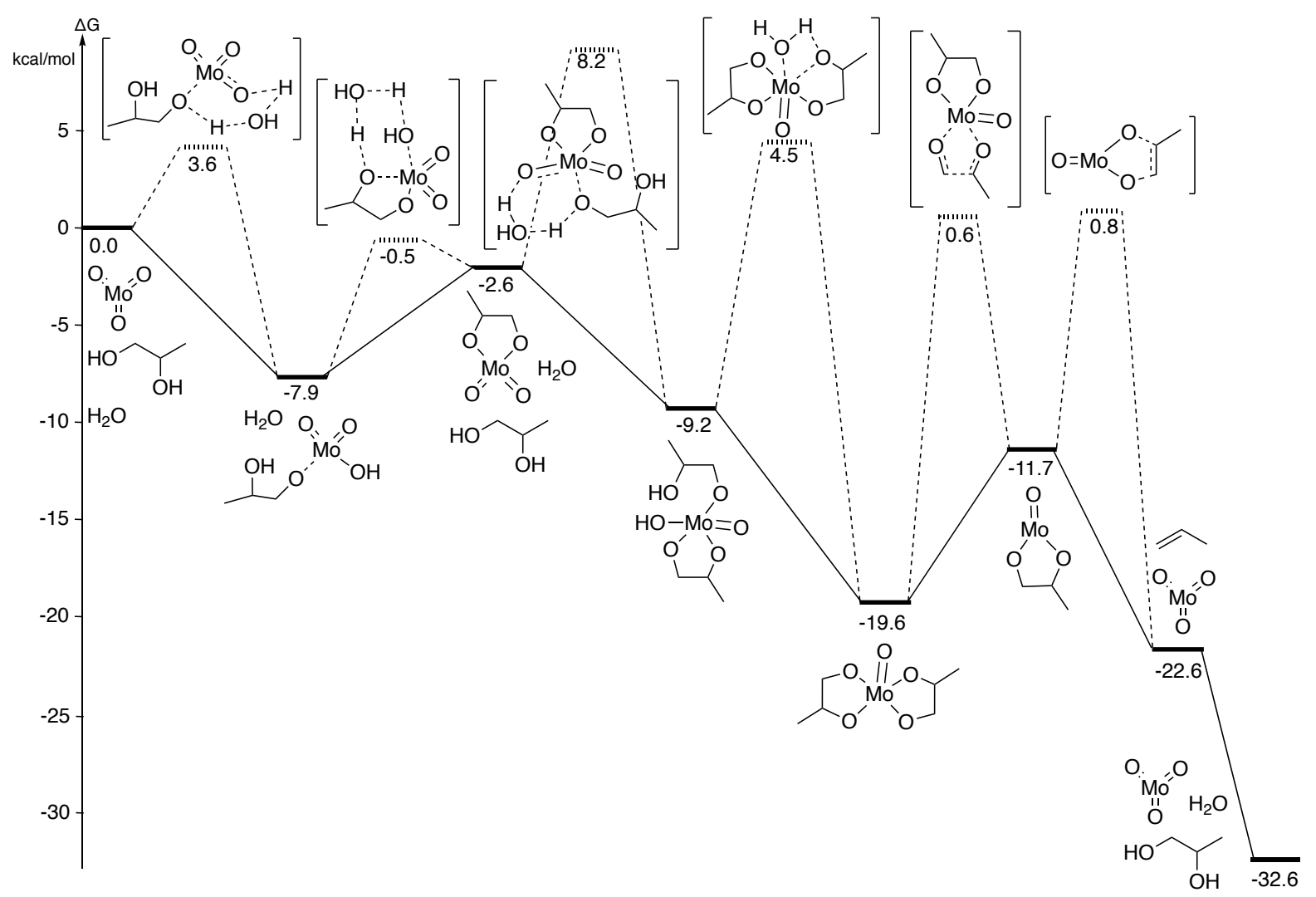

Scheme 39. Free energy profile for AHM-catalyzed DODH of 1,2-propanediol with the diol itself as reductant at $453 \mathrm{~K}^{[51]}$

As mentioned previously, the formation of acetals should be limited if the main objective of AHM-catalyzed DODH is to convert diols into olefins. Fristrup demonstrated that isopropanol could be used as reductant for AHM-catalyzed DODH of diols at high temperatures (240-250 $\left.{ }^{\circ} \mathrm{C}\right) .{ }^{[50]}$ The major byproducts of this reaction were carbonyl compounds formed by dehydration of the diol and alcohols formed by H-transfer from isopropanol to the carbonyl compounds. In this system, the overall aliphatic olefin product yield was as high as $77 \%$, and the total yield of reduced species (i.e., olefin and alcohols) was as high as $92 \%$.

In this study, $\mathrm{H}_{2}$ was initially tested as reductant for the AHM-catalyzed DODH of 1,2tetradecanediol. By comparing the product distribution of the same reaction but under $\mathrm{N}_{2}$ atmosphere, the $\mathrm{H}_{2}$ was figured out to be inactive in this system. Isopropanol was then tested, $49 \%$ of 1-tetradecene was formed and the total yield of reduced species was above $65 \%$. Alcohols, including $\mathrm{MeOH}, \mathrm{EtOH},{ }^{n} \mathrm{PrOH},{ }^{i} \mathrm{PrOH},{ }^{t} \mathrm{BuOH}$, and 3-pentanol, were screened at 240-250 ${ }^{\circ} \mathrm{C}$ in a pressurized autoclave for the DODH of 1,2-decanediol. The highest olefin yield was achieved by using ${ }^{i} \mathrm{PrOH}$ as reductant and solvent. $49 \%$ of 1-decene was obtained. Later on, different molybdenum resources, including $\mathrm{AHM}, \mathrm{MoO}_{2} \mathrm{Me}_{2}(\text { bipy })_{2},\left(\mathrm{Bu}_{4} \mathrm{~N}\right)_{2} \mathrm{Mo}_{6} \mathrm{O}_{19}$, $\mathrm{AHM}$ with $\mathrm{Bu}_{4} \mathrm{NOH}$, and $\mathrm{AHM}$ with $\mathrm{AcOH}$ were investigated. Among these, the combination 
of $\mathrm{AHM}$ and $\mathrm{Bu}_{4} \mathrm{NOH}$ gave the highest 1-decene yield. The addition of $\mathrm{Bu}_{4} \mathrm{NOH}$ benefited the DODH of 1,2-decanediol and also the H-transfer from alcohol to carbonyl compounds; $55 \%$ of 1 -decene and $22 \%$ of 2-decanol were formed, and no carbonyl compounds were detected. $\mathrm{C}_{6}$ vicinal diols were then applied to this AHM-catalyzed DODH system (Scheme 40). $77 \%$ of 1 hexene was formed from 1,2-hexanediol. In the case of secondary $\mathrm{OH}$ groups, $42 \%$ of 3-hexene was formed from 3,4-hexanediol, and $29 \%$ of cyclohexene was formed from cis-1,2cyclohexanediol. Remarkably, $14 \%$ of cyclohexene was formed from trans-1,2cyclohexanediol, which is not an active substrate in rhenium-catalyzed DODH reactions. In terms of the DODH of biomass-based glycerol and erythritol, only $4 \%$ of allyl alcohol was generated from glycerol and 39\% of 2,5-dihydrofuran was generated from erythritol, while no 1,3-butadiene was detected. Allyl alcohol conversion was as high as $86 \%$ to form $8 \% 1,5$ hexadiene and $22 \%$ propylene.

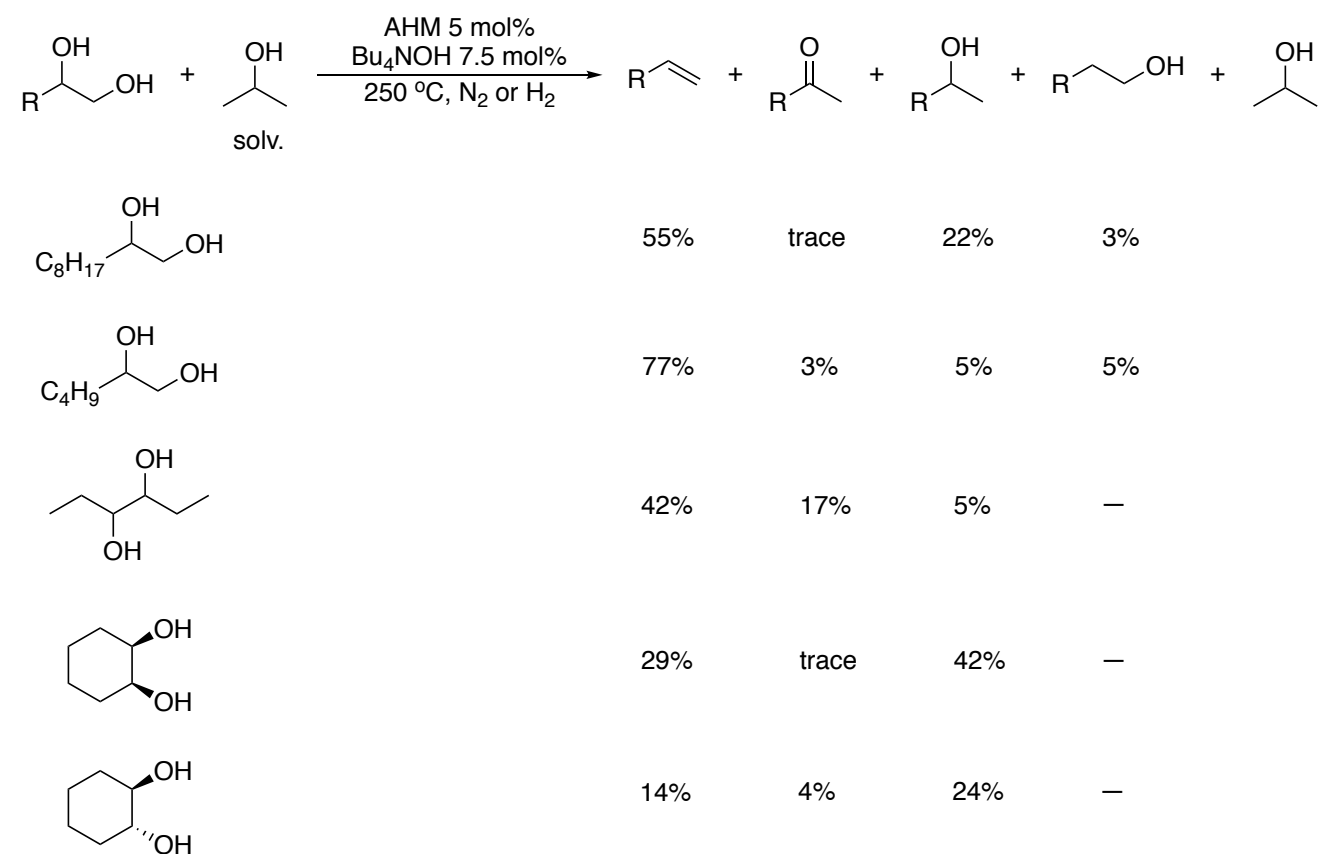

Scheme 40. AHM-catalyzed DODH of diols with isopropanol as reductant. ${ }^{[50]}$

Additionally, DFT calculations were carried out to study the mechanism of AHM-catalyzed DODH in which the reductant is ${ }^{i} \mathrm{PrOH}$ instead of the diol itself. Using the diol itself or isopropanol as reductant, the reduction step proceeds through a Mo-diolate intermediate; that is, when the diol is used as reductant a Mo ${ }^{\mathrm{VI}}$-bisdiolate is involved, and when isopropanol is used as reductant a $\mathrm{Mo}^{\mathrm{VI}} \mathrm{O}(\mathrm{OH})\left(\mathrm{O}^{i} \mathrm{Pr}\right)($ diolate $)$ is involved. Besides, the transition state for the reduction with the diol is $10.4 \mathrm{kcal} / \mathrm{mol}$ lower in energy than the one using isopropanol as reductant. This explains the need for a higher reaction temperature $\left(240-250{ }^{\circ} \mathrm{C}\right)$ when ${ }^{i} \mathrm{PrOH}$ is oxidized instead of the diol $\left(190-200{ }^{\circ} \mathrm{C}\right)$. The free energy profile for the AHM-catalyzed 
DODH of 1,4-anhydroerythritol with ${ }^{i} \mathrm{PrOH}$ as reductant according to Fristrup is shown in Scheme 41. It starts with the condensation of 1,4-anhydroerythritol and $\mathrm{MoO}_{3}$ to form a $\mathrm{Mo}^{\mathrm{VI}}$ diolate. Next, ${ }^{i} \mathrm{PrOH}$ coordinates to this Mo-diolate. With the help of water, a $\mathrm{Mo}^{\mathrm{VI}} \mathrm{O}(\mathrm{OH})\left(\mathrm{O}^{i} \mathrm{Pr}\right)($ diolate) species then forms by intramolecular H-transfer. Finally, acetone and water are released to generate a reduced $\mathrm{Mo}^{\mathrm{IV}}$-diolate species, followed by olefin extrusion to regenerate $\mathrm{MoO}_{3}$.
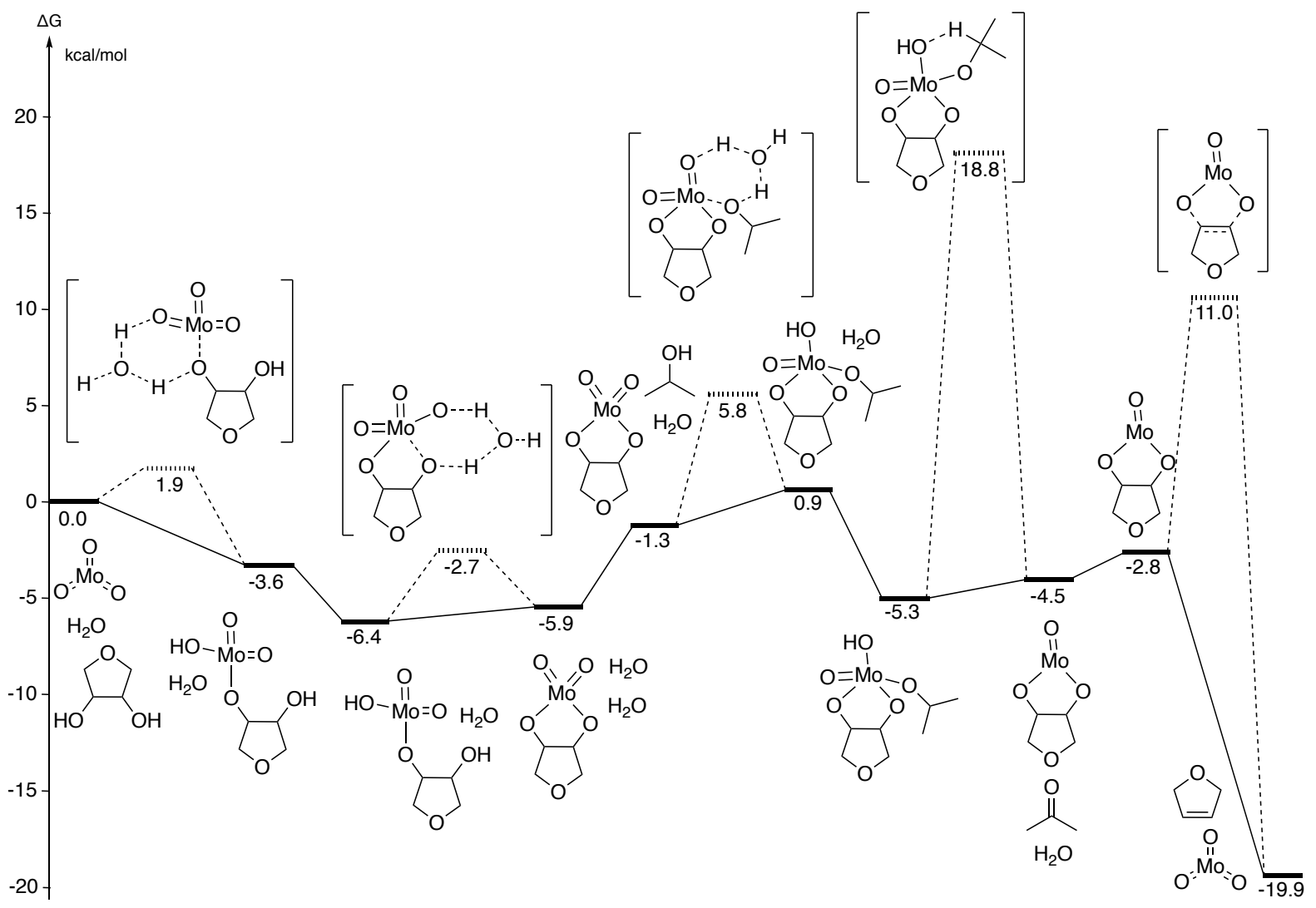

Scheme 41. Free energy profile for the AHM-catalyzed DODH of 1,4-anhydroerythritol with ${ }^{i} \mathrm{PrOH}$ as reductant. ${ }^{[50]}$

Recently, an $\mathrm{AHM} / \mathrm{Na}_{2} \mathrm{SO}_{3}$ system was reported for the deoxydehydration of vicinal diols. ${ }^{[52]}$ The reaction conditions were optimized to be $5 \mathrm{~mol} \%$ AHM as catalyst, 1.5 equiv. of $\mathrm{Na}_{2} \mathrm{SO}_{3}$ as reductant, toluene as solvent, and the reaction mixture was heated in a sealed thick walled pressure tube at 170 or $190{ }^{\circ} \mathrm{C}$. Moderate olefin product yields were achieved in this reaction system. The highest olefin yield obtained for the DODH of 1-phenyl-1,2-ethanediol was $23 \%$. In terms of aliphatic diols, $13 \%$ of 1-octene was formed from 1,2-octanediol and $21 \%$ of 1 decene was formed from 1,2-decanediol. Although the olefin product yields were not as high as the previous two systems reported by Fristrup, ${ }^{[49,50]}$ the reaction conditions were relatively mild with respect to those in their previous studies $\left(170-190{ }^{\circ} \mathrm{C} v s 190-200{ }^{\circ} \mathrm{C}\right.$ and $\left.240-250{ }^{\circ} \mathrm{C}\right)$. 


\subsubsection{Dioxo-Mo(VI) Complexes}

In 2013, the first DODH reactions catalyzed by dioxo-Mo complexes were reported by Montilla and Galindo. ${ }^{[53]}$ Acylpyrazolonate ligands $\left(\mathrm{HQ}^{\mathrm{R}}\right.$, Scheme 42$)$, which act as modified $\beta$ diketonate ligands, were investigated for the dioxo-Mo complexes. These $\mathrm{MoO}_{2}\left(\mathrm{Q}^{\mathrm{R}}\right)_{2}$ complexes were synthesized through ligand exchange by mixing a $\mathrm{MoO}_{2}$ (acac) $)_{2}$ solution with $\mathrm{HQ}^{\mathrm{R}}$. Their catalytic capacity was investigated by using 1-phenyl-1,2-ethanediol as substrate and $\mathrm{PPh}_{3}$ (1.1 equiv.) as reductant (Scheme 43). In case of $\mathrm{MoO}_{2}\left(\mathrm{Q}^{\mathrm{Cy}}\right)_{2}$ and $\mathrm{MoO}_{2}\left(\mathrm{Q}^{\mathrm{He}}\right)_{2}$ as catalyst, $10 \%$ and $13 \%$ of styrene was formed, respectively.

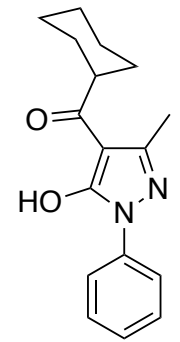

$\mathrm{HQ}^{\mathrm{Cy}}$

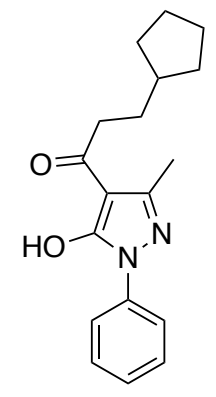

$\mathrm{HQ}^{\mathrm{EtCp}}$

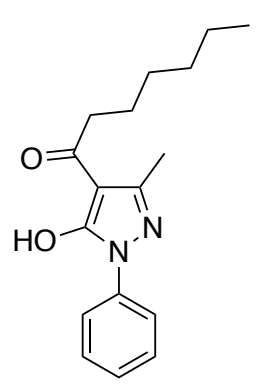

$\mathrm{HQ}^{\mathrm{He}}$

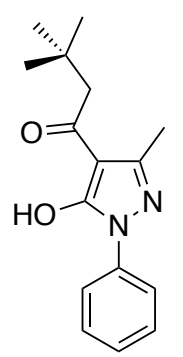

$\mathrm{HQ}^{\mathrm{nPe}}$

Scheme 42. Acylpyrazolonate ligands $\left(\mathrm{HQ}^{\mathrm{R}}\right)$ for dioxo-Mo complexes.

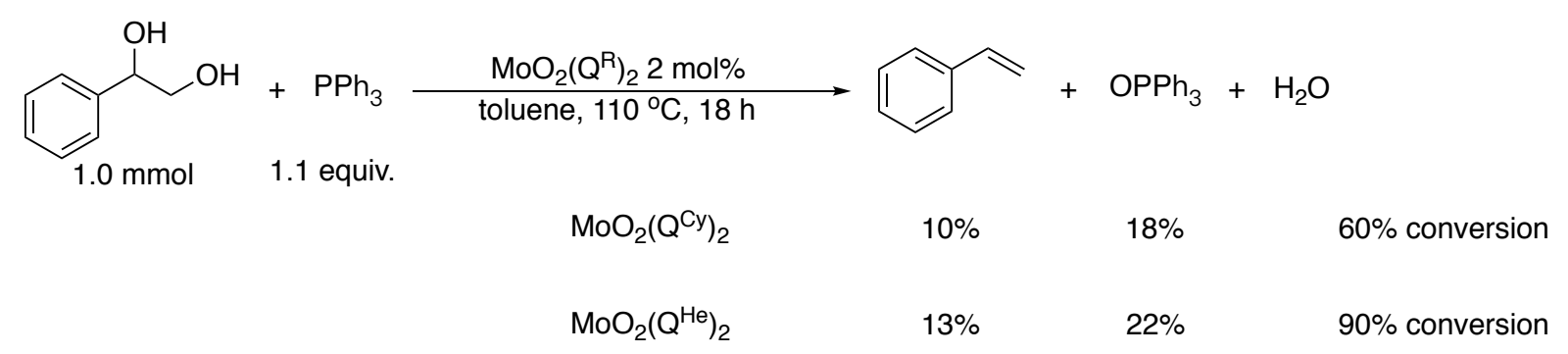

Scheme 43. DODH catalyzed by dioxo-Mo complexes supported by acylpyrazolonate ligands.

In 2016, a series of bis(phenolato)molybdenum complexes was reported by Okuda. ${ }^{[54]}$ These dioxo-molybdenum complexes were synthesized by adding triethylamine $\left(\mathrm{Et}_{3} \mathrm{~N}\right)$ into a mixture of $\mathrm{MoO}_{2} \mathrm{Cl}_{2}$ and the bis(phenol) ligand (Scheme 45). These five dioxo-molybdenum complexes were then investigated as catalyst for the DODH of 1,4-anhydroerythritol using 3-octanol as solvent and reductant. The highest 2,5-dihydrofuran yield (37\%) was obtained when $\mathbf{3 1}$ was used as catalyst. By increasing the amount of 3-octanol from 10 equiv. to 20 equiv., the olefin yield increased from $37 \%$ to $57 \%$. Besides, the reaction time and temperature could be reduced by applying microwave irradiation. 

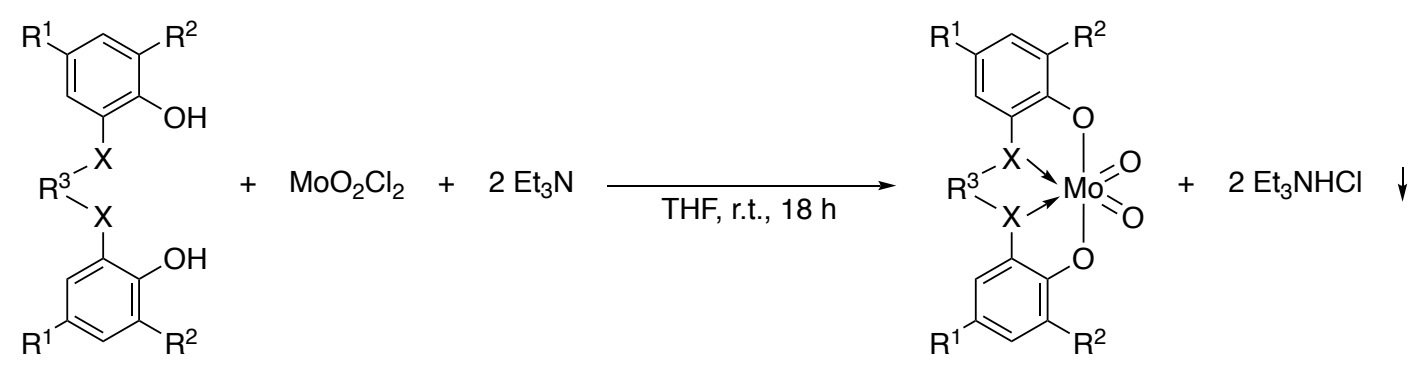

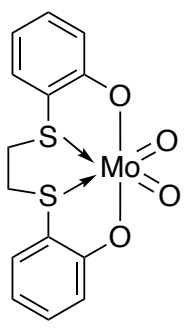

28

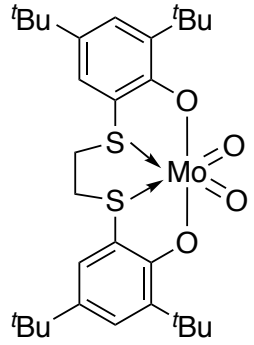

29

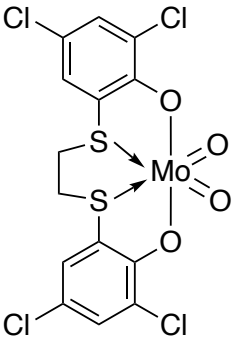

30

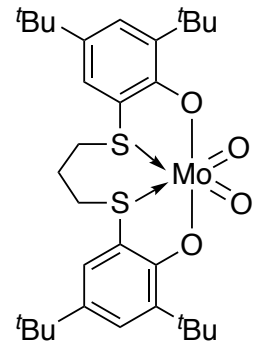

31

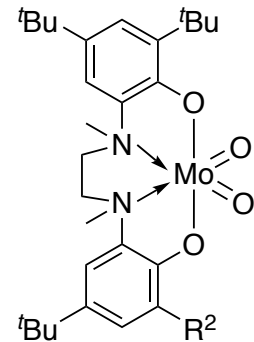

32

Scheme 44. Synthesis of bis(phenolato)molybdenum complexes

Later on, De Vos reported on $\mathrm{MoO}_{2}(\mathrm{acac})_{2}$-catalyzed DODH of vicinal diols. ${ }^{[55]}$ In this work, the authors studied a series of $\beta$-diketones with different steric and electronic properties as ligand precursors for the Mo catalyst. 1,2-Hexanediol was used as the model substrate with 10 $\mathrm{mol} \%$ of $\mathrm{MoO}_{2}(\mathrm{acac})_{2}$ as catalyst, 1.5 equiv. of $\mathrm{PPh}_{3}$ as reductant, and $2 \mathrm{~mL}$ of mesitylene as solvent at $200{ }^{\circ} \mathrm{C}$ for $2 \mathrm{~h}$ under $\mathrm{N}_{2}$. In order to investigate their effect on DODH catalysis 0.5 equiv. of a series of $\beta$-diketones, including 1,1,1,5,5,5-hexafluoroacetylacetone (HFAAH), 1,1,1-trifluoroacetylacetone (TFAAH), acetylacetone (ACACH), dibenzoylmethane (DBMH), 2,2,6,6-tetramethylheptane-3,5-dione (TMHDH), were then added to the reaction. The addition of the bulky TMHDH resulted in the highest 1-hexene yield (36\%), which signifies a significantly higher than without the addition of a $\beta$-diketone (15\%).

The authors proposed that TMHDH has both an electronic and a steric effect on the DODH reaction. Electronically, this electron-donating ligand would increase the electron density at Mo, which could facilitate the olefin extrusion step of the catalytic cycle. Sterically, the bulky ligand would stabilize the molybdenum complex. A black precipitate was formed from a reaction mixture in the absence of a bulky ligand. The same observation was reported by Fristrup, and based on element analysis, this black precipitate contained mostly $\mathrm{C}$ and Mo. ${ }^{[50]}$ The addition of bulky diketone ligands into the reaction resulted in a dark colored mixture during the reaction, but not in the formation of a black precipitate. Likely these bulky ligands hamper the oligomerization of Mo, thereby stabilizing the Mo complex. ESI-MS analysis was performed on reaction mixtures with and without $\mathrm{TMHDH}$, and samples were centrifuged before analysis. In the reaction without TMHDH, centrifugation caused precipitation and the ESI-MS spectrum 
did not contain any clear peak of a Mo species. For the reaction with addition of TMHDH, several peaks related to Mo species were detected on basis of the molecular weights and isotopic distributions. In addition, $\mathrm{MoO}(\mathrm{TMHD})_{2}$ was detected, which indicated that reduction of $\mathrm{MoO}_{2} \mathrm{TMHD}_{2}$ by $\mathrm{PPh}_{3}$ had taken place, and that reduction of $\mathrm{MoO}_{2}(\mathrm{TMHD})_{2}$ could happen before its condensation with the diol substrate.

Optimization of the amount of TMHDH resulted in an excellent 1-hexene yield of 94\% when using 4 equiv. of TMHDH. The turn-over frequency (TOF) of this reaction was $4.7 \mathrm{~h}^{-1}$, which represents the highest TOF obtained for Mo-catalyzed DODH of 1,2-hexanediol. When $\mathrm{MoO}_{2}(\mathrm{TMHD})_{2}$ was used as catalyst the 1-hexene yield was higher than when using $\mathrm{MoO}_{2}(\mathrm{acac})_{2}$ as catalyst. Unexpectedly, the yield was lower than the one obtained from the $\mathrm{MoO}_{2}(\mathrm{acac})_{2} / \mathrm{TMHDH}$ system. In addition, switching the catalyst from $\mathrm{MoO}_{2}(\mathrm{acac})_{2}$ to $\mathrm{AHM}$, the 1 -hexene yield was increased from $12 \%$ to $80 \%$ by adding 4 equiv. of TMHDH. Several vicinal diols were then applied to this $\mathrm{MoO}_{2}$ (acac) 2 /TMHDH system (Table 3). Both $\mathrm{PPh}_{3}$ and 2-octanol were investigated as reductant. Remarkable, $51 \%$ of styrene was formed from 1 phenyl-1,2-ethanediol at only $150{ }^{\circ} \mathrm{C}$, which is a relatively low reaction temperature for a Mocatalyzed DODH reaction (Table 3, entry 4). Besides, in terms of the DODH of 1,4anhydroerythritol, $56 \%$ of 2,5-dihydrofuran was formed (Table 3, entry 5).

Table 3. DODH of vicinal diols by the $\mathrm{MoO}_{2}(\mathrm{acac})_{2} / \mathrm{TMHDH}$ system. ${ }^{[\mathrm{a}]}$

\begin{tabular}{|c|c|c|c|c|c|c|c|}
\hline entry & substrate & reductant & solvent & $\mathrm{T} /{ }^{\circ} \mathrm{C}$ & products & yield $/ \%$ & $t / h$ \\
\hline 1 & & $\mathrm{PPh}_{3}$ & mesitylene & 200 & & 93 & 2 \\
\hline 2 & & $\mathrm{PPh}_{3}$ & mesitylene & 170 & & 23 & 14 \\
\hline 3 & & $\mathrm{PPh}_{3}$ & mesitylene & 200 & & 59 & 2 \\
\hline 4 & & $\mathrm{PPh}_{3}$ & mesitylene & 150 & & 51 & 2 \\
\hline 5 & & $\mathrm{PPh}_{3}$ & mesitylene & 200 & & 56 & 18 \\
\hline 6 & 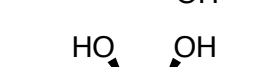 & $\mathrm{PPh}_{3}$ & mesitylene & 200 & & 3,15 & 2 \\
\hline 7 & $\mathrm{HO}-$ & 2-octanol & 2-octanol & 200 & & 1,15 & 18 \\
\hline 8 & $\mathrm{H}$ & $\mathrm{PPh}_{3}$ & mesitylene & 200 & & 92 & 2 \\
\hline 9 & EtOOC & 2-octanol & 2-octanol & 200 & $\mathrm{EtOOC}^{-}$ & 35 & 2 \\
\hline
\end{tabular}

[a] Reaction conditions: substrate $(0.5 \mathrm{mmol}), \mathrm{MoO}_{2}(\mathrm{acac})_{2}(0.05 \mathrm{mmol}, 10 \mathrm{~mol} \%$ loading), TMHDH (2.0 mmol, 4 equiv.), $\mathrm{PPh}_{3}$ (0.75 mmol, 1.5 equiv.) or 2-octanol (25 equiv.), solvent ( $2 \mathrm{~mL}$ ), and $\mathrm{N}_{2}$ atmosphere. 
Very recently, Kilyanek reported two dioxo-Mo complexes supported by a dianionic ONO pincer ligand, which were found to be active DODH catalysts. ${ }^{[56]}$ These complexes were obtained by stirring the ONO pincer ligand and $\mathrm{MoO}_{2}(\mathrm{acac})_{2}$ in $\mathrm{CH}_{2} \mathrm{Cl}_{2}$ at room temperature for $48 \mathrm{~h}$ (Scheme 45). In DODH reactions catalyzed by 47 and $48 \mathrm{PPh}_{3}, 3$-octanol, $\mathrm{C}, \mathrm{Zn}$, $\mathrm{Na}_{2} \mathrm{SO}_{3}$, and isopropanol were screened as sacrificial reductant. When 1-phenyl-1,2-ethanediol was investigated as substrate, both the olefin and aldehydes were detected in an approximately 3:1 ratio. This result indicated that both reduction of Mo via oxo-abstraction and via deformylation are competitive in this reaction system. A number of different diols, including 1,2-octanediol, 1-phenyl-1,2-ethanediol, $(R, R)-(+)$-hydrobenzoin, and diethyl tartrate (DET), were explored for this Mo-catalyzed DODH system. The highest olefin product yield was obtained using $(R, R)-(+)$-hydrobenzoin as substrate, $\mathbf{4 7}$ as catalyst, and $\mathrm{PPh}_{3}$ as reductant at 150 ${ }^{\circ} \mathrm{C}$ for $48 \mathrm{~h} ; 62 \%$ of trans-stilbene and $21 \%$ of benzaldehyde were formed. When using DET as substrate, no aldehydes were observed but the olefin yield was also quite low, ranging from 5 to $26 \%$ depending on the reducing agent. For the conversion of aliphatic vicinal diols a higher reaction temperature $\left(190{ }^{\circ} \mathrm{C}\right)$ was required; $59 \%$ of 1 -octene was generated from 1,2octanediol when using 47 as catalyst and $\mathrm{PPh}_{3}$ as reductant.

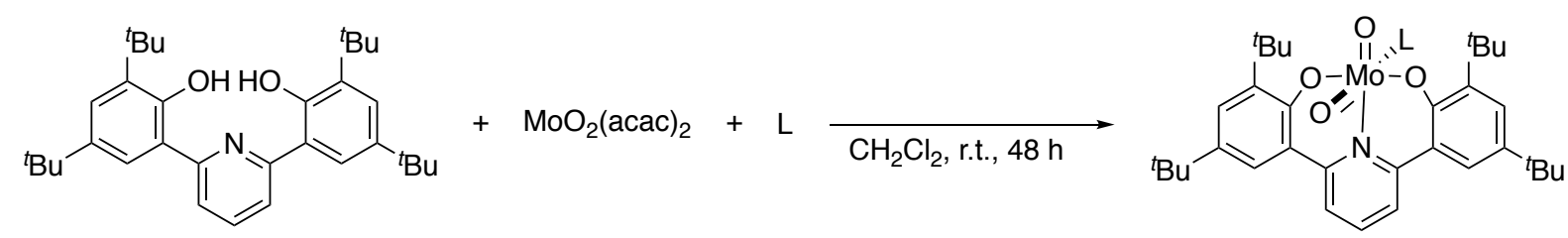

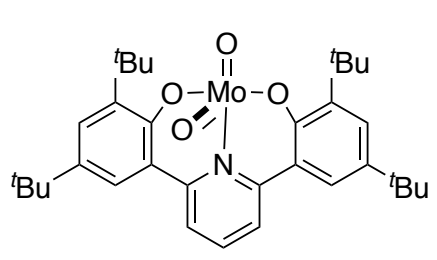

47

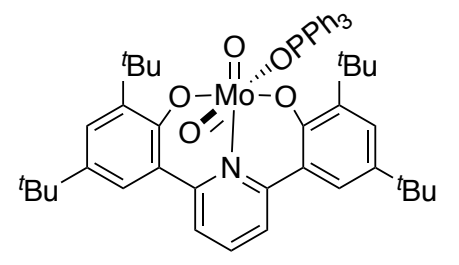

48

Scheme 45. Synthesis of dianionic ONO pincer ligand supported Mo complexes 47 and 48.

A preliminary kinetic study was carried out by using 1-phenyl-1,2-ethanediol as substrate. Time-course profiles of both styrene yield and 1-phenyl-1,2-ethanediol conversion were reported based on ${ }^{1} \mathrm{H}$ NMR monitoring. An early, relatively rapid, and non-linear growth of styrene was observed, in addition to a plateau in styrene concentration after $15 \mathrm{~h}$. The timecourse profile of styrene did not correspond to a first- or second-order production of styrene, while the time-course profile of 1-phenyl-1,2-ethanediol obeyed a zero-order dependence on diol. On the basis of these results the authors concluded that several species might be involved 
in this reaction system and that the rate of product formation was not only dependent on the concentration of reductant and catalyst.

\subsection{Vanadium-Based Catalysts}

The first DODH reaction catalyzed by oxo-vanadium complexes was reported by Nicholas in 2013. ${ }^{[57]}$ Commercial metavanadate salts $\left(\mathrm{NaVO}_{3}, \mathrm{NH}_{4} \mathrm{VO}_{3},{ }^{n} \mathrm{Bu}_{4} \mathrm{NVO}_{3}\right)$, $O$-ligated oxoanion derivatives $\left(\mathrm{NaVO}_{2}(\mathrm{acac})_{2}, \quad\left(\mathrm{Bu}_{4} \mathrm{~N}\right) \mathrm{VO}_{2}(\mathrm{CA})_{2}\right), \quad$ and a $N, N, O$-tridentate complex $[\mathrm{Bu} 4 \mathrm{~N}]$ (dipic) $\mathrm{VO}_{2}$ (dipic $=2,6$-pyridinedicarboxylate) were initially explored as catalysts for the DODH of 1-phenyl-1,2-ethanediol. $\mathrm{NaVO}_{3}, \mathrm{NH}_{4} \mathrm{VO}_{3}$, and ${ }^{n} \mathrm{Bu}_{4} \mathrm{NVO}_{3}$ were active when using sulfite, $\mathrm{PPh}_{3}, \mathrm{H}_{2}$, or a secondary alcohol as reductant, while $\left(\mathrm{NaVO}_{2} \text { (acac) }\right)_{2}$ and $\left.\left(\mathrm{Bu}_{4} \mathrm{~N}\right) \mathrm{VO}_{2}(\mathrm{CA})_{2}\right)$ were ineffective catalysts with sulfite or $\mathrm{PPh}_{3}$ as reductant. The most active catalyst among these vanadium sources was $\left[\mathrm{Bu}_{4} \mathrm{~N}\right]\left(\right.$ dipic) $\mathrm{VO}_{2}$. Full substrate conversion and $95 \%$ of styrene was obtained using this compound as catalyst and $\mathrm{PPh}_{3}$ as reductant.

With $10 \mathrm{~mol} \%$ of $\left[\mathrm{Bu}_{4} \mathrm{~N}\right]$ (dipic) $\mathrm{VO}_{2}$ as catalyst and 1.5 equiv. of $\mathrm{PPh}_{3}$ as reductant, the DODH of several vicinal diols was investigated. In terms of aliphatic vicinal diols, $87 \%$ of 1 -octene was formed from 1,2-octanediol at $170{ }^{\circ} \mathrm{C}$ in $48 \mathrm{~h}$, and $85 \%$ of 1 -hexene was formed from 1,2hexanediol at $170{ }^{\circ} \mathrm{C}$ in $36 \mathrm{~h}$. However, only $15 \%$ of cyclohexene was formed at $25 \%$ conversion of cis-1,2-cyclohexanediol, likely due to the steric/conformational effects or competing cis-trans isomerization of the diol. Additionally, pinacol could be converted to the corresponding olefin in $85 \%$ yield with $90 \%$ substrate conversion. Besides, in the DODH of biomass-based diethyl tartrate (DET) $85 \%$ of diethyl fumarate (DEF) was formed.

A catalytic cycle of the $\left[\mathrm{Bu}_{4} \mathrm{~N}\right]\left(\right.$ dipic) $\mathrm{VO}_{2}$-catalyzed $\mathrm{DODH}$ was proposed based on the mechanism for Re-catalyed DODH reactions. Two possible pathways are showed in Scheme 46. In pathway $\mathrm{A}$, (dipic) $\mathrm{VO}_{2}^{-}$condenses with the diol to form a $\mathrm{V}^{\mathrm{V}}$-diolate, which is then reduced to form a $\mathrm{V}^{\mathrm{III}}$-diolate intermediate. A fragmentation of this $\mathrm{V}^{\mathrm{III}}$-diolate then forms the olefin and regenerates (dipic) $\mathrm{VO}_{2}^{-}$to close the catalytic cycle. In pathway $\mathrm{B}$, reduction of (dipic) $\mathrm{VO}_{2}^{-}$to generate (dipic) $\mathrm{VO}^{-}$is the first step instead of condensation. This is followed by the condensation of (dipic) $\mathrm{VO}^{-}$with the diol to form the $\mathrm{V}^{\mathrm{III}}$-diolate intermediate, and by olefin extrusion. DFT studies on both pathway A and pathway B showed that pathway B is energetically preferred over pathway A. ${ }^{[58,59]}$ In terms of olefin extrusion from VII-diolate intermediate, a [2+2] retrocycloaddition mechanism was found to be more favorable than a $[3+2]$ retrocycloaddtion mechanism. ${ }^{[59]}$ 


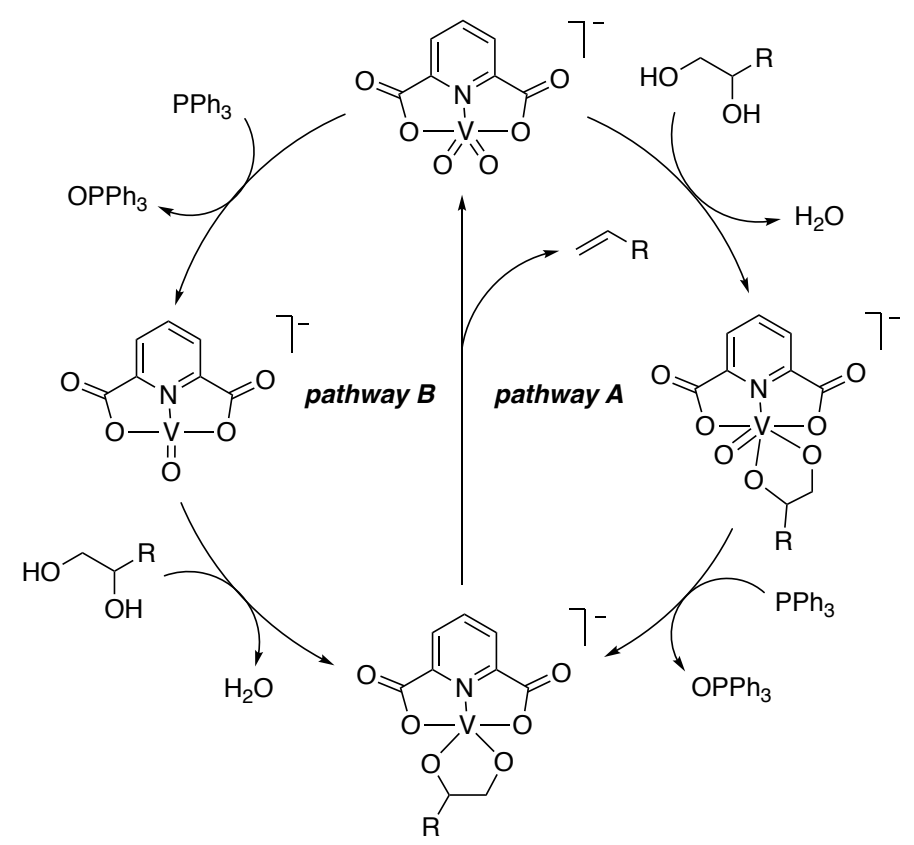

Scheme 46. Proposed catalytic cycle for $\left[\mathrm{Bu}_{4} \mathrm{~N}\right]($ dipic) $) \mathrm{VO}_{2}$-catalyzed DODH. ${ }^{[57]}$

Next to the $N, N, O$-tridentate complex $\left[\mathrm{Bu}_{4} \mathrm{~N}\right]\left(\right.$ dipic) $\mathrm{VO}_{2}$, three more oxo-vanadium complexes of the type $\mathrm{Z}^{+} \mathrm{LVO}_{2}{ }^{-}$were reported by Nicholas as catalysts for the DODH of vicinal diols (Scheme 47). ${ }^{[60]}$ Initially the DODH capacity of these four complexes was evaluated using different potential reductants, i.e., $\mathrm{Na}_{2} \mathrm{SO}_{3}, \mathrm{PPh}_{3}, \mathrm{H}_{2}$, and $\mathrm{CO}$, for the DODH of 1-phenyl-1,2ethanediol. All reactions were performed in benzene at $160{ }^{\circ} \mathrm{C}$ with 1.5 equiv. of solid reductant or $20 \mathrm{~atm}$ of the gaseous ones and $10 \mathrm{~mol} \%$ of vanadium catalysts for $24 \mathrm{~h}$. In the case of 49 , both sulfite and $\mathrm{PPh}_{3}$ were efficient reductants and the styrene yield was $95 \%$ and $87 \%$, respectively. Complex $\mathbf{5 0}$ was relatively inactive, with less than $8 \%$ of styrene formed at a rather low substrate conversion. For $\mathbf{5 1}$ and 52, a very similar catalytic performance was observed: high conversions were achieved with $\mathrm{Na}_{2} \mathrm{SO}_{3}, \mathrm{H}_{2}$, and $\mathrm{CO}$ as reductant, but only moderate amounts of styrene were formed; in addition, low substrate conversion and low styrene yield were obtained with $\mathrm{PPh}_{3}$ as reductant. Two vicinal diols, 1,2-hexanediol and DET, were tested with different reductants and $\mathbf{5 2}$ as catalyst. The application of CO as reductant gave $67 \%$ of DEF from DET and $97 \%$ of 1 -hexene from 1,2-hexanediol.

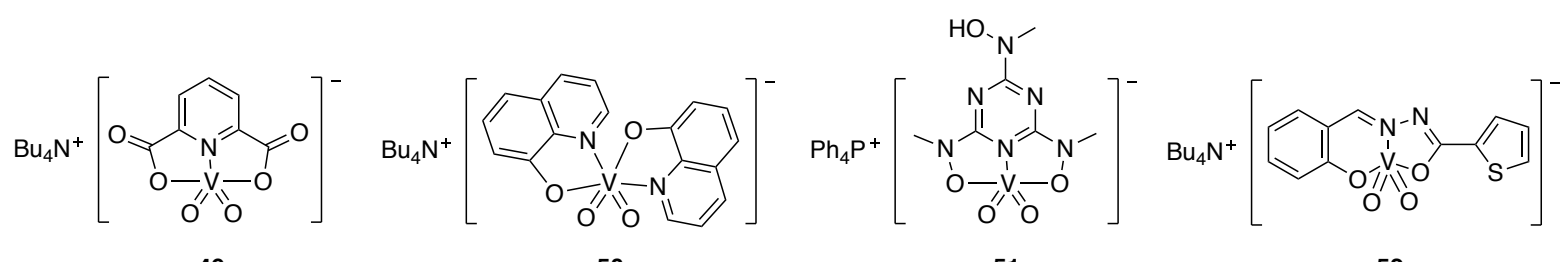

49

50

51

52

Scheme 47. Oxo-vanadium complexes of the type $\mathrm{Z}^{+} \mathrm{LVO}_{2}{ }^{-}$tested for DODH. 
Additionally, the ambient reactivity of these four complexes with 1-phenyl-1,2-ethanediol was investigated. On the basis of NMR analysis and visible color changes, only $\mathbf{5 0}$ reacted with 1phenyl-1,2-ethanediol at room temperature. The authors proposed the formation of vanadiumdiolate 53 on the basis of ${ }^{1} \mathrm{H}$ NMR and ${ }^{13} \mathrm{C}$ NMR analysis (Scheme 48). When 53 was heated in the presence of $\mathrm{Na}_{2} \mathrm{SO}_{3}$, no styrene formation was observed, indicating that $\mathbf{5 3}$ is a dead-end species. These observations also explained the low catalytic activity of $\mathbf{5 0 .}$

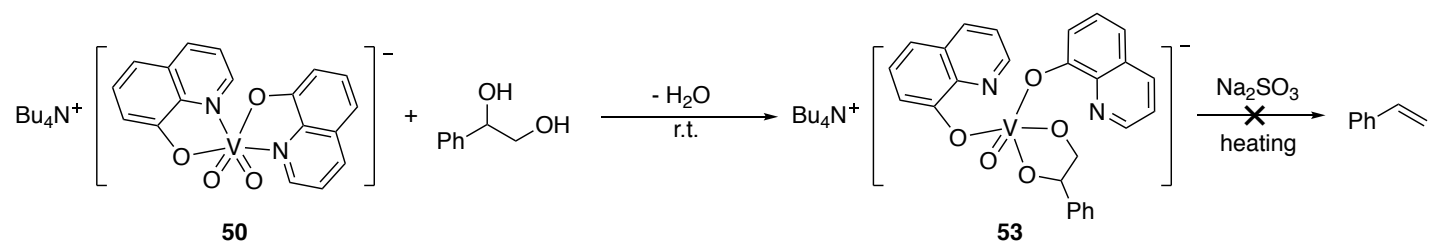

Scheme 48. Reaction between 1-phenyl-1,2-ethanediol and complex $\mathbf{5 0 .}$

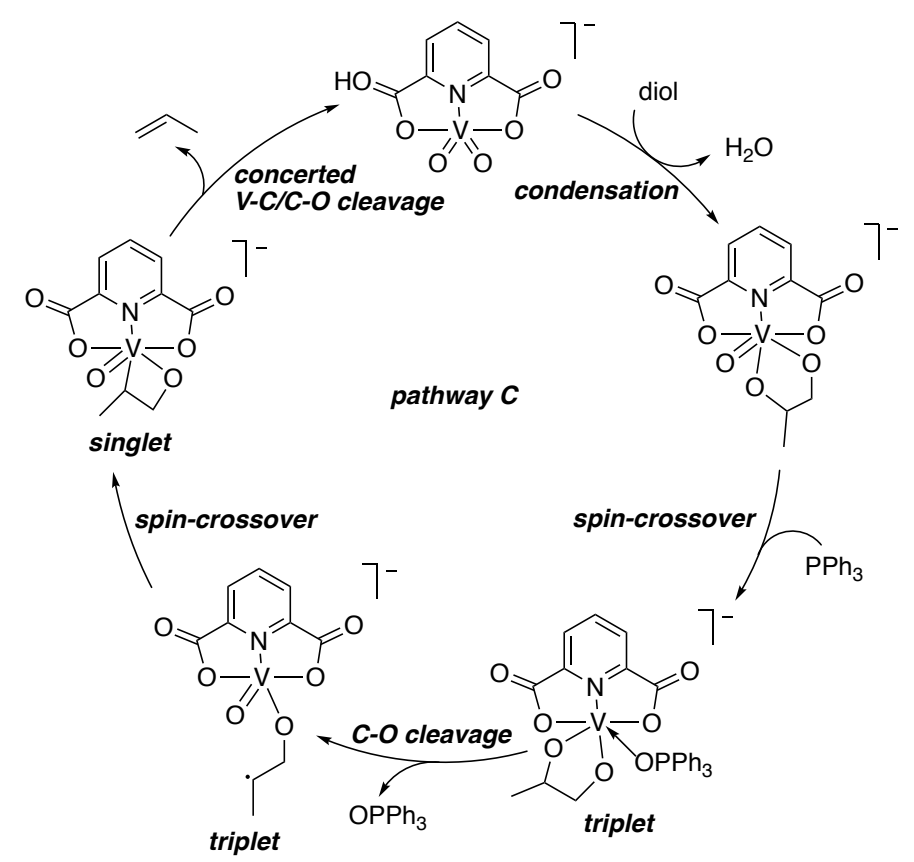

Scheme 49. Proposed catalytic cycle of $\left[\mathrm{Bu}_{4} \mathrm{~N}\right]\left(\right.$ dipic) $\mathrm{VO}_{2}$-catatzlyed DODH based on DFT calculation by $\mathrm{Fu}^{\left[{ }^{[61]}\right.}$

The mechanism of $\left[\mathrm{Bu}_{4} \mathrm{~N}\right]$ (dipic) $\mathrm{VO}_{2}$-catalyzed $\mathrm{DODH}$ with $\mathrm{PPh}_{3}$ as reductant was also studied by $\mathrm{Fu}$ and co-workers using DFT. ${ }^{[61]}$ In their study, not only the previously proposed pathways $\mathrm{A}$ and $\mathrm{B}$ was calculated, a pathway involving a new olefin-formation mechanism was also investigated (pathway C, Scheme 49). This pathway starts with the condensation of diol and (dipic) $\mathrm{VO}_{2}^{-}$to form a $\mathrm{LV}^{\mathrm{V}} \mathrm{O}$ (diolate) species $\left(\mathrm{L}=\right.$ dipic). This $\mathrm{LV}^{\mathrm{V}} \mathrm{O}$ (diolate) species is then reduced by $\mathrm{PPh}_{3}$, followed by a spin-crossover step to from a triplet $\mathrm{V}^{\mathrm{III}}$-diolate. Next, a single $\mathrm{C}-\mathrm{O}$ bond cleavage takes place, followed by another spin-crossover step, to form a singlet alkylvanadium(V) intermediate. Then the olefin product is generated by a final concerted $\mathrm{V}-$ 
$\mathrm{O} / \mathrm{C}-\mathrm{O}$ bond cleavage from the singlet alkylvanadium(V) intermediate. On the basis of DFT calculations, pathway $\mathrm{C}$ is energetically more favorable compared to pathways $\mathrm{A}$ and $\mathrm{B}$. It was also found that the overall free energy barriers of $\mathrm{LV}^{\mathrm{V}} \mathrm{O}$ (diolate) reduction and olefin extrusion are very close, that is $34.3 \mathrm{kcal} / \mathrm{mol}$ and $33.7 \mathrm{kcal} / \mathrm{mol}$, respectively. In another words, both of these two steps are likely to affect the reaction rate.

Last but not the least, a $\mathrm{NH}_{4} \mathrm{VO}_{3}$-catalyzed DODH of glycerol was reported by Fristrup in $2018 .{ }^{[62]}$ With 1 mol\% of $\mathrm{NH}_{4} \mathrm{VO}_{3}$ as catalyst, the disproportionation of glycerol gave $22 \%$ of allyl alcohol as DODH product at $275^{\circ} \mathrm{C}$ in $5 \mathrm{~h}$. Acrolein was also detected from the reaction mixture. The formation of acrolein could be the dehydrogenation of allyl alcohol, or two sequential dehydrations of glycerol. Deuterium-labelled glycerol, i.e., 2-[ $\left[\mathrm{D}_{1}\right]$ glycerol and $1,1,3,3-\left[\mathrm{D}_{4}\right]$ glycerol, was then evaluated to figure out the formation of acrolein. If the formation of acrolein arises from dehydrogenation of allyl alcohol, then only 2-[ $\left.\mathrm{D}_{1}\right]$ acrolein and 1,1,3-

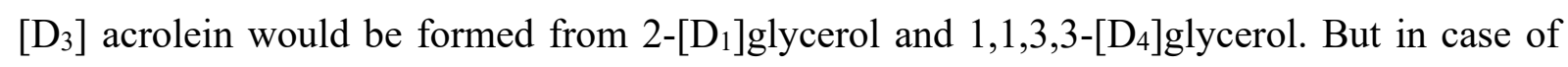
$\mathrm{NH}_{4} \mathrm{VO}_{3}$-catalyzed DODH of 2-[D $]$ glycerol, a mixture of acrolein and 2-[D $]$ glycerol with a ratio roughly equal to 1:1 was observed. This result indicated that the formation of acrolein results from two sequential dehydrations of glycerol.

\subsection{Aim and Scop of this Thesis}

As an introductory text, this chapter has aimed to provide the reader with a general overview of deoxydehydration reactions of vicinal diols and biomass-derived polyols catalyzed by transition metal complexes. Rhenium complexes, molybdenum complexes, and vanadium complexes have shown catalytic activity for these DODH reactions. Rhenium-catalyzed DODH of vicinal diols allows for quite high olefin product selectivities with high to quantitive substrate conversions. Even in the case of biomass derived polyol substrates for rhenium-catalyzed DODH reactions, moderate to high olefin product yields are achieved. Most of the active rhenium catalysts are high-valent rhenium-oxo complexes. Only a limited number of low-valent rhenium compounds have been applied as pre-catalysts for DODH reactions. Nevertheless, low-valent rhenium complexes are more stable than the high-valent ones, which means the development of low-valent rhenium pre-catalysts is quite attractive. However, the drawback of all the rhenium-based catalysts and pre-catalysts is the scarcity and high cost of rhenium, which then asks for the development of other metal-based deoxydehydration catalysts, i.e., ones based on molybdenum and vanadium. Molybdate and several dioxomolybdenum complexes have been reported as DODH catalysts, although mostly moderate olefin yields are obtained. Overall, side reactions such as dehydration and oxidative cleavage of the diol substrate are observed in 
Mo-catalyzed DODH. If the objective of Mo-catalyzed DODH is the production of olefins, then prevention of these side reactions is a challenge. Since only a limited number of Mo-based DODH catalysts have been reported, there is quite some room to discover new Mo-based catalyst for DODH reactions. In the case of vanadium-catalyzed DODH, the reaction conditions are typically harsher than for Re-based and Mo-based catalysts; typically a high temperature and long reaction time are required. Only metavanadates and $N, N, O$-tridentate ligand-supported dioxovanadium complexes have been reported for DODH catalysis, which also indicates that $\mathrm{V}$-based DODH catalysts have not been widely explored thus far.

The general aim of this thesis focusses on the development of new catalyst systems for the DODH of diols and biomass derived polyols. Where Chapters 2 and 3 solely focus on high valent rhenium complexes, in Chapter 4 molybdenum complexes with Cp-based ligand are studied, and the use of low-valent rhenium pre-catalysts is described in Chapter 5.

Chapter 2 explores a $\mathrm{Cp}$-based trioxo-rhenium complex, $\mathrm{Cp}^{\mathrm{tt}} \mathrm{ReO}_{3}\left(\mathrm{Cp}^{\mathrm{tt}}=1,3\right.$-di-tertbutylcyclopentadienyl) as catalyst for the DODH of diols and biomass derived polyols using secondary alcohols as reductant. This study follows previous work of Klein Gebbink et. al., where a series of $\mathrm{Cp}$-based trioxo-rhenium complexes has been reported and investigated for their catalytic active in the DODH of 1,2-octanediol with $\mathrm{PPh}_{3}$ as reductant. ${ }^{[22]}$ The investigations on the $\mathrm{Cp}^{\mathrm{tt}} \mathrm{ReO}_{3}$,complex include in situ NMR experiments, aiming to further investigate catalyst evolution under catalytic conditions.

Chapter 3 describes the application dioxo-rhenium complexes as catalysts for the DODH of diols and polyols. Both tetradentate $\mathrm{N}_{2} \mathrm{Py}_{2}$ aminopyridine ligand-supported $\mathrm{ReO}_{2}{ }^{+}$complexes and monodentate pyridine-supported $\mathrm{ReO}_{2}{ }^{+}$complex have been investigated. The interest in these complexes arises form the question if DODH catalysis proceeds through a $\mathrm{Re}^{\mathrm{V}} \leftrightarrow \mathrm{Re}^{\mathrm{VII}}$ pathway or a $\operatorname{Re}^{\mathrm{V}} \leftrightarrow \mathrm{Re}^{\mathrm{III}}$ pathway when starting with a dioxo-rhenium species, since both pathways have been proposed for the use of trioxo-rhenium complexes in DODH catalysis. ${ }^{[14]}$ The possible use of aminopyridine ligands in DODH catalysis may accelerate catalyst development through ligand design, since modifications of $\mathrm{Cp}$-based ligand are rather limited. As part of this study, time-course profiles of the DODH reaction using the $\mathrm{ReO}_{2}{ }^{+}$complexes are explored in order to shed light on the role of these complexes as either catalysts or precatalysts.

After Chapters $\mathbf{2}$ and 3, which focus on rhenium-based catalysis, Chapter $\mathbf{4}$ focusses on the development of molybdenum-based DODH catalysts as an alternative for catalysts based on 
rather scarce and expensive rhenium. Previous studies have shown that the catalytic properties of $\mathrm{Cp}^{\prime} \mathrm{ReO}_{3}$ type complexes in DODH reactions are affected by modifications of the Cp ligand. Chapter 4 therefore investigates if the corresponding Cp-based Mo-complexes also show catalytic activity towards the DODH of diols and polyols. Next to catalyst identification and optimization, this chapter also addresses the mechanism of operation of one of the Mocomplexes through a series of stochiometric experiments.

Although $\mathrm{Cp}^{\prime} \mathrm{ReO}_{3}$ complexes, such as the one described in Chapter 2, are very efficient DODH catalysts, their overall synthesis suffers from rather low yields based on the starting amount of rhenium (4-49\%). The low yield is mainly due to the decomposition of the trioxorhenium species under the oxidizing conditions of its synthesis from $\mathrm{Cp}^{\prime} \operatorname{Re}(\mathrm{CO})_{3} .^{[22]} \mathrm{A}$ possible way to solve this problem is to use $\mathrm{Cp} \operatorname{Re}(\mathrm{CO})_{3}$ as a pre-catalyst and form the corresponding $\mathrm{Cp}^{\prime} \mathrm{ReO}_{3}$ species in situ during catalysis in the presence of oxygen. Yet, on the basis of the work of Ellman and Bergman though, $\mathrm{Cp}^{*} \mathrm{Re}(\mathrm{CO})_{3}$ is not active towards the deoxydehydration of diols under aerobic conditions. ${ }^{[48]}$ Accordingly, Chapter 5 explores the development of low valent rhenium complexes for DODH reactions and reports on the DODH activity of a series of low valent rhenium complexes supported by anionic NNO-type ligands $(\mathrm{NNO}=2-(((2-($ dimethylamino $)$ ethyl $)($ methyl $)$ amino $)$ methyl $)$ phenol $)$. Both diol and biomassbased polyol substrates could be applied with these complexes under aerobic conditions, to form corresponding olefins with moderate to high yields.

\subsection{References}

[1] P. Lanzafame, G. Centi, S. Perathoner, Chem. Soc. Rev. 2014, 43, 7562-7580.

[2] E. P. Ahern, P. Deane, T. Persson, O. Brian, Renew. Energy 2015, 78, 648-656.

[3] T. A. Bender, J. A. Dabrowski, M. R. Gagné, Nat. Rev. Chem. 2018, 2, 35-46.

[4] R. Korea, S. Jechan, G. Chem, Green Chem. 2019, 21, 3715-3743.

[5] A. Margellou, K. S. Triantafyllidis, Catalysts 2019, 9, 43.

[6] X. Zhang, F. Jordan, M. Szostak, Org. Chem. Front. 2018, 5, 2515-2521.

[7] M. Rahman, A. Mukherjee, I. S. Kovalev, D. S. Kopchuk, G. V Zyryanov, M. V Tsurkan, A. Majee, B. C. Ranu, V. N. Charushin, O. N. Chupakhin, et al., Adv.Synth. Catal. 2019, 361, 2161-2214.

[8] L. L. Adduci, M. P. McLaughlin, T. A. Bender, J. J. Becker, M. R. Gagné, Angew. Chem. Int. Ed. 2014, 53, 1646-1649.

[9] M. Schlaf, Dalt. Trans. 2006, 4645-4653.

[10] X. Yih, W. Gao, H. Chyuan, H. Voon, J. Ching, W. Hsin, K. Teong, Renew. Sustain. Energy Rev. 2019, 112, 834-852.

[11] S. Raju, M. E. Moret, R. J. M. Klein Gebbink, ACS Catal. 2015, 5, 281-300.

[12] J. R. Dethlefsen, P. Fristrup, ChemSusChem 2015, 8, 767-775.

[13] L. J. Donnelly, S. P. Thomas, J. B. Love, Chem. Asian J. 2019, 14, 3782-3790.

[14] S. M. Kilyanek, K. A. Denike, S. M. Kilyanek, R. Soc. open sci. 2019, 6, 1-16. 
[15] G. K. Cook, M. A. Andrews, J. Am. Chem. Soc. 1996, 118, 9448-9449.

[16] K. P. Gable, Organometallics 1994, 13, 2486-2488.

[17] K. P. Gable, T. N. Phan, J. Am. Chem. Soc. 1994, 116, 833.

[18] K. P. Gable, B. Ross, ACS Symp. Ser. 2006, 921, 143-155.

[19] B. Herrmann, W. A.; Serrano, R.; Ziegler, M . L .; Pfisterer, H.; Nuber, Angew. Chem. Int. Ed. 1985, 24, 50-52.

[20] S. Raju, J. T. B. H. Jastrzebski, M. Lutz, R. J. M. Klein Gebbink, ChemSusChem 2013, 6, 1673-1680.

[21] S. Raju, 2015, PhD thesis, Utrecht University (the Netherlands).

[22] S. Raju, C. A. M. R. Van Slagmaat, J. Li, M. Lutz, J. T. B. H. Jastrzebski, M. E. Moret, R. J. M. Klein Gebbink, Organometallics 2016, 35, 2178-2187.

[23] J. Li, M. Lutz, M. Otte, R. J. M. Klein Gebbink, ChemCatChem 2018, 10, 4755-4760.

[24] J. E. Ziegler, M. J. Zdilla, A. J. Evans, M. M. Abu-Omar, Inorg. Chem. 2009, 48, 9998-10000.

[25] J. P. Collman, L. M. Slaughter, T. A. Eberspacher, T. Strassner, J. I. Brauman, D.Garching, R. V June, Inorg. Chem. 2001, 40, 9114-9122.

[26] A. Dehestani, W. H. Lam, D. A. Hrovat, E. R. Davidson, W. T. Borden, J. M. Mayer, J. Am. Chem. Soc 2005, 127, 3423-3432.

[27] S. Bi, J. Wang, L. Liu, P. Li, Z. Lin, Organometallics 2012, 31, 6139-6147.

[28] S. Vkuturi, G. Chapman, I. Ahmad, K. M. Nicholas, Inorg. Chem. 2010, 49, 47444746.

[29] I. Ahmad, G. Chapman, K. M. Nicholas, Organometallics 2011, 30, 2810-2818.

[30] P. Liu, K. M. Nicholas, Organometallics 2013, 32, 1821-1831.

[31] J. Yi, S. Liu, M. M. Abu-Omar, ChemSusChem 2012, 5, 1401-1404.

[32] M. Shiramizu, F. D. Toste, Angew. Chemie - Int. Ed. 2012, 51, 8082-8086.

[33] M. Shiramizu, F. D. Toste, Angew. Chemie - Int. Ed. 2013, 52, 12905-12909.

[34] S. Qu, Y. Dang, M. Wen, Z. X. Wang, Chem. - A Eur. J. 2013, 19, 3827-3832.

[35] D. Wu, Y. Zhang, H. Su, Chem. - An Asian J. 2016, 11, 1565-1571.

[36] S. Liu, A. Senocak, J. L. Smeltz, L. Yang, B. Wegenhart, J. Yi, H. I. Kenttämaa, E. A. Ison, M. M. Abu-Omar, Organometallics 2013, 32, 3210-3219.

[37] J. R. Dethlefsen, P. Fristrup, ChemCatChem 2015, 7, 1184-1196.

[38] M. Lupacchini, A. Mascitti, V. Canale, L. Tonucci, E. Colacino, M. Passacantando, A. Marrone, N. Alessandro, Catal. Sci. Technol. 2019, 9, 3005-3296.

[39] C. Boucher-Jacobs, K. M. Nicholas, Organometallics 2015, 34, 1985-1990.

[40] A. Jefferson, R. S. Srivastava, Polyhedron 2018, DOI 10.1016/j.poly.2018.11.061.

[41] C. Boucher-Jacobs, K. M. Nicholas, ChemSusChem 2013, 6, 597-599.

[42] J. Michael McClain, K. M. Nicholas, ACS Catal. 2014, 4, 2109-2112.

[43] R. T. Larson, A. Samant, J. Chen, W. Lee, M. A. Bohn, D. M. Ohlmann, S. J. Zuend, F. D. Toste, J. Am. Chem. Soc. 2017, 139, 14001-14004.

[44] X. Li, Y. Zhang, ChemSusChem 2016, 9, 2774-2778.

[45] D. S. Morris, K. Van Rees, M. Curcio, M. Cokoja, F. E. Kühn, F. Duarte, J. B. Love, Catal. Sci. Technol. 2017, 7, 5644-5649.

[46] J. Shakeri, H. Hadadzadeh, H. Farrokhpour, M. Joshaghani, M. Weil, PerrhenateCatalyzed Deoxydehydration of a Vicinal Diol: A Comparative Density Functional Theory Study, 2017.

[47] B. Wozniak, Y. Li, S. Tin, J. G. De Vries, Green Chem. 2018, 20, 4433-4437.

[48] J. A. Ellman, E. Arceo, R. G. Bergman, J. Am. Chem. Soc. 2010, 132, 11408-11409.

[49] J. R. Dethlefsen, D. Lupp, B. Oh, P. Fristrup, ChemSusChem 2014, 7, 425-428.

[50] J. R. Dethlefsen, D. Lupp, A. Teshome, L. B. Nielsen, P. Fristrup, ACS Catal. 2015, 5, 3638-3647. 
[51] D. Lupp, N. J. Christensen, J. R. Dethlefsen, P. Fristrup, Chem. - A Eur. J. 2015, 21, 3435-3442.

[52] C. A. Navarro, A. John, Inorg. Chem. Commun. 2019, 99, 145-148.

[53] L. Hills, R. Moyano, F. Montilla, A. Pastor, A. Galindo, E. Álvarez, F. Marchetti, C. Pettinari, Eur. J. Inorg. Chem. 2013, 3352-3361.

[54] K. Beckerle, A. Sauer, T. P. Spaniol, J. Okuda, Polyhedron 2016, 116, 105-110.

[55] M. Stalpaert, D. De Vos, D. De Vos, ACS Sustain. Chem. Eng. 2018, 6, 12197-12204.

[56] R. Tran, S. M. Kilyanek, Dalt. Trans. 2019, 48, 16304-16311.

[57] G. Chapman, K. M. Nicholas, Chem. Commun. 2013, 49, 8199-8201.

[58] A. Galindo, Inorg. Chem. 2016, 55, 2284-2289.

[59] L. C. De Vicente Poutás, M. Castiñeira Reis, R. Sanz, C. S. López, O. N. Faza, Inorg. Chem. 2016, 55, 11372-11382.

[60] T. V. Gopaladasu, K. M. Nicholas, ACS Catal. 2016, 6, 1901-1904.

[61] Y. Y. Jiang, J. L. Jiang, Y. Fu, Organometallics 2016, 35, 3388-3396.

[62] A. R. Petersen, L. B. Nielsen, J. R. Dethlefsen, P. Fristrup, ChemCatChem 2018, 10, 769-778. 


\title{
Chapter 2
}

\section{A C p $^{\text {tt }}$-based Trioxo-Rhenium Catalyst for the Deoxydehydration of Diols and Polyols}

\begin{abstract}
Trioxo-rhenium complexes are well known catalysts for the deoxydehydration (DODH) of vicinal diols (glycols). In this work, we report on the DODH of diols and biomass-derived polyols using $\mathrm{Cp}^{\text {tt }} \mathrm{ReO}_{3}$ as a new catalyst $\left(\mathrm{Cp}^{\text {tt }}=1,3\right.$-di-tert-butylcyclopentadienyl). The DODH reaction was optimized using $2 \mathrm{~mol} \%$ of $\mathrm{Cp}^{\text {tt }} \mathrm{ReO}_{3}$ and 3-octanol as both reductant and solvent. The $\mathrm{Cp}^{\mathrm{tt}} \mathrm{ReO}_{3}$ catalyst exhibits an excellent activity for biomass-derived polyols. Specifically, glycerol is almost quantitatively converted to allyl alcohol and mucic acid gives $75 \%$ of muconates at $91 \%$ conversion. In addition, the loading of $\mathrm{Cp}^{\mathrm{tt}} \mathrm{ReO}_{3}$ can be reduced to $0.1 \mathrm{~mol} \%$ to achieve a turn-over number as high as 900 per Re when using glycerol as substrate. Examination of DODH reaction profiles by NMR spectroscopy indicates that catalysis is related to $\mathrm{Cp}$-ligand release, which raises questions on the nature of the actual catalyst.
\end{abstract}

This chapter is based on:

J. Li, M. Lutz, M. Otte, R. J. M. Klein Gebbink, ChemCatChem. 2018, 10, 4755-4760. 


\subsection{Introduction}

Due to the anticipated depletion of fossil feedstocks, the search for alternative and renewable chemical feedstocks receives a lot of attention. ${ }^{[1,2]}$ Biomass is such a potential resource for the sustainable production of commodity chemicals and other chemical building blocks. ${ }^{[3-5]}$ Biomass-derived feedstocks, such as sugars and polyols, are highly oxygenated, mostly in the form of hydroxyl groups. In order to make use of these feedstocks, (partial) deoxygenation is required. Deoxydehydration (DODH) reactions, ${ }^{[6-8]}$ which constitute a combination of deoxygenation ${ }^{[9,10]}$ and dehydration, ${ }^{[11]}$ can efficiently convert vicinal diols and polyols into olefins. ${ }^{[12-14]}$

Trioxo-rhenium complexes are known as active catalysts for DODH reactions since the first catalytic DODH reaction was described by Cook and Andrews. ${ }^{[12]}$ In this very early work, a $\mathrm{Cp}^{*} \mathrm{ReO}_{3}$ complex (Scheme 2.1.1, left) was used to catalytically convert polyols into olefins. Later, Gable and coworkers studied olefin extrusion reactions from $\mathrm{Tp} * \operatorname{Re}$ (glycolate) complexes $\left(\mathrm{Tp}^{*}=\right.$ hydrido-tris-(3,5-dimethylpyrazolyl)borate), and in doing so used the $6 \mathrm{e}^{-}$ Tp* ligand as an alternative for the $6 \mathrm{e}^{-} \mathrm{Cp}^{*}$ ligand. ${ }^{[15]}$ Recently, we reported on a bulky $\mathrm{Cp}$ based trioxo-rhenium catalyst, $\mathrm{Cp}^{\mathrm{ttt}} \mathrm{ReO}_{3}\left(\mathrm{Cp}^{\mathrm{ttt}}=1,2,4\right.$-tri-tert-butylcyclopentadienyl, Scheme 2.1.1, middle). ${ }^{[16]}$ This trioxo-rhenium complex is able to effectively catalyze the DODH of a series of different diols and polyols. The electron-rich $\mathrm{Cp}^{\text {tt }}$ ligand of the complex stabilizes the high-valent rhenium center, avoiding over-reduction, and hampers catalyst dimerization leading to decomposition, to result in high TONs. Interestingly, a slight change of the ligand (removing one tert-butyl group) resulted in a different DODH reactivity of the trioxo-rhenium complex. ${ }^{[17]}$ We observed an induction period in the $\mathrm{Cp}^{\mathrm{ttt}} \mathrm{ReO}_{3}$-catalyzed DODH of 1,2octanediol, while there was almost no induction period in the reaction catalyzed by the $\mathrm{Cp}^{\mathrm{tt}} \mathrm{ReO}_{3}$ complex $\left(\mathrm{Cp}^{\mathrm{tt}}=\right.$ 1,3-di-tert-butylcyclopentadienyl, Scheme 2.1.1, right $)$. This result encouraged us to further investigate the catalytic properties of the less bulky $\mathrm{Cp}^{\text {tt }} \mathrm{ReO}_{3}$ complex. Here, we report on the DODH of diols and biomass-derived polyols using $\mathrm{Cp}^{\mathrm{tt}} \mathrm{ReO}_{3}$.

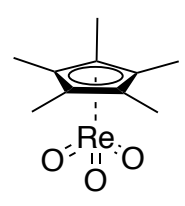

$\mathrm{Cp}^{*} \mathrm{ReO}_{3}$

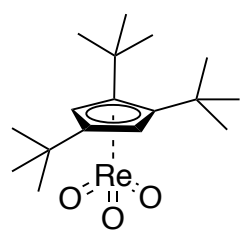

$\mathrm{Cp}^{\mathrm{ttt}} \mathrm{ReO}_{3}$

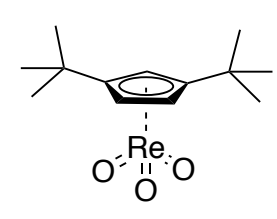

$\mathrm{Cp}^{\mathrm{tt}} \mathrm{ReO}_{3}$

Scheme 2.1.1 Cp-base trioxo-Rhenium catalysts. 


\subsection{Results and Discussion}

\subsubsection{Synthesis of rhenium complexes}

We synthesized $\mathrm{Cp}^{\text {tt }} \mathrm{ReO}_{3}$ by making use of a reported method. ${ }^{[17]}$ It's a two-step synthesis procedure (Scheme 2.2.1). An excess of substituted cyclopentadiene was mixed with dirhenium decacarbonyl and refluxed in neat conditions under nitrogen atmosphere in order to generate the rhenium tricarbonyl complex. Gradual heating of the reaction mixture from $150{ }^{\circ} \mathrm{C}$ to 200 ${ }^{\circ} \mathrm{C}$ lead to complete conversion of the rhenium starting material, yielding $82 \%$ of the rhenium tricarbonyl complex $\mathrm{Cp}^{\mathrm{tt}} \mathrm{Re}(\mathrm{CO})_{3}$. Next, this rhenium tricarbonyl complex was oxidized to obtain the corresponding trioxo-rhenium complex $\mathrm{Cp}^{\text {tt }} \mathrm{ReO}_{3}$ by using $t \mathrm{BuOOH}$ as oxidant. A color change from colorless to bright yellow indicated the formation of trioxo-rhenium species. ${ }^{1} \mathrm{H}$ and ${ }^{13} \mathrm{C}$ NMR matched the data reported by Klein Gebbink et al. ${ }^{[17]}$

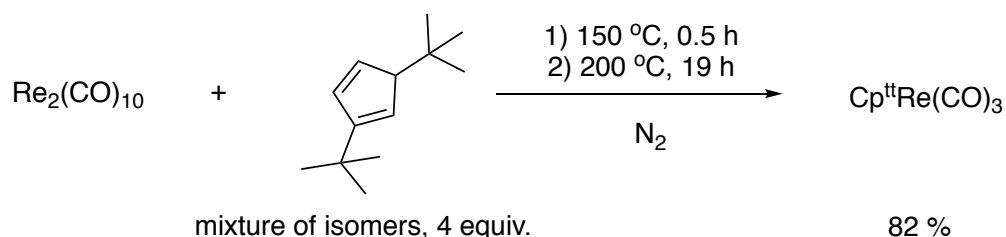

$$
\begin{aligned}
& \mathrm{Cp}^{\mathrm{tt}} \mathrm{Re}(\mathrm{CO})_{3} \quad \frac{t \mathrm{BuOOH} 6 \text { equiv. }}{\text { benzene, } 50^{\circ} \mathrm{C}, 50 \mathrm{~min}, \mathrm{~N}_{2}} \quad \mathrm{Cp}^{\mathrm{tt}} \mathrm{ReO}_{3} \\
& 19 \%
\end{aligned}
$$

Scheme 2.2.1 Synthesis of $\mathrm{Cp}^{\mathrm{tt}} \mathrm{Re}(\mathrm{CO})_{3}$ and $\mathrm{Cp}^{\mathrm{tt}} \mathrm{ReO}_{3}$

\subsubsection{Catalytic performances in DODH of diols and polyols}

We started our investigation on the use of $\mathrm{Cp}^{\mathrm{tt}} \mathrm{ReO}_{3}$ as a catalyst for the DODH of vicinal diols into olefins by using 1,2-octanediol as a substrate (Table 2.2.1). Initial reactions were performed with $2 \mathrm{~mol} \% \mathrm{Cp}^{\mathrm{tt}} \mathrm{ReO}_{3}$ at $135{ }^{\circ} \mathrm{C}$ in chlorobenzene and 1.1 equivalent of sacrificial reducing agent under an inert nitrogen atmosphere. The use of triphenylphosphine $\left(\mathrm{PPh}_{3}\right)$ as reducing agent gave an excellent yield at full conversion (entry 1), which matched the data reported in our previous study. ${ }^{[17]}$ Sodium sulfite and active carbon gave a very poor conversion, probably because of their poor solubility in the chlorobenzene reaction medium (entry 2 and 3 ). The use of molecular hydrogen (40 bar) resulted in only $1.2 \%$ n-octane as the over-reduced product at $23 \%$ substrate conversion (entry 4 ). 
Secondary alcohols have been reported as both reductants and solvents for Re-catalyzed DODH reactions. ${ }^{[18]}$ Using 3-octanol as reductant, a 93\% yield of 1-octene was achieved when the reaction was carried out at $135^{\circ} \mathrm{C}$ for $15 \mathrm{~h}$ (entry 5). Increasing, the reaction temperature to 170 ${ }^{\circ} \mathrm{C}$ lead to a decreased 1-octene yield at complete conversion (entry 6). Besides, even under aerobic conditions, i.e. carrying the reaction out in air, $68 \%$ of 1 -octene was formed at $76 \%$ conversion using $\mathrm{Cp}^{\text {tt }} \mathrm{ReO}_{3}$ as catalyst and 3-octanol as reductant (entry 7). In our previous studies on the more bulky $\mathrm{Cp}^{\mathrm{ttt}} \mathrm{ReO} \mathrm{O}_{3}$ catalyst, we also observed that aerobic reaction conditions would decrease the activity of the catalyst. ${ }^{[19]}$ Both $\mathrm{PPh}_{3}$ and 3-octanol gave high yield, considering the solvent chlorobenzene was neither green nor good at dissolving biomassderivatives, 3-octanol was chosen as the reducing agent in subsequent DODH reactions with $\mathrm{Cp}^{\mathrm{tt}} \mathrm{ReO}_{3}$.

Table 2.2.1. Optimization of reaction conditions and sacrificial reducing agent in the DODH of 1,2octanediol to 1-octene catalyzed by $\mathrm{Cp}^{\mathrm{tt}} \mathrm{ReO}_{3}{ }^{\left[{ }^{[a]}\right.}$

\begin{tabular}{ccccc}
\hline entry & reductant & conditions & yield & conversion \\
\hline $1^{[\mathrm{b}]}$ & $\mathrm{PPh}_{3}$ & $135^{\circ} \mathrm{C}, 15 \mathrm{~h}, \mathrm{~N}_{2}$ & $93 \%$ & $>99 \%$ \\
$2^{[\mathrm{b}]}$ & $\mathrm{Na}_{2} \mathrm{SO}_{3}$ & $135^{\circ} \mathrm{C}, 15 \mathrm{~h}, \mathrm{~N}_{2}$ & N.D. & $6 \%$ \\
$3^{[\mathrm{b}]}$ & $\mathrm{C}$ & $135^{\circ} \mathrm{C}, 16 \mathrm{~h}, \mathrm{~N}_{2}$ & N.D. & $40 \%$ \\
$4^{[\mathrm{b}]}$ & $\mathrm{H}_{2}^{[\mathrm{d}]}$ & $135^{\circ} \mathrm{C}, 16 \mathrm{~h}, \mathrm{~N}_{2}$ & $1.2 \%{ }^{[\mathrm{e}]}$ & $23 \%$ \\
$5^{[\mathrm{c}]}$ & 3 -octanol & $135^{\circ} \mathrm{C}, 15 \mathrm{~h}, \mathrm{~N}_{2}$ & $93 \%$ & $>99 \%$ \\
$6^{[\mathrm{c}]}$ & 3 -octanol & $170^{\circ} \mathrm{C}, 2 \mathrm{~h}, \mathrm{~N}_{2}$ & $81 \%$ & $>99 \%$ \\
$7^{[\mathrm{c}]}$ & 3 -octanol & $135^{\circ} \mathrm{C}, 15 \mathrm{~h}$, air & $68 \%$ & $76 \%$ \\
\hline
\end{tabular}

[a] Reaction conditions: 1,2-octanediol (0.5 mmol), $\mathrm{Cp}^{\mathrm{tt}} \mathrm{ReO}_{3}(0.01 \mathrm{mmol}, 2 \mathrm{~mol} \%)$, reductant $(0.55$ mmol, 1.1 equivalent $)$. [b] $\mathrm{PhCl}(0.5 \mathrm{~mL})$ was used as solvent, the yield and conversion were determined by gas chromatography using mesitylene $(0.5 \mathrm{mmol})$ as an internal standard. [c] 3-octanol $(0.5 \mathrm{~mL})$ was used as both reductant and solvent, the yield and conversion were determined by ${ }^{1} \mathrm{H}$ NMR using mesitylene $(0.5 \mathrm{mmol})$ as an internal standard. [d] Pressure of $\mathrm{H}_{2}: 40$ bar. [e] Yield of n-octane.

Following these optimization studies, the substrate scope using a variety of vicinal diols and biomass-derived polyols was investigated under optimized reaction conditions (Table 2.2.2). 1,4-anhydroerythritol gave $83 \%$ of 2,5-dihydrofuran (entry 2). The aromatic vicinal diol 1phenyl-1,2-ethanediol gave $76 \%$ yield of styrene at full conversion (entry 3 ), while $(R, R)-1,2-$ diphenyl-1,2-ethanediol selectively gave trans-stilbene in 95\% yield (entry 5). Interestingly, we observed a higher yield (90\%) of styrene when $\mathrm{PPh}_{3}$ was used as reductant (entry 4). The lower yield of styrene could be explained by ketal formation from the diol substrate and 3octanone (dehydrogenation product of 3-octanol) during the reaction. A 99\% styrene yield was realized with the $\mathrm{Cp}^{\text {ttt }} \mathrm{ReO}_{3}$ catalyst while $\mathrm{PPh}_{3}$ was used as reductant. ${ }^{[16]}$ Overall though, the 
conversions and yields that can be achieved in DODH reactions of vicinal diols with the less bulky $\mathrm{Cp}^{\text {tt }} \mathrm{ReO}_{3}$ catalyst are quite similar to those with the $\mathrm{Cp}^{\mathrm{ttt}} \mathrm{ReO}_{3}$ catalyst.

Table 2.2.2 DODH of vicinal diols and polyols to olefins catalyzed by $\mathrm{Cp}^{\mathrm{tt}} \mathrm{ReO}_{3} .^{[\mathrm{a}]}$

\begin{tabular}{|c|c|c|c|c|}
\hline entry & substrate & product & yield $^{[b]}$ & conversion \\
\hline 1 & Ol & & $93 \%$ & $>99 \%$ \\
\hline 2 & & & $83 \%$ & $>99 \%$ \\
\hline 3 & & & $76 \%$ & $>99 \%$ \\
\hline $4^{[c]}$ & & & $90 \%$ & $>99 \%$ \\
\hline 5 & & & $95 \%$ & $>99 \%$ \\
\hline 6 & & & $99 \%$ & $>99 \%$ \\
\hline 7 & & & $\begin{array}{c}69 \% \\
(74 \%)^{[\mathrm{f}]}\end{array}$ & $93 \%$ \\
\hline 8 & $-10-$ & & $\begin{array}{c}71 \% \\
(84 \%)^{[\mathrm{g}]}\end{array}$ & $93 \%$ \\
\hline $9^{[\mathrm{d}]}$ & & & $\begin{array}{c}87 \% \\
(94 \%)^{[\mathrm{f}]}\end{array}$ & $>99 \%$ \\
\hline $10^{[\mathrm{d}]}$ & & & $\begin{array}{c}90 \% \\
(95 \%)^{[\mathrm{g}]}\end{array}$ & $>99 \%$ \\
\hline $11^{[\mathrm{e}]}$ & $\mathrm{HO}-$ & & $\begin{array}{c}57 \% \\
(61 \%)^{[\mathrm{f}]}\end{array}$ & $87 \%$ \\
\hline
\end{tabular}

[a] Reaction conditions: substrates $(0.5 \mathrm{mmol}), \mathrm{Cp}^{\mathrm{tt}} \mathrm{ReO}_{3}(0.01 \mathrm{mmol}, 2 \mathrm{~mol} \%), 3$-octanol $(0.5 \mathrm{~mL}, 0.1$ $\mathrm{M}), \mathrm{N}_{2}, 135{ }^{\circ} \mathrm{C}, 15 \mathrm{~h}$. [b] Determined by ${ }^{1} \mathrm{H}$ NMR using mesitylene $(0.5 \mathrm{mmol})$ as an internal standard. [c] Reaction conditions: substrates $(0.5 \mathrm{mmol}), \mathrm{Cp}^{\mathrm{tt}} \mathrm{ReO}_{3}(0.01 \mathrm{mmol}, 2 \mathrm{~mol} \%), \mathrm{PPh}_{3}(0.55 \mathrm{mmol}, 1.1$ equiv), $\mathrm{PhCl}(0.5 \mathrm{~mL}, 0.1 \mathrm{M}), \mathrm{N}_{2}, 135^{\circ} \mathrm{C}, 15 \mathrm{~h}$. [d]170 ${ }^{\circ} \mathrm{C}, 1.5 \mathrm{~h}, \mathrm{~N}_{2}$. [e] air. [f] Total yield of 1,3butadiene and 2,5-dihydrofuran. [g] Total yield of 1,3-butadiene and 1,4-anhydroethreitol. 
Glycerol is the by-product formed during the transesterification of vegetable oils for the production of biodiesel. ${ }^{[20,21]}$ Under our optimized reaction conditions, glycerol was almost quantitatively converted to allyl alcohol (entry 6), which is a versatile intermediate for various useful chemicals such as agrochemicals, resins, medicines, perfumes, and so on. ${ }^{[22]}$ When our previous $\mathrm{Cp}^{\text {ttt }} \mathrm{ReO}_{3}$ was used as catalyst for the deoxydehydration of glycerol, 91\% of allyl alcohol was obtained at full conversion. ${ }^{[16]}$ Erythritol, which can be produced from glucose by fermentation, ${ }^{[23]}$ was converted to 1,3 -butadiene $(69 \%)$ with 2,5 -dihydrofuran $(5 \%)$ as byproduct under optimized reaction conditions (entry 7). Another $\mathrm{C}_{4}$ sugar alcohol, DL-threitol, gave $71 \%$ of 1,3 -butadiene with $13 \%$ of 1,4 -anhydroethreitol as by-product (entry 8 ). With these two reactions, 1,3-butadiene, an industrially important building block, can be formed from sustainable starting materials. Interestingly, for these two reactions, increasing the temperature from $135^{\circ} \mathrm{C}$ to $170{ }^{\circ} \mathrm{C}$ and decreasing the reaction time from $15 \mathrm{~h}$ to $1.5 \mathrm{~h}$ lead to an increased 1,3-butadiene yield of 87 and 90\%, respectively (entry 9 and 10). We also observed that even under aerobic conditions erythritol gave $57 \%$ of 1,3 -butadiene at $87 \%$ conversion with $4 \%$ of 2,5-dihydrofuran as by-product (entry 11). For the $\mathrm{Cp}^{\mathrm{ttt}} \mathrm{ReO}_{3}$-catalyzed DODH of erythritol and DL-threitol, 1,3-butadiene was formed at a lower 67 and 59\% yield, respectively, under $\mathrm{N}_{2}$ at $170^{\circ} \mathrm{C}$.

Table 2.2.3 Comparison of alcohols as solvent/reductant for DODH of glycerol

\begin{tabular}{cccc}
\hline entry & alcohol & $\begin{array}{c}\text { yield }^{[\mathrm{b}]} \\
\text { (allyl alcohol) }\end{array}$ & $\begin{array}{c}\text { yield }^{[\mathrm{b}]} \\
\text { (alkene from alcohol) }\end{array}$ \\
\hline 1 & 1-butanol & $11 \%$ & trace \\
2 & $i$-butanol & $38 \%$ & trace \\
3 & 3-pentanol & $76 \%$ & $34 \%$ \\
4 & 3-octanol & $98 \%$ & $24 \%$ \\
5 & 2,4-dimethyl-3-pentanol & $99 \%$ & trace \\
\hline
\end{tabular}

[a] Reaction conditions: glycerol $(0.5 \mathrm{mmol}), \mathrm{Cp}^{\mathrm{tt}} \mathrm{ReO}_{3}(0.01 \mathrm{mmol}, 2 \mathrm{~mol} \%)$, primary or secondary alcohol $(0.5 \mathrm{~mL}, 0.1 \mathrm{M}), \mathrm{N}_{2}, 135{ }^{\circ} \mathrm{C}, 15 \mathrm{~h}$. [b] Determined by ${ }^{1} \mathrm{H}$ NMR using mesitylene $(0.5 \mathrm{mmol})$ as an internal standard.

For the very useful deoxydehydration of glycerol, we planned to investigate this reaction with different $\mathrm{Cp}^{\text {tt }} \mathrm{ReO}_{3}$ loadings and using different alcohols as sacrificial reductant. Considering there would be a competition between deoxydehydration of glycerol and dehydration of the alcohol, since rhenium complexes can also catalyse the dehydration of secondary alcohols, ${ }^{[8]}$ we started the investigation with testing different alcohols to find the most suitable reductant (Table 2.2.3). Finally, 2,4-dimethyl-3-pentanol, which is difficult to be dehydrated, was chosen as the reductant for this experiment. Then different loadings of $\mathrm{Cp}^{\mathrm{tt}} \mathrm{ReO}_{3}$ were tested and the 
loading could be lowered to $0.1 \mathrm{~mol} \%$ (Table 2.2.4). Using this catalyst loading glycerol could be converted to allyl alcohol at $90 \%$ yield with a total turn-over number per Re of 900 . To our knowledge, this is the highest TON reported for a homogeneous Re-catalyst in the DODH of glycerol.

Table 2.2.4 DODH of glycerol with different loading of $\mathrm{Cp}^{\mathrm{tt}} \mathrm{ReO}_{3}$

\begin{tabular}{ccccc}
\hline entry & catalyst loading & time & yield $^{[\mathrm{b}]}$ & TON \\
\hline 1 & $2 \mathrm{~mol} \%$ & $15 \mathrm{~h}$ & $99 \%$ & 49.5 \\
2 & $0.5 \mathrm{~mol} \%$ & $60 \mathrm{~h}$ & $83 \%$ & 166 \\
3 & $0.1 \mathrm{~mol} \%$ & $300 \mathrm{~h}$ & $90 \%$ & 900
\end{tabular}

[a] Reaction conditions: glycerol (0.5 mmol), $\mathrm{Cp}^{\mathrm{tt}} \mathrm{ReO}_{3}$ (x mol\%), 2,4-dimethyl-3-pentanol (0.5 mL, 0.1 $\mathrm{M}), \mathrm{N}_{2}, 135{ }^{\circ} \mathrm{C}$. [b] Determined by ${ }^{1} \mathrm{H}$ NMR using mesitylene $(0.5 \mathrm{mmol})$ as an internal standard.

Encouraged by the results of $\mathrm{Cp}^{\text {tt }} \mathrm{ReO}_{3}$-catalyzed DODH reactions of glycerol and $\mathrm{C}_{4}$ sugar alcohols, we then tested the $\mathrm{C}_{5}$ sugar alcohols xylitol, D-arabinitol, and adonitol (Scheme 2.2.2). Instead of $(E)$-2,4-pentadienol, $(E)$-5-penta-1,3-diene ether was formed in this reaction, as was earlier noted by Toste and coworkers. ${ }^{[13]}$ Under our reaction conditions, xylitol, D-arabinitol, and adonitol formed the (E)-5-penta-1,3-diene ethers at a yield of $46 \%, 48 \%$, and $42 \%$, respectively. Interestingly, when methyltrioxorhenium (MTO) was used as catalyst for these reactions under more harsh reaction conditions, xylitol gave much more product $(61 \%)$ than adonitol $(33 \%) .{ }^{[13]}$ Next to the reactions on $\mathrm{C}_{5}$ sugar alcohols, we also carried out reactions on two $\mathrm{C}_{6}$ sugar alcohols (Scheme 2.2.3). D-mannitol gave approx. 35\% yield of 1,3,5-hexatriene, while D-sorbitol only gave $17 \%$ yield of $1,3,5$-hexatriene.

Adipic acid, a building block for the large-volume production of nylon-6,6 polyamide, ${ }^{[24]}$ is mainly produced from non-renewable petroleum-based cyclohexane. The production procedures include a nitric acid oxidation process, which emits large amounts of nitrous oxides. ${ }^{[25]}$ An alternative way to produce adipic acid is using sustainable mucic acid to form muconates through DODH chemistry, followed by hydrogenation and hydrolysis. ${ }^{[26]}$ Accordingly, we have investigated the activity of the $\mathrm{Cp}^{\mathrm{tt}} \mathrm{ReO}_{3}$ catalyst in the DODH of mucic acid. Under modified reaction conditions, mucic acid gave $75 \%$ of isopentylmuconate at $91 \%$ conversion after $12 \mathrm{~h}$ using 3-pentanol as reducing agent at $120{ }^{\circ} \mathrm{C}$. Under the same reaction conditions, when our previous $\mathrm{Cp}^{\text {ttt }} \mathrm{ReO}_{3}$ catalyst was uses as catalyst only $28 \%$ of muconates were formed at $48 \%$ conversion (Scheme 2.2 .4 ), and when MTO was used as catalyst $71 \%$ of muconates were formed at $98 \%$ conversion. ${ }^{[26]}$ 


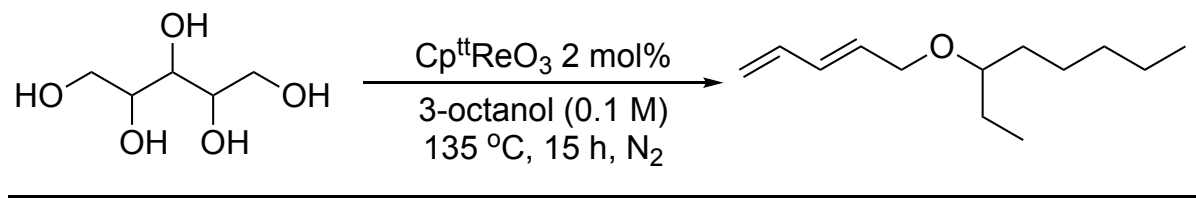<smiles>OC[C@H](O)[C@H](O)CO</smiles>

xylitol

$46 \%$ yield<smiles>OC[C@H](O)[C@H](O)CO</smiles>

D-arabinitol $48 \%$ yield<smiles>OCC(O)[C@@H](O)[C@H](O)CO</smiles>

adonitol $42 \%$ yield

Scheme 2.2.2. $\mathrm{Cp}^{\mathrm{tt}} \mathrm{ReO}_{3}$-catalyzed $\mathrm{DODH}$ of $\mathrm{C}_{5}$ sugar alcohols.

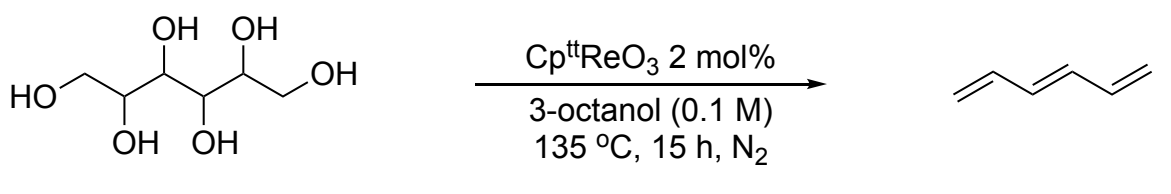<smiles>OC[C@@H](O)C(O)[C@H](O)CO</smiles>

D-mannitol $35 \%$ yield<smiles>OC[C@@H](O)C(O)[C@H](O)CO</smiles>

D-sorbitol $17 \%$ yield

Scheme 2.2.3. $\mathrm{Cp}^{\mathrm{tt}} \mathrm{ReO}_{3}$-catalyzed $\mathrm{DODH}$ of $\mathrm{C}_{6}$ sugar alcohols.<smiles>O=C(O)C(O)[C@H](O)[C@H](O)[C@H](O)C(=O)O</smiles>

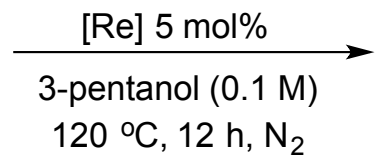<smiles>CCC(CC)OC(=O)/C=C/C=C/C(=O)O</smiles><smiles>CCC(CC)OC(=O)/C=C/C=C/C(=O)OC(CC)CC</smiles>

$[\mathrm{Re}]=\mathrm{Cp}^{\text {tt ReO }} 3$, yield: $75 \%$, conversion: $91 \%$ $[R e]=\mathrm{Cp}^{\text {ttt }} \mathrm{ReO}_{3}$, yield: $28 \%$, conversion: $48 \%$

Scheme 2.2.4. $\mathrm{Cp}^{\mathrm{tt}} \mathrm{ReO}_{3}$-catalyzed $\mathrm{DODH}$ of mucic acid.

Finally, we have also applied the $\mathrm{Cp}^{\mathrm{tt}} \mathrm{ReO}_{3}$ catalyst to DODH reactions of a number of sugar compounds, 2-Vinylfuran (2-VF) and furan were formed as the main products, which is in line with the observations of Toste. ${ }^{[13]}$ Under our optimized reaction conditions, using 3-octanol as the reducing agent at $135{ }^{\circ} \mathrm{C}$ for $15 \mathrm{~h}, 2$-vinylfuran was the main product albeit at low yield (Table 2.2.5 entries 1-3). An interesting observation was that when using 3-pentanol as reductant and solvent, the reaction mixture was more homogenous than when using 3-octanol. 3-pentanol was then chosen as the reductant and solvent for the DODH of sugar compounds. For the three sugars we have tested, D-glucose gave a very poor yield (entry 1, 4, 7), while Dmannose gave the highest yield up to 39\% (entry 9). Besides, in terms of product selectivity, 
the reaction of D-galactose is quite sensitive to the reaction conditions; the ratio of 2-VF and furan products changes when using a different reductant (entry 2, 5, 8). D-galactose selectively forms furan as the only product when 3-pentanol was used as reductant (entry 8). For Dmannose, a different reductant does not have an obvious effect on product selectivity (entry 3 , $6,9)$, although consistently giving the highest product yields amongst the three sugar substrates.

Table 2.2.5 DODH of sugars to 2-vinylfuran (2-VF) and furan catalyzed by $\mathrm{Cp}^{\mathrm{tt}} \mathrm{ReO}_{3}{ }^{[\mathrm{a}]}$

\begin{tabular}{ccccc}
\hline entry & sugar & conditions & yield $^{[\mathrm{b}]}$ & ratio (2-VF :furan) \\
\hline 1 & D-glucose & 3-octanol,135 ${ }^{\circ} \mathrm{C}, 15 \mathrm{~h}$ & $8 \%$ & $1.7: 1$ \\
2 & D-galactose & 3-octanol,135 ${ }^{\circ} \mathrm{C}, 15 \mathrm{~h}$ & $22 \%$ & $1.2: 1$ \\
3 & D-mannose & 3-octanol,135 ${ }^{\circ} \mathrm{C}, 15 \mathrm{~h}$ & $21 \%$ & $2.5: 1$ \\
4 & D-glucose & 3-pentanol, $135^{\circ} \mathrm{C}, 15 \mathrm{~h}$ & trace & -- \\
5 & D-galactose & 3-pentanol, $135^{\circ} \mathrm{C}, 15 \mathrm{~h}$ & $13 \%$ & $1: 1.6$ \\
6 & D-mannose & 3-pentanol, $135^{\circ} \mathrm{C}, 15 \mathrm{~h}$ & $26 \%$ & $2.3: 1$ \\
7 & D-glucose & 3-pentanol, $155^{\circ} \mathrm{C}, 12 \mathrm{~h}$ & trace & -- \\
$8^{[\mathrm{c}]}$ & D-galactose & 3-pentanol, $155^{\circ} \mathrm{C}, 12 \mathrm{~h}$ & $14 \%$ & -- \\
9 & D-mannose & 3-pentanol, $155^{\circ} \mathrm{C}, 12 \mathrm{~h}$ & $39 \%$ & $2.3: 1$ \\
\hline
\end{tabular}

[a] Reaction conditions: sugars $(0.5 \mathrm{mmol}), \mathrm{Cp}^{\mathrm{tt}} \mathrm{ReO}_{3}(0.01 \mathrm{mmol}, 2 \mathrm{~mol} \%), \mathrm{N}_{2}$. [b] Total yield of 2-VF and furan, determined by ${ }^{1} \mathrm{H}$ NMR using mesitylene $(0.5 \mathrm{mmol})$ as an internal standard. [c] No 2-VF formation.

The above results show that the less bulky $\mathrm{Cp}^{\mathrm{tt}} \mathrm{ReO}_{3}$ complex catalyzes the DODH of both aromatic and aliphatic vicinal diols with high yield and product selectivity. Extending the substrate scope to bio-based polyols, the high yield and product selectivity for this catalyst remains. Specifically, glycerol is almost quantitatively converted to allyl alcohol and mucic acid gives $75 \%$ of muconates at $91 \%$ conversion. Besides, even for more complicated sugar alcohols and sugars, the DODH reaction can be realized at moderate yields. Based on these data, we compared the $\mathrm{Cp}^{\mathrm{tt}} \mathrm{ReO}_{3}$ catalyst with our previous generation catalyst $\mathrm{Cp}^{\mathrm{ttt}} \mathrm{ReO}_{3}$ for which the advantageous performance in DODH catalysis was attributed to its overall steric bulk provide by the $\mathrm{Cp}^{\text {ttt }}$ ligand. Both catalysts show a high DODH reactivity and selectivity for general vicinal diols, while in particular for bio-based polyols $\mathrm{Cp}^{\mathrm{tt}} \mathrm{ReO}$ shows a significantly improved reactivity and product selectivity. This comparison challenges the initial hypothesis that DODH catalysis improves with ligand bulk for $\mathrm{Cp}^{\prime} \mathrm{ReO}_{3}$ type catalysts.

\subsubsection{Investigation of catalyst evolution under catalytic conditions}


In our previous work, we found a difference in the kinetic profile of the DODH reaction of 1,2octanediol when either $\mathrm{Cp}^{\mathrm{ttt}} \mathrm{ReO}_{3}$ or $\mathrm{Cp}^{\mathrm{tt} R e O} \mathrm{R}_{3}$ was used as catalyst. ${ }^{[17]} \mathrm{A}$ clear induction period was observed for the $\mathrm{Cp}^{\text {ttt }} \mathrm{ReO}_{3}$-catalyzed DODH reaction, while there was almost no induction period for the $\mathrm{Cp}^{\mathrm{tt} R e O} \mathrm{R}_{3}$-catalyzed reaction. This observation was a further indication that the Cp-ligand structure has an effect on DODH catalysis, not only in terms of activity and selectivity, but also in terms of kinetics and catalyst evolution.

In order to further investigate catalyst evolution under catalytic conditions, the catalytic DODH of 1,2-octanediol by a number of Cp'Re complexes was examined using in situ NMR experiments. Considering side reactions of secondary alcohols and possible peak overlap, the following reaction conditions were chosen: 1,2-octanediol ( $0.05 \mathrm{mmol}), \mathrm{PPh}_{3}(0.055 \mathrm{mmol}, 1.1$ equiv.), mesitylene (0.05 mmol, 1.0 equiv, internal standard), Re-catalyst (10 $\mathrm{mol} \% \mathrm{Re})$, toluene- $\mathrm{D}_{8}(0.5 \mathrm{~mL}), 135^{\circ} \mathrm{C}, \mathrm{N}_{2}$. Since all of the in situ $\mathrm{NMR}$ experiments were performed in an NMR tube without stirring during the reaction, the final yield may not reach the reported values for reactions carried out in pressure tubes.

In the experiment using $\mathrm{Cp}^{\mathrm{tt}} \mathrm{ReO}_{3}$, peaks in the vinylic and the allylic region, e.g. between 6.30,5.70 and $2.85,-2.70 \mathrm{ppm}$, started to appear from the very start of the experiment (Scheme 2.2.5). These peaks could be assigned to free $\mathrm{Cp}^{\mathrm{tt}} \mathrm{H}$ ligand. The observation of free ligand during catalysis was interpreted to originate from ligand dissociation. In a similar manner, ligand dissociation was also observed in the experiment using $\mathrm{Cp}^{\mathrm{ttt}} \mathrm{ReO}_{3}$, albeit at a slower rate than for $\mathrm{Cp}^{\mathrm{tt} R e O} \mathrm{R}_{3}$ (Scheme 2.2.5). In the former case, $60 \%$ of ligand dissociation occurred after 5 min, during which $8 \%$ of 1 -octene was formed. After $30 \mathrm{~min}$, maximum ligand dissociation (94\%) was reached, and the DODH reaction finished after $50 \mathrm{~min}$ at $88 \%$ 1-octene yield (Scheme 2.2.6). When $\mathrm{Cp}^{\text {ttt }} \mathrm{ReO}_{3}$ was used as catalyst, maximum ligand dissociation (27\%) was reached at $80 \mathrm{~min}$, and the DODH reaction finished after $150 \mathrm{~min}$ at $93 \%$ product yield (Scheme 2.2.6). In this case, NMR signals related to typical Cp'Re-based reaction intermediates like Cp'Re-glycolates were also observed (spectra in experimental section 2.4.5). ${ }^{[27]}$

The time course profile of the olefin generation matches our previous results, i.e. there is no clear induction period for the $\mathrm{Cp}^{\mathrm{tt}} \mathrm{ReO}_{3}$-catalyzed DODH reaction, while there is an obvious induction period for the $\mathrm{Cp}^{\text {ttt }} \mathrm{ReO}_{3}$-catalyzed reaction. In addition, initial olefin product formation is related to the rate of ligand dissociation, while the final amount of product is not related to the extent of overall ligand dissociation. 
a. $[\mathrm{Re}]=\mathrm{Cp}^{\mathrm{tt}} \mathrm{ReO}_{3}$

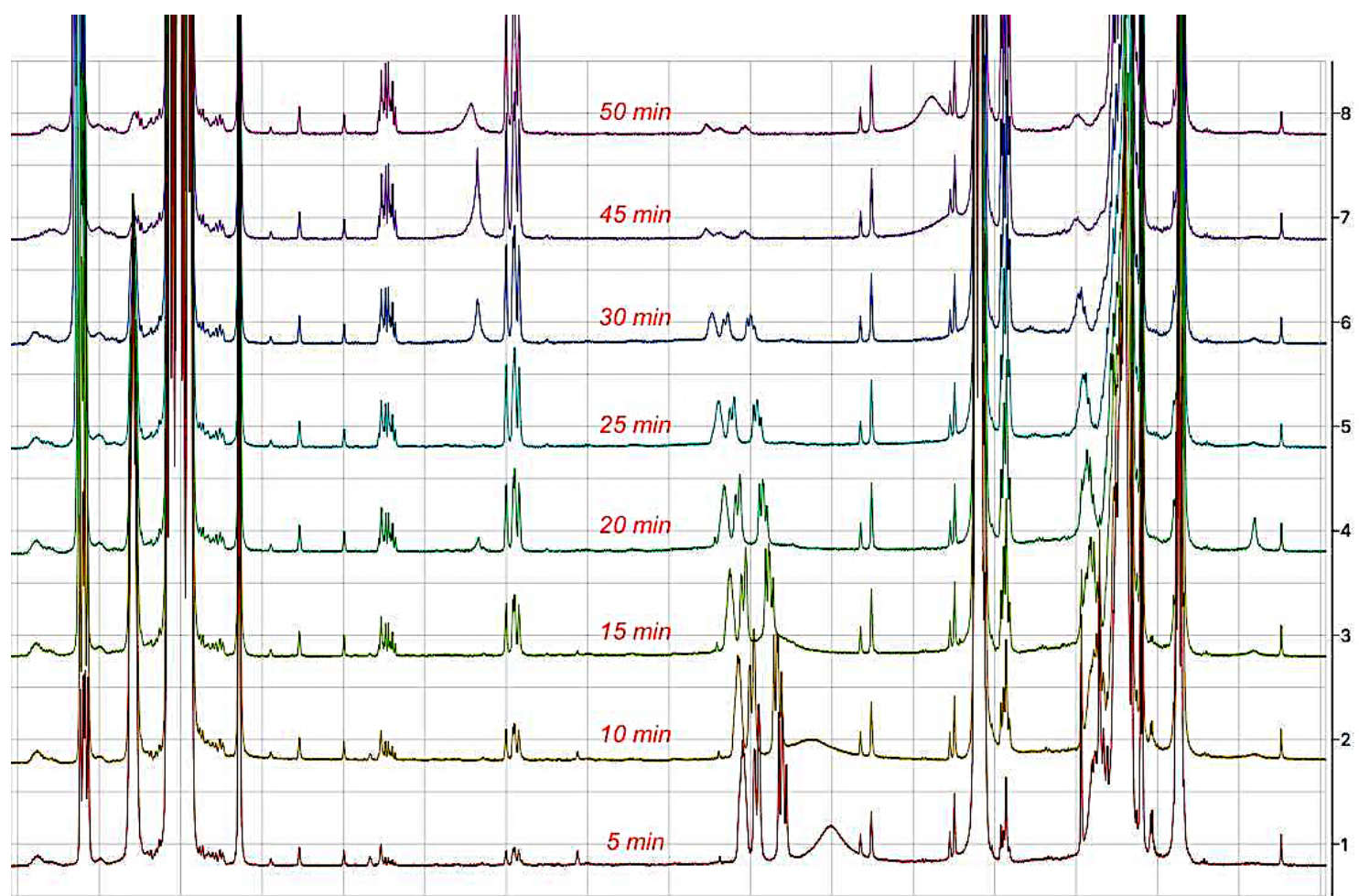

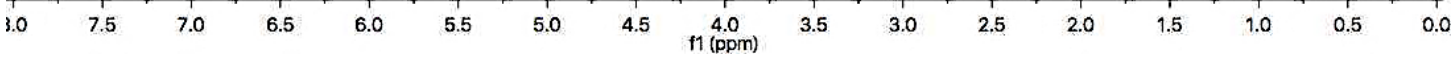

b. $[\mathrm{Re}]=\mathrm{Cp}^{\mathrm{ttt}} \mathrm{ReO}_{3}$

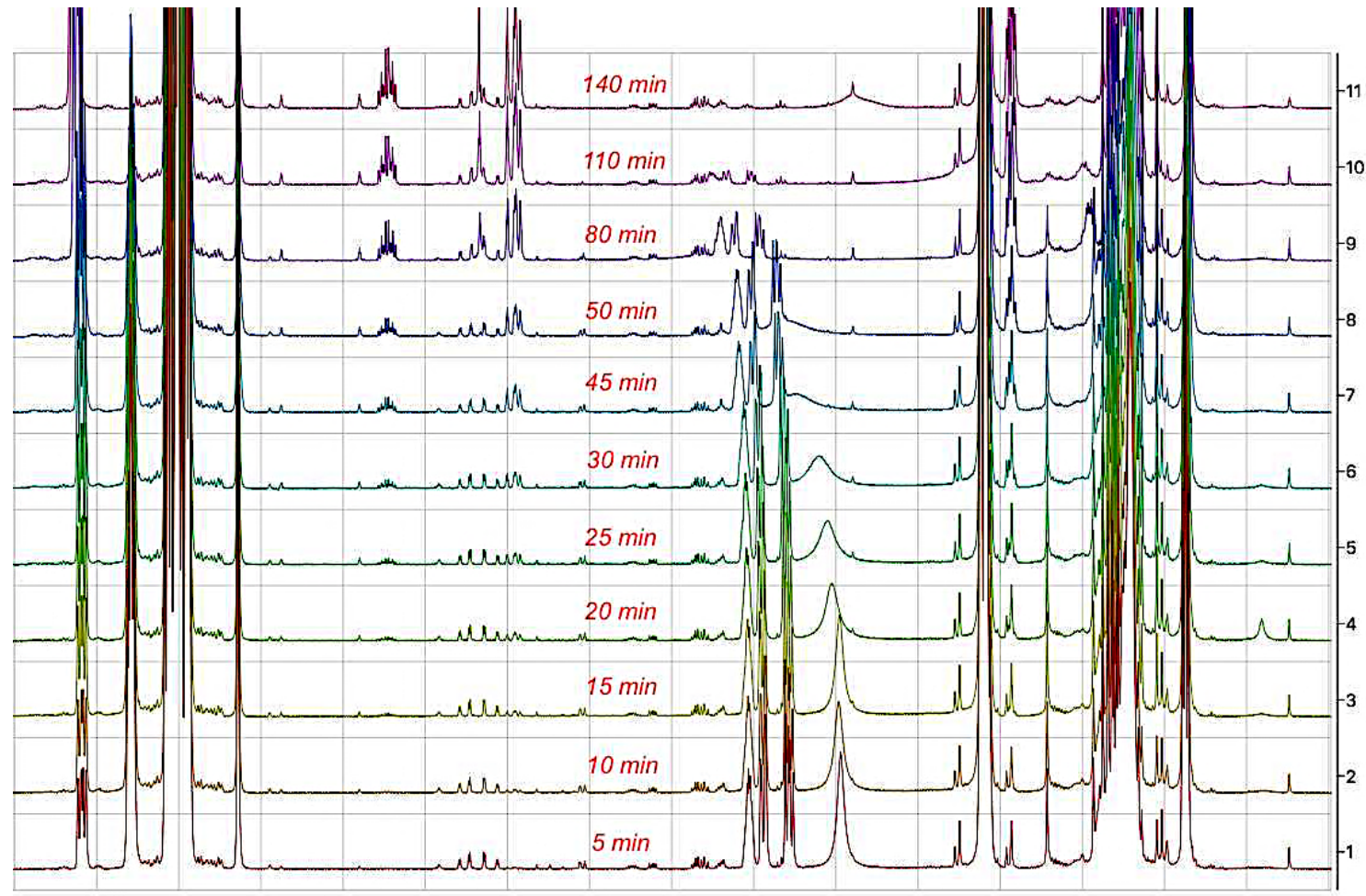

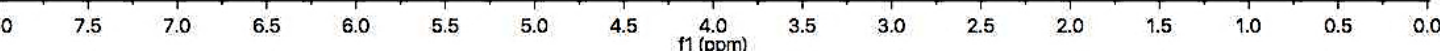


c. $[\mathrm{Re}]=\mathrm{Cp}^{\mathrm{tt}}{ }_{2} \mathrm{Re}_{2} \mathrm{O}_{3}\left(\mathrm{ReO}_{4}\right)_{2}$

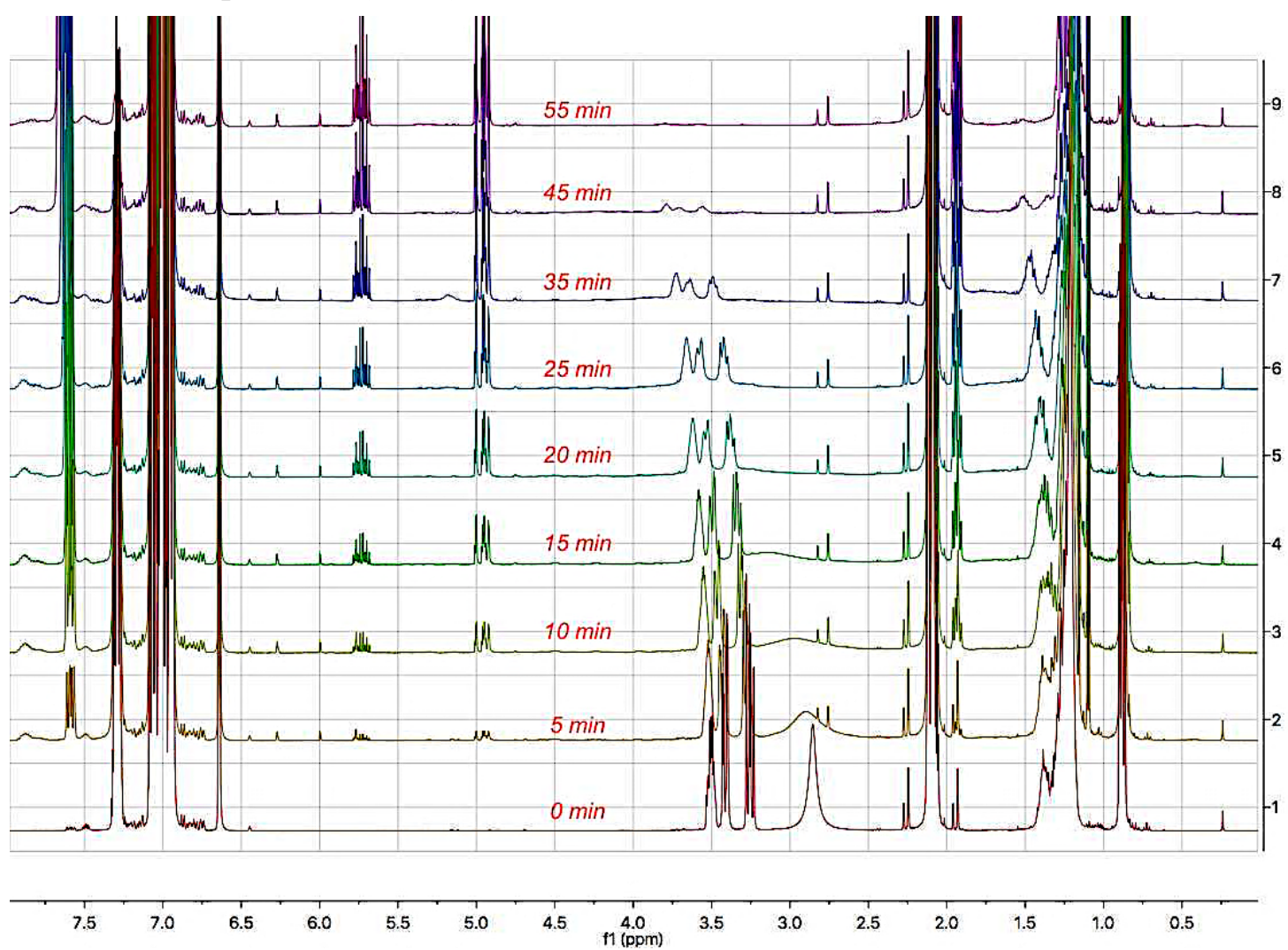

d. $[\mathrm{Re}]=\mathrm{Cp}^{\mathrm{tt}} \mathrm{ReO}\left(\mathrm{OCH}_{2} \mathrm{CH}_{2} \mathrm{O}\right)$
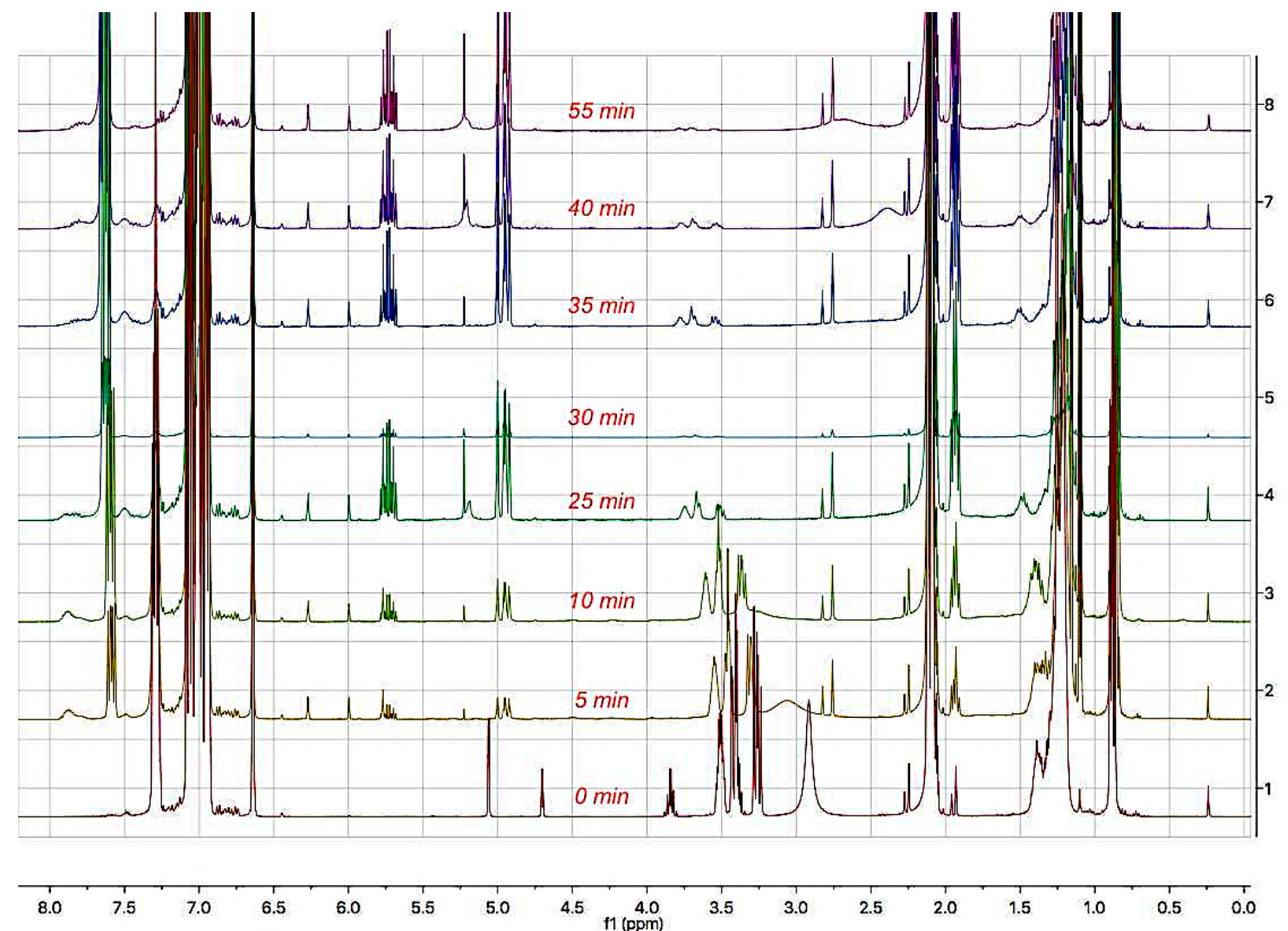
e. $[\mathrm{Re}]=\mathrm{Cp}^{\mathrm{ttt}} \mathrm{ReO}\left(\mathrm{OCH}_{2} \mathrm{CH}_{2} \mathrm{O}\right)$

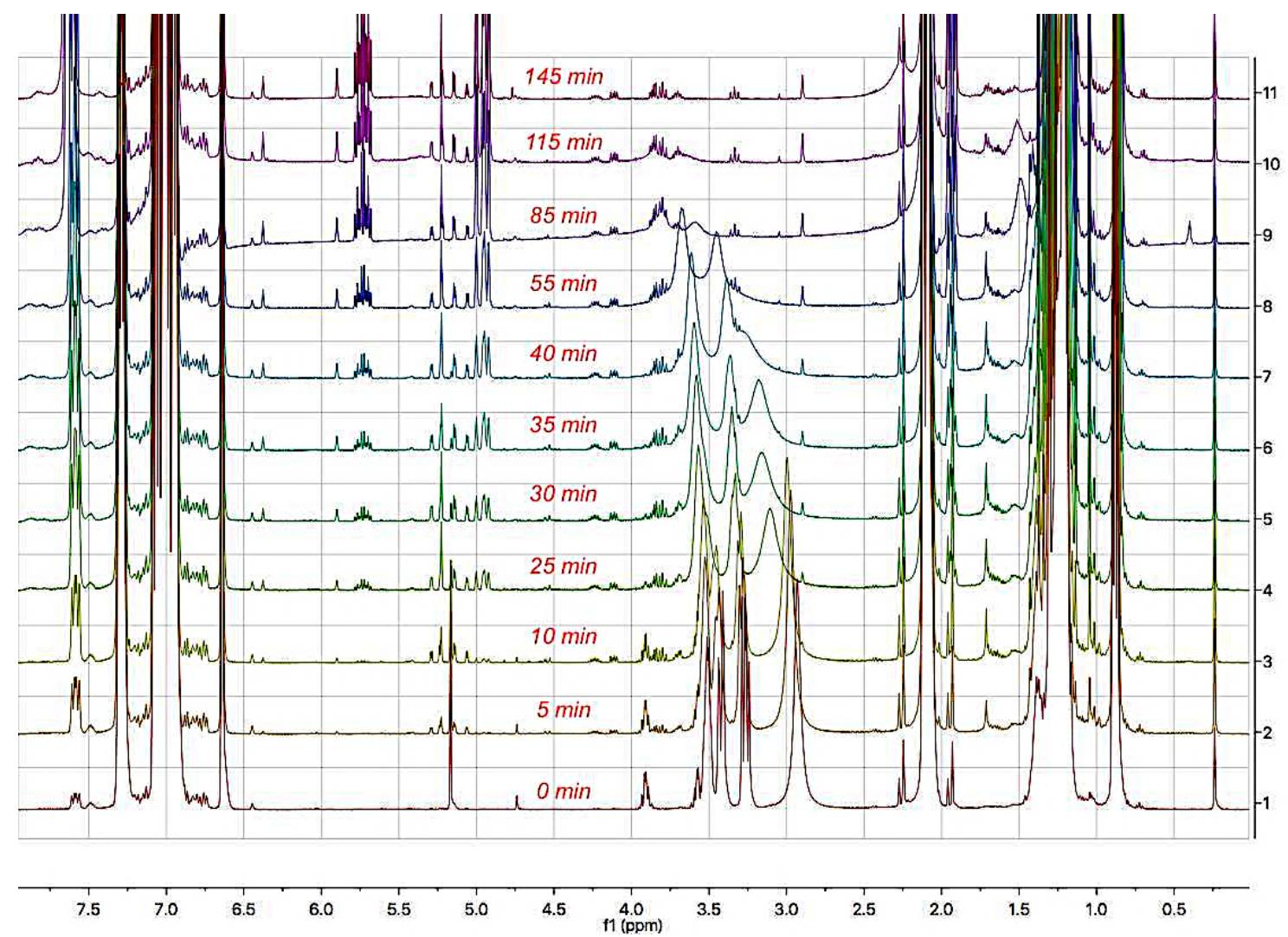

Scheme 2.2.5 ${ }^{1} \mathrm{H}$ NMR spectra of in situ NMR experiment of Re-catalyzed DODH. Reaction conditions: 1,2-octanediol (0.05 mmol), $\mathrm{PPh}_{3}$ (0.055 mmol, 1.1 equiv.), mesitylene ( $0.05 \mathrm{mmol}, 1.0$ equiv, internal standard), Re-catalyst (10 mol\% Re), toluene- $\mathrm{D}_{8}(0.5 \mathrm{~mL}), 135^{\circ} \mathrm{C}, \mathrm{N}_{2}$.

The observation of ligand dissociation raises questions on the nature of the active species in $\mathrm{Cp}^{\prime} \mathrm{ReO}_{3}$-catalyzed DODH reactions. We have therefore also examined ligand dissociation for some other molecular Cp'Re complexes under catalytic conditions using the NMR protocol. The tetranuclear Re-complex $\mathrm{Cp}^{\mathrm{tt}}{ }_{2} \mathrm{Re}_{2} \mathrm{O}_{3}\left(\mathrm{ReO}_{4}\right)_{2}$, which is formed by stirring $\mathrm{Cp}^{\mathrm{tt}} \mathrm{ReO}_{3}$ in dichloromethane overnight at room temperature, was earlier reported to catalyze the DODH reaction. ${ }^{[17]}$ Also for this complex, free $\mathrm{Cp}^{\text {tt }} \mathrm{H}$ ligand was detected during the reaction (Scheme 2.2.5). Interestingly, ligand dissociation was even faster than for $\mathrm{Cp}^{\mathrm{tt}} \mathrm{ReO}_{3} ; 88 \%$ of ligand dissociation occurred after $10 \mathrm{~min}$ and the DODH reaction was finished in about $50 \mathrm{~min}$ at $90 \%$ product yield and without a significant induction period (Scheme 2.2.6). $\mathrm{Re}(\mathrm{V})$-diolate species have been reported as intermediates in DODH reactions from which olefin extrusion takes place to form $\mathrm{Re}(\mathrm{VII})$ trioxo species to close the catalytic cycle. ${ }^{[8]}$ The $\mathrm{Cp}$ ' $\mathrm{ReO}\left(\mathrm{OCH}_{2} \mathrm{CH}_{2} \mathrm{O}\right)$ complexes $\left(\mathrm{Cp}^{\prime}=\mathrm{Cp}^{\mathrm{tt}}, \mathrm{Cp}^{\mathrm{tt}}\right)$ were synthesized on the basis of a reported procedure. ${ }^{[28]}$ Investigation of these glycolate complexes using the same NMR experiment showed that these have similar DODH reaction and ligand dissociation profiles as the corresponding trioxo-Re species (Scheme 2.2.6). When $\mathrm{Cp}^{\text {tt }} \mathrm{ReO}\left(\mathrm{OCH}_{2} \mathrm{CH}_{2} \mathrm{O}\right)$ was used as catalyst, the signals of 
$\mathrm{Cp}^{\text {tt }} \mathrm{ReO}\left(\mathrm{OCH}_{2} \mathrm{CH}_{2} \mathrm{O}\right)$ disappeared almost at the beginning of the reaction. When $\mathrm{Cp}^{\mathrm{ttt}} \mathrm{ReO}\left(\mathrm{OCH}_{2} \mathrm{CH}_{2} \mathrm{O}\right)$ was used as catalyst, it was slowly converted in around $30 \mathrm{~min}$, and next to olefin product formation concomitant formation of $\mathrm{Cp}^{\mathrm{ttt}} \mathrm{ReO}$-octanediolate was also observed (Scheme 2.2.5).
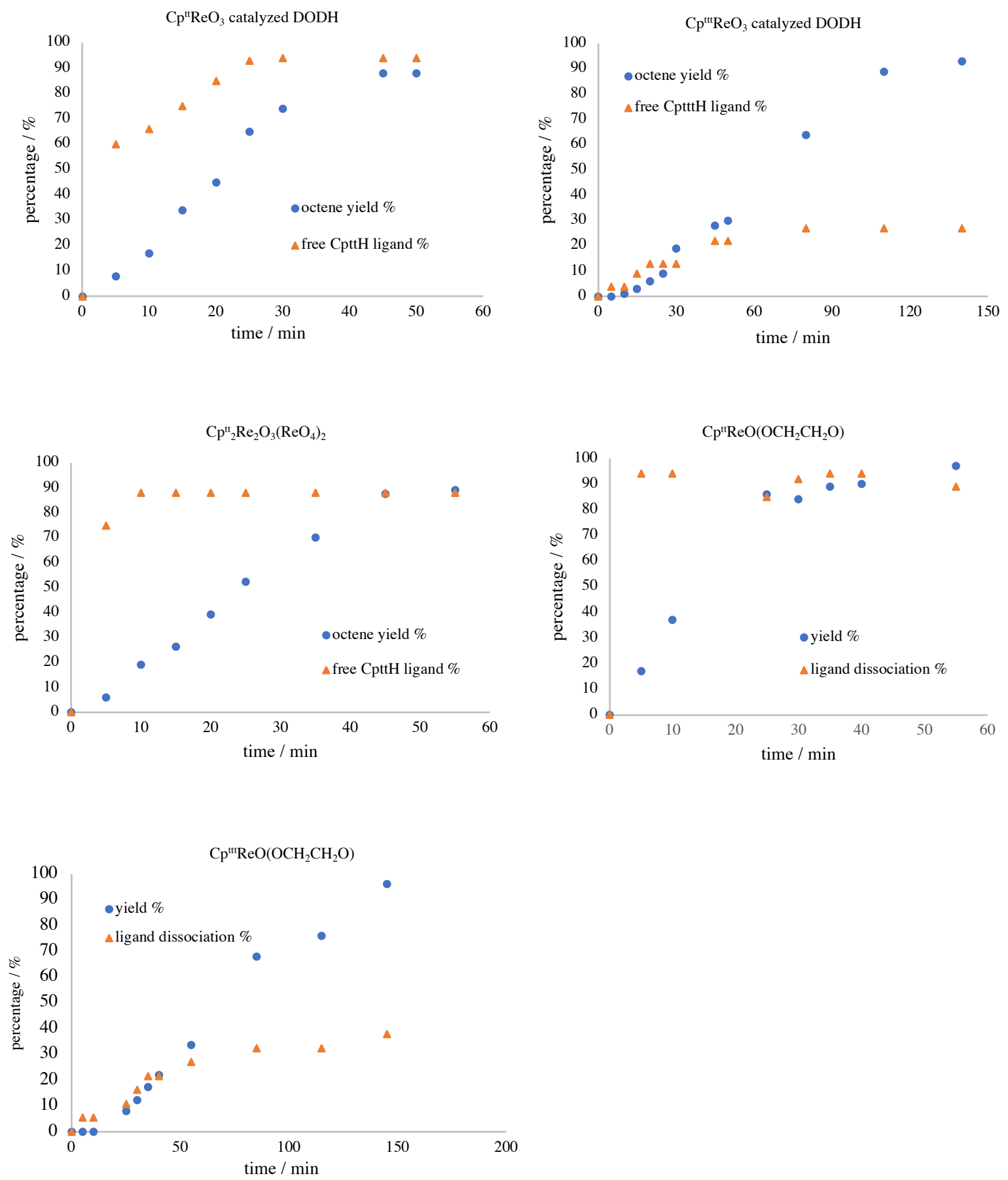

Scheme 2.2.6 In situ NMR experiments of $\mathrm{Cp}^{\prime} \mathrm{ReO}_{3}$-catalyzed DODH of 1,2-octanediol; monitoring of product yield and free Cp' ligand formation. Reaction conditions: 1,2-octanediol (0.05 mmol), $\mathrm{PPh}_{3}$ ( $0.055 \mathrm{mmol}, 1.1$ equiv.), mesitylene ( $0.05 \mathrm{mmol}, 1.0$ equiv, internal standard), Re-catalyst (10 mol\% Re), toluene- $\mathrm{D}_{8}(0.5 \mathrm{~mL}), 135{ }^{\circ} \mathrm{C}, \mathrm{N}_{2}$. 
Since ligand dissociation was observed for all Cp'Re complexes tested above, one could hypothesize that the actual active species in these systems does not contain a Cp' ligand. The same catalytic NMR-experiment was therefore carried out using a perrhenate devoid of a Cp'ligand as catalyst, i.e. $\mathrm{Bu}_{4} \mathrm{NReO}_{4}$. In this case, no olefin product formation could be detected at all. For perrhenate-catalyzed DODH of aliphatic diols, ${ }^{[29-35]}$ either a long reaction time $(>24 \mathrm{~h})$ or a high catalyst loading $(10 \mathrm{~mol} \%)$ is needed in order to reach full conversion. Besides, even in the case of full conversion of aliphatic diols and polyols, product selectivity was not as high as for $\mathrm{Cp}^{\prime} \mathrm{ReO}_{3}$ systems. Especially, for the DODH of glycerol, when lutidinium perrhenate was used as catalyst, only moderate amounts $(21 \%)$ of allyl alcohol were formed, ${ }^{[33]}$ while glycerol is almost quantitively converted to allyl alcohol using $\mathrm{Cp}^{\mathrm{tt}} \mathrm{ReO}_{3}$. These data strongly indicate that inorganic perrhenate is not the active species in $\mathrm{Cp}^{\prime} \mathrm{ReO}_{3}$-catalyzed DODH reactions. We also compared our $\mathrm{Cp}^{\mathrm{tt}} \mathrm{ReO}_{3}$ catalyst with another homogenous trioxo-rhenium catalyst, $\mathrm{MTO}\left(\mathrm{MeReO}_{3}\right) \cdot{ }^{[13,14]}$ For the DODH of simple diols, both of them show good activity. For more complicated polyol substrates like sugar alcohols and sugars, the two catalysts have a very different product selectivity. This notion indicates that the active species in the case of $\mathrm{Cp}^{\mathrm{tt}} \mathrm{ReO}_{3}$ and $\mathrm{MTO}$ are not the same.

\subsection{Conclusions}

In conclusion, we have shown efficient catalytic DODH reactions of vicinal diols and biomassderived polyols to olefins using the new $\mathrm{Cp}^{\text {tt }} \mathrm{ReO}_{3}$ catalyst. Secondary alcohols like 3-octanol and 3-pentanol are the reductant and solvent of choice for these reactions. Under optimized reaction conditions, $\mathrm{Cp}^{\mathrm{tt}} \mathrm{ReO}_{3}$ not only initiates the catalytic conversion of vicinal diols into olefins at high yields, but also exhibits an excellent activity for biomass-derived polyols. Specifically, when using $\mathrm{Cp}^{\mathrm{tt}} \mathrm{ReO}_{3}$ as catalyst, glycerol is almost quantitively converted to allyl alcohol and mucic acid gives $75 \%$ of muconates at $91 \%$ conversion. Besides, the loading of $\mathrm{Cp}^{\mathrm{tt}} \mathrm{ReO}_{3}$ can be reduced to $0.1 \mathrm{~mol} \%$ to achieve a turn-over number as high as 900 per Re in the DODH of glycerol, indicating a rather stable active species. Time course profile experiments have shown ligand dissociation during the reaction with different dissociation rates for different substituted Cp' ligands. In addition, ligand dissociation seems to be related to (initial) catalytic activity. These observations raise questions on the nature of the active species in DODH catalysis, on the role of the Cp' ligand in catalysis, and in a more general sense on the relation between the Cp' ligand structure and the stability of the corresponding $\mathrm{Cp}^{\prime} \mathrm{ReO}_{3}$ complexes. Comparison with perrhenate salts seems to rule out a simple and purely inorganic active species in DODH catalysis using $\mathrm{Cp}^{\prime} \mathrm{ReO}_{3}$ complexes. Current investigations in our laboratories focus on further DODH catalyst development and optimization, and on deciphering 
the role of organometallic, ligand-based species and the nature of active species in DODH catalysis.

\subsection{Experimental Section}

\subsubsection{General}

All chemicals including solvents were degassed by either freeze-pump-thaw cycles or degasification under vacuum. Triphenylphosphine was crystallized in ethanol and dried under vacuum. $\mathrm{Cp}^{\mathrm{tt}} \mathrm{ReO}_{3}$ was prepared according to a known literature procedure. ${ }^{[17]}$ Unless otherwise stated, all other commercial chemicals were used without further purification. NMR spectra were recorded on a Varian VNMRS400 (400 MHz) at $298 \mathrm{~K}$. ESI-MS spectra were recorded using a Waters LCT Premier XE instrument. GC measurements were performed using a Perkin Elmer Autosystem XL Gas Chromatograph equipped with a Perkin Elmer Elite-17 column (Length: 30m, I.D.: $0.32 \mathrm{~mm}$, Film thickness: $0.50 \mu \mathrm{m}$ ), and with FID detector. GC method: $40{ }^{\circ} \mathrm{C}, 5 \mathrm{~min} ; 3{ }^{\circ} \mathrm{C} / \mathrm{min}$ to $55^{\circ} \mathrm{C} ; 20^{\circ} \mathrm{C} / \mathrm{min}$ to $250{ }^{\circ} \mathrm{C} ; 250{ }^{\circ} \mathrm{C}, 10 \mathrm{~min}$. All olefinic products are known compounds and were calibrated against mesitylene for quantification.

\subsubsection{Synthesis of $\mathrm{Cp}^{\mathrm{tt}} \mathrm{ReO}\left(\mathrm{OCH}_{2} \mathrm{CH}_{2} \mathrm{O}\right)^{[28]}$}

To a mixture of $\mathrm{Cp}^{\mathrm{tt}} \mathrm{ReO}_{3}(83 \mathrm{mg}, 0.2 \mathrm{mmol})$, polymer-bond $\mathrm{PPh}_{3}(3 \mathrm{mmol} / \mathrm{g}, 80 \mathrm{mg}, 1.2$ equiv.) mortar-ground $3 \AA$ molecular sieves (0.5 g), and para-toluenesulphonic acid monohydrate (38 $\mathrm{mg}, 0.2 \mathrm{mmol}, 1.0$ equiv.) in THF (15 mL), ethylene glycol (100 mg, excess) was added, causing a color change from yellow to purple. The reaction mixture was stirred at room temperature under $\mathrm{N}_{2}$ for $3.3 \mathrm{~h}$ and filtered. The resulting purple solution was evaporated to dryness, followed by hexane extraction of the residue and solvent removal in vacuo to yield $50 \%$ of $\mathrm{Cp}^{\mathrm{tt}} \mathrm{ReO}\left(\mathrm{OCH}_{2} \mathrm{CH}_{2} \mathrm{O}\right)$ as a purple solid (44 mg). Crystallization from hexane solution at $-30{ }^{\circ} \mathrm{C}$ afforded crystals suitable for XRD.

${ }^{1} \mathrm{H} \mathrm{NMR}(400 \mathrm{MHz}), \mathrm{CDCl}_{3}$ (7.26 ppm): $\delta 1.38$ (s, 18H, $\left.t \mathrm{Bu}\right), 3.53\left(\mathrm{~m}, 2 \mathrm{H}, \mathrm{CH}_{2}\right), 3.97$ (m, 2H, $\left.\mathrm{CH}_{2}\right), 5.08$ (s, 1H, CpH), 5.51 (s, 2H, CpH). ${ }^{13} \mathrm{C} \mathrm{NMR} \mathrm{(100} \mathrm{MHz),} \mathrm{CDCl}_{3}$ (77.13 ppm): $\delta 31.16$, 33.66, 81.49, 93.99, 100.41, 121.33; IR (ATR): 523, 604, 629, 663, 847, 874, 910, 948, 1026, 1071, 1205, 1232, 1250, 1323, 1362, 1458, 2837, 2907, $2958 \mathrm{~cm}^{-1}$; HR-ESI-MS (in $\mathrm{CH}_{2} \mathrm{Cl}_{2} /$ pyridine/formic acid): calc. for $\left[\mathrm{C}_{15} \mathrm{H}_{25} \mathrm{O}_{3} \mathrm{Re}+\mathrm{H}+\mathrm{Py}\right]^{+}:$520.1862, found: 520.1884; elemental analysis calc. (\%) for $\mathrm{C}_{15} \mathrm{H}_{25} \mathrm{O}_{3} \mathrm{Re}$ (440.1361): $\mathrm{C} 40.99, \mathrm{H}$ 5.73; found: $\mathrm{C} 40.60, \mathrm{H}$ 6.01 . 


\section{X-ray crystal structure determination of $\mathrm{Cp}^{\mathrm{tt}} \mathrm{ReO}\left(\mathrm{OCH}_{2} \mathrm{CH}_{2} \mathrm{O}\right)$}

$\mathrm{C}_{15} \mathrm{H}_{25} \mathrm{O}_{3} \mathrm{Re}, \mathrm{Fw}=439.55$, red block, $0.29 \times 0.11 \times 0.10 \mathrm{~mm}^{3}$, monoclinic, $\mathrm{P} 2{ }_{1} / \mathrm{n}$ (no. 14), $\mathrm{a}=$ 12.0370(4), $\mathrm{b}=16.3721(3), \mathrm{c}=15.9942(6) \AA, \beta=91.762(2)^{\circ}, \mathrm{V}=3150.50(17) \AA^{3}, \mathrm{Z}=8, \mathrm{D}_{\mathrm{x}}$ $=1.853 \mathrm{~g} / \mathrm{cm}^{3}, \mu=7.72 \mathrm{~mm}^{-1} .91422$ Reflections were measured on a Bruker Kappa ApexII diffractometer with sealed tube and Triumph monochromator $(\lambda=0.71073 \AA)$ at a temperature of $150(2) \mathrm{K}$ up to a resolution of $(\sin \theta / \lambda)_{\max }=0.65 \AA^{-1}$. The Eval15 software ${ }^{[36]}$ was used for the intensity integration. A small second crystal fragment was ignored during the integration. A numerical absorption correction and scaling was performed with SADABS ${ }^{[37]}$ (correction range 0.28-0.76). 7241 Reflections were unique $\left(\mathrm{R}_{\text {int }}=0.026\right)$, of which 6812 were observed $[\mathrm{I}>2 \sigma(\mathrm{I})]$. The structure was solved with Patterson superposition methods using SHELXT. ${ }^{[38]}$ Least-squares refinement was performed with SHELXL-2014 ${ }^{[39]}$ against $\mathrm{F}^{2}$ of all reflections. Non-hydrogen atoms were refined freely with anisotropic displacement parameters. All hydrogen atoms were located in difference Fourier maps. Hydrogen atoms of the $\mathrm{Cp}$ rings were refined freely with isotropic displacement parameters. All other hydrogen atoms were refined with a riding model. 379 Parameters were refined with no restraints. R1/wR2 [I > 2 $\sigma(\mathrm{I})]: 0.0123$ / 0.0293. R1/wR2 [all refl.]: 0.0140 / 0.0298. $\mathrm{S}=1.014$. Residual electron density between -0.41 and $1.81 \mathrm{e} / \AA^{3}$. Geometry calculations and checking for higher symmetry was performed with the PLATON program. ${ }^{[40]}$

CCDC 1849410 contains the supplementary crystallographic data for this paper. These data can be obtained free of charge from The Cambridge Crystallographic Data Centre via www.ccdc.cam.ac.uk/data_request/cif.

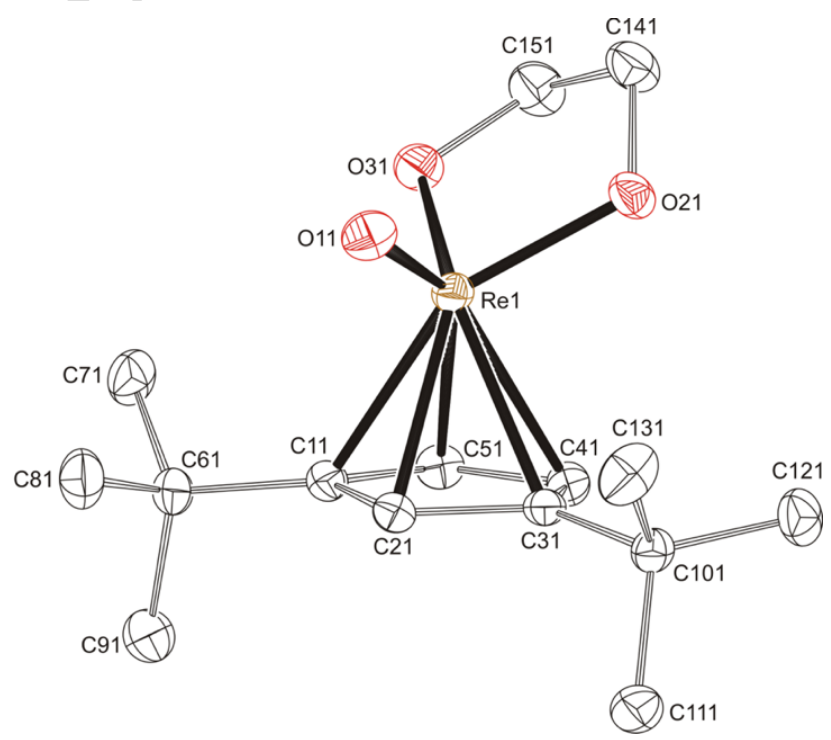

Figure 2.4.1. Displacement ellipsoid plot (50\% probability level) of $\mathrm{Cp}^{\mathrm{tt}} \mathrm{ReO}\left(\mathrm{OCH}_{2} \mathrm{CH}_{2} \mathrm{O}\right)$. Only one of two independent molecules is shown. Hydrogen atoms are omitted for clarity. 


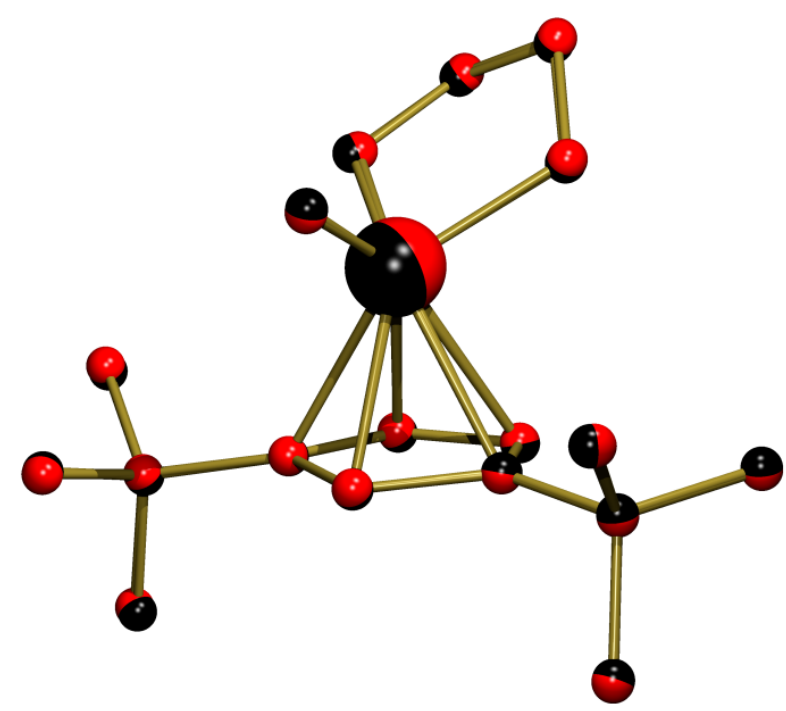

Figure 2.4.2. Quaternion fit between the two independent molecules in $\mathrm{Cp}^{\mathrm{tt}} \mathrm{ReO}\left(\mathrm{OCH}_{2} \mathrm{CH}_{2} \mathrm{O}\right)$. The two molecules are shown in black and red.

Table 2.4.1. Selected bond distances $[\AA]$, angles and torsion angles $\left[^{\circ}\right]$ in the crystal structure of $\mathrm{Cp}^{\text {tt }} \mathrm{ReO}\left(\mathrm{OCH}_{2} \mathrm{CH}_{2} \mathrm{O}\right)$. The ring slippage is defined as distance between the perpendicular projection of the Re onto the ring and the ring centroid $[\AA]$ as calculated with Platon ${ }^{[40]}$.

\begin{tabular}{|l|l|l|}
\hline & $\mathrm{x}=1$ & $\mathrm{x}=2$ \\
\hline $\operatorname{Re}[\mathrm{x}]-\mathrm{O} 1[\mathrm{x}]$ & $1.6968(14)$ & $1.6946(14)$ \\
\hline $\operatorname{Re}[\mathrm{x}]-\mathrm{O} 2[\mathrm{x}]$ & $1.9491(13)$ & $1.9488(14)$ \\
\hline $\operatorname{Re}[\mathrm{x}]-\mathrm{O} 3[\mathrm{x}]$ & $1.9549(13)$ & $1.9604(14)$ \\
\hline $\operatorname{Re}[\mathrm{x}]-\mathrm{C} 1[\mathrm{x}]$ & $2.2955(18)$ & $2.2815(18)$ \\
\hline $\operatorname{Re}[\mathrm{x}]-\mathrm{C} 2[\mathrm{x}]$ & $2.2216(18)$ & $2.2028(18)$ \\
\hline $\operatorname{Re}[\mathrm{x}]-\mathrm{C} 3[\mathrm{x}]$ & $2.2508(17)$ & $2.2406(18)$ \\
\hline $\operatorname{Re}[\mathrm{x}]-\mathrm{C} 4[\mathrm{x}]$ & $2.3918(19)$ & $2.4065(19)$ \\
\hline $\operatorname{Re}[\mathrm{x}]-\mathrm{C} 5[\mathrm{x}]$ & $2.3968(18)$ & $2.4162(19)$ \\
\hline $\mathrm{O} 1[\mathrm{x}]-\operatorname{Re}[\mathrm{x}]-\mathrm{O} 2[\mathrm{x}]$ & $107.00(7)$ & $106.90(7)$ \\
\hline $\mathrm{O} 1[\mathrm{x}]-\operatorname{Re}[\mathrm{x}]-\mathrm{O} 3[\mathrm{x}]$ & $111.18(7)$ & $110.11(7)$ \\
\hline $\mathrm{O} 2[\mathrm{x}]-\operatorname{Re}[\mathrm{x}]-\mathrm{O} 3[\mathrm{x}]$ & $79.97(6)$ & $80.28(6)$ \\
\hline $\mathrm{O} 2[\mathrm{x}]-\mathrm{C} 14[\mathrm{x}]-\mathrm{C} 15[\mathrm{x}]-\mathrm{O} 3[\mathrm{x}]$ & $39.7(2)$ & $40.3(2)$ \\
\hline $\mathrm{C} 1[\mathrm{x}]-\mathrm{C} 2[\mathrm{x}]-\mathrm{C} 3[\mathrm{x}]-\mathrm{C} 4[\mathrm{x}]$ & $-5.1(2)$ & $-6.0(2)$ \\
\hline $\operatorname{Ring} \operatorname{sippage}$ & 0.204 & 0.245 \\
\hline
\end{tabular}




\subsubsection{Synthesis of $\mathrm{Cp}^{\mathrm{ttt}} \mathrm{ReO}-\mathrm{octanediolate}$}

Following the same procedure as for $\mathrm{Cp}^{\mathrm{tt}} \mathrm{ReO}\left(\mathrm{OCH}_{2} \mathrm{CH}_{2} \mathrm{O}\right)$ and using $\mathrm{Cp}^{\mathrm{ttt}} \mathrm{ReO}_{3}$ (94 mg, 0.2 mmol), polymer-bond $\mathrm{PPh}_{3}(3 \mathrm{mmol} / \mathrm{g}, 73 \mathrm{mg}, 1.1$ equiv.) mortar-ground $3 \AA$ molecular sieves ( $1 \mathrm{~g})$, para-toluenesulphonic acid monohydrate (38 mg, $0.2 \mathrm{mmol}, 1.0$ equiv.) and octanediol (292 mg, $2 \mathrm{mmol}, 10$ equiv.), $57 \mathrm{mg}$ (50\%) of Cp $\mathrm{p}^{\text {ttt }} \mathrm{ReO}$-octanediolate was obtained as a purple oil. ESI-MS (MeCN/ formic acid): calc. for $\left[\mathrm{C}_{25} \mathrm{H}_{45} \mathrm{O}_{3} \mathrm{Re}+\mathrm{H}\right]^{+}$: 581.2999, found: 581.2968. The ${ }^{1} \mathrm{H}$ NMR spectra is shown below; the spefied peaks in the 5.37 - 5.08 ppm region belong to the $\mathrm{Cp}^{\mathrm{ttt}}-\mathrm{H}$ protons and the peaks in the $4.37-3.29 \mathrm{ppm}$ region belong to the $-\mathrm{OCH}_{2} \mathrm{CHO}$ part.

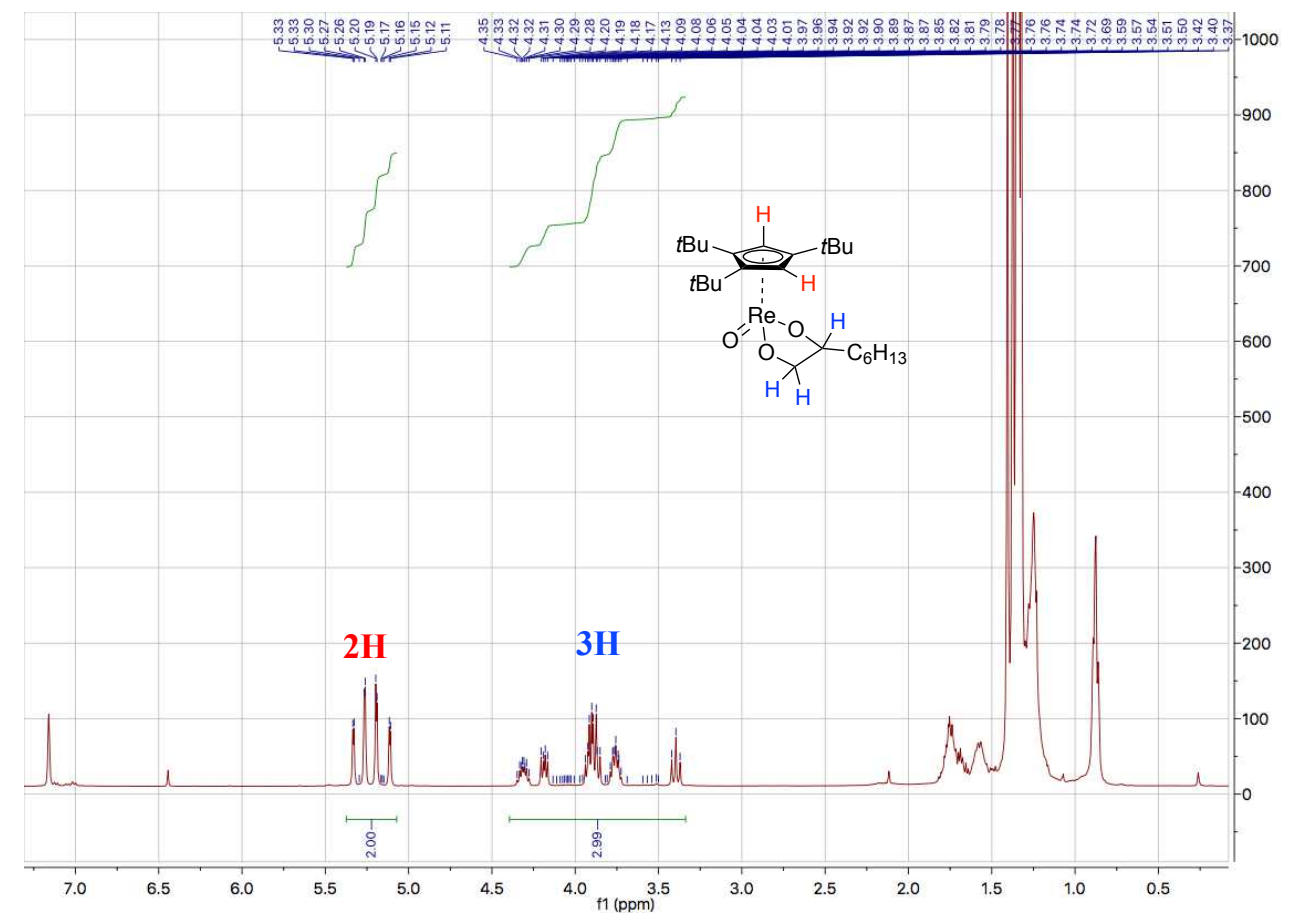

\subsubsection{General procedure for catalytic deoxydehydration using $\mathrm{PhCl}$ as solvent}

Unless otherwise noted, all reaction mixtures were prepared inside a Glove box under nitrogen atmosphere in a $15 \mathrm{~mL}$ thick-walled glass pressure tube (Ace) fitted with a Teflon screw-cap. 1,2-octanediol (0.5 mmol), $\mathrm{Cp}^{\mathrm{tt}} \mathrm{ReO}_{3}(0.01 \mathrm{mmol})$, reductant $(0.55 \mathrm{mmol})$, and mesitylene $(0.5$ mmol) were dissolved in chlorobenzene $(5 \mathrm{~mL})$ and mixed well. Then, the closed reaction vessel was brought into a preheated silicone oil bath at $135^{\circ} \mathrm{C}$. After the reaction, aliquots of the reaction mixture were diluted with acetone (for both olefin and diol analysis) or ethylacetate (for additional diol analysis, in case of fuel diol conversion). GC measurements were performed using a Perkin Elmer Autosystem XL Gas Chromatograph equipped with a Perkin Elmer Elite- 
17 column (Length: $30 \mathrm{~m}$, I.D.: $0.32 \mathrm{~mm}$, Film thickness: $0.50 \mu \mathrm{m}$ ), and with FID-detector. GC method: $40{ }^{\circ} \mathrm{C}, 5 \mathrm{~min} ; 3{ }^{\circ} \mathrm{C} / \mathrm{min}$ to $55^{\circ} \mathrm{C} ; 20^{\circ} \mathrm{C} / \mathrm{min}$ to $250{ }^{\circ} \mathrm{C} ; 250{ }^{\circ} \mathrm{C}, 10 \mathrm{~min}$. All olefinic products are known compounds and were calibrated against mesitylene for quantification.

\subsubsection{General procedure for catalytic deoxydehydration using alcohol as solvent}

Unless otherwise noted, all reaction mixtures were prepared inside a Glove box under nitrogen atmosphere in a $15 \mathrm{~mL}$ thick-walled glass pressure tube (Ace) fitted with a Teflon screw-cap. Diols or polyols $(0.5 \mathrm{mmol}), \mathrm{Cp}^{\mathrm{tt}} \mathrm{ReO}_{3}(0.01 \mathrm{mmol})$ and mesitylene $(0.5 \mathrm{mmol})$ were dissolved in an alcohol $(5 \mathrm{~mL}$ or $1 \mathrm{~mL})$. Then, the closed reaction vessel was brought into a preheated silicone oil bath at $135^{\circ} \mathrm{C}$ or $170{ }^{\circ} \mathrm{C}$. The suspension became a homogeneous solution during heating. After reaction, an aliquot $(\sim 0.1 \mathrm{~mL})$ of the reaction mixture was taken, diluted with $\mathrm{CDCl}_{3}(\sim 0.4 \mathrm{~mL})$ and analyzed by ${ }^{1} \mathrm{H}$ NMR. Peaks of the olefin product were used to calculate the yield (listed below). ${ }^{1} \mathrm{H}$ NMR peak of internal standard (mesitylene) (400 $\mathrm{MHz}, \mathrm{CDCl}_{3}$ ): $\delta$ 6.78 (s, $3 \mathrm{H}$, used for calculation), 2.28 (s, 9H).

\begin{tabular}{|c|c|c|c|}
\hline entry & product & structure & ${ }^{1} \mathrm{H} \mathrm{NMR}\left(\mathrm{CDCl}_{3}, 400 \mathrm{MHz}\right)$ \\
\hline 1 & 1-octene & & $\begin{array}{c}\delta 1.00-0.81(\mathrm{~m}, 3 \mathrm{H}), 1.50-1.18 \\
(\mathrm{~m}, 8 \mathrm{H}), 2.11-1.98(\mathrm{~m}, 2 \mathrm{H}), \\
5.09-4.86(\mathrm{~m}, 2 \mathrm{H}), 5.82(\mathrm{ddt}, J \\
\quad=16.9,10.2,6.7 \mathrm{~Hz}, 1 \mathrm{H}) .\end{array}$ \\
\hline 2 & 2,5-dihydrofuran & & $\delta 5.87(\mathrm{~s}, 2 \mathrm{H}), 4.62(\mathrm{~s}, 4 \mathrm{H})$ \\
\hline 3 & styrene & & $\begin{array}{c}\delta 5.22(\mathrm{dd}, J=10.9,0.9 \mathrm{~Hz}, 1 \mathrm{H}) \\
5.73(\mathrm{dd}, J=17.6,0.9 \mathrm{~Hz}, 1 \mathrm{H}) \\
6.70(\mathrm{dd}, J=17.6,10.9 \mathrm{~Hz}, 1 \mathrm{H}) \\
7.26-7.19(\mathrm{~m}, 1 \mathrm{H}), 7.34-7.27 \\
(\mathrm{~m}, 2 \mathrm{H}), 7.41-7.36(\mathrm{~m}, 2 \mathrm{H})\end{array}$ \\
\hline 4 & $\begin{array}{c}(E)-1,2- \\
\text { diphenylethene }\end{array}$ & & $\begin{array}{c}\delta 7.10(\mathrm{~s}, 1 \mathrm{H}), 7.27-7.21(\mathrm{~m}, \\
2 \mathrm{H}), 7.37-7.31(\mathrm{~m}, 4 \mathrm{H}), 7.52- \\
7.47(\mathrm{~m}, 4 \mathrm{H}) .\end{array}$ \\
\hline 5 & allyl alcohol & $\mathrm{\sim OH}^{\mathrm{O}}$ & $\begin{array}{r}\delta 4.10(\mathrm{~d}, J=5.1 \mathrm{~Hz}, 2 \mathrm{H}), 5.11 \\
(\mathrm{dd}, J=10.4,1.5 \mathrm{~Hz}, 1 \mathrm{H}), 5.25 \\
(\mathrm{dd}, J=17.2,1.7 \mathrm{~Hz}, 1 \mathrm{H}), 5.97 \\
(\mathrm{ddt}, J=17.0,10.2,5.1 \mathrm{~Hz}, 1 \mathrm{H})\end{array}$ \\
\hline
\end{tabular}




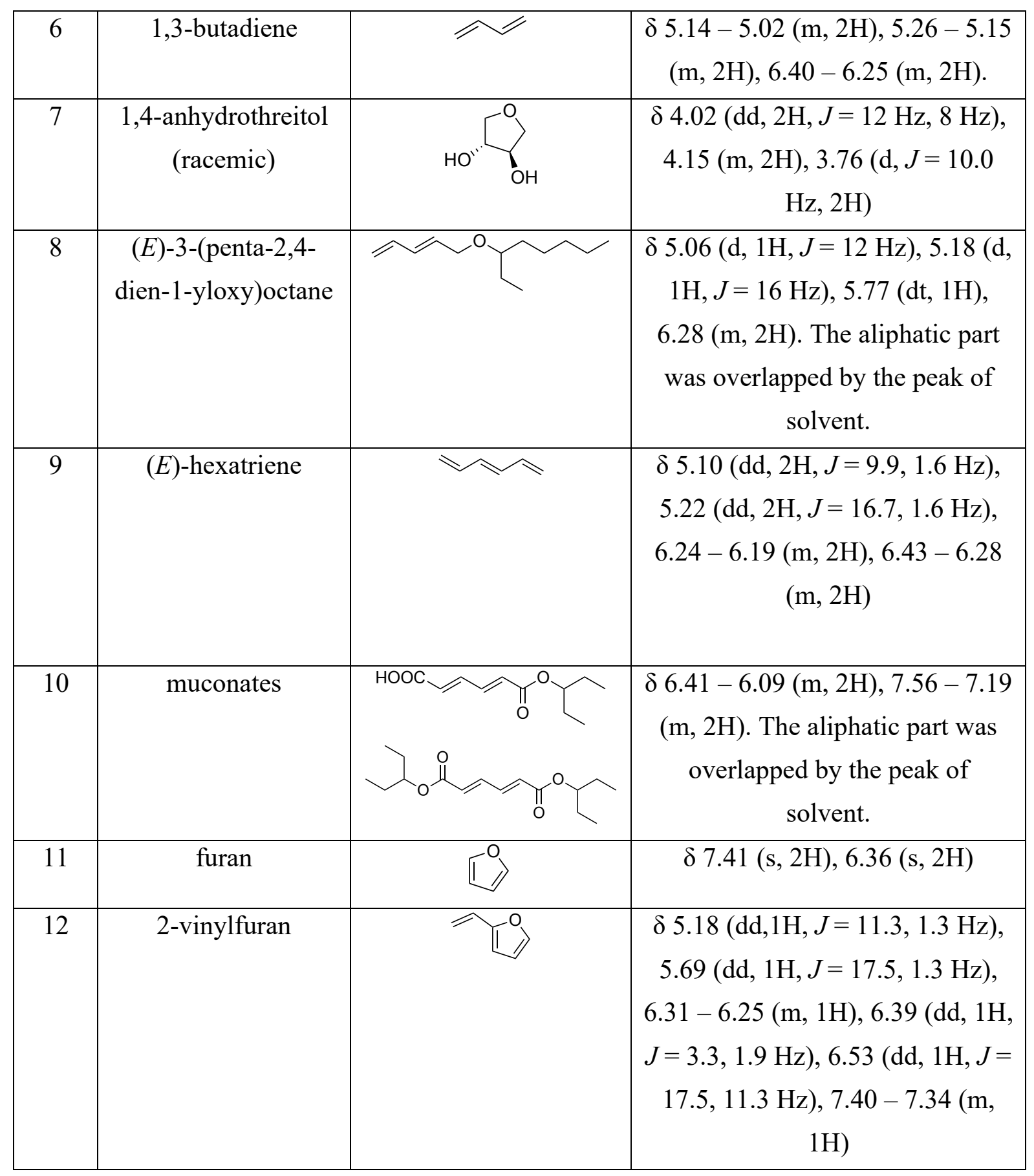

\subsection{References}

[1] P. Lanzafame, G. Centi, S. Perathoner, Chem. Soc. Rev. 2014, 43, 7562-7580.

[2] E. P. Ahern, P. Deane, T. Persson, B. Ó. Gallachóir, J. D. Mur phy, Renewable Energy 2015, 78, 648-656.

[3] T. Werpy, G. Petersen, A. Aden, J. Bozell, J. Holladay, J. White, A. Manheim, D. Eliot, L. Lasure, S. Jones, Top Value Added Chemicals from Biomass, Volume 1 Results of Screening for Potential Candidates from Sugars and Synthesis Gas, U.S. Department of Energy, 2004. 
[4] A. Corma Canos, S. Iborra, A. Velty, Chem. Rev. 2007, 107, 2411-2502.

[5] J. J. Bozell, G. R. Petersen, Green Chem. 2010, 12, 539.

[6] J. R. Dethlefsen, P. Fristrup, ChemSusChem 2015, 8, 767-775.

[7] C. Boucher-Jacobs, K. M. Nicholas, Top. Curr. Chem. 2014, 353, 163-184.

[8] S. Raju, M. E. Moret, R. J. M. Klein Gebbink, ACS Catal. 2015, 5, 281-300.

[9] L. L. Adduci, M. P. McLaughlin, T. A. Bender, J. J. Becker, M. R. Gagné, Angew. Chem. 2014, 126, 1672-1675; Angew. Chem. Int. Ed. 2014, 53, 1646-1649.

[10] M. Schlaf, Dalt. Trans. 2006, 4645-4653.

[11] T. J. Korstanje, E. F. De Waard, J. T. B. H. Jastrzebski, R. J. M. K. Gebbink, ACS Catal. 2012, 2, 2173-2181.

[12] G. K. Cook, M. A. Andrews, J. Am. Chem. Soc. 1996, 118, 9448-9449.

[13] M. Shiramizu, F. D. Toste, Angew. Chem. 2012, 124, 8206-8210; Angew. Chem. Int. Ed. 2012, 51, 8082-8086.

[14] M. Shiramizu, F. D. Toste, Angew Chem. 2012, 125, 13143-13147; Angew. Chemie. Int. Ed. 2013, 52, 12905-12909.

[15] K. P. Gable, A. AbuBaker, K. Zientara, A. M. Wainwright, Organometallics 1999, 18, 173-179.

[16] S. Raju, J. T. B. H. Jastrzebski, M. Lutz, R. J. M. Klein Gebbink, ChemSusChem 2013, 6, 1673-1680.

[17] S. Raju, C. A. M. R. Van Slagmaat, J. Li, M. Lutz, J. T. B. H. Jastrzebski, M. E. Moret, R. J. M. Klein Gebbink, Organometallics 2016, 35, 2178-2187.

[18] E. Arceo, J. A. Ellman, R. G. Bergman, J. Am. Chem. Soc. 2010, 132, 11408-11409.

[19] S. Raju, PhD thesis, Utrecht University (the Netherlands), 2015.

[20] C. H. Zhou, J. N. Beltramini, Y. X. Fan, G. Q. Lu, Chem. Soc. Rev. 2008, 37, 527-549.

[21] M. Pagliaro, R. Ciriminna, H. Kimura, M. Rossi, C. Della Pina, Angew. Chem. 2007, 119, 4516-4522; Angew. Chem. Int. Ed. 2007, 46, 4434-4440.

[22] A. Konaka, T. Tago, T. Yoshikawa, A. Nakamura, T. Masuda, Appl. Catal. B Environ. 2014, 146, 267-273.

[23] E. S. Koh, T. H. Lee, D. Y. Lee, H. J. Kim, Y. W. Ryu, J. H. Seo, Biotechnol. Lett. 2003, 25, 2103-2105.

[24] S. Van De Vyver, Y. Román-Leshkov, S. Van de Vyver, Y. Román-Leshkov, Catal. Sci. Technol. 2013, 3, 1465.

[25] A. Alshammari, A. Koeckritz, V. N. Kalevaru, A. Bagabas, A. Martin, ChemCatChem 2012, 4, 1330-1336.

[26] X. Li, D. Wu, T. Lu, G. Yi, H. Su, Y. Zhang, Angew. Chem. 2014, 126, 4284-4288; Angew. Chem. Int. Ed. 2014, 53, 4200-4204.

[27] in situ NMR experiments of $\mathrm{Cp}^{*} \mathrm{ReO}_{3}$-catalyzed DODH of 1,2-octanediol: 1,2octanediol (0.05 mmol), $\mathrm{PPh}_{3}(0.055 \mathrm{mmol}, 1.1$ equiv.), mesitylene (0.05 mmol, 1.0 equiv, internal standard), $\mathrm{Cp}^{*} \mathrm{ReO}_{3}(10 \mathrm{~mol} \%)$, toluene-D8 $(0.5 \mathrm{~mL}), 135{ }^{\circ} \mathrm{C}, \mathrm{N}_{2}$. An overlap of free $\mathrm{Cp} * \mathrm{H}$ ligand and substrate in the highfield of NMR spectram made it difficult to give a correct number of ligand dissociation. After the reaction, approximately $20 \%$ of ligand was dissociated.

[28] J. J. J. Juliette, K. P. Gable, J. Am. Chem. Soc. 1995, 117, 955-962.

[29] S. Vkuturi, G. Chapman, I. Ahmad, K. M. Nicholas, Inorg. Chem. 2010, 49, 47444746.

[30] I. Ahmad, G. Chapman, K. M. Nicolas, Organometallics 2011, 30, 2810-2818.

[31] J. M. McClain, K. M. Nicolas, ACS Catal. 2014, 4, 2109-2112.

[32] H. Sun, C. Hu, Z. Hao, Y. Zuo, T. Wang, C. Zhong, Chin. J. Org. Chem. 2015, 35, 1904-1909.

[33] D. S. Morris, K. van Rees, M. Curcio, M. Cokoja. F. E. Kuhn, F. Duarte, J. B. Love, 
Catal. Sci. Technol. 2017, 7, 5644-5649.

[34] J. Gossett, R. Srivastava, Tetrahedron Letters 2017, 58, 3760-3763.

[35] J. Shakeri, H. Hadadzadeh, H. Farrokhpour, M. Joshaghani, M. Weil, J. Phys. Chem. A 2017, 121, 8688-8696.

[36] A. M. M. Schreurs, X. Xian, L. M. J. Kroon-Batenburg, J. Appl. Cryst. 2010, 43, 7082.

[37] G. M. Sheldrick (2014). SADABS and TWINABS. Universität Göttingen, Germany.

[38] G. M. Sheldrick, Acta Cryst. 2015, A71, 3-8.

[39] G. M. Sheldrick, Acta Cryst. 2015, C71, 3-8.

[40] A. L. Spek, Acta Cryst. 2009, D65, 148-155. 
Chapter 2 A C $p^{t t}$-based Trioxo-Rhenium Catalyst for the Deoxydehydration of Diols and Polyols 


\title{
Chapter 3
}

\section{N-Donor Ligand Supported " $\mathrm{ReO}_{2}{ }^{+}$": A Pre-Catalyst for the Deoxydehydration of Diols and Polyols}

\begin{abstract}
A selected number of tetradentate $\mathrm{N}_{2} \mathrm{Py}_{2}$ ligand supported $\mathrm{ReO}_{2}{ }^{+}$complexes and a monodentate pyridine-supported $\mathrm{ReO}_{2}{ }^{+}$complex have been investigated as catalysts for the deoxydehydration (DODH) of diols and polyols. In situ ${ }^{1} \mathrm{H}$ NMR experiments showed that these $\mathrm{N}$-donor ligand supported $\mathrm{ReO}_{2}{ }^{+}$complexes are only the pre-catalyst of the DODH reaction. Treatment of $\left(\mathrm{N}_{2} \mathrm{Py}_{2}\right) \mathrm{ReO}_{2}{ }^{+}$with an excess amount of water generates an active species for DODH catalysis; use of the Re-product of this reaction shows a much shorter induction period compared to the pristine complex. No ligand is coordinated to the "water-treated" complex indicating that the real catalyst is formed after ligand dissociation. IR analysis suggested that this catalyst to be a rhenium-oxide/hydroxide oligomer. The monodentate pyridine ligand is much easier to dissociate from the metal center than a tetradentate $\mathrm{N}_{2} \mathrm{Py}_{2}$ ligand, which makes the $\mathrm{Py}_{4} \mathrm{ReO}_{2}{ }^{+}$initiated DODH reaction more efficient. For the $\mathrm{Py}_{4} \mathrm{ReO}_{2}{ }^{+}$initiated DODH of diols and biomass-based polyols, both $\mathrm{PPh}_{3}$ and 3-pentanol could be used as reductant. Excellent olefin yields are achieved.
\end{abstract}




\subsection{Introduction}

Cellulosic biomass is currently being considered as a potential renewable feedstock for the chemical industry. ${ }^{[1]}$ Unlike petroleum-based resources, the typical platform molecules that can be obtained after depolymerization of cellulosic biomass are over-functionalized with oxygenbased functional groups. Accordingly, one of the challenges of using cellulosic biomass for chemical production is its defunctionalization to building blocks of lower oxygen-content. Several pathways, for example, dehydration, ${ }^{[2]}$ deoxygenation, ${ }^{[3,4]}$ and deoxydehydration, ${ }^{[5]}$ have been reported for this purpose during the past two decades. Among these, deoxydehydration (DODH) reactions are known as an efficient way to remove vicinal hydroxyl groups to form the corresponding olefins. Metal complexes, such as vanadium complexes, ${ }^{[6-9]}$ molybdenum complexes ${ }^{[10-17]}$ and rhenium complexes, ${ }^{[5,18]}$ have been reported to be able to catalyze the DODH of diols and polyols. In terms of activity and selectivity, rhenium complexes shown unique properties amongst these complexes. Trioxo-rhenium complexes are known as catalysts for DODH reactions since the first $\mathrm{Cp}^{*} \mathrm{ReO}_{3}$-catalyzed DODH reaction was described by Cook and Andrews. ${ }^{[19]}$ Later on, new catalysts based on Cp-ligands were reported by Klein Gebbink et al. ${ }^{[20,21]}$ Next to the development of new Re-based DODH catalysts, investigations in this field have also focused on the mechanism by which the rhenium catalysts operate in DODH reactions. ${ }^{[22]}$ It is generally agreed that the catalytic cycle of these high-valent rhenium catalysts consists of three steps: a. reduction of the $\operatorname{Re}(\mathrm{VII})$ trioxo complex to a $\operatorname{Re}(\mathrm{V})$ dioxo species, b. condensation of the diol substrate to form a Re-diolate intermediate, and c. olefin extrusion from the reduced diolate intermediate to form the organic reaction product and regenerate the $\operatorname{Re}(\mathrm{VII})$ trioxo complex (Scheme 3.1). The reduction step can proceed either before or after the condensation step, and the order of these steps is highly depended on the combination of metal, reductant, and substrate. From these mechanistic considerations it becomes clear that only two oxo ligands are involved in actual bond making and breaking in the catalytic cycle, and that one oxo ligand (shown in red in Scheme 3.1) can in principle be considered as a spectator ligand. The question thus arises whether or not dioxo-rhenium complexes are also capable of catalyzing DODH reactions of diols and polyols.

Using a dioxo-rhenium complex as the catalyst, catalysis could proceed through a $\operatorname{Re}(\mathrm{V}) \leftrightarrow \operatorname{Re}(\mathrm{III})$ cycle instead of a $\operatorname{Re}(\mathrm{VII}) \leftrightarrow \operatorname{Re}(\mathrm{V})$ one. In 2013 , a $\operatorname{Re}(\mathrm{V}) \leftrightarrow \operatorname{Re}(\mathrm{III})$ catalytic cycle was proposed by Abu-Omar et al. for a DODH reaction catalyzed by methyltrioxorhenium (MTO) using a secondary alcohol as reductant (Scheme 3.2). ${ }^{[23]}$ In 
this mechanism, MTO is reduced to methyldioxorhenium (MDO) via reduction by the secondary alcohol or via oxidative cleavage of an aromatic diolate ligand of a Re(VII)-diolate formed through condensation of the diol with MTO. MDO then condenses with a next diol to form a $\operatorname{Re}(\mathrm{V})$-diolate intermediate, which would be further reduced by a secondary alcohol to form a $\operatorname{Re}(\mathrm{III})$-diolate species, followed by olefin extrusion to regenerate MDO. In this reaction sequence, the dioxo-rhenium species MDO is considered as the true catalyst of the DODH reaction.

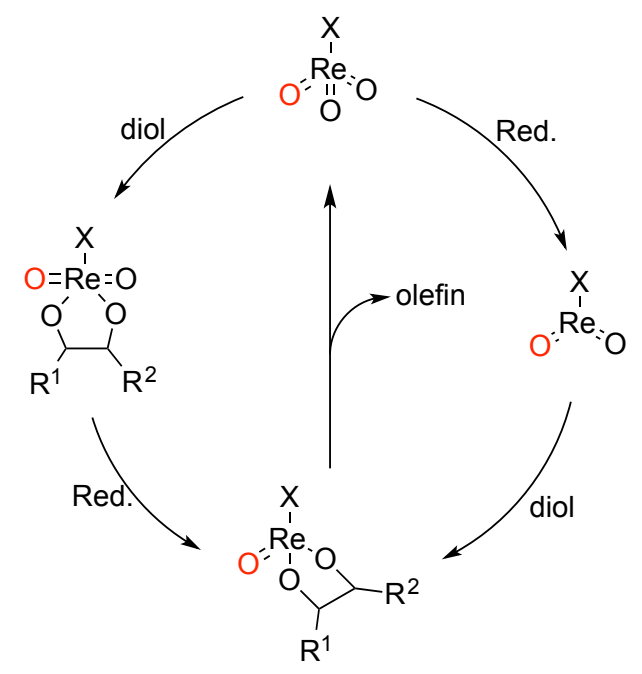

Scheme 3.1 Proposed catalytic cycle of the trioxo-rhenium catalyzed DODH of diols.

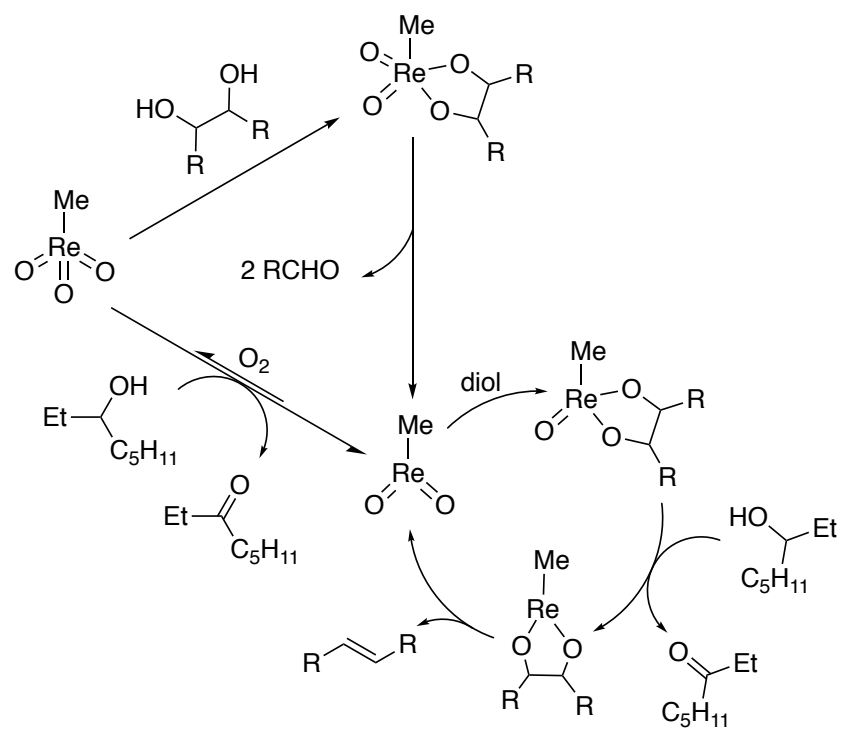

Scheme 3.2 Proposed mechanism of MTO-catalyzed DODH via a $\operatorname{Re}(\mathrm{V}) \leftrightarrow \operatorname{Re}(\mathrm{III})$ cycle. ${ }^{[23]}$

Besides the mechanistic proposal by Abu-Omar, Nicholas et al. have investigated trans$\left[\left(\mathrm{Py}_{4}\right) \mathrm{ReO}_{2}\right]^{+}$dioxo-rhenium complexes, i.e. trans- $\left[\left(\mathrm{Py}_{4}\right) \mathrm{ReO}_{2}\right] \mathrm{PF}_{6}$ and trans $-\left[\left(\mathrm{Py}_{4}\right) \mathrm{ReO}_{2}\right] \mathrm{Cl}$, as catalyst for the deoxydehydration of 1,2-decanediol using zinc as reductant. ${ }^{[24]}$ Even though this reaction starts from a $\operatorname{Re}(\mathrm{V})$ dioxo species, a $\operatorname{Re}(\mathrm{V}) \leftrightarrow \operatorname{Re}(\mathrm{VII})$ catalytic cycle was proposed. 
In a reaction of 1,2-decanediol (1.6 equiv.) and trans-[( $\left.\left.\mathrm{Py}_{4}\right) \mathrm{ReO}_{2}\right] \mathrm{Cl}$ (1.0 equiv.), 98\% of 1decene (with respect to $\mathrm{Re}$ ) formed and no oxidation products of the diol (aldehydes, ketones) were detected. This result indicated that the starting $\operatorname{Re}(\mathrm{V})$ complex is not reduced by the diol, i.e. a $\operatorname{Re}(\mathrm{V}) \leftrightarrow \operatorname{Re}(\mathrm{VII})$ redox change is involved in the reaction and a $\left[(\mathrm{Py})_{\mathrm{n}} \mathrm{Re}(\mathrm{VII}) \mathrm{O}_{3}\right]^{+}$ intermediate is generated during the reaction (Scheme 3.3). In other words, catalytic cycles involving either a $\operatorname{Re}(\mathrm{V}) \leftrightarrow \operatorname{Re}(\mathrm{III})$ or a $\operatorname{Re}(\mathrm{V}) \leftrightarrow \operatorname{Re}(\mathrm{VII})$ interconversion have been proposed for DODH catalysis starting from a dioxo-rhenium species.

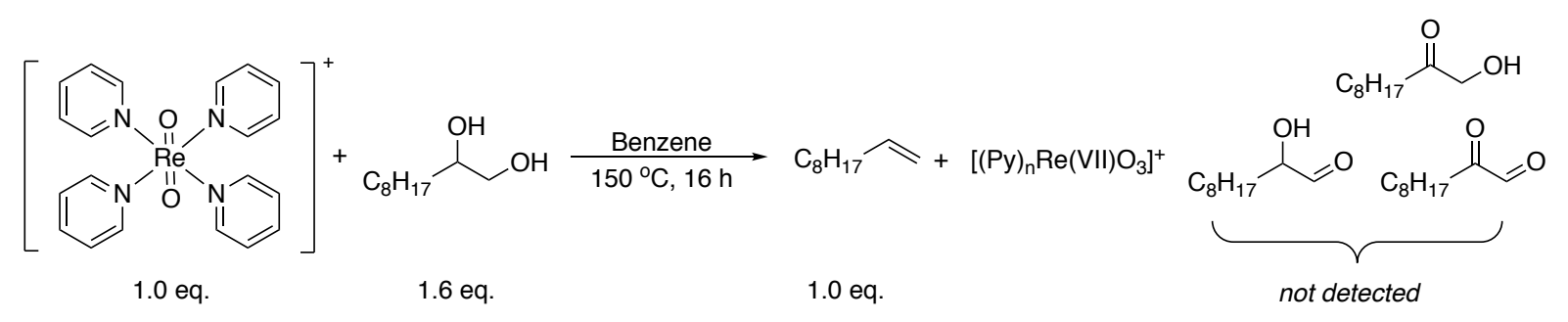

Scheme 3.3 Stochiometric reaction of 1,2-decanediol and trans-[(Py4) $\left.\mathrm{ReO}_{2}\right] \mathrm{Cl}^{[25]}$

Recently, a series of cis-dioxorhenium(V/VI) complexes containing tetradentate $\mathrm{N}_{2} \mathrm{Py}_{2}$ ligands were reported by Che and co-workers. ${ }^{[25]}$ The authors showed, amongst other, that the $\left[(\mathrm{BPMCN}) \mathrm{ReO}_{2}\right]^{2+} \quad$ ion $\quad\left(\mathrm{BPMCN} \quad=\quad N^{1}, N^{2}\right.$-dimethyl- $N^{1}, N^{2}$-bis(pyridin-2ylmethyl)cyclohexane-1,2-diamine), which was prepared by constant potential oxidation of $\left[(\mathrm{BPMCN}) \mathrm{ReO}_{2}\right]^{+}$, is able to oxidize hydrocarbons with weak $\mathrm{C}-\mathrm{H}$ bonds $(75.5-76.3 \mathrm{kcal}$ $\mathrm{mol}^{-1}$ ) via hydrogen atom abstraction. In view of the discussion above, dioxorhenium(V) complexes like the ones reported by Che could be interesting catalyst candidates for deoxydehydration reactions. Accordingly, we set out to synthesize cis-dioxorhenium(V) complexes supported by tetradentate $\mathrm{N}_{2} \mathrm{Py}_{2}$ ligands and to investigate these as catalysts for the DODH of vicinal diols.

\subsection{Results and Discussion}

\subsubsection{Synthesis of rhenium complexes}

For our initial study, cis-[(S,S-BPBP) $\left.\mathrm{ReO}_{2}\right] \mathrm{PF}_{6}(\mathbf{1})\left(S, S-\mathrm{BPBP}=(2 S, 2\right.$ 'S $)-1,1^{\prime}$-bis(pyridin-2ylmethyl)-2,2'-bipyrrolidine), cis-[(BPMEN)ReO 2$] \mathrm{PF}_{6}(2)\left(\mathrm{BPMEN}=N^{1}, N^{2}\right.$-dimethyl- $N^{1}, N^{2}$ -bis(pyridin-2-ylmethyl)ethane-1,2-diamine) and cis-[(B $\left.\left.{ }^{\text {mdm }} \mathrm{PMEN}\right) \mathrm{ReO}_{2}\right] \mathrm{PF}_{6}(3)\left(\mathrm{B}^{\mathrm{mdm}} \mathrm{PMEN}\right.$ $=\quad N^{1}, N^{2}$-bis((4-methoxy-3,5-dimethylpyridin-2-yl)methyl)- $N^{1}, N^{2}$-dimethyl ethane-1,2diamine) (Scheme 3.2.1) were synthesized according to the protocol developed by Che et al. 
for the synthesis of $1 .^{[25]}$ To this end, reaction of $\mathrm{IReO}_{2}\left(\mathrm{PPh}_{3}\right)_{2}$ with the corresponding $\mathrm{N}_{2} \mathrm{Py} 2$ ligand in dichloromethane afforded crude $c i s-\left[\left(\mathrm{N}_{2} \mathrm{Py}_{2}\right) \mathrm{ReO}_{2}\right] \mathrm{I}$, which was then reacted with $\mathrm{NH}_{4} \mathrm{PF}_{6}$ to afford $\mathbf{2}$ and $\mathbf{3}$ in $40 \%$ and $31 \%$ yields, respectively. The structures of $\mathbf{2}$ and $\mathbf{3}$ were established by X-ray crystal structure determination (Figure 3.2.1). Diffraction-quality crystals of 2 were obtained by vapor diffusion of diethyl ether into an acetonitrile solution of the complex, while diffraction-quality crystals of $\mathbf{3}$ were obtained by vapor diffusion of diethyl ether into a methanol solution of the complex.

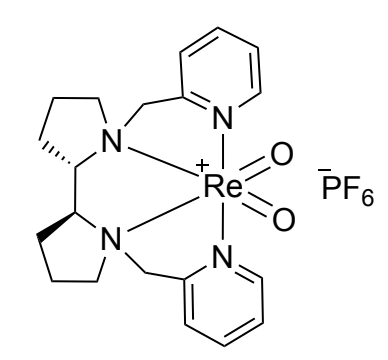

cis-[(S,S-BPBP)ReO $]_{2} \mathrm{PF}_{6}(1)$

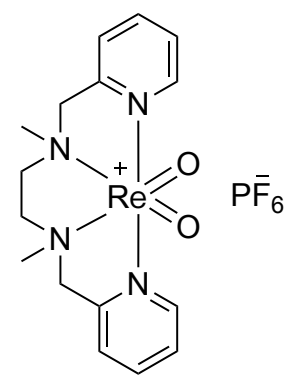

cis-[(BPMEN)ReO $\mathrm{ReF}_{6}(2)$

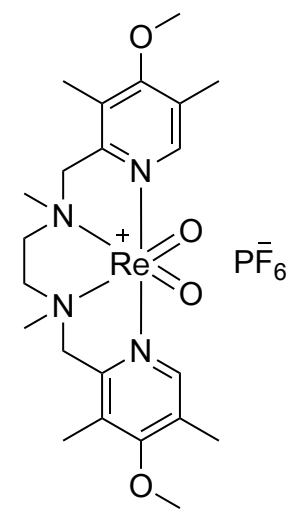

cis-[(B $\left.{ }^{\text {mdm }} \mathrm{PMEN}^{\mathrm{ReO}} \mathrm{Re}_{2}\right] \mathrm{PF}_{6}(\mathbf{3})$

Scheme 3.2.1 Dioxorhenium complexes 1, 2, and 3.
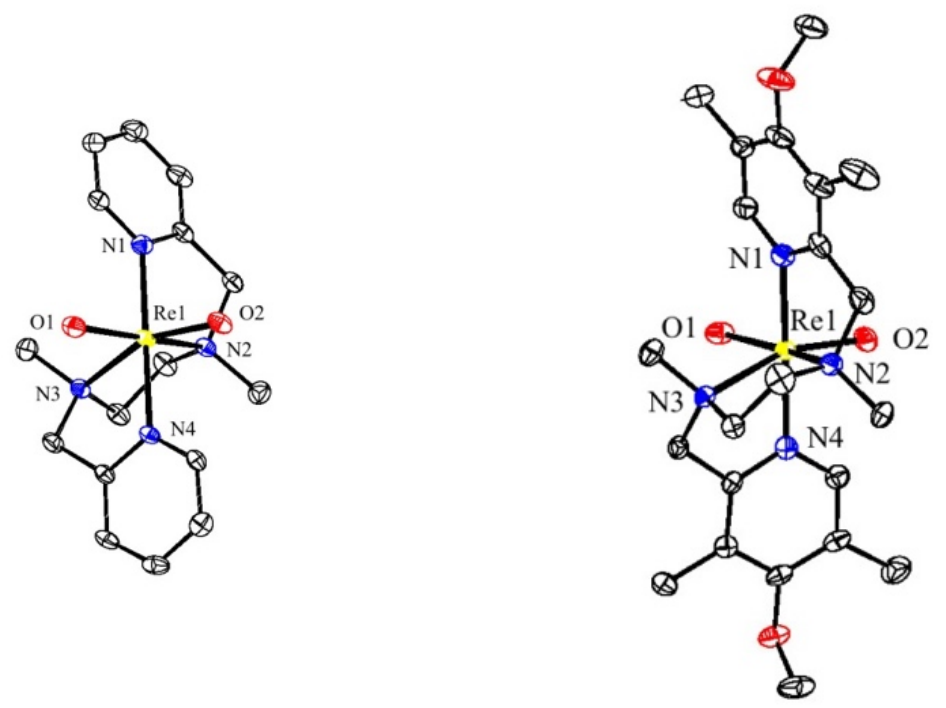

Figure 3.2.1 Molecular structures of $c i s-\left[(\mathrm{BPMEN}) \mathrm{ReO}_{2}\right]^{+}$(left) and $c i s-\left[\left(\mathrm{B}^{\mathrm{mdm}} \mathrm{PMEN}\right) \mathrm{ReO}_{2}\right]^{+}$(right) in the crystal, drawn at the $50 \%$ probability level. Hydrogen atoms and the $\mathrm{PF}_{6}$ counterions are omitted for clarity. For compound 3, the co-crystallized methanol solvent molecule is omitted as well.

These two new cis-dioxorhenium(V) complexes adopt a pseudo-octahedral geometry with a cis- $\alpha$ configuration of the ligand, similar to the geometry of $\mathbf{1}$. Also the bond distances and angles are very similar to that of $c i s-\left[(S, S-\mathrm{BPBP}) \mathrm{ReO}_{2}\right]^{+}$reported by Che. ${ }^{[25]}$ Selected bond 
distances and angles are given in Table 3.2.1. For all of these three structures, the N(pyridine)Re distances are shorter than the $\mathrm{N}($ amine $)-\mathrm{Re}$ distances and the planes of the pyridine rings are tilted under a small angle with respect to the $\mathrm{N}$ (pyridine)-Re bonds (Table 3.2.2). Complexes 1, 2, and $\mathbf{3}$ are chiral at the amine nitrogens. Complex $\mathbf{1}$ and $\mathbf{2}$ are enantiopure in the crystal, while complex 3 is racemic in the crystal. Besides, the tetradentate $\mathrm{N}_{2} \mathrm{Py}_{2}$ ligands of these complexes are well-known ligands for non-heme iron and manganese oxidation catalysts. Interestingly, for both $\mathrm{N}_{2} \mathrm{Py}_{2}$ supported high-valent rhenium complexes and $\mathrm{N}_{2} \mathrm{Py}_{2}$ supported low-valent iron/manganese complexes, the same pseudo-octahedral geometry is observed. Further characterization of complexes 2 and 3 included ${ }^{1} \mathrm{H}$ NMR, ${ }^{13} \mathrm{C}$ NMR, ESI-MS, and elemental analysis (see Experimental Section).

Table 3.2.2 Selected bond distances $(\AA)$ and angles $\left(^{\circ}\right)$ of cis-dioxorhenium complexes, cis-[(S,SBPBP) $\left.\mathrm{ReO}_{2}\right] \mathrm{PF}_{6}(\mathbf{1}),{ }^{[26]} c i s-\left[(\mathrm{BPMEN}) \mathrm{ReO}_{2}\right] \mathrm{PF}_{6}(\mathbf{2})$, and $c i s-\left[\left(\mathrm{BP}^{\mathrm{mdm}} \mathrm{MEN}\right) \mathrm{ReO}_{2}\right] \mathrm{PF}_{6}$ (3)

\begin{tabular}{llll}
\hline & $\mathbf{1}$ & \multicolumn{1}{c}{$\mathbf{2}$} & $\mathbf{3}$ \\
\hline Re-O1 & $1.765(4)$ & $1.750(3)$ & $1.745(3)$ \\
Re-O2 & $1.749(4)$ & $1.747(4)$ & $1.749(3)$ \\
Re-N1 & $2.122(5)$ & $2.126(4)$ & $2.122(4)$ \\
Re-N4 & $2.132(5)$ & $2.124(4)$ & $2.116(4)$ \\
Re-N2 & $2.258(5)$ & $2.286(4)$ & $2.266(4)$ \\
Re-N3 & $2.252(4)$ & $2.284(4)$ & $2.279(4)$ \\
O1-Re-O2 & $122.5(2)$ & $123.1(2)$ & $122.60(16)$ \\
N1-Re-N4 & $176.3(2)$ & $174.53(16)$ & $174.85(13)$ \\
N2-Re-N3 & $75.47(19)$ & $75.89(15)$ & $76.69(13)$ \\
\hline
\end{tabular}

Table 3.2.1 Angle between pyridine ring and N-Re bond $\left[^{\circ}\right]$

\begin{tabular}{lccc}
\hline & $\mathbf{1}$ & $\mathbf{2}$ & $\mathbf{3}$ \\
\hline $\mathrm{N} 1-\mathrm{Re}$ & $2.0(3)$ & $6.8(2)$ & $2.67(19)$ \\
$\mathrm{N} 4-\mathrm{Re}$ & $1.8(3)$ & $6.7(2)$ & $0.93(18)$ \\
\hline
\end{tabular}

\subsubsection{Initial catalytic activity investigation of complexes 1-3}

Next, we investigated the use of $\mathbf{1}, \mathbf{2}$, and $\mathbf{3}$ as catalysts in the DODH of vicinal diols by using 1,2-octanediol as a benchmark substrate and triphenylphosphine $\left(\mathrm{PPh}_{3}\right)$ as reductant. Only trace amounts of 1-octene formed when the reaction was performed at $135{ }^{\circ} \mathrm{C}$ using $2 \mathrm{~mol} \% 1$ as catalyst and 1.1 equiv. of $\mathrm{PPh}_{3}$ as reductant. The reaction temperature was then gradually increased from $135{ }^{\circ} \mathrm{C}$ to $180{ }^{\circ} \mathrm{C}$. The yield of 1 -octene jumped from $11 \%$ to quantitative when 
the temperature was increased from $165^{\circ} \mathrm{C}$ to $180^{\circ} \mathrm{C}$ (Table 3.2.3, entries 1-4). Similarly, when 2 was used as catalyst, an elevated reaction temperature was also necessary; the yield of 1octene dramatically increased when the reaction temperature was increased from $150{ }^{\circ} \mathrm{C}$ to 180 ${ }^{\circ} \mathrm{C}$ (Table 3.2.3, entries 5,6). For all three complexes, full conversion and quantitative 1-octene yield were achieved when the reaction was performed at $180{ }^{\circ} \mathrm{C}$ for $15 \mathrm{~h}$ under $\mathrm{N}_{2}$ (Table 3.2.3, entries 4,5 , and 7).

Table 3.2.3 Deoxydehydration of 1,2-octanediol catalyzed by dioxorhenium complexes. ${ }^{\text {[a] }}$

\begin{tabular}{|c|c|c|c|c|c|}
\hline entry & catalyst & time & temperature & yield $^{[b]}$ & conversion \\
\hline 1 & 1 & $15 \mathrm{~h}$ & $135^{\circ} \mathrm{C}$ & $2 \%$ & $2 \%$ \\
\hline 2 & 1 & $15 \mathrm{~h}$ & $150^{\circ} \mathrm{C}$ & $6 \%$ & $7 \%$ \\
\hline 3 & 1 & $15 \mathrm{~h}$ & $165^{\circ} \mathrm{C}$ & $11 \%$ & $12 \%$ \\
\hline 4 & 1 & $15 \mathrm{~h}$ & $180^{\circ} \mathrm{C}$ & $>99 \%$ & $>99 \%$ \\
\hline 5 & 2 & $15 \mathrm{~h}$ & $150^{\circ} \mathrm{C}$ & $16 \%$ & $16 \%$ \\
\hline 6 & 2 & $15 \mathrm{~h}$ & $180^{\circ} \mathrm{C}$ & $>99 \%$ & $>99 \%$ \\
\hline 7 & 3 & $15 \mathrm{~h}$ & $180^{\circ} \mathrm{C}$ & $>99 \%$ & $>99 \%$ \\
\hline 8 & 1 & $3 \mathrm{~h}$ & $180^{\circ} \mathrm{C}$ & $27 \%$ & $27 \%$ \\
\hline 9 & 2 & $3 \mathrm{~h}$ & $180^{\circ} \mathrm{C}$ & $34 \%$ & $34 \%$ \\
\hline 10 & 3 & $3 \mathrm{~h}$ & $180^{\circ} \mathrm{C}$ & $41 \%$ & $41 \%$ \\
\hline 11 & $\mathrm{IReO}_{2}\left(\mathrm{PPh}_{3}\right)_{2}$ & $3 \mathrm{~h}$ & $180^{\circ} \mathrm{C}$ & $14 \%$ & $16 \%$ \\
\hline 12 & trans- $\left[\left(\mathrm{Py}_{4}\right) \mathrm{ReO}_{2}\right] \mathrm{PF}_{6}$ & $3 \mathrm{~h}$ & $180^{\circ} \mathrm{C}$ & $>99 \%$ & $>99 \%$ \\
\hline $13^{[\mathrm{c}]}$ & 1 & $7 \mathrm{~h}$ & $180^{\circ} \mathrm{C}$ & $75 \%$ & $75 \%$ \\
\hline $14^{[\mathrm{c}]}$ & 2 & $7 \mathrm{~h}$ & $180^{\circ} \mathrm{C}$ & $90 \%$ & $90 \%$ \\
\hline $15^{[\mathrm{c}]}$ & 3 & $7 \mathrm{~h}$ & $180^{\circ} \mathrm{C}$ & $84 \%$ & $84 \%$ \\
\hline
\end{tabular}

[a] Reaction conditions: 1,2-octanediol ( $0.5 \mathrm{mmol}), \mathrm{PPh}_{3}(0.55 \mathrm{mmol}, 1.1$ equiv. $)$, catalyst (0.01 mmol, $2 \mathrm{~mol} \%$ ), $\mathrm{PhCl}(5 \mathrm{~mL}), \mathrm{N}_{2}$. [b]1-Octene yield was determined by ${ }^{1} \mathrm{H}$ NMR using mesitylene ( $\left.0.5 \mathrm{mmol}\right)$ as an internal standard. [c] For the initial $3 \mathrm{~h}$, the reaction was performed under $\mathrm{N}_{2}$; for the next $4 \mathrm{~h}$, the reaction was performed under air.

In order to compare the reactivity of $\mathbf{1 , 2}$, and $\mathbf{3}$, a shorter reaction time was chosen. After $3 \mathrm{~h}$ of reaction at $180{ }^{\circ} \mathrm{C}$, significantly lower olefin yields (27-41\%) were found than for a reaction time of $15 \mathrm{~h}$ at this reaction temperature, albeit at 100\% 1-octene selectivity. These findings show that the nature of $\mathrm{N}_{2} \mathrm{Py}_{2}$ ligand has an effect on the proficiency of the Re-dioxo complexes in catalysis and that these complexes do not show any isomerization of the olefin product under the current conditions. Remarkably, in DODH reactions catalyzed by $\mathrm{Cp}$-based trioxo-rhenium 
complexes, olefin isomers are formed when the reactions are performed at higher temperatures $\left(180^{\circ} \mathrm{C}\right) \cdot{ }^{[26]}$

The precursor of these dioxo complexes, i.e. iododioxobis(triphenylphosphine)rhenium $\left(\mathrm{IReO}_{2}\left(\mathrm{PPh}_{3}\right)_{2}\right)$, was also investigated for its DODH activity and gave a 1-octene yield of only $14 \%$ with $2 \%$ of octene isomers being formed. Besides, trans-[( $\left.\left.\mathrm{Py}_{4}\right) \mathrm{ReO}_{2}\right] \mathrm{PF}_{6}$ was tested for this DODH reaction, aiming at providing information on the effect of the configuration of the oxo ligands (cis or trans) on catalysis. Surprisingly, this complex showed the best activity among all dioxorhenium complexes tested in our study (Table 3.2.3, compare entries 8-11). After the reaction mixture was heated at $180{ }^{\circ} \mathrm{C}$ for $3 \mathrm{~h}$, a full substrate conversion and quantitative 1-octene product yield was achieved with trans-[( $\left.\left.\mathrm{Py}_{4}\right) \mathrm{ReO}_{2}\right] \mathrm{PF}_{6}$ (entry 11), while the reactions using the three $\mathrm{N}_{2} \mathrm{Py}_{2}$-ligated cis-dioxorhenium complexes reached much lower conversions (entries 8-10). As mentioned in the introduction section, Nicholas et al. have carried out a stochiometric reaction between 1,2-decanediol (1.6 equiv.) and trans$\left[\left(\mathrm{Py}_{4}\right) \mathrm{ReO}_{2}\right] \mathrm{Cl}$ (1.0 equiv.) to form 1.0 equiv. of 1 -decene and no diol oxidation products. From this observation, they concluded that the starting $\operatorname{Re}(\mathrm{V})$ complex is converted to a $\left[(\mathrm{Py})_{\mathrm{n}} \mathrm{Re}(\mathrm{VII}) \mathrm{O}_{3}\right]^{+}$species, which would also involve pyridine ligand(s) dissociation, and that DODH catalysis using this Re-dioxo complex would proceed through a $\operatorname{Re}(\mathrm{V}) \leftrightarrow \operatorname{Re}(\mathrm{VII})$ cycle. ${ }^{[25]}$ On basis of these considerations, we assume that $\left[\left(\mathrm{N}_{2} \mathrm{Py}_{2}\right) \mathrm{ReO}_{2}\right]^{+}$-catalyzed DODH reactions can also proceed through a $\operatorname{Re}(\mathrm{V}) \leftrightarrow \operatorname{Re}(\mathrm{VII})$ cycle. In this case though, the formal oxidation to a $\mathrm{Re}(\mathrm{VII})$-trioxo species (resulting from a single DODH reaction) would be more difficult compared to trans-[( $\left.\left.\mathrm{Py}_{4}\right) \mathrm{ReO}_{2}\right] \mathrm{PF}_{6}$, since the tetradentate $\mathrm{N}_{2} \mathrm{Py}_{2}$ ligand is more strongly coordinated to the Re center than the monodentate pyridine donors in trans$\left[\left(\mathrm{Py}_{4}\right) \mathrm{ReO}_{2}\right] \mathrm{PF}_{6}$. This could then explain why trans-[( $\left.\left.\mathrm{Py}_{4}\right) \mathrm{ReO}_{2}\right] \mathrm{PF}_{6}$ has a higher catalytic activity compared to complexes $\mathbf{1 - 3}$.

As a last aspect of these initial studies, we investigated the sensitivity of DODH catalysis by complexes 1-3. Accordingly, the reaction mixtures of entries 7-9 were then heated for another $4 \mathrm{~h}$ under air in the closed reaction vessel. Interestingly, the presence of $\mathrm{O}_{2}$ does not seem to hamper the reactivity and might even slightly promote the reactions (Table 3.2.3, entries 1315).

\subsubsection{Initial mechanistic studies}

After the initial study of the catalytic DODH activity of complexes 1-3, the time-course profiles of the DODH of 1,2-octanediol by these $\mathrm{N}_{2} \mathrm{Py}_{2}$-ligated Re-dioxo complexes were investigated. 
In situ ${ }^{1} \mathrm{H}$ NMR experiments were carried out using 1,2-octanediol (0.05 mmol), $\mathrm{PPh}_{3}(0.055$ mmol, 1.1 equiv.), Re-catalyst ( $0.005 \mathrm{mmol}, 10 \mathrm{~mol} \%)$, and mesitylene ( $0.05 \mathrm{mmol}, 1.0$ equiv., internal standard) in toluene- $\mathrm{D}_{8}(0.5 \mathrm{~mL})$ at $180^{\circ} \mathrm{C}$ under an inert $\mathrm{N}_{2}$ atmosphere.

a.

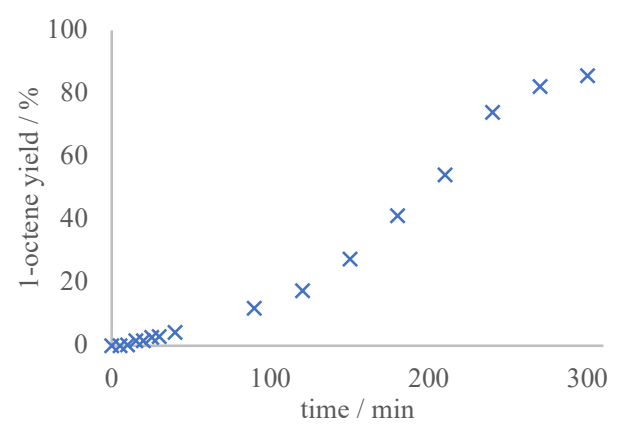

c.

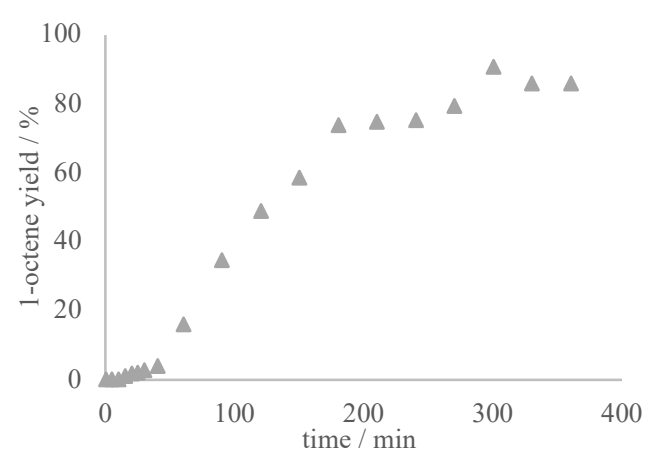

e.

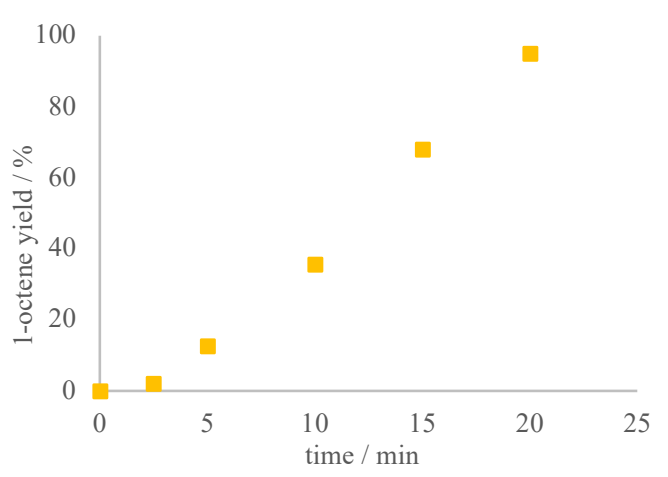

b.

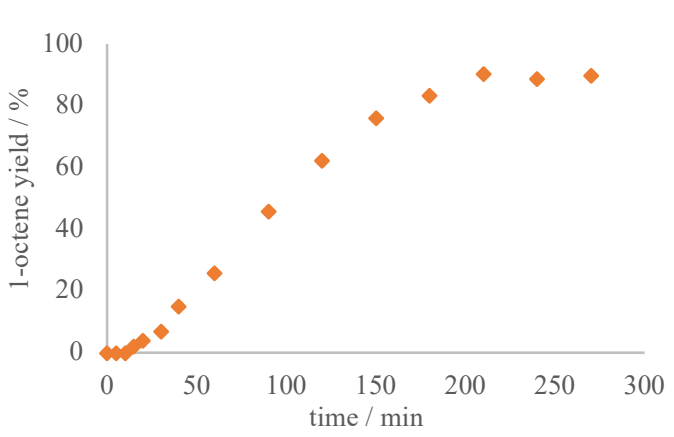

d.

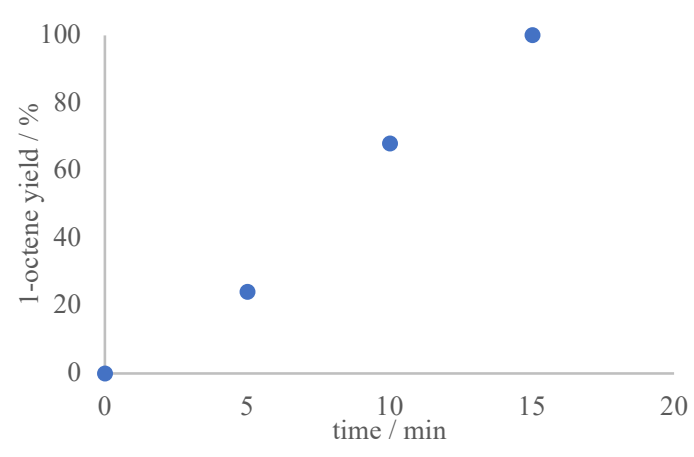

Scheme 3.2.2 Time course profiles of the formation of 1-octene in Re-catalyzed DODH of 1,2octanediol with $\mathrm{PPh}_{3}$ as reductant using different Re-catalysts: a. cis-[(BPMEN)ReO $\left.\mathrm{Re}_{2}\right] \mathrm{PF}_{6}$ (2); b. cis$\left[\left(\mathrm{BP}^{\mathrm{mdm}} \mathrm{MEN}\right) \mathrm{ReO}_{2}\right] \mathrm{PF}_{6}$ (3); c. cis-[(BPMEN)ReO $\left.\mathrm{Re}_{2}\right] \mathrm{BPh}_{4}$ (6), d. trans-[( $\left.\left.\mathrm{Py}_{4}\right) \mathrm{ReO}_{2}\right] \mathrm{PF}_{6}$ (4); e. pyridinium perrhenate. Reaction conditions: 1,2-octanediol (0.05 mmol), $\mathrm{PPh}_{3}(0.055 \mathrm{mmol}, 1.1$ equiv.), Re-catalyst $(0.005 \mathrm{mmol}, 10 \mathrm{~mol} \%)$, mesitylene $(0.05 \mathrm{mmol}, 1.0$ equiv., internal standard $)$, toluene- $\mathrm{D}_{8}$ $(0.5 \mathrm{~mL}), 180^{\circ} \mathrm{C}, \mathrm{N}_{2}$.

Except $\quad c i s-\left[(\mathrm{BPMEN}) \mathrm{ReO}_{2}\right] \mathrm{PF}_{6} \quad$ (2), cis-[(BPmdm MEN)ReO $\left.\mathrm{Re}_{2}\right] \mathrm{PF}_{6} \quad$ (3), and trans$\left[\left(\mathrm{Py}_{4}\right) \mathrm{ReO}_{2}\right] \mathrm{PF}_{6}$, also the dioxorhenium complex cis-[(BPMEN) $\left.\mathrm{ReO}_{2}\right] \mathrm{BPh}_{4}(6)$ was included in these studies in order to investigate a possible effect of the counter anion on catalyst activity. 
For complexes $\mathbf{2}, \mathbf{3}$, and $\mathbf{6}$, an induction period was observed. For the reaction catalyzed by $\mathbf{2}$, a typical sigmoidal trend for 1-octene formation was found. No 1-octene formation was observed during the initial $5 \mathrm{~min}$., followed by a gradual increase in 1-octene formation until $120 \mathrm{~min}$. After this induction period, formation of 1-octene proceeded at a much higher rate, with the highest yield (86\%) reached after $300 \mathrm{~min}$ (Scheme 3.2.2, a). Modification of the $\mathrm{N}_{2} \mathrm{Py} 2$ ligand framework lead to changes in this reaction profile. When cis-[(BPmdm $\left.M E N) \mathrm{ReO}_{2}\right] \mathrm{PF}_{6}$ (3) was used as catalyst, the sigmoidal reaction curve showed a much shorter induction period. In this case the highest product yield (90\%) was reached after $210 \mathrm{~min}$ (Scheme 3.2.2, b). Besides, changing the counter anion also resulted in a different reaction profile, i.e. the induction period was significantly shorter for the $\mathrm{BPh}_{4}^{-}$salt 6 than for $\mathrm{PF}_{6}{ }^{-}$salt 2 (Scheme 3.2.2, a and c). However, the three complexes $\mathbf{2 , 3}$, and $\mathbf{6}$ give a very similar final 1-octene yield and reached this yield within approximately the same time.

In the reaction profile for the DODH reaction catalyzed by trans- $\left[\left(\mathrm{Py}_{4}\right) \mathrm{ReO}_{2}\right] \mathrm{PF}_{6}$ no induction period was observed and $24 \%$ of 1 -octene had formed after $5 \mathrm{~min}$, while full conversion was achieved after $15 \mathrm{~min}$. The reaction rate in this case was much higher than that for the other three complexes. In all of these four reactions, no formation of olefin products resulting from 1 -octene isomerization was observed.

After the investigation of the time-course profiles of these " $\mathrm{ReO}_{2}$ "-catalyzed deoxydehydrations, the reaction mixtures were analyzed by means of ESI-MS measurements. For the DODH reaction of 1,2-octanediol catalyzed by $\mathbf{1}$, both protonated ligand (ES+ $m / z$ 323.2225; calc. 323.2230) and $\mathrm{ReO}_{4}{ }^{-}$(ES- $m / z$ 250.8320; calc. 250.9360) signals were detected by ESI-MS measurements on the crude reaction mixture after the reaction (Figure 3.2.2). The signal for the protonated ligand signal was also detected when subjecting pristine complex 1 to ESI-MS analysis, in addition to the signal of the $\left[(S, S-B P B P) \mathrm{ReO}_{2}\right]$ cation $(\mathrm{m} / z$ 541.1534; calc. $541.1608)$. The signal for the intact $\left[(S, S-\mathrm{BPBP}) \mathrm{ReO}_{2}\right]$ cation was, however not observed in the analysis of the crude DODH reaction mixture. The absence of $\mathbf{1}$, as well as the appearance of protonated ligand and $\mathrm{ReO}_{4}^{-}$, indicates that the starting Re-dioxo complex decomposes under the conditions of the DODH reaction and that perrhenate is formed during the reaction. In case of the DODH of 1,2-octanediol catalyzed by $\mathbf{1}$, besides the signal for the protonated ligand, signals at $\mathrm{m} / \mathrm{z} 480.2455,576.2290,669.2780,857.2693$, were detected in positive ion mode. While the signals at $\mathrm{m} / \mathrm{z} 480.2455,576.2290,857.2693 \mathrm{did}$ not match the isotope distribution of either mono- or multi-rhenium species, the signal at $\mathrm{m} / \mathrm{z} 669.2780 \mathrm{can}$ be assigned to the $[(S, S \text {-BPBP }) \mathrm{ReO}(1,2 \text {-octanediolate })]^{+}$ion (calc. 669.2809), which represents the product formed upon the condensation of $\left[(S, S \text {-BPBP }) \mathrm{ReO}_{2}\right]^{+}$and 1,2-octanediol. This diolate could 
either form 1-octene by olefin extrusion and generate $\left[(S, S \text {-BPBP }) \mathrm{ReO}_{3}\right]^{+}$, or be reduced by $\mathrm{PPh}_{3}$ to form $[(S, S \text {-BPBP }) \operatorname{Re}(1,2 \text {-octanediolate })]^{+}$, followed by olefin extrusion to regenerate $\left[(S, S \text {-BPBP }) \mathrm{ReO}_{2}\right]^{+}$. In the former case, a $20 \mathrm{e}^{-}$species $\left[(S, S-\mathrm{BPBP}) \mathrm{ReO}_{3}\right]^{+}$would be formed, which could set the stage for $\mathrm{N}_{2} \mathrm{Py}_{2}$ ligand dissociation and formal decomposition of the starting dioxo-complex.
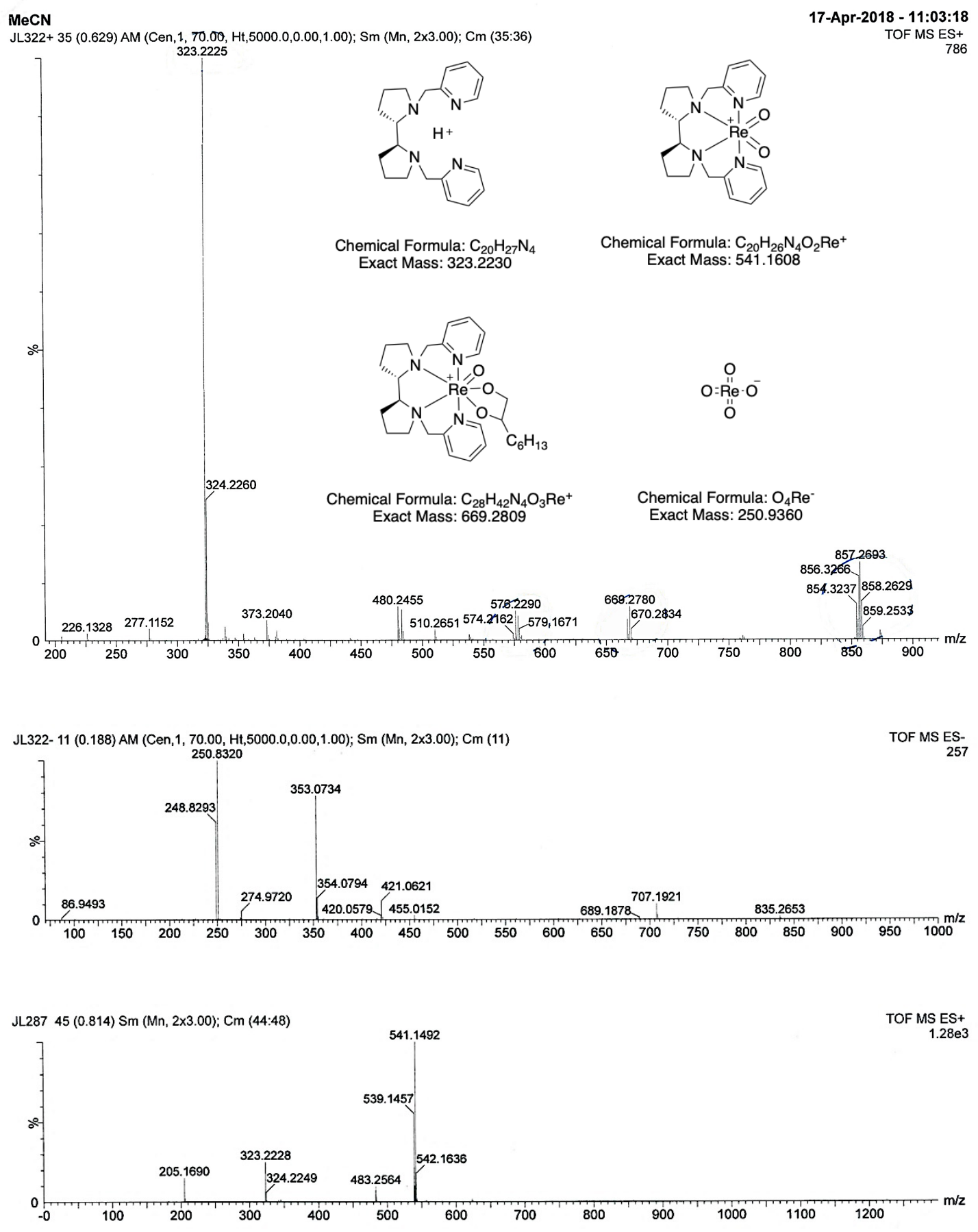

Figure 3.2.2 ESI-MS analysis: top. MS ES+ trace of the crude reaction mixture of the DODH reaction of 1,2-octanediol by $\mathbf{1}$; middle. MS ES- trace of the crude reaction mixture of the DODH reaction of 1,2-octanediol by $\mathbf{1}$; bottom. MS ES+ trace of $\mathbf{1}$. 
These combined MS and reaction profile observations indicate that complexes $\mathbf{2}, \mathbf{3}$, and $\mathbf{6}$ act as pre-catalysts in DODH reactions. Our initial assumption was that the $\mathrm{N}_{2} \mathrm{Py}_{2}$-supported complexes show slower kinetics due the more difficult formation of a putative $\operatorname{Re}(\mathrm{VII})$ trioxo species as a result of stronger ligand chelation (vide supra). The MS data now show the presence of protonated ligand and the perrhenate anion $\mathrm{ReO}_{4}^{-}$in the crude DODH reaction mixtures of these complexes, suggesting that full ligand dissociation and rhenium oxidation may take place as part of pre-catalyst activation.

Based on these observations, we decided to investigate the DODH activity of the pyridinium perrhenate salt $[\mathrm{PyH}]\left[\mathrm{ReO}_{4}\right]$. Pyridinium perrhenate was earlier reported as catalyst for the DODH of diols by Love and co-workers. ${ }^{[27]}$ In their work, aromatic vicinal diols were converted to the corresponding olefins with moderate to excellent yields ( $22 \%$ to quantative) at a relatively low temperature $\left(90^{\circ} \mathrm{C}\right)$ in chloroform using $5 \mathrm{~mol} \%$ lutidinium perrhenate as catalyst and 1.09 equiv. $\mathrm{PPh}_{3}$ as reductant. For aliphatic vicinal diol substrates, a higher reaction temperature of $140{ }^{\circ} \mathrm{C}$ was needed for the DODH reaction to proceed, and only moderate olefin yields (21$51 \%$ ) were obtained after $16 \mathrm{~h}$. When carrying out the DODH reaction of 1,2-octanediol with $[\mathrm{PyH}]\left[\mathrm{ReO}_{4}\right]$ as catalyst under our reaction conditions, we found quantitative 1-octene formation within approx. $20 \mathrm{~min}$ without the formation of octane isomers. The time-course profile of this reaction showed a very short induction period and indicated that the reaction rate was not as high as for trans-[( $\left.\left.\mathrm{Py}_{4}\right) \mathrm{ReO}_{2}\right] \mathrm{PF}_{6}$ (Scheme 3.2.2, $\mathrm{d}$ and e). This comparison between time-course profiles seems to suggest that perrhenate is the active species that is formed when trans-[( $\left.\left.\mathrm{Py}_{4}\right) \mathrm{ReO}_{2}\right] \mathrm{PF}_{6}$ is used in DODH catalysis. On the other hand, the difference in reaction rates does not rule out the possible involvement of yet another active species.

\subsubsection{Investigation of the active species}

In order to further probe the nature of the active species in DODH reactions catalyzed by Redioxo complexes, we decided to explore the DODH reaction of erythritol using these complexes. Erythritol is an interesting substrate in DODH chemistry, since it can lead to the formation of 1,3-butadiene as the reaction product starting from a bio-based source. In addition, this tetraol substrate can engage in a number of side-reactions, including dehydrative cyclisation and internal deoxydehydration, and its product distribution profile has been used to investigate the involvement of different active species during DODH catalysis. For the $\mathrm{Cp}^{*} \mathrm{ReO}_{3}$-catalyzed DODH of erythritol using $\mathrm{PPh}_{3}$ as reductant and $\mathrm{PhCl}$ as solvent, instead of 2,5-dihydrofuran, cis-2-butene-1,4-diol and 3-butene-1,2-diol were detected as byproduct. Also, for the $\mathrm{Cp}^{\mathrm{ttt}} \mathrm{ReO}_{3}$-catalyzed DODH of erythritol using $\mathrm{PPh}_{3}$ as reductant and $\mathrm{PhCl}$ as solvent, both cis- 
2-butene-1,4-diol and trans-2-butene-1,4-diol were detected as byproduct while 2,5dihydrofuran was not detected. ${ }^{[28]}$ However, the formation of 2,5-dihydrofuran is highly depended on the solvent and reductant; when 3-octanol was used as solvent and reductant, 2,5dihydrofuran was the only byproduct detected with either $\mathrm{Cp}^{\mathrm{ttt}} \mathrm{ReO}_{3}, \mathrm{Cp}^{\mathrm{tt}} \mathrm{ReO}_{3}$, or MTO as catalyst. ${ }^{[20,21,29]}$

cis-[(BPMEN)ReO 2$] \mathrm{PF}_{6}(2)$, trans-[( $\left.\left.\mathrm{Py}_{4}\right) \mathrm{ReO}_{2}\right] \mathrm{PF}_{6}(4)$, and pyridinium perrhenate were then tested for the DODH of erythritol using $\mathrm{PPh}_{3}$ as reductant and $\mathrm{PhCl}$ as solvent. The reactions were performed at $180{ }^{\circ} \mathrm{C}$ for $1.5 \mathrm{~h}$ under $\mathrm{N}_{2}$. The total yield of 1,3-butadiene and 2,5dihydrofuran was $57 \%, 80 \%$, and $83 \%$, respectively. In addition, different product distributions were observed; the ratio of 1,3-butadiene and 2,5-dihydrofuran products was 5.3:1, 9.0:1, and 15.6:1, respectively (Figure 3.2.3). Upon prolonging the reaction from $1.5 \mathrm{~h}$ to $3 \mathrm{~h}$, the total yield of 1,3-butadiene and 2,5-dihydrofuran increased to $68 \%$ and $84 \%$ for 2 and trans$\left[\left(\mathrm{Py}_{4}\right) \mathrm{ReO}_{2}\right] \mathrm{PF}_{6}$, while a lower $72 \%$ was observed for the perrhenate catalyzed reaction. The latter decrease could be the result of secondary reactions of the rather reactive butadiene product under the reactions conditions in the presence of $[\mathrm{PyH}]\left[\mathrm{ReO}_{4}\right]$. The ratio of 1,3-butadiene and 2,5-dihydrofuran products slightly changed to 5.2:1, 9.5:1, and 11:1 for the prolonged reactions.
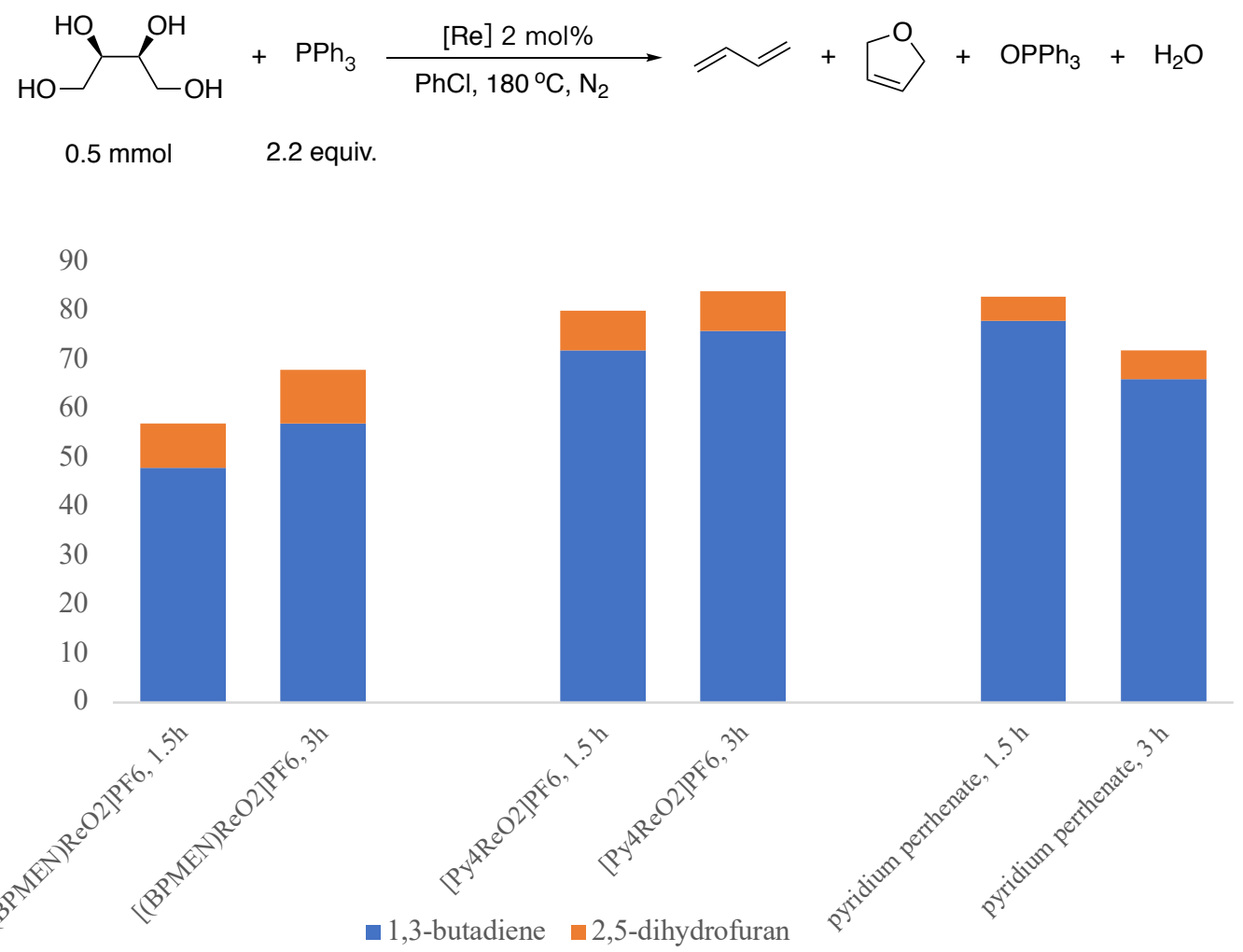

Scheme 3.2.3 DODH of erythritol using cis-[(BPMEN)ReO $\left.\mathrm{R}_{2}\right] \mathrm{PF}_{6}(2)$, trans-[( $\left.\left.\mathrm{Py}_{4}\right) \mathrm{ReO}_{2}\right] \mathrm{PF}_{6}$ (4), and pyridinium perrhenate as catalyst. 
Overall, the product distribution was quite consistent for these three catalysts. The differences observed in product formation and distribution in these experiments do not provide solid proof that perrhenate is the (only) active species in " $\mathrm{ReO}_{2}$ " catalyzed DODH reactions. In addition, the absence of cis-2-butene-1,4-diol, trans-2-butene-1,4-diol and 3-butene-1,2-diol by-products indicated that these three reactions do not proceed through the same active species and/or do not form the same Re-based side products as $\mathrm{Cp}^{*} \mathrm{ReO}_{3}$ and $\mathrm{Cp}^{\mathrm{tt}} \mathrm{ReO}_{3}$ in the $\mathrm{PPh}_{3} / \mathrm{PhCl}_{\text {system. }}$. On the other hand, as mentioned above, in all cases of using a secondary alcohol as both solvent and reductant, 2,5-dihydrofuran was the only detected byproduct, just like for our experiments using the $\mathrm{PPh}_{3} / \mathrm{PhCl}$ conditions; indicating that for the Re-dioxo and perrhenate systems the same or similar active species could actually be involved as for the Re-trioxo systems.

Since neither the time-course profile nor the product distribution studies could provide full evidence that perrhenate is the active species in Re-dioxo catalyzed DODH reaction, we have sought for other means of probing the nature of the active species in these reactions. On basis of the time-course profile the DODH reaction catalyzed by 2 (Figure 3.2.2.a), the activation/formation of the active species could proceed in a two-step manner. After a small amount of olefin product had formed, a second phase in product formation was observed before the rate of product formation really took on. Accordingly, we considered the possibility that the active species might be generated through the involvement of the initial rhenium complexes and one of the products formed in the DODH reaction, i.e. next to olefin also water and triphenylphosphine oxide $\left(\mathrm{OPPh}_{3}\right)$.

We first turned our attention to the possible role of water on the speciation of rhenium in the DODH reactions. It is known that in the present of water methyltrioxorhenium (MTO) will form a gold-colored rhenium oligomer $\left\{\mathrm{H}_{0.5}\left[\left(\mathrm{CH}_{3}\right)_{0.92} \mathrm{ReO}_{3}\right]\right\}$ in high yield (ca. $\left.70 \%\right)$ at $70{ }^{\circ} \mathrm{C}$, in addition to the formation of $\mathrm{O}_{2}, \mathrm{HReO}_{4}$, and methane (ca. $30 \%$ in total). ${ }^{[30,31]}$ So we were curious about the species formed from the Re-dioxo complexes and water. Accordingly, cis[(BPMEN)ReO $\mathrm{BBPh}_{4}(6)$ was heated in $\mathrm{CD}_{3} \mathrm{CN}$ at $180{ }^{\circ} \mathrm{C}$ for $2 \mathrm{~h}$ in the presence of 50 equiv. of water. ${ }^{1} \mathrm{H}$ NMR analysis of the reaction after this period did not indicate the presence of non-coordinated BPMEN ligand. Next, this "water-treated" complex, i.e. the resulting reaction mixture, was used as catalyst in the DODH of 1,2-octanediol under our standard reaction conditions. In this case, $86 \%$ of 1 -octene formed after $2 \mathrm{~h}$ at $180{ }^{\circ} \mathrm{C}$ and again without the formation of olefin isomers. The time-course profile of this reaction shows that only $3 \%$ of 1 octene had formed after $10 \mathrm{~min}$, but that the overall induction period was significantly shorter than using pristine $c i s-\left[(\mathrm{BPMEN}) \mathrm{ReO}_{2}\right] \mathrm{BPh}_{4}$ as catalyst (Figure 3.2.3). After the induction period, the two reaction profiles are rather similar, which indicates that the same active species 
might be involved and the formation of this species might involve a reaction with water at high temperature. Comparing the time-course profile of DODH reactions using complex 6 and "water-treated" 6 as catalyst, the latter one is much faster. In both cases though, no olefin isomers were formed during the reaction and the final yield of 1 -octene was the same (95\%).

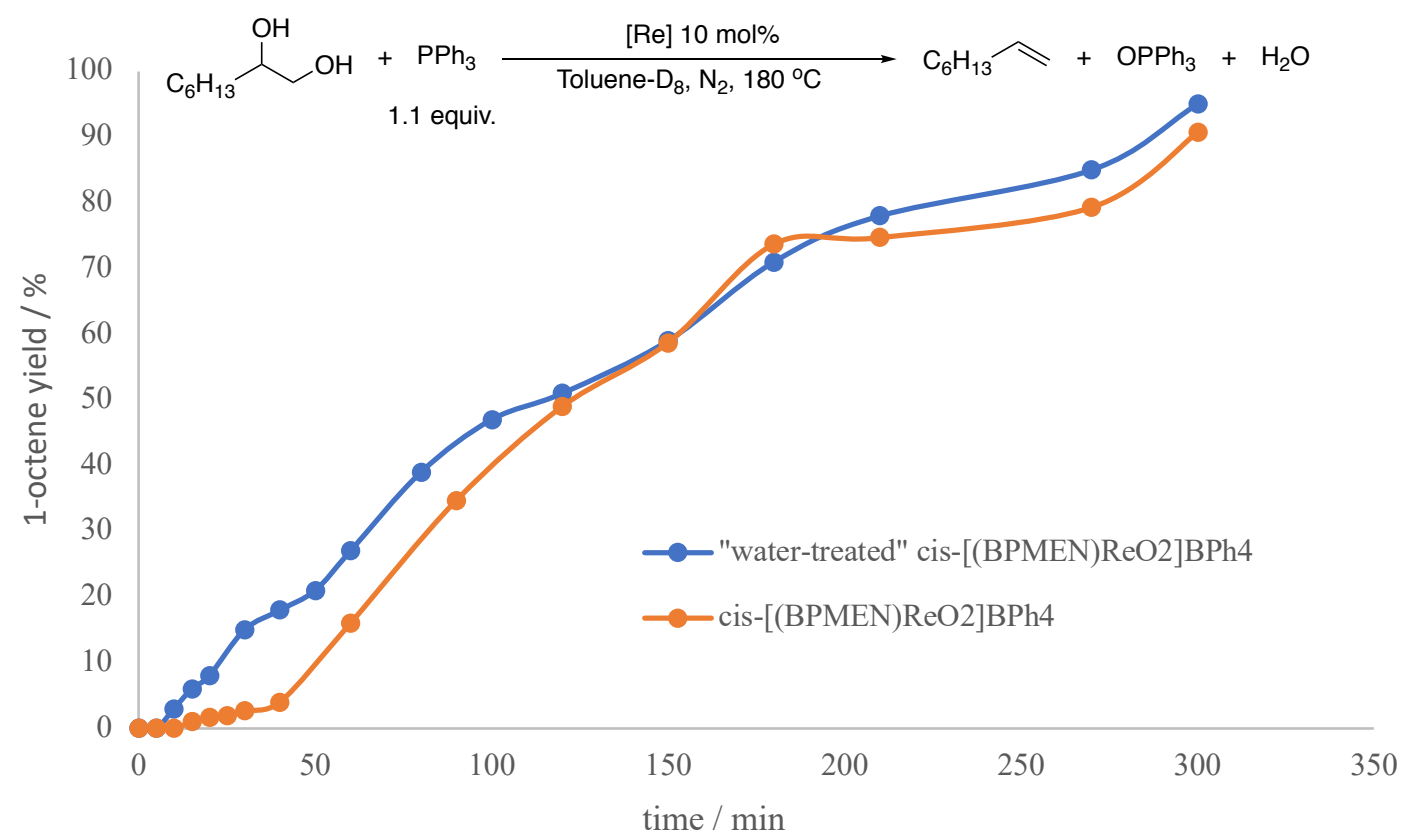

Figure 3.2.3 Time-course profile of the DODH reaction of 1,2-octanediol using cis[(BPMEN)ReO $\left.\mathrm{R}_{2}\right] \mathrm{BPh}_{4}$ and "water-treated" cis-[(BPMEN) $\left.\mathrm{ReO}_{2}\right] \mathrm{BPh}_{4}$ as catalyst (a line connecting the data point is added to aid the eye). Reaction conditions: 1,2-octanediol (0.05 mmol), $\mathrm{PPh}_{3}(0.055 \mathrm{mmol}$, 1.1 equiv.), Re-catalyst ( $0.005 \mathrm{mmol}, 10 \mathrm{~mol} \%)$, mesitylene ( $0.05 \mathrm{mmol}, 1.0$ equiv., internal standard), toluene- $\mathrm{D}_{8}(0.5 \mathrm{~mL}), 180{ }^{\circ} \mathrm{C}, \mathrm{N}_{2}$.

Next, we compared the IR spectra of 6 before and after treatment with water to that of pyridinium perrhenate (Figure 3.2.4). The IR spectrum of pristine cis-[(BPMEN)ReO $\left.\mathrm{R}_{2}\right] \mathrm{BPh}_{4}$ shows a sharp and intense signal at $813 \mathrm{~cm}^{-1}$ assigned to $\mathrm{Re}=\mathrm{O}$ stretching, while the IR of pyridinium perrhenate shows relatively broad and intense signals at 863,741 , and $672 \mathrm{~cm}^{-1}$ assigned to $\mathrm{Re}=\mathrm{O}$ stretching of the perrhenate anion. In the IR spectrum of "water-treated" cis[(BPMEN)ReO $\left.\mathrm{Re}_{2}\right] \mathrm{BPh}_{4}$ the most intense signal in the $500-1000 \mathrm{~cm}^{-1}$ range was found at $907 \mathrm{~cm}^{-}$ 1 , which again was assigned to $\mathrm{Re}=\mathrm{O}$ stretching, albeit at significant higher wavenumber compared to pristine 6. Two less intense bands were also observed in this range, at 761 and 706 $\mathrm{cm}^{-1}$. Comparing these three spectra, it is obvious that no $c i s-\left[(\mathrm{BPMEN}) \mathrm{ReO}_{2}\right] \mathrm{BPh}_{4}$ is left after water treatment. The similarities in the $500-1000 \mathrm{~cm}^{-1}$ range for pyridinium perrhenate and "water-treated" cis-[(BPMEN) $\left.\mathrm{ReO}_{2}\right] \mathrm{BPh}_{4}$ suggest that $\mathrm{ReO}_{4}{ }^{-}$is formed upon water treatment 
of 6. In the range of 1000-2000 $\mathrm{cm}^{-1}$, very different signals were observed likely due to the presence of different organic ligands.

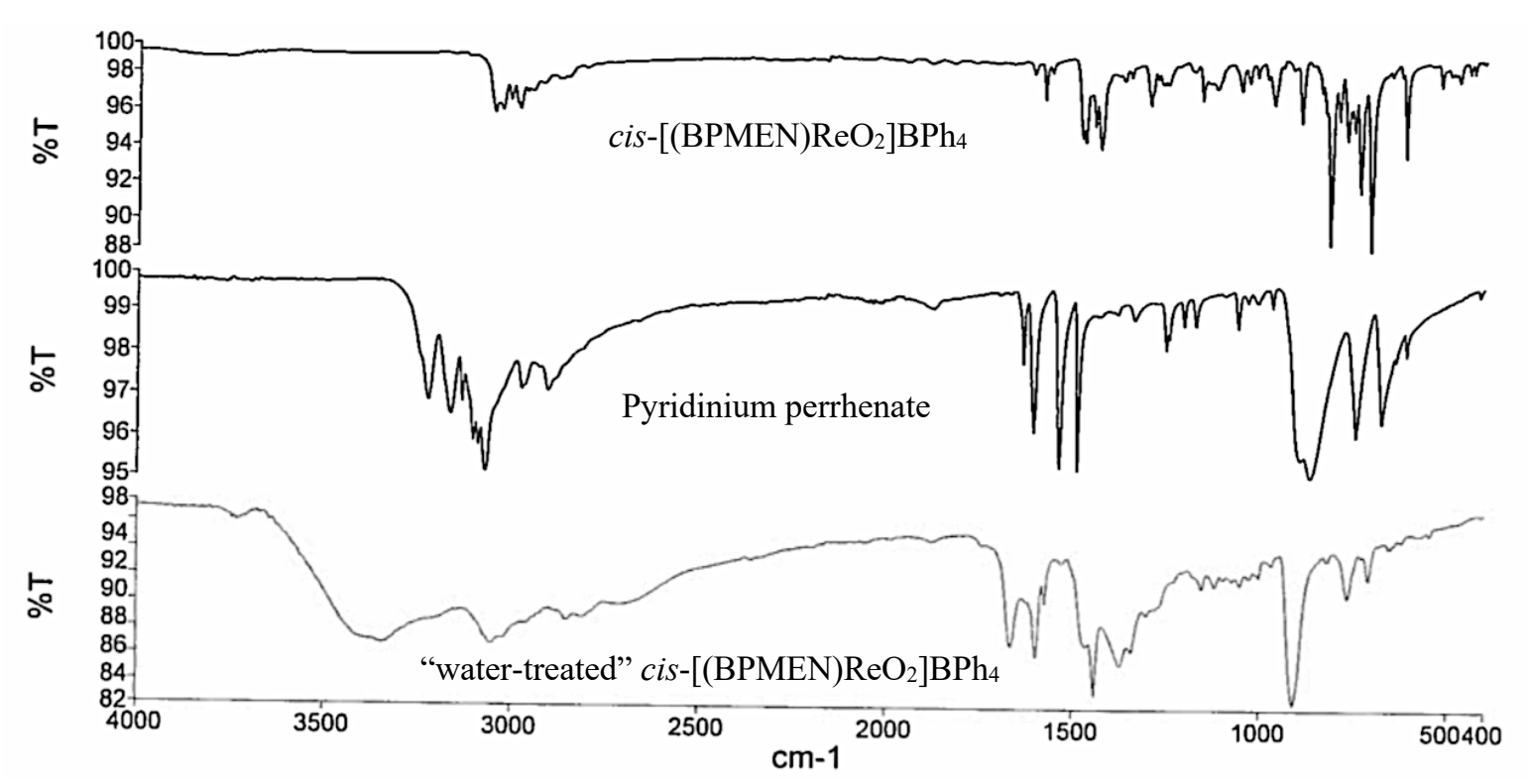

Figure 3.2.4 IR spectra of $c i s-\left[(B P M E N) \mathrm{ReO}_{2}\right] \mathrm{BPh}_{4}$, pyridinium perrhenate, and "water-treated" cis-

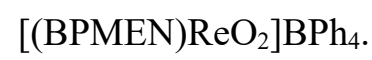

Recently, Marrone and d'Alessandro et. al. have reported a study on the active species in rhenium-catalyzed DODH reactions using secondary alcohols as reductant. ${ }^{[32]}$ An induction period was observed for the DODH of glycerol using methyltrioxorhenium (MTO), trioxorhenium $\left(\mathrm{ReO}_{3}\right)$, rhenium pentachloride $\left(\mathrm{ReCl}_{5}\right)$, hepta-oxo-dirhenium $\left(\mathrm{Re}_{2} \mathrm{O}_{7}\right)$, rhenium triiodide ( $\left.\mathrm{ReI}_{3}\right)$, and $\mathrm{IReO}_{2}\left(\mathrm{PPh}_{3}\right)_{2}$ as catalyst and 2,4-dimethyl-3-pentanol (DMP) as reductant. After removal of the volatile reaction products and the DMP reductant, the residues of these reactions were used as the catalyst in subsequent DODH experiments and no induction periods were observed. IR spectra of these active residues were collected and compared (Figure 3.2.3). A few intense and broad signals were detected in the $1800-3750 \mathrm{~cm}^{-1}$ range, and these signals could be assigned to $\mathrm{C}-\mathrm{H}$ and $\mathrm{O}-\mathrm{H}$ stretching vibrations. In our IR spectra of "water-treated" cis-[(BPMEN)ReO $\left.\mathrm{Re}_{2}\right] \mathrm{BPh}_{4}$, these kind of intense and broad signals $\left(3346,3053,2852 \mathrm{~cm}^{-1}\right)$ were also observed in this range. In the range of $1000-1750 \mathrm{~cm}^{-1}$, multiple intense signals were detected by Marrone and d'Alessandro while in our case, much less intense signals were observed. Since this range is where $\mathrm{C}-\mathrm{O}$ stretching and $\mathrm{C}-\mathrm{C}-\mathrm{H}, \mathrm{C}-\mathrm{O}-\mathrm{H}$ bending vibrations are located, these differences indicate that related species may have formed but these are not identical. In both studies, the most intense signals appeared in the $600-1000 \mathrm{~cm}^{-1}$ range. In the study of Marrone and d'Alessandro, the most intense signal appears at $920 \mathrm{~cm}^{-1}$ for the $\mathrm{Re}=\mathrm{O}$ stretching vibration in all cases studied, independent from the rhenium sources. In our case this 
vibration is found at $907 \mathrm{~cm}^{-1}$. Besides, a less intense band around $700 \mathrm{~cm}^{-1}$ was observed in all cases by Marrone and d'Alessandro, and assigned to either the out-of-plane bending of $\mathrm{O}-\mathrm{H}$ bonds or the stretching of Re-O-Re oxo-bridges. Overall, rather similar spectra were obtained in these two studies. By further investigating the MTO-catalyzed DODH of glycerol, Marrone and d'Alessandro proposed a Re(VII) alkoxide oligomer as the actual active species, could form alongside methane from the reaction of MTO and the secondary alcohol reductant. A very important observation from their study is the formation of a catalytically active black solid in all cases. In our present study though, we did not observe the formation of black precipitates.

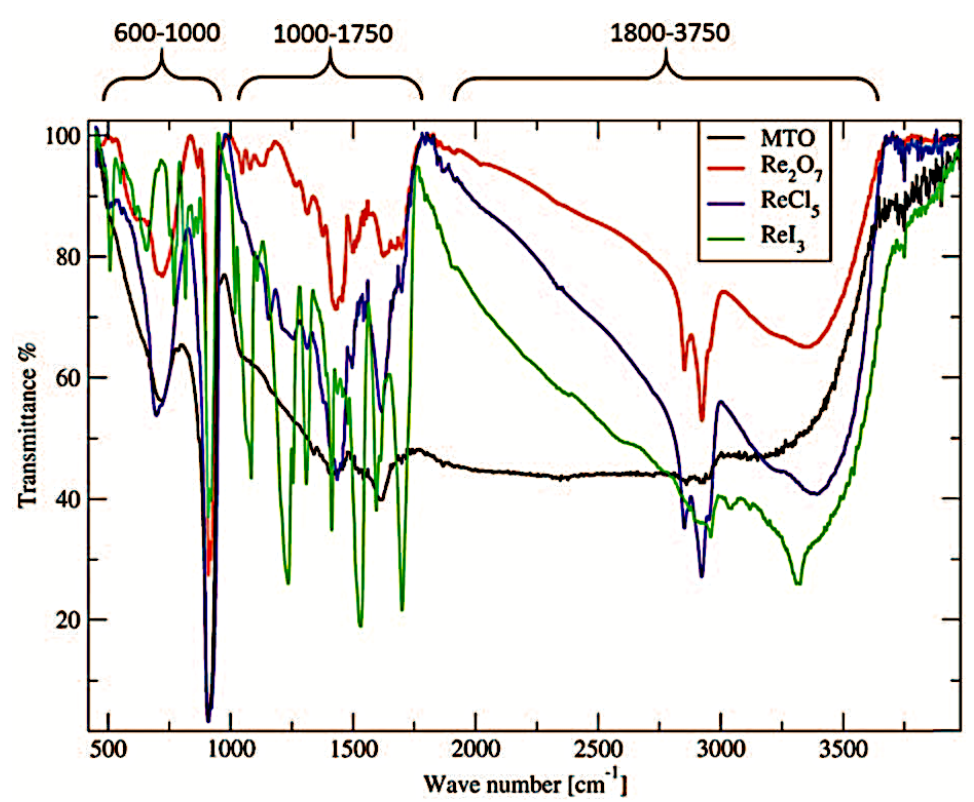

Figure 3.2.3 IR spectra of the reaction residue from rhenium-catalyzed DODH of glycerol (Reproduced by permission of The Royal Society of Chemistry). ${ }^{[32]}$

As described in Marrone and d'Alessandro's work, an active DODH species is formed from the reaction of the Re source and a secondary alcohol. Although in our system, we do not use a secondary alcohol reductant, an active species seems to form from a reaction with water, and obviously a vicinal diol is present as the substrate. A possibility would be that in our case a rhenium-oxide/hydroxide oligomer is formed instead of a $\operatorname{Re}(\mathrm{VII})$ alkoxide oligomer as proposed by Marrone and d'Alessandro. The differences seen in the 1000-1750 $\mathrm{cm}^{-1}$ range in IR analysis would support this assumption. As mentioned before, IR analysis of the $\left\{\mathrm{H}_{0.5}\left[\left(\mathrm{CH}_{3}\right)_{0.92} \mathrm{ReO}_{3}\right]\right\}$ oligomer, the reaction product of MTO and water, shows signals at 912 (vs), $881(\mathrm{sh}), 851$ (sh), and $758 \mathrm{~cm}^{-1}(\mathrm{~m}) \cdot{ }^{[31]}$ These signals could be assigned to $\mathrm{Re}=\mathrm{O}$ stretching vibrations. Although not identical, we observed quite similar IR vibrations in the $600-1000 \mathrm{~cm}^{-1}$ region (Table 3.2.4). For the $\left\{\mathrm{H}_{0.5}\left[\left(\mathrm{CH}_{3}\right)_{0.92} \mathrm{ReO}_{3}\right]\right\}$ oligomer, a methyl group is bond to the rhenium center, although not in a 1:1 ratio. In our case, no coordinated ligand was 
observed after the water treatment at $180{ }^{\circ} \mathrm{C}$. This comparison lends further credit to the proposed formation of a rhenium-oxide/hydroxide oligomer as the active species in DODH catalysis.

Table 3.2.4 Comparison of IR signals in 600-1000 $\mathrm{cm}^{-1}$ region of "water-treated" cis$\left[(\mathrm{BPMEN}) \mathrm{ReO}_{2}\right] \mathrm{BPh}_{4},\left\{\mathrm{H}_{0.5}\left[\left(\mathrm{CH}_{3}\right)_{0.92} \mathrm{ReO}_{3}\right]\right\},{ }^{[31]}$ and the $\mathrm{Re}(\mathrm{VII})$ alkoxide oligomer. ${ }^{[32]}$

\begin{tabular}{ccc}
\hline "water-treated" & $\left\{\mathrm{H}_{0.5}\left[\left(\mathrm{CH}_{3}\right)_{0.92} \mathrm{ReO}_{3}\right]\right\}$ & $\mathrm{Re}(\mathrm{VII})$ alkoxide oligomer \\
cis-[(BPMEN)ReO$\left.{ }_{2}\right] \mathrm{BPh}_{4}$ & & \\
\hline $907(\mathrm{vs})$ & $912(\mathrm{vs})$ & \\
& $881(\mathrm{sh})$ & \\
& $851(\mathrm{sh})$ & \\
$761(\mathrm{~m})$ & $758(\mathrm{~m})$ & around $700(\mathrm{~ms})$ \\
$706(\mathrm{w})$ & & \\
\hline
\end{tabular}

\subsubsection{Substrate scope}

Previously, trans-[(Py4) $\left.\mathrm{ReO}_{2}\right] \mathrm{PF}_{6}(10 \mathrm{~mol} \%)$ was used by Nicholas et al. as catalyst in the DODH of 1,2-decanediol using $\mathrm{Zn}$ as reductant and benzene as solvent to give $67 \%$ of 1 -decene with full substrate conversion at $150{ }^{\circ} \mathrm{C}$ in $24 \mathrm{~h}$. In our system, 1,2-octanediol was quantitively converted to 1 -octene at $180{ }^{\circ} \mathrm{C}$ in $3 \mathrm{~h}$ using only $2 \mathrm{~mol} \%$ of trans-[( $\left.\left.\mathrm{Py}_{4}\right) \mathrm{ReO}_{2}\right] \mathrm{PF}_{6}$. Remarkably, upon increase of the catalyst loading under our conditions to $10 \mathrm{~mol} \%$, the reaction was done in $15 \mathrm{~min}$ at $180^{\circ} \mathrm{C}$. For the Cp-based trioxorhenium-catalyzed DODH systems, much longer reaction times are needed to realize the full conversion of 1,2-octanediol. As mentioned before, no isomers were observed under our reaction conditions, while small amount of isomers were observed under the same conditions for Cp-based trioxorhenium catalysts. ${ }^{[26]}$ Besides, for the deoxydehydration of erythritol (vide supra), trans-[( $\left.\left.\mathrm{Py}_{4}\right) \mathrm{ReO}_{2}\right] \mathrm{PF}_{6}$ was quite a competitive catalyst (Scheme 3.2.3.). This initial catalytic capacity test of trans-[( $\left.\left.\mathrm{Py}_{4}\right) \mathrm{ReO}_{2}\right] \mathrm{PF}_{6}$ encouraged us to apply this pre-catalyst to other substrates. When the aromatic vicinal diol 1-phenylethane1,2-diol was used as substrate, a quantitative styrene yield was obtained (Table 3.2.4, entry 1). For the DODH of 1,4-anhydroerythritol, 97\% of 2,5-dihydrofuran was formed (entry 2); this 2,5-dihydrofuran yield is competitive to the one obtained from the MTO/3-pentanol system, which provides $95 \%$ of 2,5-dihydrofuran. ${ }^{[29]}$ Glycerol, a biomass derived triol, was also investigated in our reaction system and gave a quantitative amount of allyl alcohol (entry 3 ). Although quantitative allyl alcohol formation is also obtained by the $\mathrm{Cp}^{\mathrm{tt}} \mathrm{ReO}_{3} / 3$-octanol system, ${ }^{[22]}$ the air stable property of trans-[( $\left.\left.\mathrm{Py}_{4}\right) \mathrm{ReO}_{2}\right] \mathrm{PF}_{6}$ makes this catalyst system more attractive. Besides, trans-[( $\left.\left.\mathrm{Py}_{4}\right) \mathrm{ReO}_{2}\right] \mathrm{PF}_{6}$ also catalyzes the DODH of biomass-derived L-(+)- 
tartaric acid and mucic acid. When using L-(+)-tartaric acid as substrate, there was no product detected using $\mathrm{PPh}_{3}$ as reductant and $\mathrm{PhCl}$ as solvent. This is most likely due to the poor substrate solubility in $\mathrm{PhCl}$. Using 3-pentanol as both solvent and reductant gave $84 \%$ of the corresponding olefins as a mixture of fumaric acid and fumarate esters. Along a similar vein, a total yield of muconic acid and muconates of $65 \%$ was obtained using mucic acid as substrate (entry 5). In case of $\mathrm{Cp}^{\mathrm{tt}} \mathrm{ReO}_{3}$-catalyzed DODH of mucic acid, a slightly higher product yield of $71 \%$ was found, albeit at $5 \mathrm{~mol} \%$ catalyst loading. Overall, trans-[( $\left.\left.\mathrm{Py}_{4}\right) \mathrm{ReO}_{2}\right] \mathrm{PF}_{6}$ is a good pre-catalyst for the DODH of diols and biomass-derived polyols.

Table 3.2.4 trans-[( $\left.\left.\mathrm{Py}_{4}\right) \mathrm{ReO}_{2}\right] \mathrm{PF}_{6}$ catalyzed deoxydehydration ${ }^{[\mathrm{a}]}$

\begin{tabular}{|c|c|c|c|c|}
\hline entry & substrate & product & yield & reaction conditions \\
\hline \multirow[t]{2}{*}{1} & & & & [Re] $2 \mathrm{~mol}^{2}, \mathrm{PPh}_{3}$ (1.1 equiv.) \\
\hline & & & $>99 \%$ & $\mathrm{PhCl}(0.1 \mathrm{M}), 180^{\circ} \mathrm{C}, 3 \mathrm{~h}, \mathrm{~N}_{2}$ \\
\hline \multirow[t]{2}{*}{2} & & & & {$[\mathrm{Re}] 2 \mathrm{~mol} \%, \mathrm{PPh}_{3}$ (1.1 equiv.) } \\
\hline & & & $97 \%$ & $\mathrm{PhCl}(0.1 \mathrm{M}), 180^{\circ} \mathrm{C}, 3 \mathrm{~h}, \mathrm{~N}_{2}$ \\
\hline \multirow[t]{2}{*}{3} & & & $>99 \%$ & {$[\mathrm{Re}] 2 \mathrm{~mol} \%, \mathrm{PPh}_{3}$ (1.1 equiv.) } \\
\hline & & & & $\mathrm{PhCl}(0.1 \mathrm{M}), 180^{\circ} \mathrm{C}, 3 \mathrm{~h}, \mathrm{~N}_{2}$ \\
\hline \multirow[t]{2}{*}{4} & & & & {$[\mathrm{Re}] 2 \mathrm{~mol} \%$, 3-pentanol $(0.1 \mathrm{M})$} \\
\hline & & & $84 \%$ & $180{ }^{\circ} \mathrm{C}, 3 \mathrm{~h}, \mathrm{~N}_{2}$ \\
\hline \multirow[t]{2}{*}{5} & & & & {$[\mathrm{Re}] 2 \mathrm{~mol} \%$, 3-pentanol $(0.1 \mathrm{M})$} \\
\hline & $\begin{array}{lll}0 & 0\end{array}$ & & $65 \%$ & $180{ }^{\circ} \mathrm{C}, 3 \mathrm{~h}, \mathrm{~N}_{2}$ \\
\hline
\end{tabular}

[a] Olefin yield was determined by 1H NMR using mesitylene (1.0 equiv., $0.5 \mathrm{mmol}$ ) as an internal standard.

\subsection{Conclusions}

Two new tetradentate $\mathrm{N}$-donor ligand supported $\mathrm{ReO}_{2}{ }^{+}$complexes, cis-[(BPMEN)ReO $\left.\mathrm{Re}_{2}\right] \mathrm{PF}_{6}(\mathbf{2})$ and $c i s-\left[\left(\mathrm{B}^{\mathrm{mdm}} \mathrm{PMEN}\right) \mathrm{ReO}_{2}\right] \mathrm{PF}_{6}(\mathbf{3})$, were synthesized and fully characterized in this chapter. These complexes, along with the complex cis-[(S,S-BPBP) $\left.\mathrm{ReO}_{2}\right] \mathrm{PF}_{6}(\mathbf{1})$ earlier reported by Che, were found to be active in DODH reactions of diols, suggesting that Re-dioxo complexes are able to be involved in DODH catalysis. However, an induction period was observed for the DODH reaction of 1,2-octanediol using these $\mathrm{N}_{2} \mathrm{Py}_{2}$ supported dioxorhenium complexes. Under the same reaction conditions, no induction period was observed for trans$\left[\left(\mathrm{Py}_{4}\right) \mathrm{ReO}_{2}\right] \mathrm{PF}_{6}$ and a much shorter induction period was observed for pyridinium perrhenate. 
ESI-MS analysis of the reaction mixtures of DODH reactions catalyzed by cis[(BPMEN) $\left.\mathrm{ReO}_{2}\right] \mathrm{PF}_{6}$ showed the formation of protonated ligand and the $\mathrm{ReO}_{4}{ }^{-}$anion during catalysis. These combined observations suggested that the Re-dioxo complexes might act as pre-catalysts in DODH catalysis. Treatment of cis-[(BPMEN) $\left.\mathrm{ReO}_{2}\right] \mathrm{BPh}_{4}$ with an excess amount of water generated a species that is also active in DODH catalysis and that displayed a much shorter induction period than the pristine complex. A similar reaction rate and final 1octene yield indicated that pristine and "water-treated" cis-[(BPMEN)ReO $\left.\mathrm{R}_{2}\right] \mathrm{BPh}_{4}$ generate the same active DODH species. By comparing the IR spectra of various complexes before and after catalysis and a number of Re-compounds from the literature, we believe that ligand dissociation takes place after the first DODH reaction in which a Re-trioxo species is formed, to subsequently form a rhenium-oxide/hydroxide oligomer that is capable of catalytic turn-over. The remarkably high catalytic activity of trans-[( $\left.\left.\mathrm{Py}_{4}\right) \mathrm{ReO}_{2}\right] \mathrm{PF}_{6}$ can be explained by the more facile dissociation of pyridine from the Re center compared to the tetradentate $\mathrm{N}_{2} \mathrm{Py}_{2}$ ligands.

Last but not the least, several vicinal diols and biomass derived polyols have been applied to the simple trans-[( $\left.\left.\mathrm{Py}_{4}\right) \mathrm{ReO}_{2}\right] \mathrm{PF}_{6}$ catalyst in combination either $\mathrm{PPh}_{3}$ or 3-pentanol as reductant. Excellent to quantitative olefin yields were obtained for vicinal diol substrates. In the case of bio-based polyols, good olefin yield was obtained when 3-pentanol was used as solvent and reductant.

\subsection{Experimental Section}

\subsubsection{General}

All chemicals including solvents were degassed by either freeze-pump-thaw cycles or degasification under vacuum. Triphenylphosphine was crystallized from ethanol and dried under vacuum. Iododioxobis(triphenylphosphine)rhenium $\left(\mathrm{IReO}_{2}\left(\mathrm{PPh}_{3}\right)_{2}\right)$ was purchased from Sigma-Aldrich and used without further purification. $c i s-\left[(S, S-\mathrm{BPBP}) \mathrm{ReO}_{2}\right] \mathrm{PF}_{6},{ }^{[25]} \mathrm{BPMEN}^{\left[{ }^{[33]}\right.}$ $\mathrm{BP}^{\mathrm{mdm}} \mathrm{MEN},{ }^{[33]}$ and trans-[( $\left.\left.\mathrm{Py}_{4}\right) \mathrm{ReO}_{2}\right] \mathrm{PF}_{6}{ }^{[24]}$ were prepared according to known literature procedures. Unless otherwise stated, all other commercial chemicals were used without further purification. NMR spectra were recorded on a Varian VNMRS400 (400 MHz) instrument at 298 K. ESI-MS spectra were recorded using a Waters LCT Premier XE instrument. IR spectra were recorded with a Perkin-Elmer Spectrum One FTIR spectrometer. All olefinic products are known compounds and were calibrated against mesitylene for quantification. 


\subsubsection{Synthesis of cis-[(BPMEN)ReO $\left.\mathrm{B}_{2}\right] \mathrm{PF}_{6}$}

To a solution of BPMEN (136 mg, $0.5 \mathrm{mmol})$ in $\mathrm{CH}_{2} \mathrm{Cl}_{2}(20 \mathrm{~mL})$, cis-[ $\left[\mathrm{Re}^{\mathrm{V}} \mathrm{O}_{2}\left(\mathrm{PPh}_{3}\right)_{2} \mathrm{I}\right](435$ $\mathrm{mg}, 0.5 \mathrm{mmol}, 1.0$ equiv.) was slowly added. The reaction mixture was stirred overnight in the dark, and the solvent was removed by rotary evaporation. Crude $c i s-\left[(B P M E N) \mathrm{ReO}_{2}\right] \mathrm{I}$ was then dissolved in $\mathrm{MeOH}(30 \mathrm{~mL}), \mathrm{NH}_{4} \mathrm{PF}_{6}(163 \mathrm{mg}, 1.0 \mathrm{mmol}, 2$ equiv.) was added and the mixture was stirred for $1 \mathrm{~h}$. $\mathrm{MeOH}$ was then removed by rotary evaporation. The product was purified on a basic alumina column using $0.4 \% \mathrm{MeOH} / \mathrm{CH}_{2} \mathrm{Cl}_{2}$ as eluent (128 mg, $0.20 \mathrm{mmol}, 40 \%$ ). Brown crystals were obtained by slow diffusion of $\mathrm{Et}_{2} \mathrm{O}$ into a $\mathrm{CH}_{2} \mathrm{Cl}_{2}$ solution of the complex.

${ }^{1} \mathrm{H}$ NMR (400 MHz), $\mathrm{CD}_{3} \mathrm{CN}(1.94 \mathrm{ppm}): \delta 8.02-7.70(\mathrm{~m}, 4 \mathrm{H}), 7.55$ (ddd, $J=5.7,1.6,0.8$ $\mathrm{Hz}, 2 \mathrm{H}), 7.32(\mathrm{td}, J=7.8,1.6 \mathrm{~Hz}, 2 \mathrm{H}), 6.42-6.23(\mathrm{~m}, 4 \mathrm{H}), 3.38(\mathrm{~s}, 6 \mathrm{H}), 2.58-2.39(\mathrm{~m}$, $2 \mathrm{H}), 2.12-2.01(\mathrm{~m}, 2 \mathrm{H}) .{ }^{13} \mathrm{C} \mathrm{NMR}(100 \mathrm{MHz}), \mathrm{C}_{6} \mathrm{D}_{6}(118.260 \mathrm{ppm}): \delta 160.58,150.10,144.39$, 123.28, 122.68, 78.99, 57.81, 55.99; HR-ESI-MS (in $\mathrm{CH}_{3} \mathrm{CN}$ ): calc. for $\left[\mathrm{C}_{16} \mathrm{H}_{22} \mathrm{~N}_{4} \mathrm{O}_{2} \mathrm{Re}\right]^{+}$: 489.1301, found: 489.1172; IR (ATR): 523, 555, 764, 829, 905, 1302, 1442, 1475, 1613, 2937 $\mathrm{cm}^{-1}$.

\subsubsection{Synthesis of cis- $\left[\left(\mathrm{BP}^{\mathrm{mdm}} \mathrm{MEN}^{\mathrm{N}}\right) \mathrm{ReO}_{2}\right] \mathrm{PF}_{6}$}

This complex was prepared in an analogous manner to $c i s-\left[(\mathrm{BPMEN}) \mathrm{ReO}_{2}\right] \mathrm{PF}_{6}$, starting from BPmdm MEN (252 mg, $0.65 \mathrm{mmol})$ and cis-[ $\left.\mathrm{Re}^{\mathrm{V}} \mathrm{O}_{2}\left(\mathrm{PPh}_{3}\right)_{2} \mathrm{I}\right]$ (565 mg, $\left.0.65 \mathrm{mmol}\right)$. Brown solid, $31 \%$ yield.

${ }^{1} \mathrm{H}$ NMR (400 MHz), $\mathrm{CD}_{3} \mathrm{CN}(1.94 \mathrm{ppm}): \delta 7.83$ (ddt, $\left.J=7.8,5.7,1.1 \mathrm{~Hz}, 2 \mathrm{H}\right), 7.81-7.74$ $(\mathrm{m}, 2 \mathrm{H}), 7.49(\mathrm{ddd}, J=5.7,1.6,0.8 \mathrm{~Hz}, 2 \mathrm{H}), 7.38-7.19(\mathrm{~m}, 10 \mathrm{H}), 6.98(\mathrm{t}, J=7.4 \mathrm{~Hz}, 8 \mathrm{H})$, $6.83(\mathrm{tt}, J=7.4,1.6 \mathrm{~Hz}, 4 \mathrm{H}), 6.44-6.19(\mathrm{~m}, 4 \mathrm{H}), 3.36(\mathrm{~s}, 6 \mathrm{H}), 2.51-2.36(\mathrm{~m}, 2 \mathrm{H}), 2.14-$ 1.98 (m, 2H); IR (ATR):556, 793, 809, 829, 879, 991, 1052, 1093, 1268, 1402, 1471, 1600, $2934 \mathrm{~cm}^{-1}$; elemental analysis calc. (\%) for $\mathrm{C}_{22} \mathrm{H}_{34} \mathrm{~F}_{6} \mathrm{~N}_{4} \mathrm{O}_{4} \mathrm{PRe}$ (750.1779): C 35.25, H 4.57, N 7.47; found: C 35.04, H 4.70, N 7.59.

\subsubsection{Synthesis of cis-[(BPMEN)ReO $\left.{ }_{2}\right] \mathrm{BPh}_{4}$}

This complex was prepared in an analogous manner to cis-[(BPMEN) $\left.\mathrm{ReO}_{2}\right] \mathrm{PF}_{6}$, starting from BPMEN (270 mg, $1.0 \mathrm{mmol})$ and cis-[Re $\left.{ }^{\mathrm{V}} \mathrm{O}_{2}\left(\mathrm{PPh}_{3}\right)_{2} \mathrm{I}\right](869 \mathrm{mg}, 1.0 \mathrm{mmol})$. Instead of $\mathrm{NH}_{4} \mathrm{PF}_{6}$, $\mathrm{NaBPh}_{4}$ was used for salt metathesis. Brown solid, $45 \%$ yield. 
${ }^{1} \mathrm{H}$ NMR (400 MHz), CD $3 \mathrm{CN}(1.94 \mathrm{ppm}): \delta 7.16(\mathrm{~s}, 2 \mathrm{H}), 6.46(\mathrm{~d}, J=15.4 \mathrm{~Hz}, 2 \mathrm{H}), 6.07$ (d, $J$ $=15.4 \mathrm{~Hz}, 2 \mathrm{H}), 3.83(\mathrm{~s}, 6 \mathrm{H}), 3.46(\mathrm{~s}, 6 \mathrm{H}), 2.61-2.37(\mathrm{~m}, 2 \mathrm{H}), 2.10(\mathrm{~s}, 8 \mathrm{H}) .{ }^{13} \mathrm{C} \mathrm{NMR}(100$ $\mathrm{MHz}), \mathrm{C}_{6} \mathrm{D}_{6}(118.260 \mathrm{ppm}): \delta 171.48,158.40,149.36,149.28,126.61,125.76,76.93,76.83$, 63.89, 63.77, 59.14, 59.06, 56.45, 14.48, 14.44, 12.59, 12.54; HR-ESI-MS (in $\mathrm{CH}_{3} \mathrm{CN}$ ): calc. for $\left[\mathrm{C}_{22} \mathrm{H}_{34} \mathrm{~N}_{4} \mathrm{O}_{4} \mathrm{Re}\right]^{+}:$605.2139, found: 605.2003; IR (ATR):611, 704, 733,768, 813, 891, 965, $1031,1157,1296,1428,1445,1470,1478,1578,2983,3051 \mathrm{~cm}^{-1}$; elemental analysis calc. (\%) for $\mathrm{C}_{40} \mathrm{H}_{42} \mathrm{BN}_{4} \mathrm{O}_{2} \operatorname{Re}$ (807.8190): C 59.47, H 5.24, N 6.93; found: C 59.76, H 5.23, N 7.14.

\section{X-ray crystal structure determination of cis-[(BPMEN)ReO $\left.\mathrm{O}_{2}\right] \mathrm{PF}_{6}$}

$\left[\mathrm{C}_{16} \mathrm{H}_{22} \mathrm{~N}_{4} \mathrm{O}_{2} \mathrm{Re}\right]\left(\mathrm{PF}_{6}\right), \mathrm{Fw}=633.54$, black block, $0.34 \times 0.09 \times 0.05 \mathrm{~mm}^{3}$, monoclinic, $\mathrm{P} 2{ }_{1}$ (no. 4), $\mathrm{a}=8.35720(19), \mathrm{b}=14.2848(3), \mathrm{c}=8.82345(17) \AA, \beta=106.059(1)^{\circ}, \mathrm{V}=1012.25(4) \AA^{3}$, $\mathrm{Z}=2, \mathrm{D}_{\mathrm{x}}=2.079 \mathrm{~g} / \mathrm{cm}^{3}, \mu=6.16 \mathrm{~mm}^{-1}$. The diffraction experiment was performed on a Bruker Kappa ApexII diffractometer with sealed tube and Triumph monochromator $(\lambda=0.71073 \AA)$ at a temperature of $150(2) \mathrm{K}$ up to a resolution of $(\sin \theta / \lambda)_{\max }=0.65 \AA^{-1}$. Intensity integration was done with the Eval15 software ${ }^{[34]}$. A numerical absorption correction and scaling was performed with SADABS ${ }^{[35]}$ (correction range 0.34-0.80). A total of 20491 reflections was measured, 4670 reflections were unique $\left(\mathrm{R}_{\text {int }}=0.023\right), 4619$ reflections were observed $[\mathrm{I}>2 \sigma(\mathrm{I})]$. The structure was solved with Patterson methods using SHELXS ${ }^{[36]}$ and subsequently completed with Fourier methods. Structure refinement was performed with SHELXL-2018 ${ }^{[37]}$ on $\mathrm{F}^{2}$ of all reflections. Non-hydrogen atoms were refined freely with anisotropic displacement parameters. All hydrogen atoms were introduced in calculated positions and refined with a riding model. 273 Parameters were refined with one restraint (floating origin). R1/wR2 [I > $2 \sigma(\mathrm{I})$ ]: $0.0166 / 0.0419$. R1/wR2 [all refl.]: $0.0169 / 0.0420$. Flack parameter ${ }^{[38]} \mathrm{x}=0.005(4)$. $\mathrm{S}=1.036$. Residual electron density between -0.55 and $1.35 \mathrm{e} / \AA^{3}$. Geometry calculations and checking for higher symmetry was performed with the PLATON program. ${ }^{[39]}$

\section{$\mathrm{X}$-ray crystal structure determination of $c i s-\left[\left(\mathrm{BP}^{\mathrm{mdm}} \mathrm{MEN}^{\mathrm{N}}\right) \mathrm{ReO}_{2}\right] \mathrm{PF}_{6}$}

$\left[\mathrm{C}_{22} \mathrm{H}_{34} \mathrm{~N}_{4} \mathrm{O}_{4} \mathrm{Re}\right]\left(\mathrm{PF}_{6}\right) \cdot 0.5 \mathrm{CH}_{3} \mathrm{OH}, \mathrm{Fw}=765.72$, brown plate, $0.49 \times 0.18 \times 0.04 \mathrm{~mm}^{3}$, monoclinic, $\mathrm{P} 21 / \mathrm{n}$ (no. 14), $\mathrm{a}=14.4596(4), \mathrm{b}=7.9988(3), \mathrm{c}=24.5644(5) \AA, \beta=102.635(2)^{\circ}$, $\mathrm{V}=2772.30(13) \AA^{3}, \mathrm{Z}=4, \mathrm{D}_{\mathrm{x}}=1.835 \mathrm{~g} / \mathrm{cm}^{3}, \mu=4.52 \mathrm{~mm}^{-1}$. The diffraction experiment was performed on a Bruker Kappa ApexII diffractometer with sealed tube and Triumph monochromator $(\lambda=0.71073 \AA)$ at a temperature of $150(2) \mathrm{K}$ up to a resolution of $(\sin \theta / \lambda)_{\max }$ $=0.65 \AA^{-1}$. The crystal appeared to be twinned with a twofold rotation about $u v w=[1,0,1]$ as twin operation. Consequently, two orientation matrices were used for the integration with the 
Eval15 software ${ }^{[34]}$. A multiscan absorption correction and scaling was performed with TWINABS $^{[35]}$ (correction range 0.24-0.43). A total of 73003 reflections was measured, 6395 reflections were unique $\left(\mathrm{R}_{\text {int }}=0.044\right), 5825$ reflections were observed $[\mathrm{I}>2 \sigma(\mathrm{I})]$. The structure was solved with Patterson superposition methods using SHELXT. ${ }^{[40]}$ Structure refinement was performed with SHELXL-2018 ${ }^{[37]}$ on $\mathrm{F}^{2}$ of all reflections. Non-hydrogen atoms were refined freely with anisotropic displacement parameters. All hydrogen atoms were introduced in calculated positions and refined with a riding model. The $\mathrm{PF}_{6}$ anion was refined with a disorder model, and the methanol solvent molecule was disordered on an inversion center. 417 Parameters were refined with 529 restraints (distances, angles and displacement parameters of

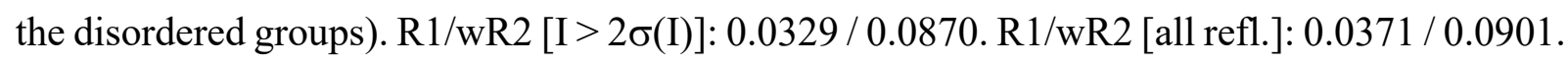
Twin fraction BASF $=0.1086(7) . \mathrm{S}=1.036$. Residual electron density between -2.46 and 2.44 $\mathrm{e} / \AA^{3}$. Geometry calculations and checking for higher symmetry was performed with the PLATON program. ${ }^{[39]}$

CCDC 1993918-1993919 contains the supplementary crystallographic data for this paper. These data can be obtained free of charge from The Cambridge Crystallographic Data Centre via www.ccdc.cam.ac.uk/data_request/cif.

\subsubsection{General procedure for catalytic deoxydehydration using $\mathrm{PhCl}$ as solvent}

Unless otherwise noted, all reaction mixtures were prepared inside a glovebox under nitrogen atmosphere in a $15 \mathrm{~mL}$ thick-walled glass pressure tube (Ace) fitted with a Teflon screw-cap. Diols (0.5 mmol), dioxorhenium complexes $(0.01 \mathrm{mmol}), \mathrm{PPh}_{3}(0.55 \mathrm{mmol})$, and mesitylene $(0.5 \mathrm{mmol})$ were dissolved in $\mathrm{PhCl}(5 \mathrm{~mL})$ and mixed well. Then, the closed reaction vessel was taken out of the glovebox and heated using a preheated silicone oil bath at $180{ }^{\circ} \mathrm{C}$. After reaction, an aliquot $(\sim 0.1 \mathrm{~mL})$ of the reaction mixture was taken, diluted with $\mathrm{CDCl}_{3}(\sim 0.4 \mathrm{~mL})$ and analyzed by ${ }^{1} \mathrm{H}$ NMR.

\subsubsection{General procedure for catalytic deoxydehydration using a secondary alcohol as solvent}

Unless otherwise noted, all reaction mixtures were prepared inside a Glove box under nitrogen atmosphere in a $15 \mathrm{~mL}$ thick-walled glass pressure tube (Ace) fitted with a Teflon screw-cap. Polyols $(0.5 \mathrm{mmol})$, dioxorhenium complexes $(0.01 \mathrm{mmol})$, and mesitylene $(0.5 \mathrm{mmol})$ were dissolved in secondary alcohol $(5 \mathrm{~mL})$ and mixed well. Then, the closed reaction vessel was 
brought into a preheated silicone oil bath at $180^{\circ} \mathrm{C}$. After reaction, an aliquot $(\sim 0.1 \mathrm{~mL})$ of the reaction mixture was taken, diluted with $\mathrm{CDCl}_{3}(\sim 0.4 \mathrm{~mL})$ and analyzed by ${ }^{1} \mathrm{H}$ NMR.

\section{4. ${ }^{1} \mathrm{H}$ NMR data for olefin products}

The intensity of the signals of the olefin products relative to aromatic signal of the mesitylene internal standard were used to calculate reaction yields (listed below). ${ }^{1} \mathrm{H}$ NMR peak of internal standard (mesitylene) (400 MHz, $\left.\mathrm{CDCl}_{3}\right): \delta 6.78$ (s, $3 \mathrm{H}$, used for calculations), $2.28(\mathrm{~s}, 9 \mathrm{H})$.

\begin{tabular}{|c|c|c|c|}
\hline entry & product & structure & ${ }^{1} \mathrm{H} \mathrm{NMR}\left(\mathrm{CDCl}_{3}, 400 \mathrm{MHz}\right)$ \\
\hline 1 & 1-octene & & $\begin{array}{c}\delta 1.00-0.81(\mathrm{~m}, 3 \mathrm{H}), 1.50-1.18 \\
(\mathrm{~m}, 8 \mathrm{H}), 2.11-1.98(\mathrm{~m}, 2 \mathrm{H}), \\
5.09-4.86(\mathrm{~m}, 2 \mathrm{H}), 5.82(\mathrm{ddt}, J \\
=16.9,10.2,6.7 \mathrm{~Hz}, 1 \mathrm{H}) .\end{array}$ \\
\hline 2 & 2,5-dihydrofuran & & $\delta 5.87(\mathrm{~s}, 2 \mathrm{H}), 4.62(\mathrm{~s}, 4 \mathrm{H})$. \\
\hline 3 & styrene & & $\begin{array}{c}\delta 5.22(\mathrm{dd}, J=10.9,0.9 \mathrm{~Hz}, 1 \mathrm{H}) \\
5.73(\mathrm{dd}, J=17.6,0.9 \mathrm{~Hz}, 1 \mathrm{H}), \\
6.70(\mathrm{dd}, J=17.6,10.9 \mathrm{~Hz}, 1 \mathrm{H}), \\
7.26-7.19(\mathrm{~m}, 1 \mathrm{H}), 7.34-7.27 \\
(\mathrm{~m}, 2 \mathrm{H}), 7.41-7.36(\mathrm{~m}, 2 \mathrm{H}) .\end{array}$ \\
\hline 4 & allyl alcohol & & $\begin{array}{l}\delta 4.10(\mathrm{~d}, J=5.1 \mathrm{~Hz}, 2 \mathrm{H}), 5.11 \\
(\mathrm{dd}, J=10.4,1.5 \mathrm{~Hz}, 1 \mathrm{H}), 5.25 \\
(\mathrm{dd}, J=17.2,1.7 \mathrm{~Hz}, 1 \mathrm{H}), 5.97 \\
(\mathrm{ddt}, J=17.0,10.2,5.1 \mathrm{~Hz}, 1 \mathrm{H}) .\end{array}$ \\
\hline 5 & 1,3-butadiene & & $\begin{array}{c}\delta 5.14-5.02(\mathrm{~m}, 2 \mathrm{H}), 5.26-5.15 \\
(\mathrm{~m}, 2 \mathrm{H}), 6.40-6.25(\mathrm{~m}, 2 \mathrm{H}) .\end{array}$ \\
\hline 6 & $\begin{array}{l}\text { 1,4-anhydrothreitol } \\
\text { (racemic) }\end{array}$ & & $\begin{array}{c}\delta 4.02(\mathrm{dd}, 2 \mathrm{H}, J=12 \mathrm{~Hz}, 8 \mathrm{~Hz}) \\
4.15(\mathrm{~m}, 2 \mathrm{H}), 3.76(\mathrm{~d}, J=10.0 \\
\mathrm{Hz}, 2 \mathrm{H})\end{array}$ \\
\hline 7 & $\begin{array}{l}\text { fumaric acid and } \\
\text { fumarates }\end{array}$ & & $\begin{array}{c}\delta 6.80(\mathrm{~s}, 2 \mathrm{H}), 6.82(\mathrm{~d}, J=0.8 \\
\mathrm{Hz}, 2 \mathrm{H}), 6.84(\mathrm{~s}, 2 \mathrm{H}) . \text { The } \\
\text { aliphatic part was overlapped by } \\
\text { the peak of solvent. }\end{array}$ \\
\hline
\end{tabular}




\begin{tabular}{|c|c|c|c|}
\hline 8 & muconates & $\begin{array}{c}\delta 6.41-6.09(\mathrm{~m}, 2 \mathrm{H}), 7.56-7.19 \\
(\mathrm{~m}, 2 \mathrm{H}) . \text { The aliphatic part was } \\
\text { overlapped by the peak of } \\
\text { solvent. }\end{array}$ \\
\hline
\end{tabular}

\subsection{References}

[1] T. A. Bender, J. A. Dabrowski, M. R. Gagné, Nat. Rev. Chem. 2018, 2, 35-46.

[2] T. J. Korstanje,; E. F. De Waard;; J. T. B. H. Jastrzebski,; R. J. M. Klein Gebbink, ACS Catal. 2012, 2, 2173-2181.

[3] M. Schlaf, Dalt. Trans. 2006, 4645-4653.

[4] L. L. Adduci, M. P. McLaughlin, T. A. Bender, J. J. Becker, M. R. Gagné, Angew. Chem. 2014, 126, 1672-1675; Angew. Chem. Int. Ed. 2014, 53, 1646-1649.

[5] S. Raju, M.-E. Moret, R. J. M. Klein Gebbink, ACS Catal. 2015, 5, 281-300.

[6] L. C. De Vicente Poutás, M. Castiñeira Reis, R. Sanz, C. S. López, O. N. Faza, Inorg. Chem. 2016, 55, 11372-11382.

[7] A. Galindo, Inorg. Chem. 2016, 55, 2284-2289.

[8] A. R. Petersen, L. B. Nielsen, J. R. Dethlefsen, P. Fristrup, ChemCatChem 2018, 10, 769-778.

[9] Y. Y. Jiang, J. L. Jiang, Y. Fu, Organometallics 2016, 35, 3388-3396.

[10] L. Hills, R. Moyano, F. Montilla, A. Pastor, A. Galindo, E. Álvarez, F. Marchetti, C. Pettinari, Eur. J. Inorg. Chem. 2013, 19, 3352-3361.

[11] J. R. Dethlefsen, D. Lupp, B.-C. Oh, P. Fristrup, ChemSusChem 2014, 7, 425-428.

[12] D. Lupp, N. J. Christensen, J. R. Dethlefsen, P. Fristrup, Chem. - A Eur. J. 2015, 21, 3435-3442.

[13] J. R.Dethlefsen, D. Lupp, A. Teshome, L. B. Nielsen, P. Fristrup, ACS Catal. 2015, 5, 3638-3647.

[14] K. Beckerle, A.Sauer, T. P.Spaniol, J. Okuda, Polyhedron 2016, 116, 105-110.

[15] M. Stalpaert, D. De Vos, ACS Sustain. Chem. Eng. 2018, 6, 12197-12204.

[16] C. A. Navarro, A. John, Inorg. Chem. Commun. 2019, 99, 145-148.

[17] R. Tran, S. M.Kilyanek, Dalt. Trans. 2019, 48, 16304-16311.

[18] J. R. Dethlefsen, P. Fristrup, ChemSusChem 2015, 8, 767-775.

[19] G. K. Cook, M. A. Andrews, J. Am. Chem. Soc. 1996, 118, 9448-9449.

[20] S. Raju, J. T. B. H. Jastrzebski, M. Lutz, R. J. M. Klein Gebbink, ChemSusChem 2013, 6, 1673-1680.

[21] J. Li, M. Lutz, M. Otte, R. J. M. Klein Gebbink, ChemCatChem 2018, 10, 4755-4760.

[22] S. M. Kilyanek, K. A. Denike, S. M. Kilyanek, R. Soc. open sci. 2019, 6, 1-16.

[23] S. Liu, A. Senocak, J. L. Smeltz, L.Yang, B. Wegenhart, J. Yi, H. I. Kenttämaa, E. A. Ison, M. M. Abu-Omar, Organometallics 2013, 32, 3210-3219.

[24] J. Michael McClain, K. M. Nicholas, ACS Catal. 2014, 4, 2109-2112.

[25] V. Y.-M. Ng, C.-W. Tse, X. Guan, X. Chang, C. Yang, K.-H. Low, H. K. Lee, J.-S. Huang, C.-M. Che, Inorg. Chem. 2017, 56 (24), 15066-15080.

[26] S. Raju, C. A. M. R. Van Slagmaat, J. Li, M. Lutz, J. T. B. H. Jastrzebski, M.-E. Moret, R. J. M. Klein Gebbink, Organometallics 2016, 35, 2178-2187. 
[27] D. S. Morris, K. Van Rees, M. Curcio, M. Cokoja, F. E. Kühn, F. Duarte, J. B. Love, Catal. Sci. Technol. 2017, 7, 5644-5649.

[28] Raju, S. 2015, PhD thesis, Utrecht University (the Netherlands)

[29] M. Shiramizu, F. D. Toste, Angew. Chem. 2012, 124, 8206-8210; Angew. Chem. Int. Ed. 2012, 51, 8082-8086.

[30] W. A. Herrmann, F. E. Kühn, Acc. Chem. Res. 1997, 30, 169-180.

[31] W. A. Herrmann, R. W. Fischer, J. Am. Chem. Soc. 1995, 117, 3223-3230.

[32] M. Lupacchini, A. Mascitti, V. Canale, L. Tonucci, E. Colacino, M. Passacantando, A. Marrone, N. d'Alessandro, Catal. Sci. Technol. 2019, 9, 3005-3296.

[33] J. Mukherjee, V. Balamurugan, R. Gupta, R. Mukherjee, Dalton Trans. 2003, 2, 36863692.

[34] A. M. M. Schreurs, X. Xian, L. M. J. Kroon-Batenburg. "EVAL15: a diffraction data integration method based on ab initio predicted profiles". J. Appl. Cryst. (2010). 43, 70-82.

[35] G. M. Sheldrick 2014. SADABS and TWINABS. Universität Göttingen, Germany.

[36] G. M. Sheldrick. Acta Cryst. 2008, A64, 112-122.

[37] G. M. Sheldrick. Acta Cryst. 2015, C71, 3-8.

[38] S. Parsons, H.D. Flack, T. Wagner. Acta Cryst. 2013, B69, 249-259.

[39] A. L. Spek. Acta Cryst. 2009, D65, 148-155.

[40] G. M. Sheldrick. Acta Cryst. 2015, A71, 3-8. 


\title{
Chapter 4
}

\section{A Cp-based Molybdenum Catalyst for the Deoxydehydration of Biomass-derived Diols}

\begin{abstract}
Dioxo-molybdenum complexes have been reported as catalyst for the deoxydehydration (DODH) of diols and polyols. In this work, we report on the DODH of diols using $\left[\mathrm{Cp}^{*} \mathrm{MoO}_{2}\right]_{2} \mathrm{O}$ as catalyst $\left(\mathrm{Cp}^{*}=1,2,3,4,5\right.$-pentamethylcyclopentadienyl). The DODH reaction was optimized using $2 \mathrm{~mol} \%$ of $\left[\mathrm{Cp}^{*} \mathrm{MoO}_{2}\right]_{2} \mathrm{O}, 1.1$ equiv. of $\mathrm{PPh}_{3}$ as reductant, and anisole as solvent. Aliphatic vicinal diols are converted to corresponding olefins with moderate yields by $\left[\mathrm{Cp}^{*} \mathrm{MoO}_{2}\right]_{2} \mathrm{O}$. Amongst these substrates, cis-1,2-cyclohexanediol, which is known as quite a challenging substrate in $\mathrm{Cp}^{\mathrm{ttt}} \mathrm{ReO}_{3}$-catalyzed $\mathrm{DODH}$, is converted to $30 \%$ of 1 -cyclohexene under optimized reaction conditions. Overall, the mass balances (up to 79\%) and TONs per Mo (up to) achievable with $\left[\mathrm{Cp}^{*} \mathrm{MoO}_{2}\right]_{2} \mathrm{O}$ are amongst the highest reported for molecular Mo-based DODH catalysts. A number of experiments aimed at providing insight in the reaction mechanism of $\left[\mathrm{Cp}^{*} \mathrm{MoO}_{2}\right]_{2} \mathrm{O}$ have led to the proposal of a new catalytic pathway in which the $\left[\mathrm{Cp}^{*} \mathrm{MoO}_{2}\right]_{2} \mathrm{O}$ catalyst is reduced in the inactive $\left[\mathrm{Cp}^{*} \mathrm{MoO}_{2}\right]_{2}$ dimer that is not catalytically competent, and an unidentified species that is catalytically competent.
\end{abstract}




\subsection{Introduction}

Deoxydehydration (DODH), known as a combination of deoxygenation and dehydration, provides an efficient means for removing vicinal hydroxyl groups from diols and polyols to form the corresponding olefins. ${ }^{[1]}$ DODH reactions allow for high oxygen-content starting materials, such as cellulosic biomass derivatives, to be converted into useful olefins. Next to a number of heterogeneous catalysts, soluble metal complexes based on rhenium, ${ }^{[1-4]}$ vanadium, ${ }^{[5-13]}$ and molybdenum, ${ }^{[14-21]}$ have been reported to catalyze the DODH of diols and polyols. In terms of activity and selectivity, rhenium complexes so far outperform homogeneous catalysts based on vanadium and molybdenum. However, the scarcity and high cost of rhenium asks for the availability of alternative catalysts based on less expensive and more abundant metals, such as Mo and V. It is for this reason that there is a current interest in the development of homogeneous catalysts derived from these latter metals for the DODH of (biomass-derived) diols and polyols.

For the homogeneous molybdenum-catalyzed DODH of diols and polyols, a relatively limited number of examples have been reported, ${ }^{[22]}$ mainly including the use of molybdate salts ${ }^{[15-17,21]}$ or dioxo-Mo(VI) complexes. ${ }^{[14,18-20]}$ Ammonium heptamolybdate $\left(\left(\mathrm{NH}_{4}\right)_{6} \mathrm{Mo}_{7} \mathrm{O}_{24}, \mathrm{AHM}\right)$, a commercially available molybdate salt, has been reported as a catalyst for the deoxydehydration of diols. The first example was reported by Fristrup and co-workers in $2014 .{ }^{[21]}$ Using $0.5 \mathrm{~mol} \%$ of AHM in a reactive distillation set-up, $16 \%$ of 1-hexene was formed as well as $5 \%$ of 2hexanone (dehydration product of 1,2-hexanediol) in neat 1,2-hexanediol, after heating the mixture at $190-220{ }^{\circ} \mathrm{C}$ until no more volatile products distilled. Under these conditions, 1,2hexanediol serves as substrate, solvent, as well as sacrificial reductant. Based on a density functional theory (DFT) study, the authors proposed a catalytic cycle that involves the condensation of two diols with a Mo(VI)-trioxo species to form an oxo-Mo(VI) bisdiolate intermediate, subsequent oxidative cleavage of one of the diolate ligands resulting in a reduced oxo-Mo(IV) monodiolate species, formaldehyde and an aldehyde (for example formaldehyde and pentanal through oxidative cleavage of 1,2-hexanediol), followed by a final olefin extrusion step that also forms back the trioxo-Mo(VI) species (Scheme 4.1.1, a). ${ }^{[17]}$ Operating through this proposed mechanism, this catalytic system forms carbonyl compounds either via the oxidative cleavage of a diol or via the dehydration of the diol. These carbonyl compounds can further react with the diol substrate to generate ketals (Scheme 4.1.2). For this reason, the olefin 
product selectivity of the DODH catalyzed by AHM will be substantially lower compared to the Re-catalyzed DODH of diols.

a.

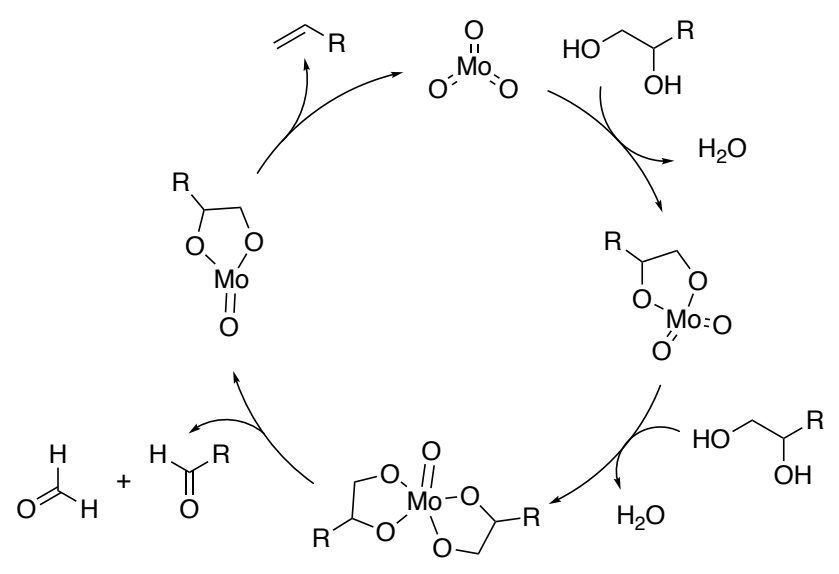

b.

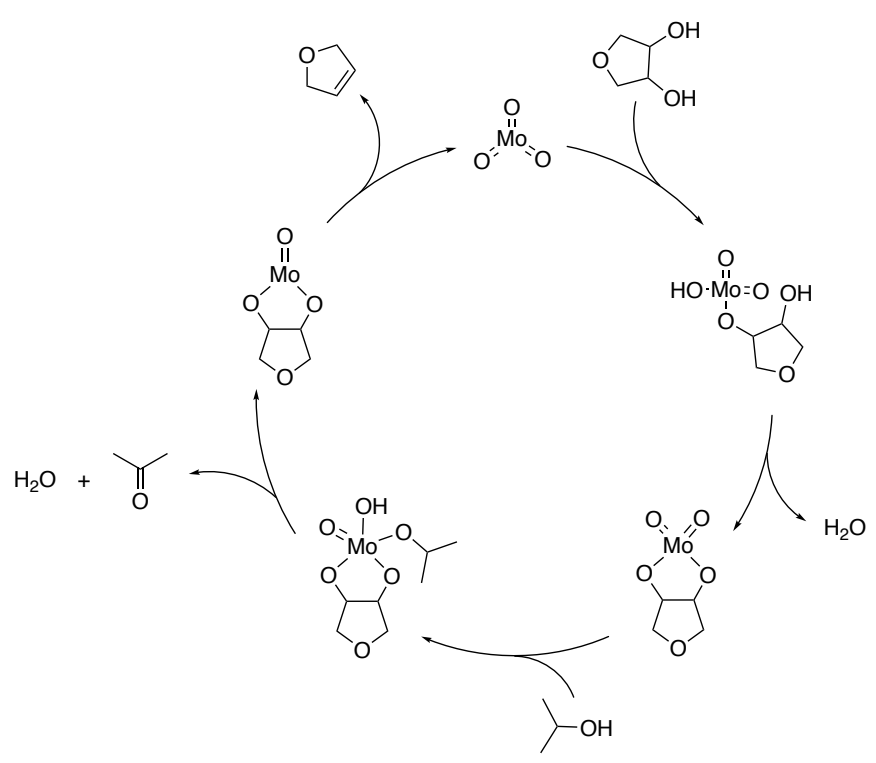

Scheme 4.1.1 Proposed catalytic cycles for AHM-catalyzed DODH of diols based on DFT studies: a. using the diol itself as reductant, ${ }^{[17]} \mathrm{b}$. using ${ }^{i} \mathrm{PrOH}$ as reductant. ${ }^{[16]}$

The secondary alcohol isopropanol was then used as the sacrificial reductant in the AHMcatalyzed deoxydehydration reaction. ${ }^{[16]}$ In this case, the reaction proceeded at $240-250{ }^{\circ} \mathrm{C}$ in a pressurized autoclave, and the olefin yield from simple aliphatic diols was as high as $77 \%$ when $\mathrm{Bu}_{4} \mathrm{NOH}$ was added to the reaction (46\% of 1-hexene was formed from 1,2-hexanediol when no base was applied). The authors claimed that the use of this particular base would not only affect the alkene yield but also change the product distribution. The use of a number of other bases did not lead to an overall improvement in catalysis, which the authors explained as a results of the high solubility of the $\left(\mathrm{Bu}_{4} \mathrm{~N}\right)_{2} \mathrm{MoO}_{4}$ salt, while other molybdate salts are quite 
insoluble. On the basis of DFT calculations, the reduction step under these conditions was found to be most favorable when both a diolate and an isopropoxide ion are coordinated to the molybdenum center (Scheme 4.1.1, b). The computed catalytic cycle consists of the condensation of the diol with $\mathrm{MoO}_{3}$ in two steps to form the dioxo-Mo(VI) diolate, followed by coordination of the isopropoxide and reduction to form an oxo-Mo(IV) diolate, water and acetone, and finally olefin extrusion. These calculations furthermore showed that the reduction of the metal center prior to extrusion of the alkene is rate-limiting under these conditions. Not only alcohols were investigated as reductant for AHM-catalyzed $\mathrm{DODH}, \mathrm{Na}_{2} \mathrm{SO}_{3}$ was also applied for this reaction. John and co-workers reported on the $\mathrm{Na}_{2} \mathrm{SO}_{3}$-mediated AHMcatalyzed DODH of diols using $5 \mathrm{~mol} \%$ of AHM as catalyst and 1.5 equiv. of $\mathrm{Na}_{2} \mathrm{SO}_{3}$ as reductant. This allowed for $23 \%$ formation of styrene from 1-phenylethane-1,2-diol. ${ }^{[21]}$ For all these AHM-catalyzed DODH systems, the TON per " $\mathrm{MoO}_{2}$ " unit was quite low, at maximum less than 5.

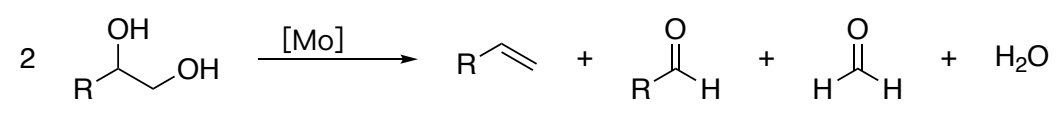

side reactions:

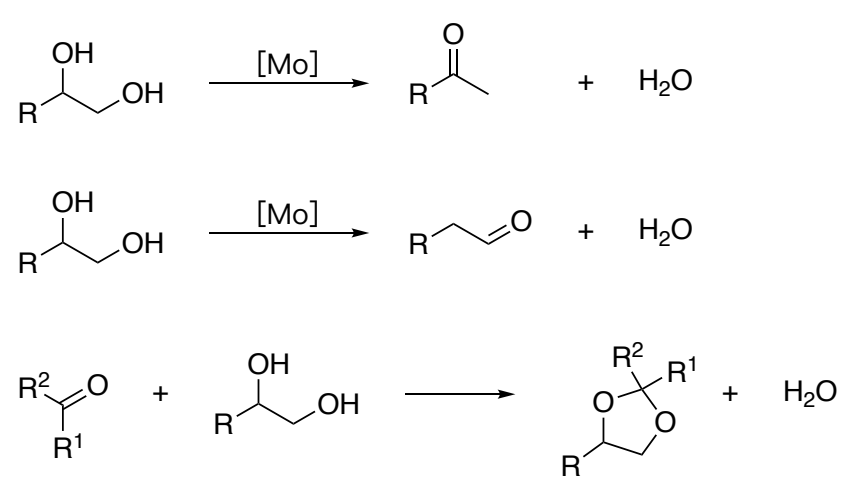

Scheme 4.1.2 Mo-catalyzed DODH of diols and side reactions observed when using the diol itself as sacrificial reductant. ${ }^{[15]}$

Only four examples have been reported of diol DODH catalyzed by ligand-supported " $\mathrm{MoO}_{2}$ " complexes. In 2013, a dioxo-Mo(VI) complex bearing an acylpyrazolonate ligand was reported as a DODH catalyst. ${ }^{[14]}$ This complex is able to form $10 \%$ of styrene from $60 \%$ conversion of 1-phenylethane-1,2-diol using a catalyst loading of $2 \mathrm{~mol} \%$ and 1.1 equiv. of $\mathrm{PPh}_{3}$ as the sacrificial reductant. The reaction can be carried out at a reaction temperature of only $110{ }^{\circ} \mathrm{C}$, which is quite low for a Mo-catalyzed DODH reaction. Octahedral dioxo-Mo(VI) complexes derived from (OSSO)-type bis(phenolate) ligands were reported as DODH catalyst precursors by Okuda and co-workers in 2016. ${ }^{[18]}$ 1,4-Anhydroerythritol was successfully converted into 2,5-dihydrofuran with $49 \%$ product yield and $89 \%$ substrate conversion using $5 \mathrm{~mol} \%$ of Mo 
Table 4.1.1 Soluble molybdenum-based catalysts and reductants in DODH catalysis.

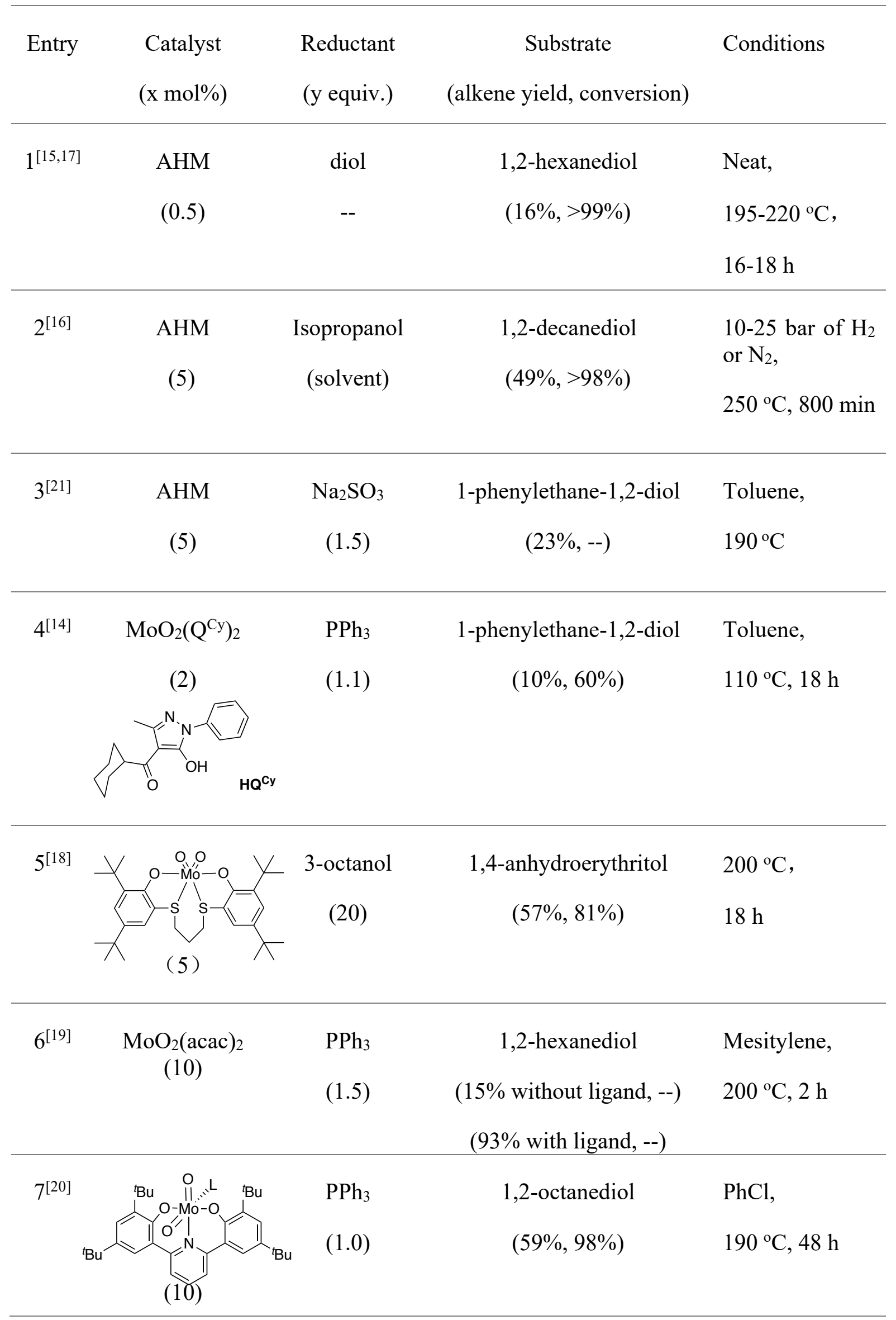


complex and 3-octanol as reductant within $1 \mathrm{~h}$ at $200{ }^{\circ} \mathrm{C}$ under microwave irradiation. According to the authors, microwave irradiation prevents the use of high reaction temperatures and long reaction times. Last year, $\mathrm{MoO}_{2}(\mathrm{acac})_{2}$ catalyzed DODH reactions were reported by De Vos et al. ${ }^{[19]}$ It was shown that the addition of the $\beta$-diketone 2,2,6,6tetramethylheptanedione (TMHDH) leads to a strong increase in yield of the desired olefin product. The excess amount of the diketone ligand (4.0 equiv. on basis of substrate) was claimed to stabilize the Mo complexes and inhibit catalyst decomposition through oligomerization of Mo, which is the proposed decomposition pathway of Mo DODH-catalysts. Very recently, Kilyanek et al. reported a dioxo-molybdenum complex supported by a dianionic ONO pincer ligand, which catalyzes the DODH of diols using $\mathrm{PPh}_{3}, \mathrm{Na}_{2} \mathrm{SO}_{3}, \mathrm{Zn}, \mathrm{C}$, 3-octanol or 2-propanol as reductant. ${ }^{[20]}$ For these ligand-supported " $\mathrm{MoO}_{2}$ " DODH catalysts similarly low TONs per " $\mathrm{MoO}_{2}$ " were found as for the AHM systems; the highest TON being around 9.

Table 4.1.1 summarizes the various approaches that have been reported toward the development of homogenous Mo-based DODH-catalysts, showing that there has not been a lot of activity in this research field. Next to the overall number of reported studies, in particular the number of ligands that have been applied in this field is rather limited, and does not extend beyond acylbased ligands, (OSSO)-type bis-phenolate ligands, and a dianionic ONO pincer-type ligand. From our experience in Re-catalyzed DODH-reactions, substituted cyclopentadienyl (Cp) ligands represent a versatile ligand platform for the development of different trioxo-Re complexes and their application in DODH-catalysis. ${ }^{[23-25]}$ Previous studies have shown that the catalytic properties of $\mathrm{CpReO}_{3}$ type complexes in DODH reactions are affected by modifications of the $\mathrm{Cp}$ ligand. We were therefore curious to investigate if the corresponding Cp-based Mo-complexes would also show catalytic activity towards the deoxydehydration of diols and polyols.

\subsection{Results and discussion}

\subsubsection{Initial catalyst screening}

For our studies on Cp-based molybdenum-oxo complexes in DODH catalysis, we have considered the use of a number of different complexes. The dinuclear oxo-bridged complex $\left[\mathrm{Cp}^{*} \mathrm{MoO}_{2}\right]_{2} \mathrm{O}^{[26]}$ was first reported by Herberhold and Thewalt et al. in 1985. ${ }^{[27]}$ This complex can be synthesized either by direct oxidation of suitable low-valent precursors (typically carbonyl-based precursors), or by hydrolysis of easily accessible high-valent precursors. ${ }^{[26]}$ This oxophilic complex has earlier been reported as a catalyst for the epoxidation of olefins. ${ }^{[28,29]}$ 
The new bulkier $\left[\mathrm{Cp}^{\mathrm{tt}} \mathrm{MoO}_{2}\right]_{2} \mathrm{O}$ complex, derived from the 1,3-di-tert-butylcyclopentadienyl ligand, was also synthesized according to a literature procedure starting from $\mathrm{Mo}(\mathrm{CO})_{6} \cdot{ }^{[30,31]}$ The substituted cyclopentadiene preligand $\mathrm{Cp}^{\mathrm{tt}} \mathrm{H}$ was refluxed with $\mathrm{Mo}(\mathrm{CO})_{6}$ in $p$-xylene overnight under nitrogen to form $\left[\mathrm{Cp}^{\mathrm{tt}} \mathrm{Mo}(\mathrm{CO})_{2}\right]_{2}$, which was oxidized by stirring under air for 3 days to obtain the target dinuclear $\left[\mathrm{Cp}^{\mathrm{tt}} \mathrm{MoO}_{2}\right]_{2} \mathrm{O}$ complex as yellow needle-like crystals. Recrystallization from $n$-hexane and diethyl ether at $-30{ }^{\circ} \mathrm{C}$ afforded crystals suitable for XRD. Previous work discussed above has shown that the active site of Mo-based DODH-catalysts is based on the " $\mathrm{MoO}_{2}$ " motif. Accordingly, these bridged $\mathrm{Cp}$-based $\mathrm{MoO}_{2}$ dimers could be interesting catalyst candidates for DODH reactions.

Besides, considering that the $\mathrm{Cp}$-based trioxo-rhenium catalysts are mononuclear species, the $\left[\mathrm{Cp}^{*} \mathrm{MoO}_{3}\right]^{-}$anion would be a close structural analogue of the CpRe-catalysts. On basis of a literature report, $\mathrm{NBu}_{4}\left[\mathrm{Cp}^{*} \mathrm{MoO}_{3}\right]$ was synthesized by slowly adding a $\mathrm{NBu} 4 \mathrm{OH}$ solution into a $\left[\mathrm{Cp}^{*} \mathrm{MoO}_{2}\right]_{2} \mathrm{O}$ solution in THF, to form colorless crystals of $\mathrm{NBu}_{4}\left[\mathrm{Cp}^{*} \mathrm{MoO}_{3}\right]$ after recrystallization in THF at $-30{ }^{\circ} \mathrm{C} .{ }^{[32]}$ In this case, it would be interesting to investigate which effect the difference in overall charge of the complex will have on catalytic activity. In addition, no trioxo-molybdenum complexes have so far been investigated for DODH reactions. Alternatively, the $\mathrm{Cp}$-based ligand could be replaced by a different and neutral $6 \mathrm{e}^{-}$spectator ligand, for example Mestacn (1,4,7-trimethyl-1,4,7-triazacyclononane). The complex $\left(\mathrm{Me}_{3} \operatorname{tacn}\right) \mathrm{MoO}_{3}$ has been synthesized on the basis of a literature procedure reported by McGowan et al. from 2001. ${ }^{[33]}$

Accordingly, we started our investigations on Mo-based DODH-catalysis by screening a number of reported Mo-complexes for their activity in the DODH reaction of 1,2-octanediol to form 1-octene, using $\mathrm{PPh}_{3}$ as the reductant and anisole as solvent. The reaction was performed at $200{ }^{\circ} \mathrm{C}$ under an $\mathrm{N}_{2}$ atmosphere for $15 \mathrm{~h}$ in a closed pressure tube with a catalyst loading of $4 \%$ based on $\mathrm{Mo}$ (Table 4.2.1). When $\left[\mathrm{Cp}^{*} \mathrm{MoO}_{2}\right]_{2} \mathrm{O}$ and $\left[\mathrm{Cp}^{\mathrm{tt}} \mathrm{MoO}_{2}\right]_{2} \mathrm{O}$ were used as catalyst, they gave almost the same 1-octene yield $(55 \%, 51 \%)$ at full substrate conversion (entries 1 and 2). For the corresponding mononuclear species, $\mathrm{NBu}_{4}\left[\mathrm{Cp}^{*} \mathrm{MoO}_{3}\right]$, the 1-octene yield was $38 \%$ at full substrate conversion (entry 3). Yet, changing catalyst to the trioxo-complex ( $\mathrm{Me}_{3}$ tacn) $\mathrm{MoO}_{3}$ gave a 1 -octene yield of only $9 \%$ at $38 \%$ of substrate conversion (entry 4 ). This observation suggests that the anionic $\mathrm{Cp}$-ligand is preferred over a neutral $6 \mathrm{e}^{-}$ligand like $\mathrm{Me}_{3}$ tacn in enabling DODH reactivity with Mo. Remarkably, when the commercially available $\mathrm{MoO}_{2}(\mathrm{acac})_{2}$ complex was applied under our reaction conditions, the 1-octene yield was $47 \%$ with full substrate conversion, which was also quite acceptable (entry 5). The commercially 
available AHM was also tested here and $38 \%$ of 1 -octene had formed from $87 \%$ of 1,2octanediol conversion (entry 6).

Table 4.2.1 Mo-catalyzed DODH of 1,2-octanediol with different Mo complexes. ${ }^{[\mathrm{a}]}$

\begin{tabular}{lllll}
\hline entry & {$[\mathrm{Mo}]$} & yield of 1 -octene $^{[\mathrm{b}]}$ & conversion $^{[\mathrm{b}]}$ & alkene selectivity \\
\hline 1 & {$\left[\mathrm{Cp}^{*} \mathrm{MoO}_{2}\right]_{2} \mathrm{O}$} & $55 \%$ & $>99 \%$ & $55 \%$ \\
2 & {$\left[\mathrm{Cp}^{\mathrm{tt}} \mathrm{MoO}_{2}\right]_{2} \mathrm{O}$} & $51 \%$ & $>99 \%$ & $51 \%$ \\
3 & $\mathrm{NBu}_{4}\left[\mathrm{Cp}^{*} \mathrm{MoO}_{3}\right]$ & $38 \%$ & $>99 \%$ & $38 \%$ \\
4 & $\left(\mathrm{Me}_{3}\right.$ tacn $) \mathrm{MoO}_{3}$ & $9 \%$ & $38 \%$ & $24 \%$ \\
5 & $\mathrm{MoO}_{2}(\mathrm{acac})_{2}$ & $47 \%$ & $>99 \%$ & $47 \%$ \\
6 & $\left(\mathrm{NH}_{4}\right)_{6} \mathrm{Mo}_{7} \mathrm{O}_{24} \cdot 4 \mathrm{H}_{2} \mathrm{O}$ & $38 \%$ & $87 \%$ & $44 \%$ \\
$7^{[\mathrm{cc}]}$ & {$\left[\mathrm{Cp}^{*} \mathrm{MoO}_{2}\right]_{2} \mathrm{O}$} & $38 \%$ & $>99 \%$ & $38 \%$ \\
$8^{[\mathrm{d}]}$ & {$\left[\mathrm{Cp}^{*} \mathrm{MoO}_{2}\right]_{2} \mathrm{O}$} & $38 \%$ & $>99 \%$ & $38 \%$ \\
\hline
\end{tabular}

[a] Reaction conditions: 1,2-octanediol ( $0.5 \mathrm{mmol}), \mathrm{PPh}_{3}$ ( $0.55 \mathrm{mmol}, 1.1$ equiv.), Mo complex ( $4 \mathrm{~mol} \%$ on the basis of Mo), anisole $(5 \mathrm{~mL}), 200{ }^{\circ} \mathrm{C}$ (temperature of oil bath), $15 \mathrm{~h}, \mathrm{~N}_{2}$, closed pressure tube. [b] Determined by gas chromatography using mesitylene $(0.5 \mathrm{mmol})$ as an internal standard. [c] $6 \mathrm{~mol} \%$ of $\mathrm{Bu}_{4} \mathrm{NOH}$ was added as a $1 \mathrm{M}$ solution of $\mathrm{Bu}_{4} \mathrm{NOH}$ in methanol. [d] Under aerobic conditions.

Among the molybdenum complexes we have tested, $\left[\mathrm{Cp}^{*} \mathrm{MoO}_{2}\right]_{2} \mathrm{O}$ gave the highest olefin yield as well as alkene product selectivity, but still not as high as in some rhenium-catalyzed DODH reactions. Since the use of $\mathrm{Bu}_{4} \mathrm{NOH}$ was reported to significantly improve the olefin yield for AHM-catalyzed DODH, ${ }^{[16]}$ we examined the effect of this additive. Yet, the use of $\mathrm{Bu}_{4} \mathrm{NOH}$ did not increase the olefin yield when $\left[\mathrm{Cp}^{*} \mathrm{MoO}_{2}\right]_{2} \mathrm{O}$ was used as catalyst (entry 7). The olefin yield and substrate conversion in this case were the same as when using $\mathrm{NBu}_{4}\left[\mathrm{Cp}^{*} \mathrm{MoO}_{3}\right]$ as the catalyst (entry 3 ). This result is in line with the visual changes while setting up the reaction: the reaction mixture changed color from bright yellow to colorless when adding $\mathrm{Bu}_{4} \mathrm{NOH}$, which indicates the in situ formation of $\mathrm{NBu}_{4}\left[\mathrm{Cp}^{*} \mathrm{MoO}_{3}\right]$. Furthermore, $38 \%$ of 1 -octene was formed when $\left[\mathrm{Cp}^{*} \mathrm{MoO}_{2}\right]_{2} \mathrm{O}$ was used as catalyst under aerobic condition (entry 8 ). This finding is suggestive of the formation of trioxo-molybdenum species under aerobic conditions. Last but not the least, $30 \%$ conversion of 1,2-octanediol was observed in the absence of any catalyst under the reaction conditions, albeit without olefin formation. This result indicates that thermal substrate degradation can take place to a substantial extent during the reaction. So far, we have not been able to track down which organic products form during this thermal reaction.

In conclusion, from all the Mo catalysts we have tested here, $\left[\mathrm{Cp}^{*} \mathrm{MoO}_{2}\right]_{2} \mathrm{O}$ gave the highest 1octene yield as well as alkene product selectivity. Accordingly, $\left[\mathrm{Cp}^{*} \mathrm{MoO}_{2}\right]_{2} \mathrm{O}$ was used in 
further optimization studies. Its higher reactivity compared to that of the mononuclear trioxo complex $\mathrm{NBu}_{4}\left[\mathrm{Cp}^{*} \mathrm{MoO}_{3}\right]$ could suggest that it operates via a dinuclear mechanism, instead of breaking up in monomeric entities during catalysis (vide infra). If so, the reactivity of $\left[\mathrm{Cp}^{*} \mathrm{MoO}_{2}\right]_{2} \mathrm{O}$ is significantly higher than that of $\mathrm{MoO}_{2}(\mathrm{acac})_{2}$ per catalytic entity. The low to moderate alkene product selectivity indicates that side reactions take place when using $\left[\mathrm{Cp}^{*} \mathrm{MoO}_{2}\right]_{2} \mathrm{O}$ as catalyst. Except 1-octene, 2,4-dihexyl-1,3-dioxolane and 2-heptyl-4-hexyl1,3-dioxolane were detected by GC and GC-MS (vide infra). These two products indicate the formation of 1-heptanal (oxidative $\mathrm{C}-\mathrm{C}$ bond cleavage product of 1,2-octanediol) and 1-octanal (dehydration product of 1,2-octanediol). Accordingly, the side reactions for AHM-catalyzed DODH reaction described by Fristrup ${ }^{[15]}$ also take place for the $\left[\mathrm{Cp}^{*} \mathrm{MoO}_{2}\right]_{2} \mathrm{O}$ catalyst. In addition, triphenylphosphine oxide $\left(\mathrm{OPPh}_{3}\right)$ was also detected by $\mathrm{GC}$ and GC-MS, which indicates that $\mathrm{PPh}_{3}$ can also act as reductant for this catalyst. Accordingly, both $\mathrm{PPh}_{3}$ and 1,2octanediol may act as the reductant in the deoxydehydration of 1,2-octanediol by $\left[\mathrm{Cp}^{*} \mathrm{MoO}_{2}\right]_{2} \mathrm{O}$.

\subsubsection{Solvent screening}

Continuing, different solvents were investigated in the DODH reaction of 1,2-octanediol with $\left[\mathrm{Cp}^{*} \mathrm{MoO}_{2}\right]_{2} \mathrm{O}$ as catalyst (Table 4.2.2). Under neat conditions, $26 \%$ of 1 -octene formed at $35 \%$ substrate conversion and an alkene product selectivity of $74 \%$ (entry 1 ). When substituted benzenes were used as the solvent, the 1-octene yield varied from $36 \%$ to $65 \%$ (entries $2-10$ ), while very high substrate conversions of $>90 \%$ could be reached for several solvents. The highest 1 -octene yield (65\%) was obtained by using $m$-dichlorobenzene as the solvent (entry 4), while the highest alkene selectivity (91\%) was achieved by using 1,2,4-trichlorobenzene as solvent (entry 7). In the latter solvent, a somewhat lower substrate conversion of $44 \%$ was found after a reaction time of $15 \mathrm{~h}$. In order to reach higher substrate conversion in this solvent, the reaction time was prolonged to $30 \mathrm{~h}$, which gave an overall conversion of $59 \%$ and a 1 -octene yield of $52 \%$, leading to a slightly decreased alkene product selectivity of $88 \%$ (entry 12 ). This result indicates that catalyst decomposition is likely to occur during prolonged reaction times. When either anisole or mesitylene were used as the reaction solvent, full substrate conversion resulted in 55\% and 52\% 1-octene yield, respectively (entries 9 and 10).

Although the halogenated benzene solvents $m$-dichlorobenzene and 1,2,4-trichlorobenzene gave the highest alkene yield and the highest alkene selectivity, respectively, these solvents were disregarded in our further catalytic studies because of the implications of their high halogen-content on practical applications. Alternatively, the Innovative Medicines Initiative (IMI)-Chem21, a public-private partnership of pharmaceutical companies, universities and 
small-to-medium enterprises supporting research into sustainable pharmaceuticals manufacturing (http://www.chem21.eu/), has listed anisole as a recommended solvent on the basis of safety $(\mathrm{S})$, occupational health $(\mathrm{H})$, environment $(\mathrm{E})$, quality (risk of impurities in the drug substance), industrial constraints (e.g. boiling point, freezing temperature, density, recyclability), and cost. ${ }^{[34,35]}$ Accordingly, we set out to evaluate anisole as the solvent of choice for further catalyst optimization.

Table 4.2.2 $\left[\mathrm{Cp}^{*} \mathrm{MoO}_{2}\right]_{2} \mathrm{O}$-catalyzed DODH of 1,2-octanediol in different solvents. ${ }^{[\mathrm{a}]}$

\begin{tabular}{llllll}
\hline entry & solvent & yield $^{[\mathrm{b}]}$ & conversion $^{[\mathrm{c}]}$ & selectivity $^{[\mathrm{e}]}$ & b.p. of solvent \\
\hline 1 & -- & $26 \%$ & $35 \%$ & $74 \%$ & - \\
2 & $\mathrm{PhCl}]$ & $37 \%$ & $94 \%$ & $39 \%$ & $132{ }^{\circ} \mathrm{C}$ \\
3 & toluene & $36 \%$ & $95 \%$ & $38 \%$ & $111^{\circ} \mathrm{C}$ \\
4 & $m$-dichlorobenzene & $65 \%$ & $92 \%$ & $70 \%$ & $172-173{ }^{\circ} \mathrm{C}$ \\
5 & $o$-dichlorobenzene & $46 \%$ & $70 \%$ & $66 \%$ & $178-180{ }^{\circ} \mathrm{C}$ \\
6 & $p$-xylene & $36 \%$ & $97 \%$ & $40 \%$ & $138{ }^{\circ} \mathrm{C}$ \\
7 & trichlorobenzene & $40 \%$ & $44 \%$ & $91 \%$ & $214{ }^{\circ} \mathrm{C}$ \\
8 & ${ }^{t}$ BuPh & $39 \%$ & $82 \%$ & $48 \%$ & $169{ }^{\circ} \mathrm{C}$ \\
9 & anisole & $55 \%$ & $>99 \%$ & $55 \%$ & $154{ }^{\circ} \mathrm{C}$ \\
$10^{[\mathrm{d}]}$ & mesitylene & $52 \%$ & $>99 \%$ & $52 \%$ & $163-166{ }^{\circ} \mathrm{C}$ \\
11 & sulfolane & $5 \%$ & $28 \%$ & $18 \%$ & $285{ }^{\circ} \mathrm{C}$ \\
$12^{[\mathrm{g}]}$ & trichlorobenzene & $52 \%$ & $59 \%$ & $88 \%$ & $214{ }^{\circ} \mathrm{C}$ \\
\hline
\end{tabular}

[a] Reaction conditions: 1,2-octanediol (0.5 mmol), $\mathrm{PPh}_{3}$ (0.55 mmol, 1.1 equiv.), [Cp $\left.{ }^{*} \mathrm{MoO}_{2}\right]_{2} \mathrm{O}(0.01$ mmol, $2 \mathrm{~mol} \%$ ), solvent ( $5 \mathrm{~mL}$ ), $200{ }^{\circ} \mathrm{C}$ (temperature of oil bath), $15 \mathrm{~h}, \mathrm{~N}_{2}$, closed pressure tube. [b] Yield of 1-octene, determined by gas chromatography using mesitylene $(0.5 \mathrm{mmol})$ as an internal standard. [c] Determined by gas chromatography using mesitylene $(0.5 \mathrm{mmol})$ as an internal standard. [d] Determined by ${ }^{1} \mathrm{H}$ NMR using dibromomethane $(0.5 \mathrm{mmol})$ as an internal standard. [e] Alkene product selectivity. [f] All solvents were purchased from Sigma-Aldrich, boiling points are reported on the basis of corresponding Safety Data Sheet. [g] Reaction time: $30 \mathrm{~h}$.

\subsubsection{Reductant screening}

As mentioned above, both $\mathrm{PPh}_{3}$ and 1,2-octanediol can act as sacrificial reductant in the DODH reaction catalyzed by $\left[\mathrm{Cp}^{*} \mathrm{MoO}_{2}\right]_{2} \mathrm{O}$. In order to enhance the formation of 1-octene, both the dehydration of 1,2-octanediol and the oxidative cleavage of 1,2-octanediol should be limited. The use of a more competitive reductant will then benefit alkene formation. Different reducing agents were tested for the DODH-reaction of 1,2-octanediol with $\left[\mathrm{Cp}^{*} \mathrm{MoO}_{2}\right]_{2} \mathrm{O}$ as the catalyst 
(Table 4.2.3). Interestingly, when the more reducing $\mathrm{P}^{n} \mathrm{Bu}_{3}$ was used as reductant, a lower 1octene yield (39\%) was obtained compared to the use of $\mathrm{PPh}_{3}$ (entries 1 and 2). The less reducing triethylphosphite gave a low $9 \%$ yield, albeit at full substrate conversion (entry 3 ). The use of indoline, $\mathrm{Na}_{2} \mathrm{SO}_{3}, 3$-octanol, or zinc powder as reductant gave 1-octene yields in the range of 20-32\%. Without an additional reductant, i.e. only using the diol itself as reductant, $18 \%$ of 1 -octene was formed (entry 8 ). Considering that the maximum yield of 1 -octene is $50 \%$ in this case, the alkene product selectivity was $36 \%$. On the basis of these findings, $\mathrm{PPh}_{3}$ was selected as the reductant for further studies.

Table 4.2.3 $\left[\mathrm{Cp}^{*} \mathrm{MoO}_{2}\right]_{2} \mathrm{O}$-catalyzed DODH of 1,2-octanediol with different reductants. ${ }^{[\mathrm{a}]}$

\begin{tabular}{lllll}
\hline entry & reductants & yield of 1-octene & conversion & alkene selectivity \\
\hline 1 & $\mathrm{PPh}_{3}$ & $55 \%$ & $>99 \%$ & $55 \%$ \\
2 & $\mathrm{P}^{n} \mathrm{Bu}_{3}$ & $39 \%$ & $>99 \%$ & $39 \%$ \\
3 & $\mathrm{P}(\mathrm{OEt})_{3}$ & $9 \%$ & $>99 \%$ & $9 \%$ \\
4 & indoline & $26 \%$ & $77 \%$ & $34 \%$ \\
5 & $\mathrm{Na}_{2} \mathrm{SO}_{3}$ & $24 \%$ & $98 \%$ & $24 \%$ \\
$6^{[\mathrm{c}]}$ & 3 -octanol & $20 \%$ & $76 \%$ & $26 \%$ \\
7 & $\mathrm{Zn}$ & $32 \%$ & $94 \%$ & $34 \%$ \\
8 & 1,2 -octanediol & $18 \%$ & $>99 \%$ & $36 \%$ \\
\hline
\end{tabular}

[a] Reaction conditions: 1,2-octanediol $(0.5 \mathrm{mmol})$, reductant $(0.55 \mathrm{mmol}, 1.1$ equiv. $),\left[\mathrm{Cp}^{*} \mathrm{MoO}_{2}\right]_{2} \mathrm{O}$ (0.01 mmol, $2 \mathrm{~mol} \%$ ), anisole $(5 \mathrm{~mL}), 200{ }^{\circ} \mathrm{C}, 15 \mathrm{~h}, \mathrm{~N}_{2}$, closed pressure tube. [b] Determined by gas chromatography using mesitylene $(0.5 \mathrm{mmol})$ as an internal standard. [c] 3-Octanol $(5 \mathrm{~mL})$ was used as solvent instead of anisole.

For most of the above reactions, very high substrate conversions were observed, indicating that other products than 1-octene dominate for most reducing agents. As summarized in Table 4.1.1, this phenomenon is not only observed for our Cp-based molybdenum system. Without excess amount of ligand or additives, low to moderate alkene product selectivities are typically obtained for Mo-catalysts. The use of excesses of organic ligands has been found to affect the alkene product selectivity. In case of the $\mathrm{MoO}_{2}(\mathrm{acac})_{2}$-catalyzed DODH of 1,2-hexanediol, the yield of 1-hexene dramatically increased when 40 equiv. of TMHDH (on the basis of $\left.\mathrm{MoO}_{2}(\mathrm{acac})_{2}\right)$ were added. The alkene product selectivity was $93 \%$ and the TON per Mo was 9. ${ }^{[19]}$ By tuning the ligand on molybdenum increased alkene product selectivities can also be obtained. The alkene product selectivity is $70 \%$ with (OSSO)-type bis-phenolate ligands in the DODH of 1,4-anhydroerythritol, and $60 \%$ with a dianionic ONO pincer-type ligand in the DODH of 1,2-octanediol. The TON per Mo in these cases is 11 and 6, respectively. ${ }^{[18,20]}$ In our 
case, the application of the $\mathrm{Cp}^{*}$ ligand also gives a quite good alkene product selectivity (55\%) and TON per Mo (14).

\subsubsection{Reaction temperature investigation}

Given the fact that full substrate conversions were observed in many of the reactions described in Tables 4.2.1-4.2.3, the high reaction temperature that was employed could be the reason for the lower alkene product selectivities. Accordingly, different reaction temperatures were investigated (Table 4.2.4). No conversion was obtained at temperatures below $170{ }^{\circ} \mathrm{C}$. When the reaction was performed at $170{ }^{\circ} \mathrm{C}$, only $9 \%$ of 1 -octene was formed while the substrate conversion was also $9 \%$, which means that the alkene product selectivity was $100 \%$ albeit at a TON per Mo of only 2 . When the reaction temperature was increased to $185^{\circ} \mathrm{C}$, the 1 -octene yield increased from $9 \%$ to $13 \%$, while the 1,2-octanediol conversion increased from $9 \%$ to $36 \%$, so the alkene product selectivity dropped dramatically from $100 \%$ to $36 \%$. When the reaction temperature was further raised to $190{ }^{\circ} \mathrm{C}$, the 1 -octene yield was $24 \%$, the $1,2-$ octanediol conversion was $62 \%$, and the alkene product selectivity of $39 \%$ was very close to the one at $185{ }^{\circ} \mathrm{C}$. At an elevated reaction temperature of $225^{\circ} \mathrm{C}$, the same 1-octene yield was achieved compared to the reaction carried out at $200{ }^{\circ} \mathrm{C}$. All the reactions described here were performed in a closed pressure tube and the temperatures are based on the temperature of the oil bath, which means neither the actual temperature nor the pressure in the reaction tube could be monitored in this experimental setup.

Table 4.2.4 $\left[\mathrm{Cp}^{*} \mathrm{MoO}_{2}\right]_{2} \mathrm{O}$-catalyzed DODH of 1,2-octanediol at different temperatures. ${ }^{[\mathrm{a}]}$

\begin{tabular}{lllll}
\hline entry & temperatures & yield of 1-octene ${ }^{[\mathrm{b}]}$ & conversion $^{[\mathrm{b}]}$ & alkene selectivity \\
\hline 1 & $170{ }^{\circ} \mathrm{C}$ & $9 \%$ & $9 \%$ & $100 \%$ \\
2 & $185^{\circ} \mathrm{C}$ & $13 \%$ & $36 \%$ & $36 \%$ \\
3 & $190^{\circ} \mathrm{C}$ & $24 \%$ & $62 \%$ & $39 \%$ \\
4 & $200{ }^{\circ} \mathrm{C}$ & $55 \%$ & $>99 \%$ & $55 \%$ \\
$\mathbf{5}$ & $225^{\circ} \mathrm{C}$ & $55 \%$ & $>99 \%$ & $55 \%$ \\
\hline
\end{tabular}

[a] Reaction conditions: 1,2-octanediol (0.5 mmol), $\mathrm{PPh}_{3}\left(0.55 \mathrm{mmol}, 1.1 \text { equiv.), [Cp }{ }^{*} \mathrm{MoO}_{2}\right]_{2} \mathrm{O}(0.01$ mmol, $2 \mathrm{~mol} \%)$, anisole $(5 \mathrm{~mL}), 15 \mathrm{~h}, \mathrm{~N}_{2}$, in closed pressure tube. [b] Determined by gas chromatography using mesitylene $(0.5 \mathrm{mmol})$ as an internal standard.

Table 4.2.4. clearly shows that an oil bath temperature of $200{ }^{\circ} \mathrm{C}$ is most optimal under the current reaction conditions. Comparing entry 4 and entry 5 , olefin formation more than doubled 
by a $10{ }^{\circ} \mathrm{C}$ change in temperature. Moreover, the alkene product selectivity increased when the temperature was increased from $190{ }^{\circ} \mathrm{C}$ to $200{ }^{\circ} \mathrm{C}$. An explanation for the latter observation could be that ketal formation during the reaction is reversible and that ketal formation is less favored at higher temperatures. Accordingly, a control experiment was done by using the ketal as substrate, but no ketal conversion was observed (Scheme 4.2.1), likely due to the lack of water in this control experiment. Water is required in the diol-ketal equilibrium to form the diol from the ketal.

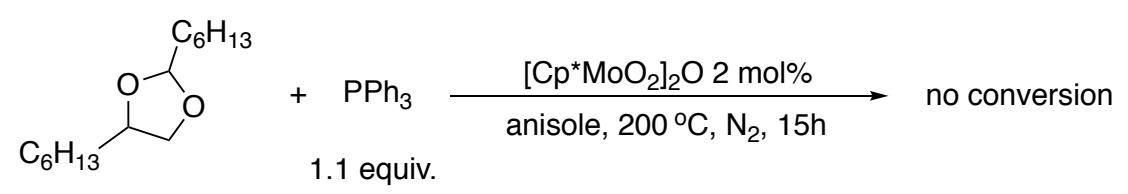

Scheme 4.2.1 Use of 2,4-dihexyl-1,3-dioxolane as a DODH substrate to form 1-octene.

\subsubsection{Mass balance investigation}

As mentioned before, poor to moderate alkene product selectivities are generally obtained for Mo-catalyzed DODH reactions. For these reactions, it is believed that reduction of Mo via oxoabstraction and via deformylation are competitive, ${ }^{[20]}$ which could explain why the alkene product selectivity is not very high. Also, it is known from literature that dehydration of the diol takes place in Mo-catalyzed DODH reactions as side-reaction, forming ketone and aldehyde byproducts. ${ }^{[15,16]}$ Furthermore, ketals can be formed as by-products in reactions where carbonyl compounds are formed (Scheme 4.1.2). For our $\left[\mathrm{Cp}^{*} \mathrm{MoO}_{2}\right]_{2} \mathrm{O}$-catalyzed DODH reactions, ketals were indeed detected by a combined GC and GC-MS analysis (Table 4.2.5), which is in line with findings by the Fristrup group. ${ }^{[15]}$ Two different ketals actually formed during these reaction: one derived from 1,2-octanediol and heptanal (the oxidative cleavage product of 1,2-octanediol) and one derived from 1,2-octanediol and octanal (the dehydration product of 1,2-octanediol).

In order to increase the alkene product selectivity, or to avoid the formation of by-products, several bases were tested by Fristrup and co-workers. The use of $\mathrm{Bu}_{4} \mathrm{NOH}$ did significantly increase the yield of olefin as well as change the distribution of products for the AHM catalyst. ${ }^{16}$ We did also use $\mathrm{Bu}_{4} \mathrm{NOH}$ as an additive for our reaction system, but did not notice an increase in the olefin yield (Table 4.2.1, entry 7). However, the use of $\mathrm{Bu}_{4} \mathrm{NOH}$ seems to change the distribution of product and by-products (Table 4.2.5, entry 3). Most importantly, less formation 
of 1-octene was noticed after applying this base (from 55\% to 38\%). In addition, there are some differences in the product distribution between directly using $\mathrm{NBu}_{4}\left[\mathrm{Cp}^{*} \mathrm{MoO}_{3}\right]$ as catalyst and forming $\mathrm{NBu}_{4}\left[\mathrm{Cp}^{*} \mathrm{MoO}_{3}\right]$ in situ, i.e. by applying a slight excess amount of base (compare Table 4.2.5, entries 2 and 3). It seems that less diol dehydration occurs, leading to a different ketal distribution; 1-octene formation is the same though in these cases. Based on the ratio of different ketals formed, we are not able to distinct the operation of a dinuclear catalyst from that of a mononuclear catalyst, even though a significantly higher amount of olefin is formed when starting from a dinuclear catalysis.

Table 4.2.5 Product profile in the DODH of 1,2-octanediol using different Mo catalysts. ${ }^{\text {[a] }}$

\begin{tabular}{llcccll}
\hline entry & {$[\mathrm{Mo}]$} & 1 -octene & & & & \\
& & & & & \\
\hline 1 & {$\left[\mathrm{Cp}^{*} \mathrm{MoO}_{2}\right]_{2} \mathrm{O}$} & $55 \%$ & $6 \%$ & $6 \%$ & $>99 \%$ & $79 \%$ \\
2 & $\mathrm{NBu}_{4}\left[\mathrm{Cp}^{*} \mathrm{MoO}_{3}\right]$ & $38 \%$ & $7 \%$ & $8 \%$ & $>99 \%$ & $68 \%$ \\
$3^{[\mathrm{b}]}$ & {$\left[\mathrm{Cp}^{*} \mathrm{MoO}_{2}\right]_{2} \mathrm{O}$} & $38 \%$ & $11 \%$ & $4 \%$ & $>99 \%$ & $68 \%$ \\
\hline
\end{tabular}

[a] Reaction conditions: 1,2-octanediol (0.5 mmol), $\mathrm{PPh}_{3}$ (0.55 mmol, 1.1 equiv.), [Mo] (4 mol\% on basis of Mo atom), anisole $(5 \mathrm{~mL}), 200{ }^{\circ} \mathrm{C}, 15 \mathrm{~h}, \mathrm{~N}_{2}$, closed pressure tube. Products were determined by gas chromatography using mesitylene $(0.5 \mathrm{mmol})$ as an internal standard. [b] $6 \mathrm{~mol} \%$ of $\mathrm{Bu}_{4} \mathrm{NOH}$ was added as a $1 \mathrm{M}$ solution of $\mathrm{Bu}_{4} \mathrm{NOH}$ in methanol. [c] mass balance $=\left(\left[\right.\right.$ yield ${ }_{(1-\text { octene })}+2 *$ yield ${ }_{(2,4-\text { dihexyl- }}$ 1,3-dioxolane $)+2 *$ yield $_{(2-\text { heptyl-4-hexyl-1,3-dioxolane })}$ / conversion) $* 100 \%$.

The quantification of ketal by-products provides a clearer view of the overall mass balance of these reactions. Although far from being perfect, a mass balance close to $80 \%$ was found for the $\left[\mathrm{Cp}^{*} \mathrm{MoO}_{2}\right]_{2} \mathrm{O}$ catalyst. Since we observed $30 \%$ of 'thermal' 1,2-octanediol conversion, i.e. in the absence of catalyst, the observed mass balances are quite acceptable. Last but not least, 2-octanone, i.e. the dehydration product of 1,2-octanediol, was difficult to detect because of peak overlap with solvent in the GC spectra. On the basis of Fristrup's work, an approximately equal amount of 2-decanone (detected as 2-decanone and 2-decanol) and decanal (detected as 1-decanol) was obtained. ${ }^{[16]}$ This result suggests that not only octanal but also 2-octanone will form from 1,2-octanediol while using a Mo-based catalyst.

\subsubsection{Substrate scope}

Next, the substrate scope of the $\left[\mathrm{Cp}^{*} \mathrm{MoO}_{2}\right]_{2} \mathrm{O}$ catalyst was investigated by applying different diols to the optimized reaction conditions. Both linear and cyclic aliphatic diols were tested 
(Table 4.2.6). In the case of linear diols, when 1,2-hexanediol was used as substrate, the 1hexene yield was only $22 \%$ (entry 3 ). Considering 1 -hexene is quite a volatile chemical, we assume that the actual yield of 1-hexene could be higher. Other aliphatic diols with longer carbon chain lengths, such as 1,2-decanediol and 1,2-dodecanediol, were therefore tested (entry 4 and 5). The yield of 1-decene and 1-dodecene in these cases is very close to the olefin yield obtained from 1,2-octanediol under the same reaction conditions (55\%). When cis-1,2cyclohexanediol and cis-1,2-cyclooctanediol were used as substrate, the corresponding olefin yield was $36 \%$ and $30 \%$, respectively. Remarkably, for the $\mathrm{Cp}^{\mathrm{ttt}} \mathrm{ReO}_{3}$-catalyzed DODH of cis1,2-cyclohexanediol, only $10 \%$ of 1 -cyclohexene is formed. ${ }^{[23]}$ In case of using 1,4anhydroerythritol as substrate, only $5 \%$ of 2,5-dihydrofuran was formed, mainly because of the poor solubility of 1,4-anhydroerythritol in anisole.

Table 4.2.6 $\left[\mathrm{Cp}^{*} \mathrm{MoO}_{2}\right]_{2} \mathrm{O}$-catalyzed DODH of diols using $\mathrm{PPh}_{3}$ as reductant. ${ }^{[\mathrm{a}]}$

\begin{tabular}{|c|c|c|c|c|}
\hline entry & diol & yield of alkene ${ }^{[b]}$ & conversion $^{[\mathrm{b}]}$ & alkene selectivity \\
\hline 1 & & $36 \%$ & $93 \%$ & $39 \%$ \\
\hline 2 & & $30 \%$ & $>99 \%$ & $30 \%$ \\
\hline 3 & & $22 \%$ & $>99 \%$ & $22 \%$ \\
\hline 4 & & $56 \%$ & $>99 \%$ & $56 \%$ \\
\hline 5 & & $51 \%$ & $>99 \%$ & $51 \%$ \\
\hline 6 & & $47 \%$ & $>99 \%$ & $47 \%$ \\
\hline 7 & & $5 \%$ & -- & -- \\
\hline 8 & & -- & -- & -- \\
\hline
\end{tabular}

[a] Reaction conditions: diol (0.5 mmol), $\mathrm{PPh}_{3}\left(0.55 \mathrm{mmol}, 1.1 \text { equiv.), [Cp }{ }^{*} \mathrm{MoO}_{2}\right]_{2} \mathrm{O}(0.01 \mathrm{mmol}, 2$ mol\%), anisole $(5 \mathrm{~mL}), 15 \mathrm{~h}, \mathrm{~N}_{2}$, closed pressure tube. [b] Determined by gas chromatography using mesitylene $(0.5 \mathrm{mmol})$ as an internal standard. 
In short, the $\left[\mathrm{Cp}^{*} \mathrm{MoO}_{2}\right]_{2} \mathrm{O}$ catalyst system can be applied to the deoxydehydration of linear and cyclic aliphatic diols to form the corresponding olefins with moderate yields. Attempts to extend the substrate scope to aromatic diols lead to $47 \%$ of styrene formation when starting from 1-phenyl-1,2-ethanediol, but in case of $(1 R, 2 R)$-1,2-diphenylethane-1,2-diol and ( $1 R, 2 S)$ 1,2-diphenylethane-1,2-diol as substrate, only benzaldehyde was formed as a detectable product. This observation indicates that Mo-catalyzed cleavage of aromatic diols apparently outperforms DODH pathways. ${ }^{[36]}$

Additionally, biomass-derived glycerol was investigated under the optimized reaction conditions (entry 8). No allyl alcohol was detected, likely due to the poor solubility of glycerol in anisole. No glycerol was dissolved in anisole during the reaction while $\left[\mathrm{Cp}^{*} \mathrm{MoO}_{2}\right]_{2} \mathrm{O}$ did completely dissolve, resulting in a biphasic mixture during the reaction. Normally, a color changing from bright yellow to yellow-orange and ending with light brown was observed for this $\left[\mathrm{Cp}^{*} \mathrm{MoO}_{2}\right]_{2} \mathrm{O}$-catalyzed DODH. But in case of the reaction with glycerol, the anisole phase containing the catalyst maintained a bright yellow color, which indicated that no catalysis took place in this case. Neat conditions were also applied to this reaction, i.e. glycerol was explored as solvent, substrate, and reductant. $\left[\mathrm{Cp}^{*} \mathrm{MoO}_{2}\right]_{2} \mathrm{O}$ did dissolve in glycerol at higher temperatures, but because of the reflux of glycerol in the top part of the reaction tube, a black residue was obtained in the bottom of the reaction tube without formation of allyl alcohol.

\subsubsection{Mechanistic Considerations}

The above study shows that the $\left[\mathrm{Cp}^{*} \mathrm{MoO}_{2}\right]_{2} \mathrm{O}$ complex can be used as a catalyst for the DODH of aliphatic diols using $\mathrm{PPh}_{3}$ as reductant. In previous work of our group on related Re-based DODH catalysts, dissociation of the Cp-ligand was observed when using $\mathrm{Cp}^{\prime} \mathrm{ReO}_{3}$ type complexes as catalyst, ${ }^{[25]}$ in addition to an induction period in the case of using $\mathrm{Cp}^{\mathrm{ttt}} \mathrm{ReO}_{3}$ and $\mathrm{Cp}^{*} \mathrm{ReO}_{3}$ as catalyst. ${ }^{[24]}$ Accordingly, we were wondering if ligand dissociation accompanied by an induction period would also be observed when using $\left[\mathrm{Cp}^{*} \mathrm{MoO}_{2}\right]_{2} \mathrm{O}$ as catalyst. A time course profile experiment was carried out by using 1,2-octanediol as the substrate, $5 \mathrm{~mol} \%$ of $\left[\mathrm{Cp}^{*} \mathrm{MoO}_{2}\right]_{2} \mathrm{O}$ as catalyst, 1.1 equiv. of $\mathrm{PPh}_{3}$ as reductant, and deuterated toluene as the solvent in a J-Young NMR tube under $\mathrm{N}_{2}$ atmosphere at $200{ }^{\circ} \mathrm{C}$. Progression of the reaction over time was monitored by ${ }^{1} \mathrm{H}$ NMR. In time intervals of 10 to 20 minutes, the reaction mixture was taken out of the heating bath and cooled to room temperature to record an ${ }^{1} \mathrm{H}$ NMR spectrum, after which the mixture was re-heated to allow the reaction to progress further. As shown in Figure 4.2.1, the reaction showed a zeroth-order rate profile without an induction period. After $10 \mathrm{~min}, 2 \%$ of 1 -octene was detected, while after $260 \mathrm{~min} 44 \%$ of 1 -octene had formed. Because 
of the way the reaction was carried out, the final 1-octene yield was not as high as reported in Table 4.2.1. No free ligand was detected by ${ }^{1} \mathrm{H}$ NMR in this time course experiment. On the other hand, free ligand was detected by GC-MS analysis at the end of the experiment. These observations suggest that the $\mathrm{Cp}^{*}$ ligand does not dissociate in the course of the DODH reaction, but does dissociate during the GC-measurement.

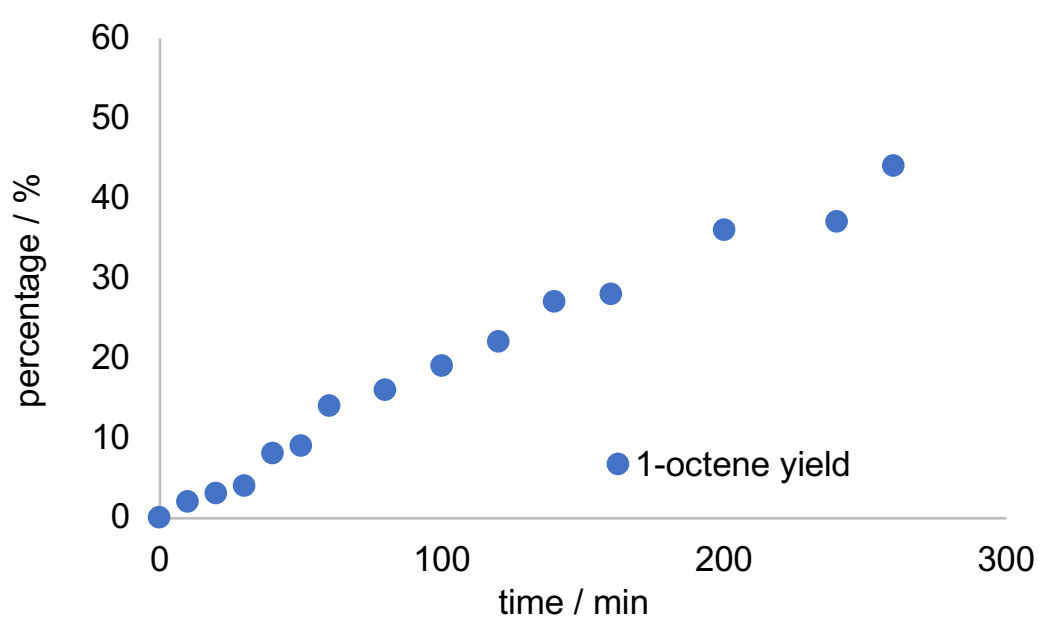

Figure 4.2.1 Time profile of the $\left[\mathrm{Cp}^{*} \mathrm{MoO}_{2}\right]_{2} \mathrm{O}$ catalyzed DODH of 1,2-octanediol.

A general mechanism for the Mo-catalyzed DODH reactions described here is likely to involve at least three general steps, i.e. a reduction of ' $\mathrm{Mo}=\mathrm{O}$ ', a condensation step between a ' $\mathrm{Mo}=\mathrm{O}$ ' unit and a diol, and an olefin extrusion step. The relative order in which the first two steps occur is likely to be highly dependent on the exact nature of the reductant and the molybdenum catalyst applied. In the case of AHM as catalyst in combination with alcohol reductants, the first step is proposed to be the condensation of ' $\mathrm{Mo}=\mathrm{O}$ ' and a diol to form a $\mathrm{Mo}^{\mathrm{VI}} \mathrm{O}_{2}$ (diolate), followed by another condensation with reductant (the diol itself or a secondary alcohol) to form $\mathrm{Mo}^{\mathrm{VI}} \mathrm{O}\left(\right.$ bisdiolate) or $\mathrm{Mo}^{\mathrm{VI}} \mathrm{O}($ diolate $)($ alkoxide $)(\mathrm{OH})\left(\right.$ Scheme 4.1.1). ${ }^{[16,17]}$ When $\mathrm{MoO}_{2}$ (acac) 2 was used as catalyst in combination of $\mathrm{PPh}_{3}$ as the reductant and an excess amount of TMHD as ligand, the catalytic cycle was initially proposed to start with the condensation of diol and $\mathrm{L}_{2} \mathrm{MoO}_{2}$, followed by reduction of $\mathrm{Mo}=\mathrm{O}$. Yet, the detection of $\left[\mathrm{MoOTMHD}_{2}\right]$ by ESI-MS indicated that reduction of "Mo=O" took place as the first step in catalysis in this case. ${ }^{[19]}$

Since we know that for the $\mathrm{Cp}^{\prime} \mathrm{ReO}_{3} / \mathrm{PPh}_{3}$ system the reduction of $\mathrm{Re}=\mathrm{O}$ happens before the condensation of diol, we initially propose a catalytic cycle for $\left[\mathrm{Cp}^{*} \mathrm{MoO}_{2}\right]_{2} \mathrm{O}$ that starts with a reduction step, followed by a condensation step to form a $\mathrm{Mo}(\mathrm{IV})$-glycolate as an intermediate (Scheme 4.2.2). In view of the dinuclear nature of $\left[\mathrm{Cp}^{*} \mathrm{MoO}_{2}\right]_{2} \mathrm{O}$, both mononuclear (pathway A) and dinuclear pathways (pathway B1 and pathway B2) can be considered. In terms of pathway $\mathrm{A}$, this proposed cycle parallels the consensus mechanism for $\mathrm{Cp}^{\prime} \mathrm{ReO}_{3}$ catalyzed 
DODH reactions. The active $\mathrm{Cp}^{*} \mathrm{MoO}_{2}{ }^{+}$species would be formed after breaking up dinuclear $\left[\mathrm{Cp}^{*} \mathrm{MoO}_{2}\right]_{2} \mathrm{O}$ complex, and reduction of $\mathrm{Cp}^{*} \mathrm{MoO}_{2}{ }^{+}$generates $\mathrm{Cp}^{*} \mathrm{MoO}^{+}$, which then condenses with the diol substrate to form $\mathrm{Cp}^{*} \mathrm{Mo}(\text { diolate })^{+}$, followed by olefin extrusion to regenerate $\mathrm{Cp}^{*} \mathrm{MoO}_{2}{ }^{+}$. Alternatively, diol condensation happens as the first step to form $\mathrm{Cp}^{*} \mathrm{MoO}(\text { diolate })^{+}$, which is then reduced to form $\mathrm{Cp}^{*} \mathrm{Mo}(\text { diolate })^{+}$. In this case, $\left[\mathrm{Cp}^{*} \mathrm{MoO}_{2}\right]_{2} \mathrm{O}$ is only a pre-catalyst and catalysis involves a Mo(VI)-Mo(IV) cycle. However, no induction period was observed based on the kinetic study presented above, which either indicates that the dissociation of $\left[\mathrm{Cp}^{*} \mathrm{MoO}_{2}\right]_{2} \mathrm{O}$ is very fast or that this mechanism is not very likely to be operative. Also, when the mononuclear complexes $\mathrm{NBu}_{4}\left[\mathrm{Cp}^{*} \mathrm{MoO}_{3}\right]$ and $\left(\mathrm{Me}_{3}\right.$ tacn) $\mathrm{MoO}_{3}$ were explored as catalyst for the DODH of 1,2-octanediol, a lower 1-octene yield was obtained (Table 4.2.1, entry 3 and 4), comparing with the ones using dinuclear complexes as catalyst (Table 4.2.1, entry 1 and 2). These considerations suggest that the catalytic cycle going through a mononuclear pathway is not favorable in this case.
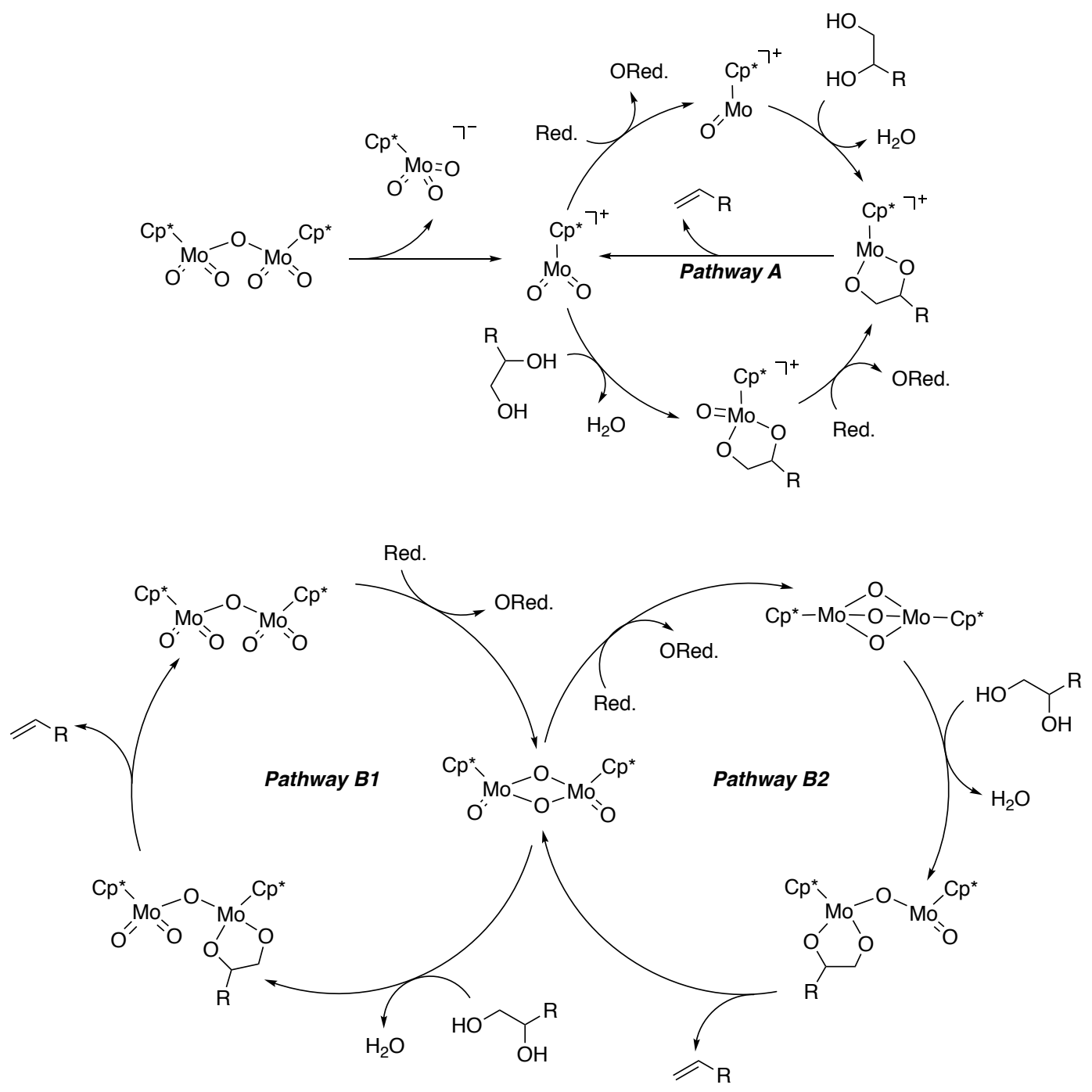

Scheme 4.2.2 Proposed catalytic cycles of $\left[\mathrm{Cp}^{*} \mathrm{MoO}_{2}\right]_{2} \mathrm{O}$-catalyzed DODH reactions. 
Considering catalytic cycles involving a dinuclear active species, two pathways (pathway B1 and pathway B2) are proposed. In pathway B1, $\left[\mathrm{Cp}^{*} \mathrm{MoO}_{2}\right]_{2} \mathrm{O}$ is reduced to form $\left[\mathrm{Cp}^{*} \mathrm{MoO}_{2}\right]_{2}$, which will then condense with the diol to form $\left[\mathrm{Cp}^{*} \mathrm{Mo}(\right.$ diolate $\left.)\right](\mu-\mathrm{O})\left[\mathrm{Cp}^{*} \mathrm{MoO}_{2}\right]$, and then extrudes the olefin product to regenerate $\left[\mathrm{Cp}^{*} \mathrm{MoO}_{2}\right]_{2} \mathrm{O}$. In this case, half of the $\left[\mathrm{Cp}^{*} \mathrm{MoO}_{2}\right]_{2} \mathrm{O}$ compound is 'untouched' during catalysis. In pathway $\mathrm{B} 2,\left[\mathrm{Cp}^{*} \mathrm{MoO}_{2}\right]_{2} \mathrm{O}$ is reduced in two steps to initially form $\left[\mathrm{Cp}^{*} \mathrm{MoO}_{2}\right]_{2}$ and subsequently $\left[\mathrm{Cp}^{*} \mathrm{Mo}\right]_{2}(\mu-\mathrm{O})_{3}$. This kind of " $\mathrm{Mo}_{2}(\mu-\mathrm{O})_{3}$ " moiety normally exists in molybdates. ${ }^{[37]}$ The doubly reduced $\left[\mathrm{Cp}^{*} \mathrm{Mo}\right]_{2}(\mu-\mathrm{O})_{3}$ will then condense with the diol to form an unsymmetrical $\left[\mathrm{Cp}^{*} \mathrm{Mo}(\right.$ diolate $\left.)\right](\mu-\mathrm{O})\left[\mathrm{Cp}^{*} \mathrm{MoO}\right]$ complex, followed by olefin product extrusion to reform $\left[\mathrm{Cp}^{*} \mathrm{MoO}_{2}\right]_{2}$. Within this binuclear reaction manifold, the singly reduced $\left[\mathrm{Cp}^{*} \mathrm{MoO}_{2}\right]_{2}$ complex connects pathways B1 and B2. Pathway B1 proceeds through a $\mathrm{Mo}^{\mathrm{VI}} \mathrm{Mo}^{\mathrm{VI}} \leftrightarrow \mathrm{Mo}^{\mathrm{V}} \mathrm{Mo}^{\mathrm{V}}$ redox cycle including the non-symmetric mixedvalent $\mathrm{Mo}^{\mathrm{VI}} \mathrm{Mo}^{\mathrm{IV}}$ species $\left[\mathrm{Cp}^{*} \mathrm{Mo}(\right.$ diolate $\left.)\right](\mu-\mathrm{O})\left[\mathrm{Cp}^{*} \mathrm{MoO}_{2}\right]$, while pathway $\mathrm{B} 2$ proceeds through a $\mathrm{Mo}^{\mathrm{V}} \mathrm{Mo}^{\mathrm{V}} \leftrightarrow \mathrm{Mo}^{\mathrm{IV}} \mathrm{Mo}^{\mathrm{IV}}$ redox cycle without the involvement of a mixed-valence intermediate. Likewise, for pathway $\mathrm{B} 1$ the starting $\left[\mathrm{Cp}^{*} \mathrm{MoO}_{2}\right]_{2} \mathrm{O}$ can be considered as the actual catalyst, while in pathway B2 it would be a pre-catalyst. Again, the absence of an induction period in the time course study seems not to support pathway B2.

In order to investigate the viability of either of these dinuclear catalytic pathways, a number of experiments were conducted. Key to these proposed pathways is the reduction $\left[\mathrm{Cp}^{*} \mathrm{MoO}_{2}\right]_{2} \mathrm{O}$ to $\left[\mathrm{Cp}^{*} \mathrm{MoO}_{2}\right]_{2}$. We then continued the mechanistic study by treating $\left[\mathrm{Cp}^{*} \mathrm{MoO}_{2}\right]_{2} \mathrm{O}$ with $\mathrm{PPh}_{3}$ (the reductant used in DODH catalysis). As it turned out, the progression of the reaction between $\left[\mathrm{Cp}^{*} \mathrm{MoO}_{2}\right]_{2} \mathrm{O}$ and $\mathrm{PPh}_{3}$ was very slow at $120{ }^{\circ} \mathrm{C}$; only $27 \% \mathrm{PPh}_{3}$ conversion occurred after $2 \mathrm{~h}$, with the color changing from bright yellow to brown. Remarkably, the reduction of $\mathrm{Cp}^{\prime} \mathrm{ReO}_{3}$ by $\mathrm{PPh}_{3}$ happens instantly at room temperature. Treatment of $\left[\mathrm{Cp}^{*} \mathrm{MoO}_{2}\right]_{2} \mathrm{O}$ with 2.0 equiv. of the stronger reductant $\mathrm{P}\left({ }^{n} \mathrm{Bu}\right)_{3}$ in toluene- $\mathrm{D}_{8}$ at $80{ }^{\circ} \mathrm{C}$ under $\mathrm{N}_{2}$ overnight gave a brown solution, and $55 \%$ of $\mathrm{P}\left({ }^{n} \mathrm{Bu}\right)_{3}$ was consumed based on ${ }^{31} \mathrm{P}$ NMR. Monitoring the reaction by means of ${ }^{1} \mathrm{H}$ NMR showed the appearance of new signals at $1.83 \mathrm{ppm}$ and $1.79 \mathrm{ppm}$. A redorange solid separated from the mixture and a solution of the solid showed a signal at $1.79 \mathrm{ppm}$ in ${ }^{1} \mathrm{H}$ NMR. The identity of the red-orange solid could be traced back to $\left[\mathrm{Cp}^{*} \mathrm{MoO}_{2}\right]_{2}$ after comparison with data from the literature. $\left[\mathrm{Cp}^{*} \mathrm{MoO}_{2}\right]_{2}$ was reported by the group of Petrignani in 1985 as the product of the reaction between $\left[\mathrm{Cp}^{*} \mathrm{Mo}(\mathrm{CO})_{2}\right]_{2}$ and the oxidant $\left({ }^{t} \mathrm{BuNC}\right)_{2} \mathrm{NiO}_{2} \cdot{ }^{[38]}$ Under aerobic conditions, $\left[\mathrm{Cp}^{*} \mathrm{MoO}_{2}\right]_{2}$ will be further oxidized to $\left[\mathrm{Cp}^{*} \mathrm{MoO}_{2}\right]_{2} \mathrm{O} .{ }^{[26]}$ These experiments lend credit to the formation of $\left[\mathrm{Cp}^{*} \mathrm{MoO}_{2}\right]_{2}$ as the reduction product of $\left[\mathrm{Cp}^{*} \mathrm{MoO}_{2}\right]_{2} \mathrm{O}$ under $\mathrm{DODH}$ conditions. In addition, these experiments clearly show that unlike in the case of $\mathrm{Cp}^{\prime} \mathrm{ReO}_{3}$ catalyzed DODH reactions, reduction of $\left[\mathrm{Cp}^{*} \mathrm{MoO}_{2}\right]_{2} \mathrm{O}$ does not take place readily. These observations are in line with the work of 
Fristrup, which showed that the reduction of Mo is the rate limiting step of the catalytic DODH cycle while using AHM as catalyst and isopropanol as reductant. ${ }^{[16]}$

For the reduction of $\mathrm{Mo}=\mathrm{O}$ units, a vicinal diol can also be used as the reductant according to literature reports. ${ }^{[15,17]}$ When heating a 1:2 ratio of $\left[\mathrm{Cp}^{*} \mathrm{MoO}_{2}\right]_{2} \mathrm{O}$ and 1,2-octanediol at $120^{\circ} \mathrm{C}$, ${ }^{1} \mathrm{H}$ NMR analysis showed the appearance of signals at $1.83 \mathrm{ppm}$ and $1.79 \mathrm{ppm}$, again indicating the formation of $\left[\mathrm{Cp}^{*} \mathrm{MoO}_{2}\right]_{2}$. In addition, no indication for the formation of 1-octene was obtained for this reaction. In a similar reaction equimolar amounts of $\left[\mathrm{Cp}^{*} \mathrm{MoO}_{2}\right]_{2} \mathrm{O}$ and 1phenyl-1,2-ethanediol were reacted in toluene- $\mathrm{D}_{8}$. By increasing the temperature from room temperature to $100{ }^{\circ} \mathrm{C}$, new signals were detected by ${ }^{1} \mathrm{H}$ NMR. After keeping the mixture at $100{ }^{\circ} \mathrm{C}$ overnight, $6 \%$ of styrene had formed, while no acetophenone or aldehydes were detected and a significant amount of 1-phenyl-1,2-ethanediol was still present.

These reduction experiments, combined with our results for the reductant screening (Table 4.2.3, entry 1 and entry 8), as well as the formation of ketals in our system, indicate that phosphines as well as diols can be used as reductant for catalytic DODH reactions using $\left[\mathrm{Cp}^{*} \mathrm{MoO}_{2}\right]_{2} \mathrm{O}$. In addition, the experiments confirm the formation of $\left[\mathrm{Cp}^{*} \mathrm{MoO}_{2}\right]_{2}$ as a reduction product from $\left[\mathrm{Cp}^{*} \mathrm{MoO}_{2}\right]_{2} \mathrm{O}$. Our next experiments then focused on the reactivity of $\left[\mathrm{Cp}^{*} \mathrm{MoO}_{2}\right]_{2}$.

If $\left[\mathrm{Cp}^{*} \mathrm{MoO}_{2}\right]_{2}$ is indeed the reduced product of $\left[\mathrm{Cp}^{*} \mathrm{MoO}_{2}\right]_{2} \mathrm{O}$ involved in the proposed catalytic cycle, it should be active in DODH catalysis. Therefore, we investigated $\left[\mathrm{Cp}^{*} \mathrm{MoO}_{2}\right]_{2}$ as catalyst for the deoxydehydration of 1,2-octanediol under standard reaction conditions. Analysis of this reaction indicated that only $8 \%$ of 1 -octene had formed at $77 \%$ substrate conversion (Scheme 4.2.3a), which actually casts doubts on the involvement of $\left[\mathrm{Cp}^{*} \mathrm{MoO}_{2}\right]_{2}$ as an intermediate in DODH catalysis by $\left[\mathrm{Cp}^{*} \mathrm{MoO}_{2}\right]_{2} \mathrm{O}$. Since $\left[\mathrm{Cp}^{*} \mathrm{MoO}_{2}\right]_{2}$ will be oxidized to $\left[\mathrm{Cp}^{*} \mathrm{MoO}_{2}\right]_{2} \mathrm{O}$ under aerobic conditions, we then performed the same reaction under aerobic conditions (Scheme 4.2.3b). In this case, $30 \%$ of 1 -octene formed at full substrate conversion, indicating that $\left[\mathrm{Cp}^{*} \mathrm{MoO}_{2}\right]_{2} \mathrm{O}$ formed in situ under these aerobic conditions. These experiments seem to rule out pathway $\mathrm{B} 2$, since in that case $\left[\mathrm{Cp}^{*} \mathrm{MoO}_{2}\right]_{2} \mathrm{O}$ can act as a pre-catalyst and catalytic turn-over can be achieved through $\left[\mathrm{Cp}^{*} \mathrm{MoO}_{2}\right]_{2}$ without $\left[\mathrm{Cp}^{*} \mathrm{MoO}_{2}\right]_{2} \mathrm{O}$ being involved after its reduction.

In a next, stochiometric experiment $\left[\mathrm{Cp}^{*} \mathrm{MoO}_{2}\right]_{2}$ was reacted with 1 equiv. of the more reactive diol substrate 1-phenyl-1,2-ethanediol at $120^{\circ} \mathrm{C}$ to result in full conversion of 1-phenyl-1,2ethanediol, as well as formation of styrene (Scheme 4.2.3c). No aldehydes were detected in this reaction. The outcome of this reaction indicates that $\left[\mathrm{Cp}^{*} \mathrm{MoO}_{2}\right]_{2}$ is able to engage in a condensation reaction with a diol substrate and in a subsequent olefin extrusion step to form an olefin at a relatively low temperature. Besides, our investigation on the of different reductants 
showed a lower 1-octene yield when the more reductive $\mathrm{P}^{n} \mathrm{Bu}_{3}$ was used (Table 4.2.3, entry 2). Using this stronger reductant, one would expect dimeric $\mathrm{Mo}^{\mathrm{VI}}-$ complex $\left[\mathrm{Cp}^{*} \mathrm{MoO}_{2}\right]_{2} \mathrm{O}$ to form $\mathrm{Mo}^{\mathrm{V}}$-dimer $\left[\mathrm{Cp}^{*} \mathrm{MoO}_{2}\right]_{2}$ easier, or even be able to reduce it further to form the $\mathrm{Mo}^{\mathrm{IV}}$-dimer $\left[\mathrm{Cp}^{*} \mathrm{Mo}\right]_{2}(\mu-\mathrm{O})_{3}$. The lower 1-octene yield when using $\mathrm{P}^{n} \mathrm{Bu}_{3}$ as the reductant therefore does not favor $\mathrm{B} 2$ and even seems to indicate that $\left[\mathrm{Cp}^{*} \mathrm{MoO}_{2}\right]_{2}$ is not even involved in the catalytic cycle.

a.

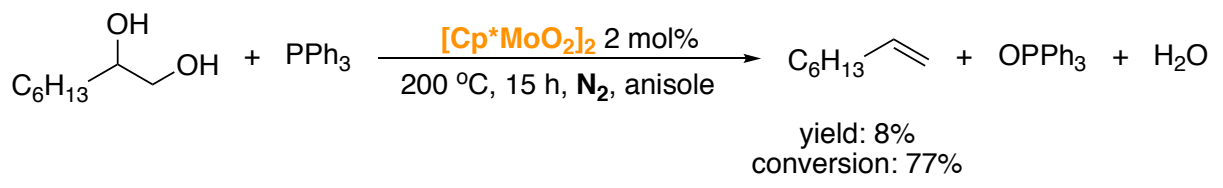

b.

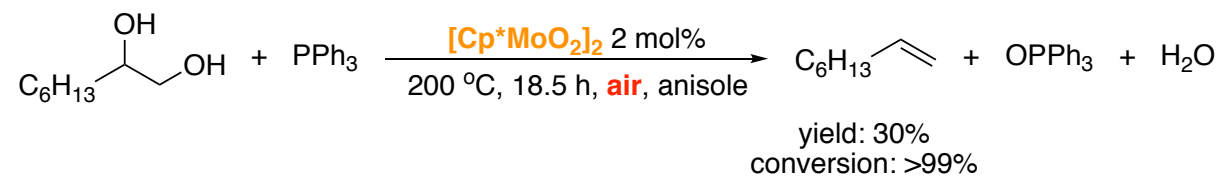

c.

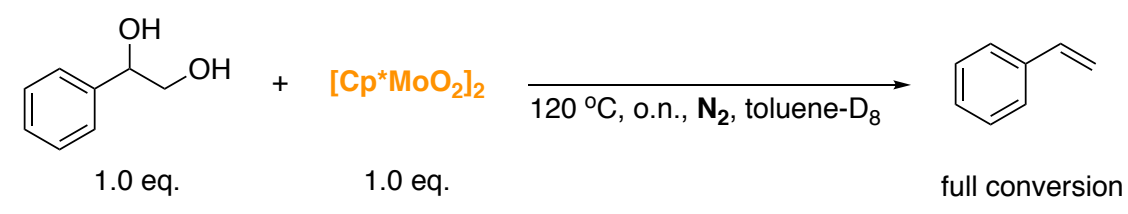

Scheme 4.2.3 Mo-catalyzed deoxydehydration of 1,2-octanediol: a. $\left[\mathrm{Cp}^{*} \mathrm{MoO}_{2}\right]_{2}$ was used as catalyst under inert conditions; b. $\left[\mathrm{Cp}^{*} \mathrm{MoO}_{2}\right]_{2}$ was used as catalyst under aerobic conditions; $c$. stochiometric reaction of 1-phenyl-1,2-ethanediol and $\left[\mathrm{Cp}^{*} \mathrm{MoO}_{2}\right]_{2}$ under inert conditions.

Overall, our data do not provide strong evidence for either mononuclear pathway A or the two dinuclear pathways B. Looking back at the reduction reaction between $\left[\mathrm{Cp}^{*} \mathrm{MoO}_{2}\right]_{2} \mathrm{O}$ and $\mathrm{PPh}_{3}$, two peak were observed by ${ }^{1} \mathrm{H}$ NMR at the end of the reaction, one representing $\left[\mathrm{Cp}^{*} \mathrm{MoO}_{2}\right]_{2}$ and the other signifying a so far unidentified reduced species. We therefore propose an alternative catalytic pathway $\mathrm{C}$, in which the reduction of $\left[\mathrm{Cp}^{*} \mathrm{MoO}_{2}\right]_{2} \mathrm{O}$ leads to the formation of $\left[\mathrm{Cp}^{*} \mathrm{MoO}_{2}\right]_{2}$ and an unidentified species $\mathbf{X}$ (Scheme 4.2.4). The former $\left[\mathrm{Cp}^{*} \mathrm{MoO}_{2}\right]_{2}$ is in a redox equilibrium $\left[\mathrm{Cp}^{*} \mathrm{MoO}_{2}\right]_{2} \mathrm{O}$ and not involved in DODH catalysis, while the latter one is the active species involved in catalysis and reacts with the diol through a condensation and an olefin extrusion step. In the first, reductive step of this pathway, only limited amounts of $\mathbf{X}$ seem to be formed and the redox equilibrium between $\left[\mathrm{Cp}^{*} \mathrm{MoO}_{2}\right]_{2} \mathrm{O}$ and $\left[\mathrm{Cp}^{*} \mathrm{MoO}_{2}\right]_{2}$, seems to serve as a 'pool' to continuously form active species $\mathbf{X}$ along with its replenishment though catalytic turn-over. This situation seems to be in line with the observed a zeroth-order rate profile for the catalytic reaction. Our current experimental data do, unfortunately, provide littile information about the identity of both intermediates $\mathbf{X}$ and $\mathbf{Y}$. 


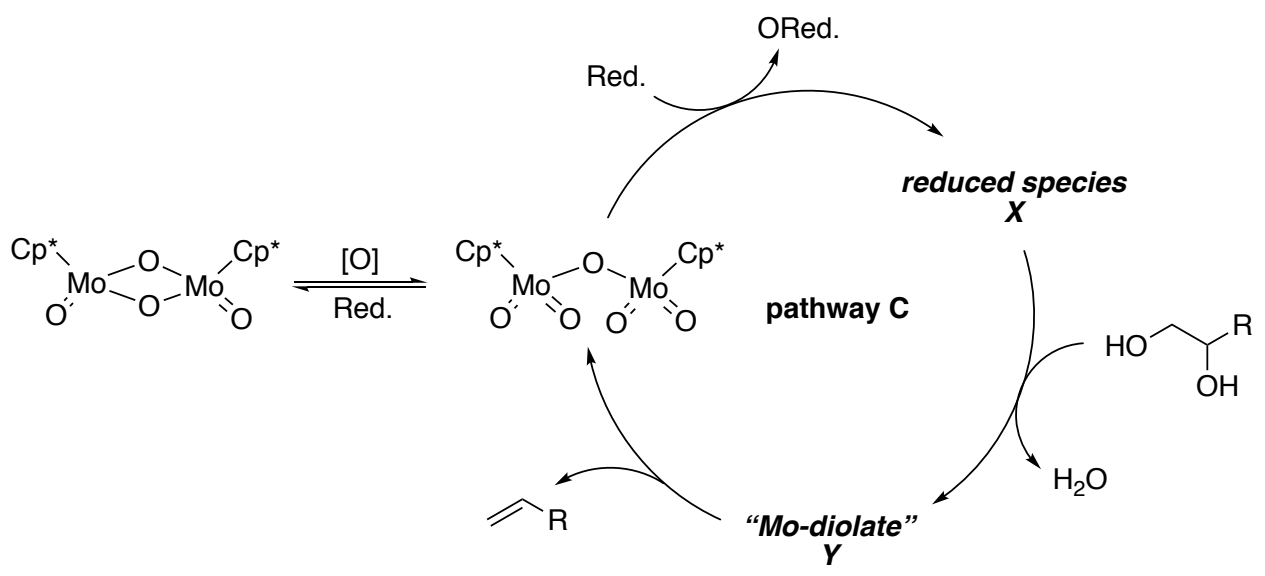

Scheme 4.2.4 Proposed catalytic cycle of $\left[\mathrm{Cp}^{*} \mathrm{MoO}_{2}\right]_{2} \mathrm{O}$-catalyzed DODH reactions involving $\left[\mathrm{Cp}^{*} \mathrm{MoO}_{2}\right]_{2}$ is an off-cycle species.

\subsection{Conclusions}

Exploratory studies in this chapter have shown that the dinuclear complex $\left[\mathrm{Cp}^{*} \mathrm{MoO}_{2}\right]_{2} \mathrm{O}$ is able to catalyze the DODH of diols using $\mathrm{PPh}_{3}$ as reductant and anisole as solvent. The reaction requires a high reaction temperature $\left(200^{\circ} \mathrm{C}\right)$ to reach high substrate conversion. This catalyst can be applied to the DODH of aliphatic vicinal diols to form the corresponding olefins with moderate yields. Especially, cis-1,2-cyclohexanediol is known as quite a challenging substrate in some rhenium-catalyzed DODH reactions. With $\left[\mathrm{Cp}^{*} \mathrm{MoO}_{2}\right]_{2} \mathrm{O}, 30 \%$ of 1-cyclohexene can be formed from cis-1,2-cyclohexanediol, which stands out compared to the $\mathrm{Cp}^{\mathrm{ttt}} \mathrm{ReO}_{3}$-catalyzed DODH reaction. However, because of the consumption of diol to form ketals during the reaction, the general olefin product yield and selectivity that has been attained with $\left[\mathrm{Cp}^{*} \mathrm{MoO}_{2}\right]_{2} \mathrm{O}$ so far is not higher than $56 \%$. For other Mo-catalyzed DODH reactions, product yields and selectivities has also always been an issue, with the exception of using excess amounts of ligands or additives. Also for our current catalyst system, the dehydration of diol substrate and its oxidative cleavage seem to be part of the overall reactions that take place.

Mechanistic studies have detected $\left[\mathrm{Cp}^{*} \mathrm{MoO}_{2}\right]_{2}$ as one of the reduction products arising from $\left[\mathrm{Cp}^{*} \mathrm{MoO}_{2}\right]_{2} \mathrm{O}$. While, $\left[\mathrm{Cp}^{*} \mathrm{MoO}_{2}\right]_{2}$ is able to engage in a condensation reaction with a diol substrate and a subsequent olefin extrusion step to form an olefin, the catalytic activity of $\left[\mathrm{Cp}^{*} \mathrm{MoO}_{2}\right]_{2}$ is much lower than that of $\left[\mathrm{Cp}^{*} \mathrm{MoO}_{2}\right]_{2} \mathrm{O}$. Along with the observation of zeroorder reaction kinetics and of a second reduction product $\mathbf{X}$ arising from $\left[\mathrm{Cp}^{*} \mathrm{MoO}_{2}\right]_{2} \mathrm{O}$, we have proposed an alternative reaction pathway in which $\left[\mathrm{Cp}^{*} \mathrm{MoO}_{2}\right]_{2}$ is an off-cycle species and 
the second reduction product is involved in actual catalytic turn-over. Further studies aim at identifying intermediate $\mathbf{X}$ and shedding further light on the DODH reaction mechanism, to ultimately aid further catalyst development.

\subsection{Experimental Section}

\subsubsection{General}

All chemicals including solvents were degassed by either freeze-pump-thaw cycles or degasification under vacuum. Triphenylphosphine was crystallized from ethanol and dried under vacuum. $\left[\mathrm{Cp}^{*} \mathrm{MoO}_{2}\right]_{2} \mathrm{O},{ }^{[30,31]}\left(\mathrm{Me}_{3}\right.$ tacn $) \mathrm{MoO}_{3},{ }^{[33]}$ and $\mathrm{NBu}_{4}\left[\mathrm{Cp}^{*} \mathrm{MoO}_{3}\right]^{[32]}$ was prepared according to a known literature procedure. Unless otherwise stated, all other commercial chemicals were used without further purification. NMR spectra were recorded on a Varian VNMRS400 (400 MHz) instrument at $298 \mathrm{~K}$. ESI-MS spectra were recorded using a Waters LCT Premier XE instrument. GC measurements were performed using a Perkin Elmer Clarus 500 Gas Chromatograph equipped with a Perkin Elmer Elite-5 column (Length: 30m, I.D.: 0.32 mm, Film thickness: $0.25 \mu \mathrm{m}, 5 \%$ phenyl-95\% methylpolysiloxane), and with FID detector. GC method: $40{ }^{\circ} \mathrm{C}, 5 \mathrm{~min} ; 3{ }^{\circ} \mathrm{C} / \mathrm{min}$ to $55^{\circ} \mathrm{C} ; 20^{\circ} \mathrm{C} / \mathrm{min}$ to $250{ }^{\circ} \mathrm{C} ; 250{ }^{\circ} \mathrm{C}, 10 \mathrm{~min} ; 20{ }^{\circ} \mathrm{C} / \mathrm{min}$ to $300{ }^{\circ} \mathrm{C} ; 300{ }^{\circ} \mathrm{C}, 5 \mathrm{~min}$. All olefinic products are known compounds and were calibrated against mesitylene for quantification.

\subsubsection{Synthesis of $\left[\mathrm{Cp}^{\mathrm{tt}} \mathrm{MoO}_{2}\right]_{2} \mathrm{O}^{[30,31]}$}

In a dried round-bottom flask, $\mathrm{Mo}(\mathrm{CO})_{6}(1.32 \mathrm{~g}, 5.0 \mathrm{mmol})$ was degassed under vacuum for 30 min. After addition of di-tert-butylcyclopentadiene (1.78 g, $10.0 \mathrm{mmol}, 2$ equiv.) and $p$-xylene $(60 \mathrm{~mL})$ the reaction system was connected with a gas bubbler to allow the formed $\mathrm{CO}$ to release. The reaction mixture was refluxed at $170{ }^{\circ} \mathrm{C}$ overnight under $\mathrm{N}_{2}$, during which the reaction mixture turned into dark red. After cooling, the solvent was removed at reduced pressure. $\left[\mathrm{Cp}^{\mathrm{tt}} \mathrm{Mo}(\mathrm{CO})_{\mathrm{n}}\right]_{2}(\mathrm{n}=2$ or 3$)$ was formed as red solid. Without further purification, benzene (60 $\mathrm{mL}$ ) was added, the reaction mixture was then stirred open to air for 4 days to obtain a greenyellow mixture. Benzene was removed under reduced pressure at room temperature and $n$ hexane was used to extract the product. Bright yellow crystal (360 mg, $0.58 \mathrm{mmol}, 23 \%$ ) was obtained by recrystallization from $n$-hexane and diethyl ether at $-30{ }^{\circ} \mathrm{C}$.

${ }^{1} \mathrm{H}$ NMR (400 MHz), $\mathrm{C}_{6} \mathrm{D}_{6}(7.16 \mathrm{ppm}): \delta 1.27(\mathrm{~s}, 18 \mathrm{H}, t \mathrm{Bu}), 6.16(\mathrm{dt}, J=12.8,7.7 \mathrm{~Hz}, 3 \mathrm{H}$, $\mathrm{CpH}) .{ }^{13} \mathrm{C}$ NMR (100 MHz), $\mathrm{C}_{6} \mathrm{D}_{6}(128.060 \mathrm{ppm}): \delta 31.17,32.05,33.72,107.34,111.49 . \mathrm{IR}$ 
(ATR): 439, 687, 755, 824, 879, 917, 1251, 1366, 1461, 2868, 2904, $2960 \mathrm{~cm}^{-1}$; elemental analysis calc. (\%) for $\mathrm{C}_{26} \mathrm{H}_{42} \mathrm{Mo}_{2} \mathrm{O}_{5}$ (626.5170): C 49.85, H 6.76; found: C 50.64, H 6.68, $\mathrm{N}<0.10$.

\section{Details on X-ray crystal structure determination of $\left[\mathrm{Cp}^{\mathrm{tt}} \mathrm{MoO}_{2}\right]_{2} \mathrm{O}$}

$\mathrm{C}_{26} \mathrm{H}_{42} \mathrm{Mo}_{2} \mathrm{O}_{5}, \mathrm{Fw}=626.47$, yellow needle, $0.33 \times 0.12 \times 0.08 \mathrm{~mm}^{3}$, orthorhombic, Pca2 1 (no. 29), $\mathrm{a}=13.3858(5), \mathrm{b}=23.6191(6), \mathrm{c}=17.7325(5) \AA, \mathrm{V}=5606.3(3) \AA^{3}, \mathrm{Z}=8, \mathrm{D}_{\mathrm{x}}=1.484$ $\mathrm{g} / \mathrm{cm}^{3}, \mu=0.93 \mathrm{~mm}^{-1}$. The diffraction experiment was performed on a Bruker Kappa ApexII diffractometer with sealed tube and Triumph monochromator $(\lambda=0.71073 \AA)$ at a temperature of $150(2) \mathrm{K}$ up to a resolution of $(\sin \theta / \lambda)_{\max }=0.65 \AA^{-1}$. The crystal appeared to be cracked, with a rotation angle of $3.8^{\circ}$ between the two crystal fragments. Consequently, two orientation matrices were used for the intensity integration with the Eval15 software ${ }^{[39]}$. A multi-scan absorption correction and scaling was performed with TWINABS ${ }^{[40]}$ (correction range 0.620.75). A total of 164120 reflections was measured, 14408 reflections were unique $\left(R_{\text {int }}=0.071\right)$, 12299 reflections were observed $[\mathrm{I}>2 \sigma(\mathrm{I})]$. The structure was solved with Patterson superposition methods using SHELXT ${ }^{[41]}$. Structure refinement was performed with SHELXL$2016^{[42]}$ on $\mathrm{F}^{2}$ of all reflections based on an HKLF-5 file ${ }^{[43]}$. Non-hydrogen atoms were refined freely with anisotropic displacement parameters. All hydrogen atoms were introduced in calculated positions and refined with a riding model. 620 Parameters were refined with one

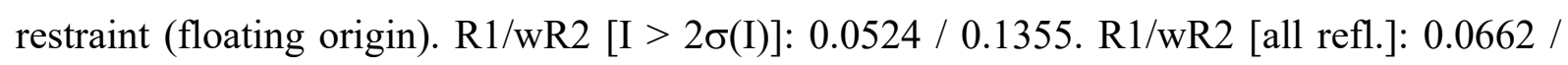
0.1436. BASF for the two crystal fragments refined to $0.2354(19)$; additional inversion twinning was not included in the refinement. $S=1.052$. Residual electron density between -1.51 and $4.41 \mathrm{e} / \AA^{3}$ (positive peak in the proximity of the metal). Geometry calculations and checking for higher symmetry was performed with the PLATON program. ${ }^{[44]}$

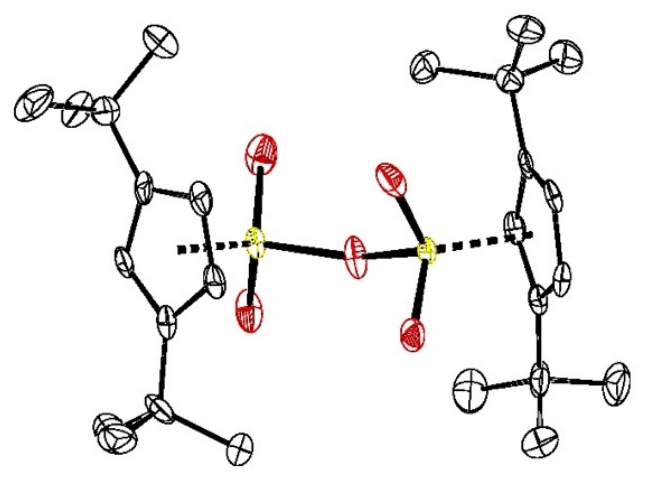

Figure 4.4.1. Displacement ellipsoid plot (50\% probability level) of $\left[\mathrm{Cp}^{\mathrm{tt}} \mathrm{MoO}_{2}\right]_{2} \mathrm{O}$. Only one of two independent molecules is shown. Hydrogen atoms are omitted for clarity. 
CCDC 1991496 contain the supplementary crystallographic data for this paper. These data can be obtained free of charge from The Cambridge Crystallographic Data Centre via www.ccdc.cam.ac.uk/data_request/cif.

\subsubsection{Synthesis of $\left(\mathrm{Me}_{3} \mathrm{tacn}\right) \mathrm{MoO}_{3}{ }^{[33]}$}

$\mathrm{MoO}_{3}(1.0 \mathrm{mmol}, 143.9 \mathrm{mg})$ and water $(10 \mathrm{~mL})$ were combined in a pressure tube under inert atmosphere. A solution of $\mathrm{Me}_{3} \operatorname{tacn}(1.1 \mathrm{mmol}, 0.2 \mathrm{~mL})$ in water $(5 \mathrm{~mL})$ was then added to the stirred suspension. The mixture was refluxed for $24 \mathrm{~h}$. The mixture was allowed to cool down slowly to room temperature, after which the solid particles were removed by filtration. Water was then removed via rotary evaporation and high vacuum. Further purification was performed via diffusion crystallisation with methanol and diethyl ether.

${ }^{1} \mathrm{H}-\mathrm{NMR}$ (400 MHz), CD ${ }_{3} \mathrm{CN}$ (1.94 ppm): $\delta 2.69$ - $2.82\left(\mathrm{~m}, 12 \mathrm{H}, \mathrm{CH}_{2}\right), 3.03\left(\mathrm{~s}, 9 \mathrm{H}, \mathrm{CH}_{3}\right) .{ }^{1} \mathrm{H}-$ NMR (400 MHz), $\mathrm{D}_{2} \mathrm{O}(4.80 \mathrm{ppm}): \delta 2.74-2.89(\mathrm{~m}, 21 \mathrm{H}$, overlap of signals from all protons). ${ }^{13} \mathrm{C}-\mathrm{NMR}(101 \mathrm{MHz}): \delta 53.45\left(\mathrm{NCH}_{3}\right), 57.95\left(\mathrm{CH}_{2}\right)$. HRMS(ESI-MS): calc. for $\left[\mathrm{C}_{9} \mathrm{H}_{22} \mathrm{MoN}_{3} \mathrm{O}_{3}\right.$ $+\mathrm{H}^{+}$]: 318.0710 ; found: 318.0614 .

\subsubsection{Synthesis of $\left[\mathrm{Cp}^{*} \mathrm{MoO}_{2}\right]_{2}$}

In a dried Schlenk, $\left[\mathrm{Cp}^{*} \mathrm{MoO}_{2}\right]_{2} \mathrm{O}(0.077 \mathrm{mmol}, 42 \mathrm{mg})$ and $\mathrm{P}\left({ }^{n} \mathrm{Bu}\right)_{3}(0.77 \mathrm{mmol}, 10.0$ equiv. $)$ were dissolved in THF (15 mL) inside a Glove box under nitrogen atmosphere, this mixture was then heated at $60{ }^{\circ} \mathrm{C}$ outside the Glove box overnight under $\mathrm{N}_{2}$. Degassed hexane was then added on top of the reaction mixture under $\mathrm{N}_{2}$. $\left[\mathrm{Cp}^{*} \mathrm{MoO}_{2}\right]_{2}$ was obtained as a red-orange solid overnight. The solution of this mixture was removed and the solid was washed with degassed hexane three times. ${ }^{1} \mathrm{H}$ NMR analysis of the product corresponded to the literature data of $\left[\mathrm{Cp}^{*} \mathrm{MoO}_{2}\right]_{2}$. Exposing the NMR sample to air resulted in a color change from red-orange to bright yellow; ${ }^{1} \mathrm{H}$ NMR analysis showed the signal for $\left[\mathrm{Cp}^{*} \mathrm{MoO}_{2}\right]_{2} \mathrm{O}$. This observation was in line with literature, that is, $\left[\mathrm{Cp}^{*} \mathrm{MoO}_{2}\right]_{2}$ will be oxidized to $\left[\mathrm{Cp}^{*} \mathrm{MoO}_{2}\right]_{2} \mathrm{O}$ under aerobic conditions.

\subsubsection{General procedure for catalytic deoxydehydration using anisole as solvent}

Unless otherwise noted, all reaction mixtures were prepared inside a Glove box under nitrogen atmosphere in a $15 \mathrm{~mL}$ thick-walled glass pressure tube (Ace) fitted with a Teflon screw-cap. The diol substrate $(0.5 \mathrm{mmol}),\left[\mathrm{Cp}^{*} \mathrm{MoO}_{2}\right]_{2} \mathrm{O}(0.01 \mathrm{mmol})$, reductant $(0.55 \mathrm{mmol})$, and 
mesitylene $(0.5 \mathrm{mmol})$ were dissolved in anisole $(5 \mathrm{~mL})$ and mixed well. Then, the closed reaction vessel was heated using a preheated silicone oil bath at $200{ }^{\circ} \mathrm{C}$. After the reaction, aliquots of the reaction mixture were diluted with acetone for GC analysis.

\subsubsection{Monitoring the reaction between $\left[\mathrm{Cp}^{*} \mathrm{MoO}_{2}\right]_{2} \mathrm{O}$ and $\mathrm{PPh}_{3}$}

$\left[\mathrm{Cp}^{*} \mathrm{MoO}_{2}\right]_{2} \mathrm{O}(0.02 \mathrm{mmol})$ and $\mathrm{PPh}_{3}(0.04 \mathrm{mmol}, 2.0$ equiv. $)$ were dissolved in toluene- $\mathrm{D}_{8}(0.5$ $\mathrm{mL}$ ) inside a Glove box under nitrogen atmosphere and the mixture was transferred into a JYoung NMR tube. ${ }^{1} \mathrm{H}$ NMR and ${ }^{31} \mathrm{P}$ NMR measurements were carried before and after keeping the mixture at $120^{\circ} \mathrm{C}$ for $1 \mathrm{~h}$. The $\mathrm{PPh}_{3}$ conversion was $22 \%$ on basis of ${ }^{31} \mathrm{P}$ NMR. After keeping the mixture at $120{ }^{\circ} \mathrm{C}$ for $2 \mathrm{~h}$, the $\mathrm{PPh}_{3}$ conversion was $27 \%$. The color of this mixture was brown, and new signals at $1.83 \mathrm{ppm}$ and $1.79 \mathrm{ppm}$ were observed by ${ }^{1} \mathrm{H}$ NMR. The signals of $\left[\mathrm{Cp}^{*} \mathrm{MoO}_{2}\right]_{2} \mathrm{O}$ were still present after $2 \mathrm{~h}$, which meant the reduction of $\left[\mathrm{Cp}^{*} \mathrm{MoO}_{2}\right]_{2} \mathrm{O}$ was not complete.

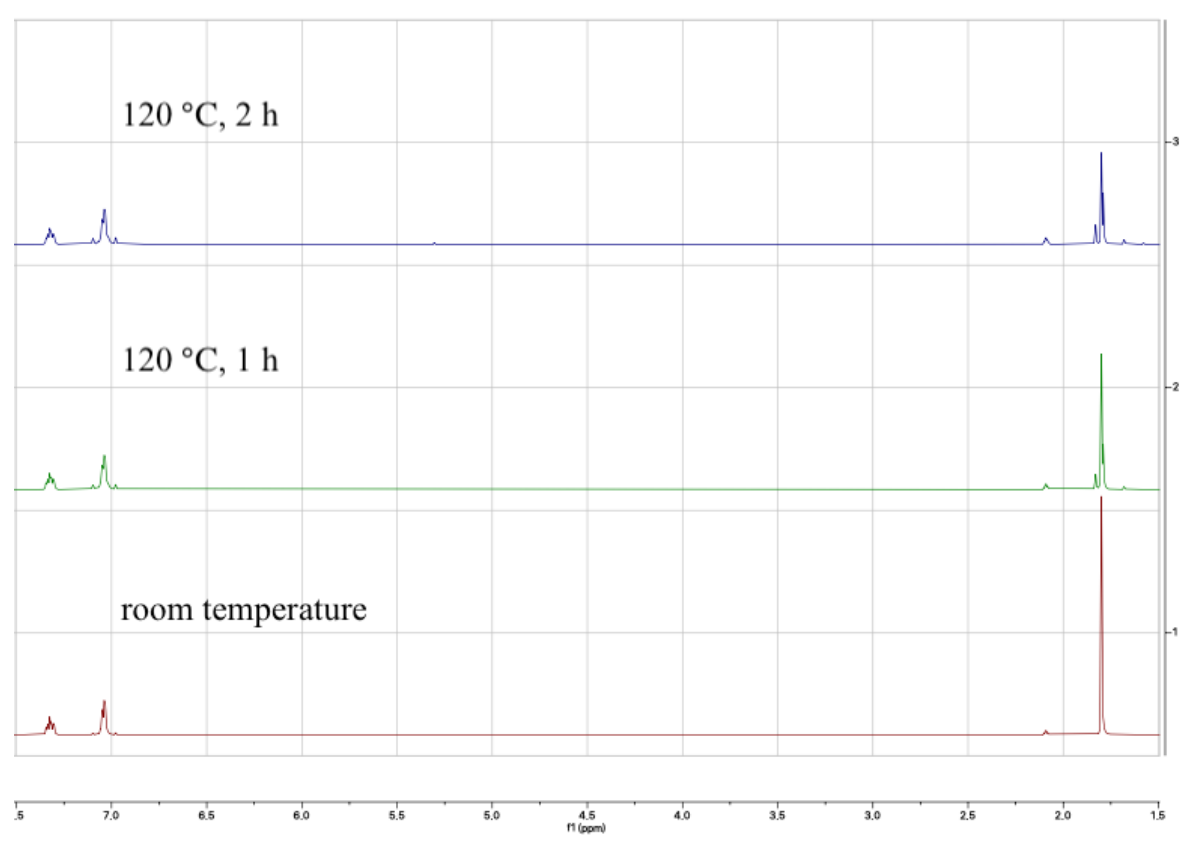

\subsubsection{Monitoring the reaction between $\left[\mathrm{Cp}^{*} \mathrm{MoO}_{2}\right]_{2} \mathrm{O}$ and 1,2-octanediol}

$\left[\mathrm{Cp}^{*} \mathrm{MoO}_{2}\right]_{2} \mathrm{O}(0.02 \mathrm{mmol})$ and 1,2-octanediol (0.04 mmol, 2.0 equiv.) were dissolved in toluene- $\mathrm{D}_{8}(0.5 \mathrm{~mL})$ inside a Glove box under nitrogen atmosphere and the mixture was transferred into a J-Young NMR tube. ${ }^{1} \mathrm{H}$ NMR measurements were carried out before and after keeping the mixture at $120^{\circ} \mathrm{C}$ for $1 \mathrm{~h}$ and $2 \mathrm{~h}$. The color of this mixture was brown, and new signals at $1.83 \mathrm{ppm}$ and $1.79 \mathrm{ppm}$ were observed by ${ }^{1} \mathrm{H}$ NMR. The signals of $\left[\mathrm{Cp}^{*} \mathrm{MoO}_{2}\right]_{2} \mathrm{O}$ 
had almost disappeared after 2 h. Comparing the data with 4.4.6, the reaction between $\left[\mathrm{Cp}^{*} \mathrm{MoO}_{2}\right]_{2} \mathrm{O}$ and 1,2-octanediol was faster than the one between $\left[\mathrm{Cp}^{*} \mathrm{MoO}_{2}\right]_{2} \mathrm{O}$ and $\mathrm{PPh}_{3}$ under the same reaction conditions.

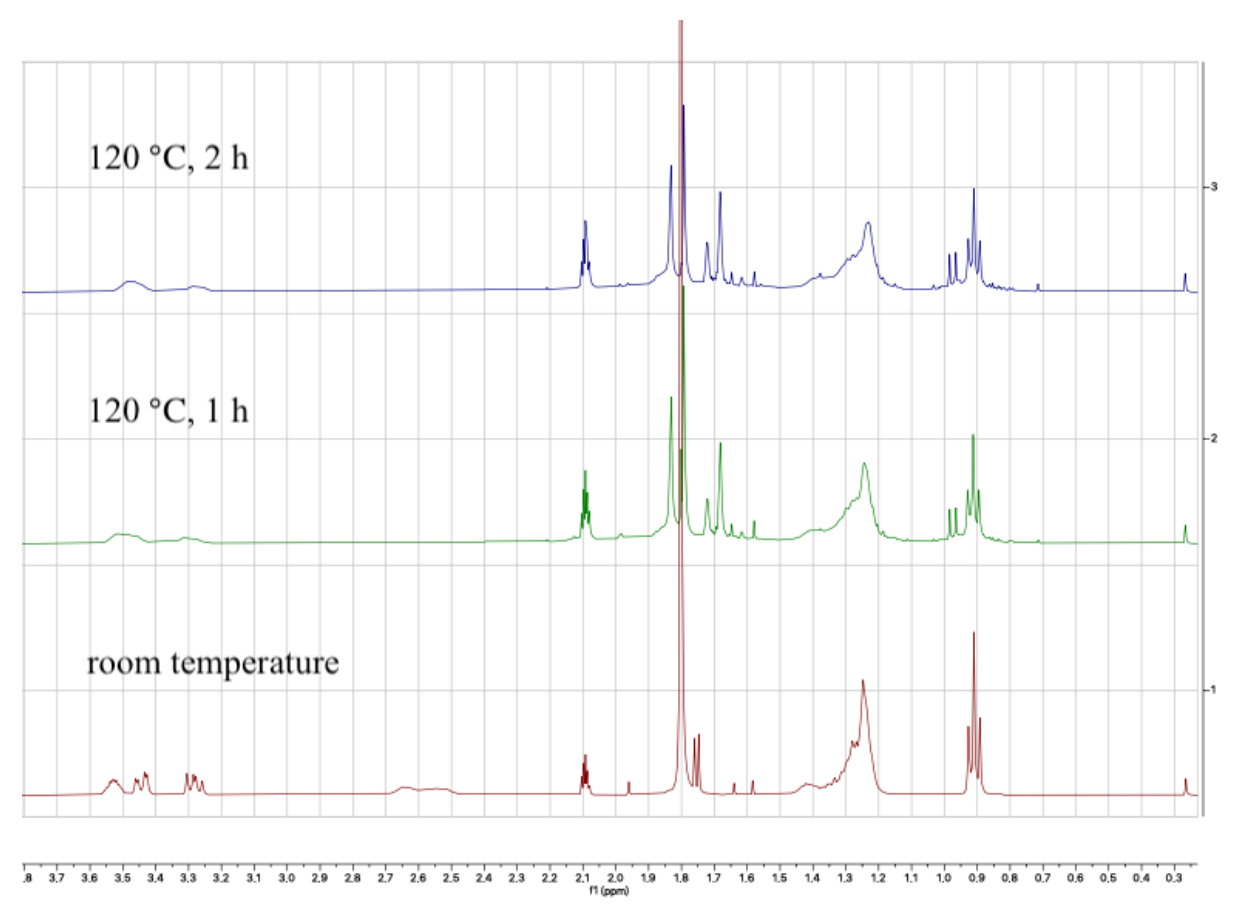

\subsubsection{Monitoring the reaction between $\left[\mathrm{Cp}^{*} \mathrm{MoO}_{2}\right]_{2} \mathrm{O}$ and $\mathrm{P}\left({ }^{n} \mathrm{Bu}\right)_{3}$}

$\left[\mathrm{Cp}^{*} \mathrm{MoO}_{2}\right]_{2} \mathrm{O}(0.02 \mathrm{mmol})$ and $\mathrm{P}\left({ }^{n} \mathrm{Bu}\right)_{3}(0.04 \mathrm{mmol}, 2.0$ equiv. $)$ were dissolved in toluene- $\mathrm{D}_{8}$ $(0.5 \mathrm{~mL})$ inside a Glove box under nitrogen atmosphere and the mixture was transferred into a J-Young NMR tube. ${ }^{1} \mathrm{H}$ NMR and ${ }^{31} \mathrm{P}$ NMR measurements were carried out after keeping the mixture at room temperature for $1 \mathrm{~h}$. The $\mathrm{P}\left({ }^{n} \mathrm{Bu}\right)_{3}$ conversion was $2 \%$ on basis of ${ }^{31} \mathrm{P}$ NMR. After keeping the mixture at room temperature overnight, the $\mathrm{P}\left({ }^{n} \mathrm{Bu}\right)_{3}$ conversion was $3 \%$. The mixture was then heated at $60{ }^{\circ} \mathrm{C}$ for $1 \mathrm{~h}$, the $\mathrm{P}\left({ }^{n} \mathrm{Bu}\right)_{3}$ conversion was $6 \%$. Then the temperature was increased from $60{ }^{\circ} \mathrm{C}$ to $80{ }^{\circ} \mathrm{C}$, the $\mathrm{P}\left({ }^{n} \mathrm{Bu}\right)_{3}$ conversion was $14 \%$ after $1 \mathrm{~h}$, and $55 \%$ overnight. The color of this mixture was brown and new peaks at $1.83 \mathrm{ppm}$ and $1.79 \mathrm{ppm}$ were observed by ${ }^{1} \mathrm{H}$ NMR. After adding degassed hexane to this reaction mixture under $\mathrm{N}_{2}$, a redorange solid precipitated. The red-orange solid was separated by removing the solution, it showed a signal at $1.79 \mathrm{ppm}$ in ${ }^{1} \mathrm{H}$ NMR. 


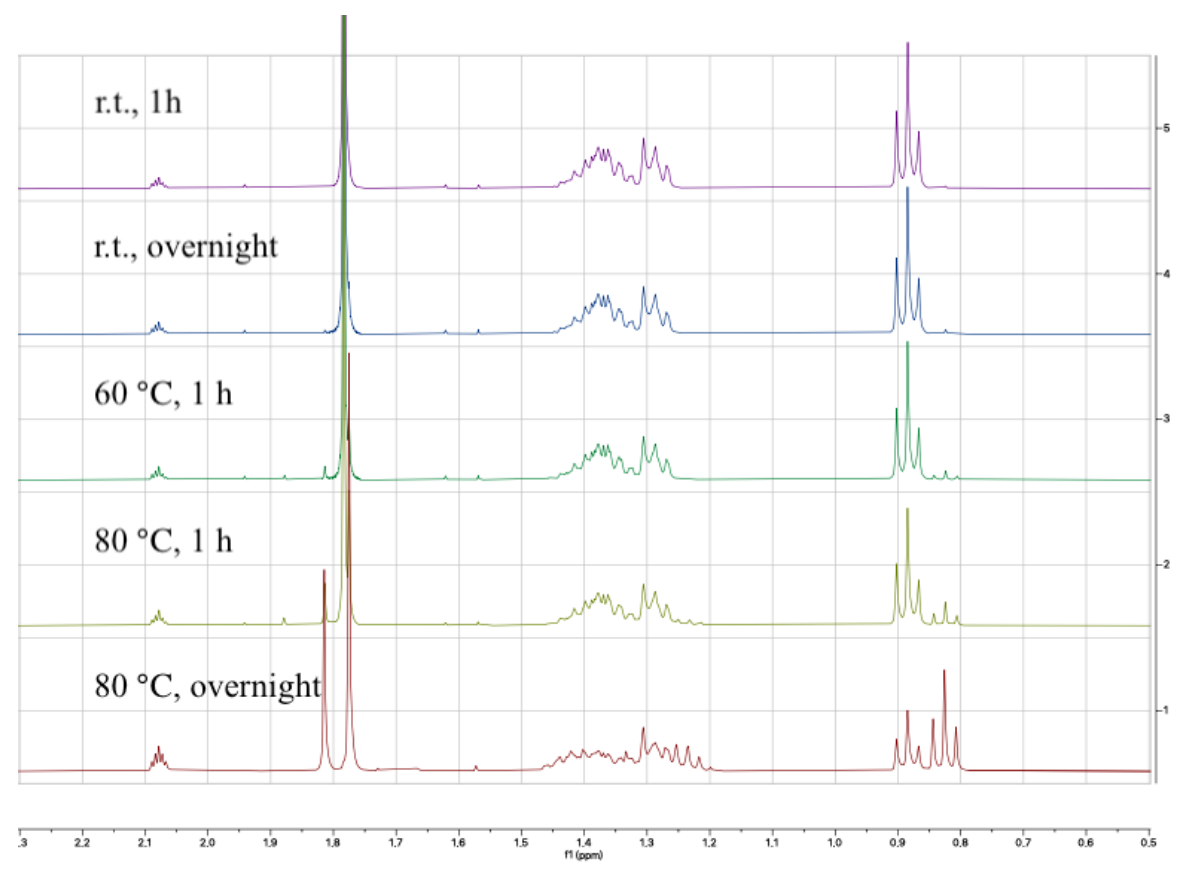

\subsubsection{Monitoring the reaction between 1-phenyl-1,2-ethanediol and $\left[\mathrm{Cp}^{*} \mathrm{MoO}_{2}\right]_{2}$}

$\left[\mathrm{Cp}^{*} \mathrm{MoO}_{2}\right]_{2}(0.004 \mathrm{mmol})$ and 1-phenyl-1,2-ethanediol (0.004 mmol, 1.0 equiv.) were dissolved in toluene- $\mathrm{D}_{8}(0.5 \mathrm{~mL})$ inside a Glove box under nitrogen atmosphere and the mixture was transferred into a J-Young NMR tube. The mixture was heated at $120{ }^{\circ} \mathrm{C}$ under $\mathrm{N}_{2} .{ }^{1} \mathrm{H}$ NMR analysis was carried out before heating and after heating for $1 \mathrm{~h}, 2 \mathrm{~h}$, and overnight. After heating for $2 \mathrm{~h}$ at $120{ }^{\circ} \mathrm{C}$, small amounts of styrene were formed, and full conversion of 1phenyl-1,2-ethanediol was obtained after heating at $120{ }^{\circ} \mathrm{C}$ overnight. Besides the signals of styrene, other non-identified signals were also obtained.

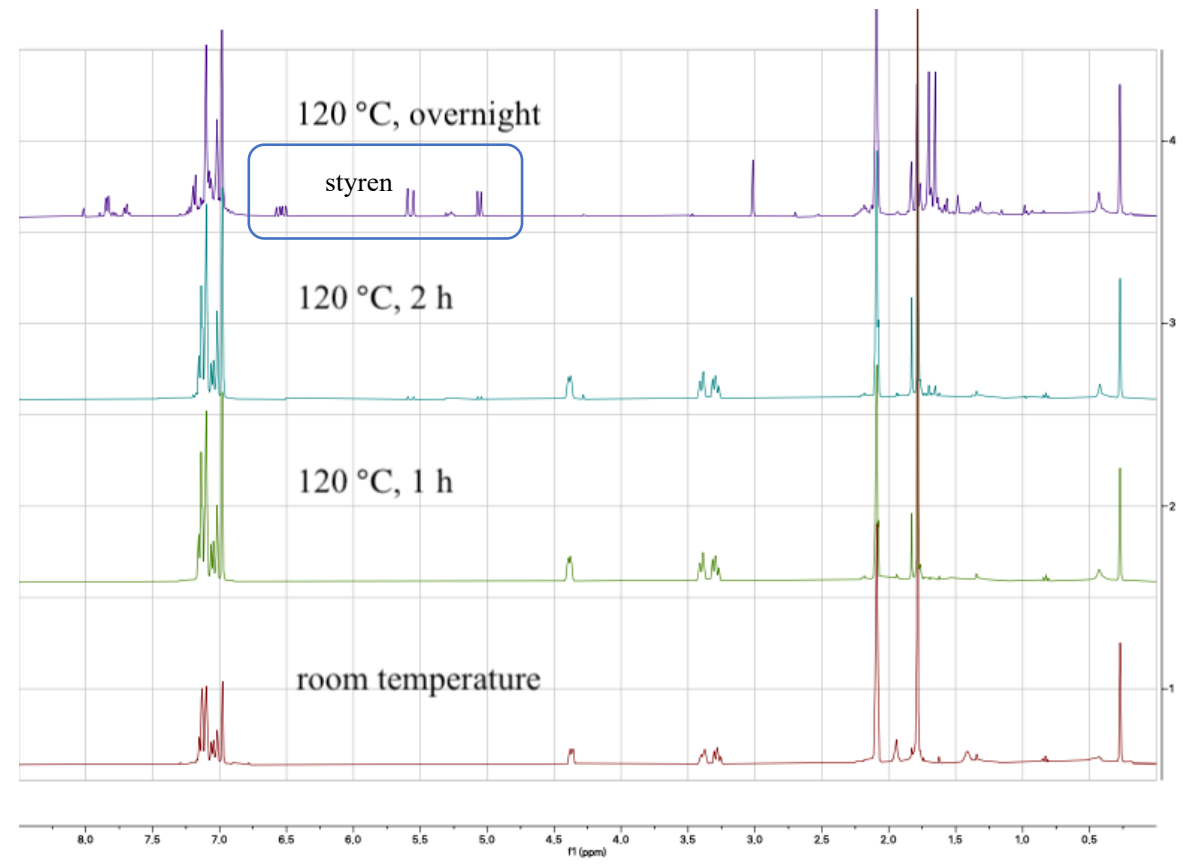




\subsubsection{Monitoring the reaction between 1-phenyl-1,2-ethanediol and $\left[\mathrm{Cp}^{*} \mathrm{MoO}_{2}\right]_{2} \mathrm{O}$}

$\left[\mathrm{Cp}^{*} \mathrm{MoO}_{2}\right]_{2} \mathrm{O}$ (0.02 mmol) and 1-phenyl-1,2-ethanediol (0.04 mmol, 2.0 equiv.) were dissolved in toluene- $\mathrm{D}_{8}(0.5 \mathrm{~mL})$ inside a Glove box under nitrogen atmosphere and the mixture was transferred into a J-Young NMR tube. Variable temperature ${ }^{1} \mathrm{H}$ NMR measurements were done at $25^{\circ} \mathrm{C}, 50{ }^{\circ} \mathrm{C}, 75^{\circ} \mathrm{C}$, and $100^{\circ} \mathrm{C}$; the mixture was measured again after the temperature went back to $25^{\circ} \mathrm{C}$. Considering new signals appeared when heating at $100{ }^{\circ} \mathrm{C}$, the mixture was then heated at $100{ }^{\circ} \mathrm{C}$ for $1 \mathrm{~h}$ and overnight; $6 \%$ of styrene was formed. No acetophenone and aldehydes were formed on the basis of ${ }^{1} \mathrm{H}$ NMR analysis, and quite a lot of 1-phenyl-1,2ethanediol starting material remained.

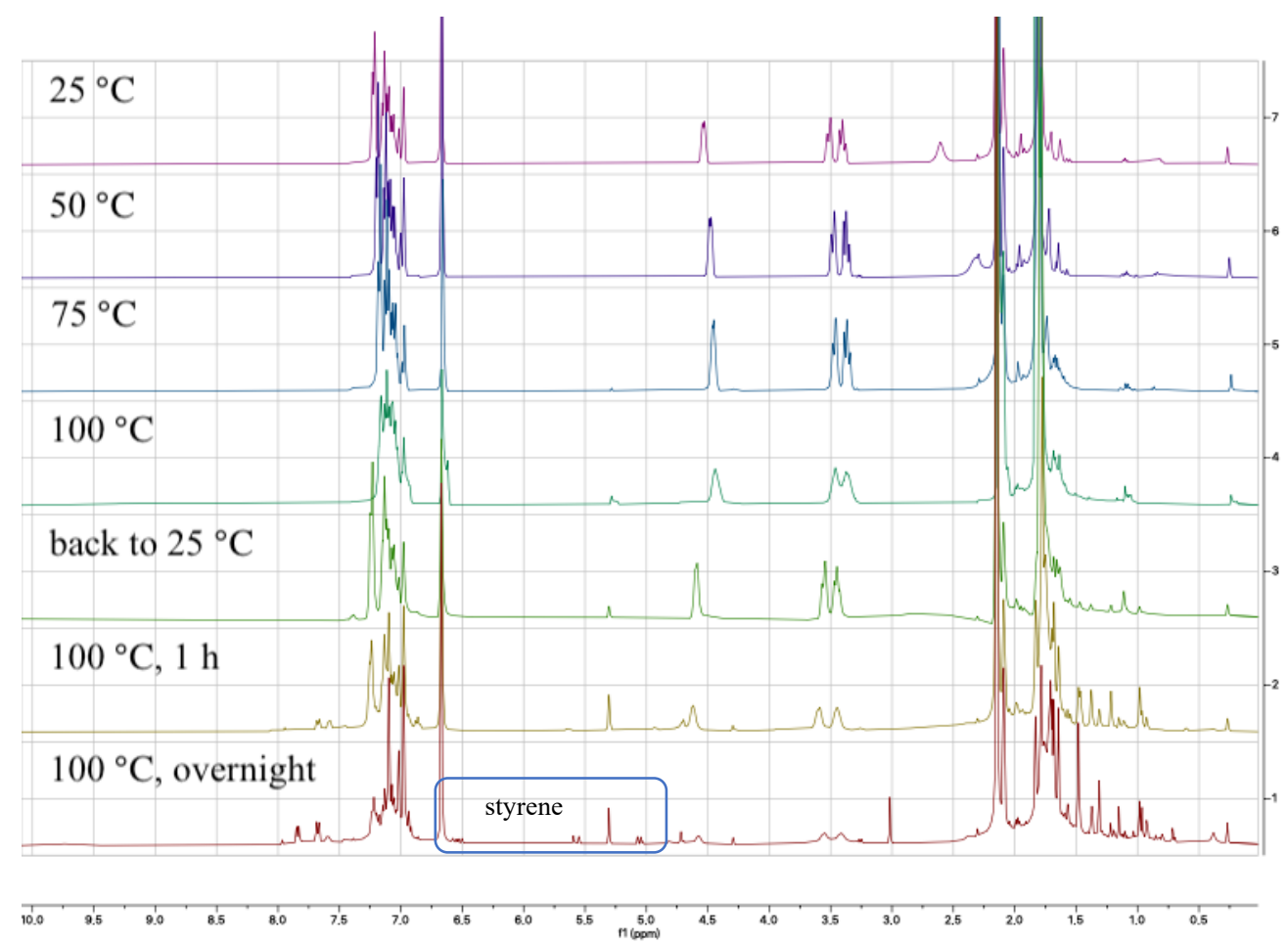

\subsection{References}

[1] S. Raju, M. E. Moret, R. J. M. Klein Gebbink, ACS Catal. 2015, 5, 281-300.

[2] J. R. Dethlefsen, P. Fristrup, ChemSusChem 2015, 8, 767-775.

[3] K. A. Denike, S. M. Kilyanek, R. Soc. open sci. 2019, 6, 1-16.

[4] L. J. Donnelly, S. P. Thomas, J. B. Love, Chem. Asian J. 2019, 14, 3782-3790.

[5] S. C. C. van der Lubbe, C. Fonseca Guerra, C. Chem. - A Eur. J. 2017, 23, 10234.

[6] E. Steffensmeier, K. M. Nicholas, Chem. Commun. 2018, 54, 790-793.

[7] G. Chapman, K. M. Nicholas, Chem. Commun. 2013, 49, 8199-8201.

[8] T. V. Gopaladasu, K. M. Nicholas, ACS Catal. 2016, 6, 1901-1904.

[9] Y. Y. Jiang, J. L. Jiang, Y. Fu, Organometallics 2016, 35, 3388-3396.

[10] A. Galindo, Inorg. Chem. 2016, 55, 2284-2289. 
[11] L. C. De Vicente Poutás, M. Castiñeira Reis, R. Sanz, C. Sliva López, O. Nieto Faza, Inorg. Chem. 2016, 55, 11372-11382.

[12] A. R. Petersen, L. B. Nielsen, J. R. Dethlefsen, P. Fristrup, ChemCatChem 2018, 10, 769-778.

[13] K. M. Kwok, C. K. S. Choong, D. S. W. Ong, J. C. Q. Ng, C. G. Gwie, L. Chen, A. Borgna, Chem CatChem 2017, 9, 2443-2447.

[14] L. Hills, R. Moyano, F. Montilla, A. Pastor, A. Galindo, E. Álvarez, F. Marchetti, C. Pettinari, Eur. J. Inorg. Chem. 2013, 19, 3352-3361.

[15] J. R. Dethlefsen, D. Lupp, B. Oh, P. Fristrup, ChemSusChem 2014, 7, 425-428.

[16] J. R. Dethlefsen, D. Lupp, A. Teshome, L. B. Nielsen, P. Fristrup, ACS Catal. 2015, 5, 3638-3647.

[17] D. Lupp, N. J. Christensen, J. R. Dethlefsen, P. Fristrup, Chem. - A Eur. J. 2015, 21, 3435-3442.

[18] K. Beckerle, A. Sauer, T. P. Spaniol, J. Okuda, Polyhedron 2016, 116, 105-110.

[19] M. Stalpaert, D. De Vos, ACS Sustain. Chem. Eng. 2018, 6, 12197-12204.

[20] R. Tran, S. M. Kilyanek, Dalt. Trans. 2019, 48, 16304-16311.

[21] C. A. Navarro, A. John, Inorg. Chem. Commun. 2019, 99, 145-148.

[22] A. R. Petersen, P. Fristrup, Chem. - A Eur. J. 2017, 23, 10235-10243.

[23] S. Raju, J. T. B. H. Jastrzebski, M. Lutz, R. J. M. Klein Gebbink, ChemSusChem 2013, 6, 1673-1680.

[24] S. Raju, C. A. M. R. Van Slagmaat, J. Li, M. Lutz, J. T. B. H. Jastrzebski, M.-E. Moret, R. J. M. Klein Gebbink, Organometallics 2016, 35, 2178-2187.

[25] J. Li, M. Lutz, M. Otte, R. J. M. Klein Gebbink, ChemCatChem 2018, 10, 4755-4760.

[26] R. Poli, Coord. Chem. Rev. 2008, 252, 1592-1612.

[27] M. Herberhold, W. Kremnitz, A. Razavi, H. Schöllhorn, U. Thewalt, Angew Chem. Int. Ed. Engl. 1985, 2, 601-602.

[28] P. Sözen-aktas, E. Manoury, F. Demirhan, R. Poli, Eur. J. Inorg. Chem. 2013, 2013, 2728-2735.

[29] C. Bhaumik, E. Manoury, J. Daran, P. Sözen-aktas, F. Demirhan, R. Poli, J. Organomet. Chem. 2014, 760, 115-123.

[30] M. Scheer, K. Schuster, K. Schenzel, E. Herrmann, Z. anorg. allg. Chem. 1991, 600, 109-119.

[31] K. Umakoshi, K. Isobe, J. Organomet. Chem. 1990, 395, 47-53.

[32] J. Sundermeyer, U. Radius, C. Burschka, Chem. Ber. 1992, 125, 2379-2384.

[33] P. C. McGowan, T. J. Podesta, M. Thornton-Pett, Inorg. Chem. 2001, 40, 1445-1453.

[34] T. Welton, R. Soc. Publ. 2015, 471.

[35] D. Prat, J. Hayler, A. Wells, Green Chem. 2014, 16, 4546-4551.

[36] A. M. Khenkin, R. Neumann, Adv. Synth. Catal. 2002, 344, 1017-1021.

[37] S. T. Pritam, S. Harbans, (Miss) Parveen. Bull. Chem. Soc. Jpn. 1983, 56, 1536-1538.

[38] H. Arzoumanian, A. Baldy, M. Pierrot, J.-F. Petrignani, J. Organomet. Chem. 1985, 294, 327-331.

[39] A. M. M. Schreurs, X. Xian, L. M. J. Kroon-Batenburg. J. Appl. Cryst. 2010, 43, 70-82.

[40] G. M. Sheldrick (2014). TWINABS. Universität Göttingen, Germany.

[41] G. M. Sheldrick. Acta Cryst. 2015, A71, 3-8.

[42] G. M. Sheldrick. Acta Cryst. 2015, C71, 3-8.

[43] R. Herbst-Irmer, G. M. Sheldrick. Acta Cryst. 1998, B54, 443-449.

[44] A. L. Spek. Acta Cryst. 2009, D65, 148-155. 


\title{
Chapter 5
}

\author{
N,N,O-supported Tricarbonylrhenium Pre-catalysts \\ for the Aerobic Deoxydehydration of Diols and Polyols
}

\begin{abstract}
Rhenium complexes are well known catalysts for the deoxydehydration (DODH) of vicinal diols (glycols). In this work, we report on the DODH of diols and biomass-derived polyols using $\mathrm{L}^{4} \mathrm{Re}(\mathrm{CO})_{3}$ as pre-catalyst $\left(\mathrm{L}^{4} \mathrm{Re}(\mathrm{CO})_{3}=\right.$ tricarbonylrhenium 2,4-di-tert-butyl-6- $(((2-$ (dimethylamino)ethyl)(methyl)amino)methyl)phenolate). The DODH reaction was optimized using $2 \mathrm{~mol} \%$ of $\mathrm{L}^{4} \mathrm{Re}(\mathrm{CO})_{3}$ as pre-catalyst and 3-octanol as both reductant and solvent under aerobic conditions, generating the active high-valent rhenium species in situ. Both diol and biomass-based polyol substrates could be applied in this system to form the corresponding olefins with moderate to high yield. Typical features of this aerobic DODH system include a low tendency for the isomerization of aliphatic external olefin products to internal olefins, a high butadiene selectivity in the DODH of erythritol, the preferential formation of 2-vinylfuran from sugar substrates, and an overall low pre-catalyst loading. Several of these features indicate the formation of an active species that is different from the species formed in DODH by rhenium-trioxo catalysts. Overall, the bench-top stable and synthetically easily accessible, lowvalent $\mathrm{NNO}$-rhenium complex $\mathrm{L}^{4} \mathrm{Re}(\mathrm{CO})_{3}$ represents an interesting alternative to high-valent rhenium catalysts in DODH chemistry.
\end{abstract}

This chapter is based on:

J. Li, M. Lutz, R. J. M. Klein Gebbink, Catal. Sci. Technol. 2020, DOI: 10.1039/d0cy00618a 


\subsection{Introduction}

Due to the increased consumption of fossil hydrocarbon resources, the development of alternative and sustainable feedstocks is highly recommended. ${ }^{[1,2]}$ Biomass-derived feedstocks are considered as attractive and renewable resources for a sustainable chemical industry. ${ }^{[3,4]}$ One of the many challenges in biomass conversion and valorization is the defunctionalization of oxygen-rich molecular components obtained after depolymerization of cellulosic biomass. ${ }^{[5]}$ Deoxydehydration (DODH) reactions, which formally combine deoxygenation ${ }^{[6,7]}$ and dehydration, ${ }^{[8]}$ can efficiently remove vicinal hydroxyl groups to form the corresponding olefin. The successful application of DODH reactions on oxygen-rich biomass components would provide access to a variety of low-volume, high-value chemicals. ${ }^{[9-11]}$

High-valent rhenium complexes are known as catalysts for the DODH of diols and polyols, ${ }^{[9]}$ while low-valent rhenium complexes, e.g., $\operatorname{Re}_{2}(\mathrm{CO})_{10}$ and $\mathrm{BrRe}(\mathrm{CO})_{5}$, can also initiate DODH reactions in the presence of oxygen. ${ }^{[12]}$ Among the high-valent rhenium complexes, Cp-based trioxorhenium complexes $\left(\mathrm{Cp}^{\prime} \mathrm{ReO}_{3}, \mathrm{Cp}^{\prime}=\right.$ substituted cyclopentadienyl) show high catalytic activity and DODH product selectivity. A drawback in the development of this type of Cp'Re complexes is that the overall yield of the synthesis of the final $\mathrm{Cp}^{\prime} \mathrm{ReO}_{3}$ complexes is rather low (4\% to $49 \%$ starting from $\mathrm{Cp}$ ' $\mathrm{H} / \mathrm{Re}$ ), mainly because the trioxo-rhenium species decomposes under the oxidizing conditions of its synthesis from $\mathrm{Cp}^{\prime} \operatorname{Re}(\mathrm{CO})_{3} \cdot{ }^{[13]} \mathrm{A}$ possible way to solve this problem is to use $\mathrm{Cp}{ }^{\prime} \operatorname{Re}(\mathrm{CO})_{3}$ as a pre-catalyst to form the corresponding $\mathrm{Cp}^{\prime} \mathrm{ReO}_{3}$ species in situ during catalysis in the presence of oxygen. Yet, on the basis of the work of Ellman and Bergman, $\mathrm{Cp}^{*} \operatorname{Re}(\mathrm{CO})_{3}$ is not active towards the deoxydehydration of diols under aerobic conditions. ${ }^{[12]}$

For this reason, we were interested in other low-valent Re-complexes that would allow for an oxidative activation to provide in-situ access to high-valent Re-trioxo complexes for DODH catalysis. Accordingly, we have started to investigate Re-complexes derived from anionic NNO-type ligands. Such ligands provide an anionic $6 \mathrm{e}^{-}$platform that is isoelectronic to Cp'type ligands, and potentially coordinate to Re in a facial fashion similar to $\mathrm{Cp}$ ' ligands. Here, we report on the synthesis and characterization of novel low-valent (NNO)Re(I) tricarbonyl complexes, in which NNO represents an open chain bis-amino-phenol ligand (NNO = 2-(( (2(dimethylamino)ethyl)(methyl)amino)methyl) phenol), and on the use of these complexes as pre-catalysts in the aerobic DODH of vicinal diols and polyols. 


\subsection{Results and Discussion}

\subsubsection{Synthesis and characterization of (NNO)Re(I) tricarbonyl complexes}

The NNO-type ligands (HL) were synthesized via direct reductive amination of N,N,N'trimethylethylenediamine with a phenolic aldehyde using $\mathrm{NaBH}(\mathrm{OAc})_{3}$ (1.5 equiv.) in dichloroethane (Scheme 5.2.1). ${ }^{[14]}$ The preligand HL was then reflux with $\operatorname{BrRe}(\mathrm{CO})_{5}$ and an excess amount of $\mathrm{NaOAc}$ in toluene to form the corresponding $\mathrm{LRe}(\mathrm{CO})_{3}$ complexes. ${ }^{[15]}$ After recrystallization, all $\mathrm{LRe}(\mathrm{CO})_{3}$ complexes were isolated as needle-like crystalline materials. The complexes synthesized in this way are summarized in Figure 5.2.1.
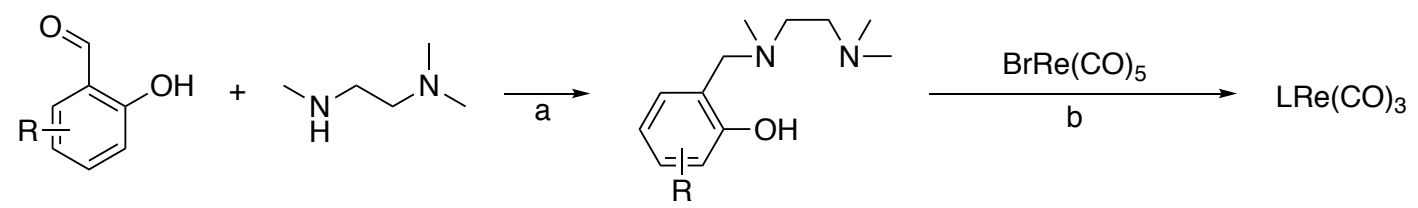

HL

Scheme 5.2.1. Synthesis of NNO-based tricarbonylrhenium complexes: a. $\mathrm{NaBH}(\mathrm{OAc})_{3}$ (1.5 equiv.), dichloroethane, r.t., overnight, $\mathrm{N}_{2} ;$ b. NaOAc (10 equiv.), toluene, reflux, 3 h, $\mathrm{N}_{2}$.

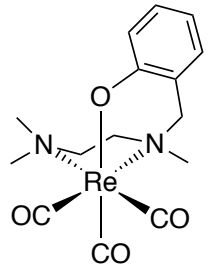

$\mathrm{L}^{1} \operatorname{Re}(\mathrm{CO})_{3}$

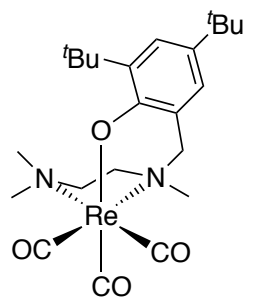

$\mathrm{L}^{4} \operatorname{Re}(\mathrm{CO})_{3}$

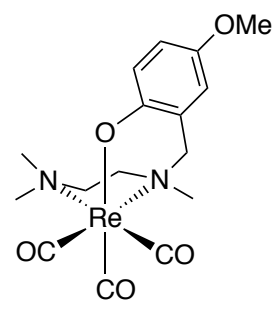

$\mathrm{L}^{2} \operatorname{Re}(\mathrm{CO})_{3}$

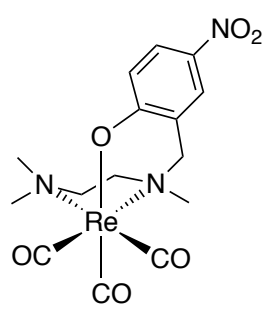

$\mathrm{L}^{3} \operatorname{Re}(\mathrm{CO})_{3}$

Figure 5.2.1. (NNO)tricarbonylrhenium complexes reported in this work.

The structures of $\mathrm{L}^{1} \mathrm{Re}(\mathrm{CO})_{3}, \mathrm{~L}^{3} \mathrm{Re}(\mathrm{CO})_{3}$, and $\mathrm{L}^{4} \mathrm{Re}(\mathrm{CO})_{3}$ were established by X-ray crystal structure determination (Figure 5.2.2). Selected geometrical parameters are given in Table 5.2.1. Diffraction-quality crystals of $\mathrm{L}^{1} \operatorname{Re}(\mathrm{CO})_{3}$ and $\mathrm{L}^{3} \mathrm{Re}(\mathrm{CO})_{3}$ were obtained by diffusion of diethyl ether into acetonitrile solutions of the complexes at room temperature. Diffraction-quality 
crystals of $\mathrm{L}^{4} \mathrm{Re}(\mathrm{CO})_{3}$ were obtained by recrystallization from $\mathrm{Et}_{2} \mathrm{O} /$ hexane $(1: 2)$ at $-30{ }^{\circ} \mathrm{C}$. In all three complexes nitrogen atom N1 is chiral, but the compounds crystallize as racemates in centrosymmetric space groups. They showcase the overall octahedral geometry of the complexes discussed here with the tripodal N,N,O-ligand coordinated to rhenium in a facial manner. Due to the chelating binding mode the bond angles around Re deviate from the perfect $90^{\circ}$ and range from 79.66(14)-96.98(17) ${ }^{\circ}$ in $\mathrm{L}^{1} \mathrm{Re}(\mathrm{CO})_{3}, 79.51(10)-96.66(13)^{\circ}$ in $\mathrm{L}^{3} \operatorname{Re}(\mathrm{CO})_{3}$, and 80.03(12)-96.17(15) ${ }^{\circ}$ in $\mathrm{L}^{4} \operatorname{Re}(\mathrm{CO})_{3}$. The five-membered chelate rings in $\mathrm{L}^{1} \operatorname{Re}(\mathrm{CO})_{3}$ and $\mathrm{L}^{3} \mathrm{Re}(\mathrm{CO})_{3}$ are best described as twist conformations, while in $\mathrm{L}^{4} \mathrm{Re}(\mathrm{CO})_{3}$ the ring adopts an envelope conformation. The six-membered chelate rings in $\mathrm{L}^{1} \operatorname{Re}(\mathrm{CO})_{3}$ and $\mathrm{L}^{3} \operatorname{Re}(\mathrm{CO})_{3}$ are in an envelope conformation, in $\mathrm{L}^{4} \mathrm{Re}(\mathrm{CO})_{3}$ it is intermediate between a boat and twist conformation as indicated by the deviation of N1 and Re1 from the least-squares plane of the phenyl ring of the phenolate donor (Table 5.2.2). Further characterization of the complexes included ${ }^{1} \mathrm{H}$ NMR, ${ }^{13} \mathrm{C}$ NMR, IR, ESI-MS, and elemental analysis (see experimental section).
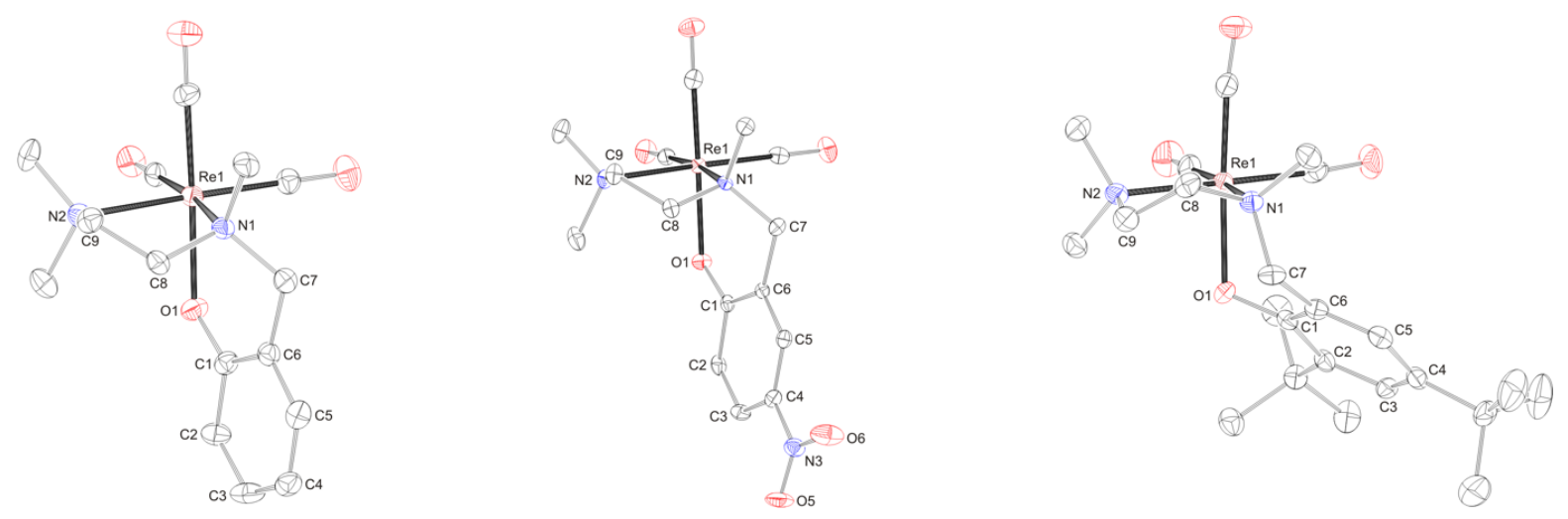

Figure 5.2.2. Molecular structures of $\mathrm{L}^{1} \mathrm{Re}(\mathrm{CO})_{3}, \mathrm{~L}^{3} \mathrm{Re}(\mathrm{CO})_{3}$, and $\mathrm{L}^{4} \mathrm{Re}(\mathrm{CO})_{3}$ in the crystal. Displacement ellipsoids are drawn at the $50 \%$ probability level. Hydrogen atoms are omitted for clarity.

Table 5.2.1. Selected bond lengths $[\AA]$, angles and torsion angles $\left[^{\circ}\right]$ in complexes $\mathrm{L}^{1} \operatorname{Re}(\mathrm{CO})_{3}$, $\mathrm{L}^{3} \operatorname{Re}(\mathrm{CO})_{3}$, and $\mathrm{L}^{4} \operatorname{Re}(\mathrm{CO})_{3}$.

\begin{tabular}{cccc}
\hline & $\mathrm{L}^{1} \operatorname{Re}(\mathrm{CO})_{3}$ & $\mathrm{~L}^{3} \operatorname{Re}(\mathrm{CO})_{3}$ & $\mathrm{~L}^{4} \operatorname{Re}(\mathrm{CO})_{3}$ \\
\hline Re1-O1 & $2.111(3)$ & $2.122(2)$ & $2.144(3)$ \\
Re1-N1 & $2.235(4)$ & $2.238(3)$ & $2.247(3)$ \\
Re1-N2 & $2.278(4)$ & $2.275(3)$ & $2.262(3)$ \\
C1-O1 & $1.330(5)$ & $1.309(4)$ & $1.354(4)$ \\
C7-N1-C8 & $109.4(3)$ & $110.1(3)$ & $108.7(3)$ \\
C1-C6-C7-N1 & $39.9(6)$ & $43.3(5)$ & $-65.1(5)$ \\
N1-C8-C9-N2 & $57.5(5)$ & $58.8(4)$ & $-60.0(4)$ \\
\hline
\end{tabular}


Table 5.2.2. Deviations of $\mathrm{N} 1$ and $\mathrm{Re} 1[\AA]$ from the least-squares plane of the phenyl ring $(\mathrm{O} 1, \mathrm{C} 1-\mathrm{C} 7)$ in complexes $\mathrm{L}^{1} \mathrm{Re}(\mathrm{CO})_{3}, \mathrm{~L}^{3} \mathrm{Re}(\mathrm{CO})_{3}$, and $\mathrm{L}^{4} \mathrm{Re}(\mathrm{CO})_{3}$.

\begin{tabular}{cccc}
\hline & $\mathrm{L}^{1} \operatorname{Re}(\mathrm{CO})_{3}$ & $\mathrm{~L}^{3} \operatorname{Re}(\mathrm{CO})_{3}$ & $\mathrm{~L}^{4} \operatorname{Re}(\mathrm{CO})_{3}$ \\
\hline $\mathrm{N} 1$ & $0.819(4)$ & $0.872(3)$ & $1.017(3)$ \\
$\mathrm{Re} 1$ & $0.0427(2)$ & $0.1875(4)$ & $1.7545(4)$ \\
\hline
\end{tabular}

In the IR spectrum of $\mathrm{BrRe}(\mathrm{CO})_{3}$, two absorption signals at 1956 and $2023 \mathrm{~cm}^{-1}$ were observed (Table 5.2.3). In case of the NNO-ligand supported tricarbonylrhenium complexes and $\mathrm{Cp}^{\mathrm{ttt}} \mathrm{Re}(\mathrm{CO})_{3}$, three absorption bands at 1851-1889, 1873-1921, and 2007-2016 $\mathrm{cm}^{-1}$ were observed. These absorption bands are attributed to the symmetric and asymmetric $v(\mathrm{CO})$ stretches. The similarity of IR spectra indicates that the NNO-ligand supported tricarbonylrhenium complexes have a similar structure in the solid state, that is, a octahedral geometry structure with the tripodal N,N,O-ligand coordinated to rhenium in a facial manner.

Table 5.2.3. Solid-state infrared $v(\mathrm{CO})$ data of penta/tricarbonylrhenium complexes.

\begin{tabular}{ccc}
\hline entry & {$[\mathrm{Re}]$} & Infrared $v(\mathrm{CO})\left(\mathrm{cm}^{-1}\right)$ \\
\hline 1 & $\mathrm{BrRe}(\mathrm{CO})_{5}$ & 1956,2023 \\
2 & $\mathrm{~L}^{1} \operatorname{Re}(\mathrm{CO})_{3}$ & $1877,1918,2014$ \\
3 & $\mathrm{~L}^{2} \operatorname{Re}(\mathrm{CO})_{3}$ & $1859,1886,2007$ \\
4 & $\mathrm{~L}^{3} \operatorname{Re}(\mathrm{CO})_{3}$ & $1884,1921,2016$ \\
5 & $\mathrm{~L}^{4} \operatorname{Re}(\mathrm{CO})_{3}$ & $1851,1894,2010$ \\
6 & $\mathrm{~L}^{5} \operatorname{Re}(\mathrm{CO})_{3}$ & $1855,1873,2007$ \\
7 & $\mathrm{Cp}^{\mathrm{ttt}} \operatorname{Re}(\mathrm{CO})_{3}$ & $1889,1911,2007$ \\
\hline
\end{tabular}

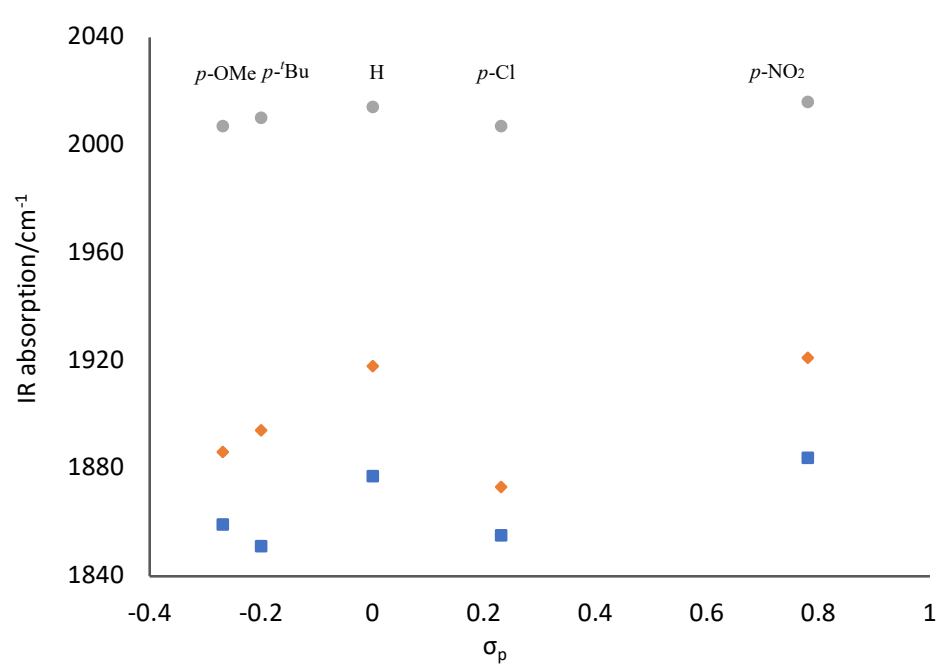

Figure 5.2.3. Relation between the Hammett parameter $\left(\sigma_{\mathrm{p}}\right)$ of the phenolate para-substituent and the IR wavenumbers of the $\mathrm{CO}$ vibrations for $\mathrm{LRe}(\mathrm{CO})_{3}$ complexes. 
Besides, a trend in the energies of the IR absorptions was observed in relation to the electronic properties of the substituents on the phenol ring. Figure 3 shows the wavenumbers of the IR absorptions plotted against the Hammett constants $\left(\sigma_{\mathrm{p}}\right)$ of the para-substituents. ${ }^{[16]}$. Although electronic effects of the ortho-substituents may also be involved for $\mathrm{L}^{4} \mathrm{Re}(\mathrm{CO})_{3}$ and $\mathrm{L}^{5} \operatorname{Re}(\mathrm{CO})_{3}$, the overall trend clearly shows that the more electron-donating para-substituents give rise to lower energies of the $\mathrm{CO}$ vibrations. In other words, the $\mathrm{CO}$ ligands are more strongly coordinated to the more electron-rich rhenium centers.

\subsubsection{Initial catalytic studies}

With the new NNO-Re complexes in hand, we started our catalytic investigation by applying the parent $\mathrm{L}^{1} \mathrm{Re}(\mathrm{CO})_{3}$ complex $(2 \mathrm{~mol} \%)$ to the deoxydehydration of 1,2-octanediol using triphenylphosphine $\left(\mathrm{PPh}_{3}\right)$ as reductant and chlorobenzene as solvent. Running the reaction under oxygen-free conditions gave no 1-octene formation, while $12 \%$ of 1 -octene was formed under aerobic conditions. This result indicates that an active DODH species, likely a high-valent rhenium species, can be formed starting from $\mathrm{L}^{1} \operatorname{Re}(\mathrm{CO})_{3}$ in the presence of oxygen.

Since secondary alcohols have been reported as both reductants and solvents for Re-catalyzed DODH reactions, ${ }^{[12]}$ we also investigated the $\mathrm{L}^{1} \mathrm{Re}(\mathrm{CO})_{3}$ initiated DODH of 1,2-octanediol using 3-octanol as both reductant and solvent: $0.5 \mathrm{mmol}$ of 1,2-octanediol was dissolved in 5 $\mathrm{mL}$ of 3 -octanol, $2 \mathrm{~mol} \%$ of $\mathrm{L}^{1} \operatorname{Re}(\mathrm{CO})_{3}$ was used as pre-catalyst (Table 5.2.4). The mixture was then heated at $180{ }^{\circ} \mathrm{C}$ in a closed pressure tube. The amount of $\mathrm{O}_{2}$ present in the reaction mixture was approximately 18 equiv. on the basis of $\mathrm{L}^{1} \mathrm{Re}(\mathrm{CO})_{3}$. A sample was taken for ${ }^{1} \mathrm{H}$ NMR analysis after the mixture was heated for $3 \mathrm{~h} .71 \%$ of 1 -octene had formed, as well as dehydration products (2-/3-octene) derived from 3-octanol. The ratio of 1-octene and 2-/3octene was 3.23:1. In order to reach full conversion of 1,2-octanediol, the mixture was heated for another $3 \mathrm{~h}$, after which $96 \%$ of 1 -octene had formed. The ratio of 1 -octene and 2-/3-octene after $3 \mathrm{~h}$ was 1.71:1, which can be explained on the basis of the continued dehydration of the 3-octanol solvent/reductant while diol DODH reaches close to full conversion (Table 5.2.4, entry 2). When applying $\operatorname{BrRe}(\mathrm{CO})_{5}$ as the pre-catalyst under these conditions for $3 \mathrm{~h}, 1,2-$ octanediol was fully converted forming $94 \%$ of 1 -octene, as well as a significant amount of 2/3-octene (ratio 0.97:1; entry 1). $\operatorname{BrRe}(\mathrm{CO})_{5}$ therefore seems to promote both the deoxydehydration of 1,2-octandiol and the dehydration of 3-octanol without a particular preference. The tendency of $\mathrm{L}^{1} \mathrm{Re}(\mathrm{CO})_{3}$ to promote the dehydration of 3-octanol is significantly lower as compared to $\mathrm{BrRe}(\mathrm{CO})_{5}$. 
Table 5.2.4. DODH of 1,2-octanediol in 3-octanol initiated by low-valent Re-carbonyl complexes under

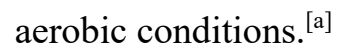

\begin{tabular}{|c|c|c|c|c|}
\hline entry & {$[\mathrm{Re}]$} & $\mathrm{t}$ & yield $^{[b]}$ & $\mathrm{n}(1-): \mathrm{n}(2-/ 3-)^{[\mathrm{c}]}$ \\
\hline 1 & $\operatorname{BrRe}(\mathrm{CO})_{5}$ & $3 \mathrm{~h}$ & $94 \%$ & 0.97:1 \\
\hline 2 & $\mathrm{~L}^{1} \mathrm{Re}(\mathrm{CO})_{3}$ & $\begin{array}{c}3 \mathrm{~h} \\
6 \mathrm{~h}^{[\mathrm{d}]}\end{array}$ & $\begin{array}{l}71 \% \\
96 \%\end{array}$ & $\begin{array}{l}3.23: 1 \\
1.71: 1\end{array}$ \\
\hline 3 & $\mathrm{~L}^{2} \mathrm{Re}(\mathrm{CO})_{3}$ & $3 \mathrm{~h}$ & $83 \%$ & 2.11:1 \\
\hline 4 & $\mathrm{~L}^{2} \operatorname{Re}(\mathrm{CO})^{3}$ & $6 \mathrm{~h}^{[\mathrm{d}]}$ & $95 \%$ & $1.5: 1$ \\
\hline 5 & $\mathrm{~L}^{3} \mathrm{Re}(\mathrm{CO})^{3}$ & $\begin{array}{c}3 \mathrm{~h} \\
6 \mathrm{~h}^{[\mathrm{d}]}\end{array}$ & $\begin{array}{l}13 \% \\
56 \%\end{array}$ & $\begin{array}{l}0.89: 1 \\
2.77: 1\end{array}$ \\
\hline 6 & $\mathrm{~L}^{3} \mathrm{Re}(\mathrm{CO})_{3}$ & $6 \mathrm{~h}$ & $13 \%$ & $0.74: 1$ \\
\hline 7 & $\mathrm{~L}^{4} \mathrm{Re}(\mathrm{CO})_{3}$ & $3 \mathrm{~h}$ & $92 \%$ & $2.52: 1$ \\
\hline 8 & $\mathrm{~L}^{5} \mathrm{Re}(\mathrm{CO})_{3}$ & $\begin{array}{c}3 \mathrm{~h} \\
6 \mathrm{~h}^{[\mathrm{d}]}\end{array}$ & $\begin{array}{l}21 \% \\
65 \%\end{array}$ & $\begin{array}{l}1.23: 1 \\
2.71: 1\end{array}$ \\
\hline \multirow[t]{2}{*}{9} & $\mathrm{Cp}^{\mathrm{ttt}} \mathrm{Re}(\mathrm{CO})_{3}$ & $3 \mathrm{~h}$ & $8 \%$ & $0.62: 1$ \\
\hline & & $6 \mathrm{~h}^{[\mathrm{d}]}$ & $8 \%$ & $0.62: 1$ \\
\hline $10^{[\mathrm{e}]}$ & $\mathrm{L}^{4} \mathrm{Re}(\mathrm{CO})_{3}$ & $3 \mathrm{~h}$ & $56 \%$ & $14: 1$ \\
\hline
\end{tabular}

[a] Reaction conditions: 1,2-octanediol $(0.5 \mathrm{mmol})$, rhenium pre-catalyst $(0.01 \mathrm{mmol}, 2 \mathrm{~mol} \%), 3-$ octanol (5 mL), $180{ }^{\circ} \mathrm{C}$ (temperature of oil bath), air. [b] 1-Octene yield determined by ${ }^{1} \mathrm{H}$ NMR using mesitylene $(0.5 \mathrm{mmol})$ as an internal standard. [c] Ratio of 1-octene and 2-/3-octene product isomers. [d] The reaction mixture was heated in a closed pressure tube with air for $3 \mathrm{~h}$, then the reaction was cooled to room temperature, a sample was taken from the reaction mixture. After sampling the reaction mixture, the pressure tube was closed again and heated for another $3 \mathrm{~h}$, in which case more air entered the reaction system. [e] Instead of $5 \mathrm{~mL}, 1 \mathrm{~mL}$ of 3-octanol was used. Conversion of 1,2-octanediol was $56 \%$.

After this initial study, the other NNO-based tricarbonylrhenium complexes were also investigated using the same DODH conditions (Table 5.2.4). With an electron-donating methoxy group at the para-position of the phenol moiety (complex $\mathrm{L}^{2} \operatorname{Re}(\mathrm{CO})_{3}$ ), a slightly higher 1-octene yield (83\%) was obtained after $3 \mathrm{~h}$ (entry 3). Upon full 1,2-octanediol conversion after $6 \mathrm{~h}$, the 1-octene yield was 95\% (entry 4). With an electron-withdrawing nitro substituent at the para-position of the phenol (complex $\left.\mathrm{L}^{3} \operatorname{Re}(\mathrm{CO})_{3}\right)$, a 1-octene yield of only $13 \%$ was achieved after $3 \mathrm{~h}$ (entry 5). After having taken a sample for analysis, and exposing the reaction mixture to more air, the 1-octene yield increased to $56 \%$ after closing the reaction tube again and heating it for another $3 \mathrm{~h}$. When this same reaction was carried for $6 \mathrm{~h}$ without opening the reaction tube (entry 6 ), the 1 -octene yield was only $13 \%$, i.e. the same as heating the mixture for $3 \mathrm{~h}$. This result indicates that the activation of $\mathrm{L}^{3} \operatorname{Re}(\mathrm{CO})_{3}$ was not complete after heating for $3 \mathrm{~h}$. After exposing the reaction mixture to more oxygen/air, $\mathrm{L}^{3} \operatorname{Re}(\mathrm{CO})_{3}$ was 
further activated, resulting in an enhanced formation of 1-octene, as well as an increased 1octene to 2-/3-octene product ratio (change from 0.89:1 to 2.77:1). In case of the bis(tert-butyl)substituted complex $\mathrm{L}^{4} \operatorname{Re}(\mathrm{CO})_{3}$, full conversion of 1,2-octanediol was achieved after $3 \mathrm{~h}$, achieving a 1-octene yield of $92 \%$ at a $2.52: 1$ ratio of 1 -octene and 2-/3-octene (entry 7 ). For the o,p-dichlorinated complex $\mathrm{L}^{5} \operatorname{Re}(\mathrm{CO})_{3}$, only $21 \%$ of 1 -octene was formed after heating for $3 \mathrm{~h}$, and $65 \%$ after heating the mixture for another $3 \mathrm{~h}$ after exposure to air (entry 8). As a comparison, $\mathrm{Cp}^{\mathrm{ttt}} \mathrm{Re}(\mathrm{CO})_{3}\left(\mathrm{Cp}^{\mathrm{ttt}}=1,2,4\right.$-tri-tert-butylcyclopentadienyl) was also investigated under these reaction conditions, providing only $8 \%$ of 1 -octene with or without additional exposure to air and extending the reaction time. Besides, the 1-octene to 2-/3-octene product ratio was $0.62: 1$.

Interestingly, this series of experiments shows the preference of the NNO-based tricarbonylrhenium complexes, upon exposure to air, to engage in diol deoxydehydration over secondary alcohol dehydration. The concentration of 1,2-octanediol in these experiments was much lower than that of 3-octanol. However, more deoxydehydration product from 1,2octanediol was formed than dehydration product from 3-octanol. A higher concentration of 1,2octanediol was tested (entry 10), by decreasing the amount of 3-octanol from 5 to $1 \mathrm{~mL}$. In this case, $56 \%$ of 1 -octene was formed at $56 \%$ of 1,2 -octanediol conversion, i.e. full selectivity for olefin formation. The ratio of 1 -octene and 2-/3-octene in this experiment was 14:1. This result strengthens the notion that $\mathrm{DODH}$ is kinetically favoured for all $\operatorname{LRe}(\mathrm{CO})_{3}$ pre-catalysts, although dehydration of the secondary alcohol reductant is always observed to a significant extent.

These initial catalysis experiments also show the beneficial effect of electron-donating substituents at the phenol moiety on both the overall DODH product formation and the DODH vs dehydration product ratio. A likely explanation for this observation is the stabilization of the high-valent $\mathrm{Re}^{\mathrm{VII}}$ center in the anticipated trioxo-complexes by the more electron-rich donor ligands, even though a more electron-rich Re-center would also lead to more firmly bound COligands which could hamper oxidation of the low-valent carbonyl complexes. The catalysis data shown in Table 5.2.4 are in line with the trend in $\mathrm{CO}$ vibrational energies depicted in Figure 5.2.3. Based on these observations, the di(tert-butyl) substituted complex $\mathrm{L}^{4} \operatorname{Re}(\mathrm{CO})_{3}$ was selected as the pre-catalyst for further investigation and optimization of DODH reactions of diols and polyols.

\subsubsection{Reductants screening}


As the next step in the protocol optimization, different alcohol reductants, including primary and secondary alcohols, were investigated (Table 5.2.5). No 1-octene was detected when 1butanol and 2-butanol were used as reductant and solvent (entries 1 and 2). Surprisingly, with 3-pentanol and 2,4-dimethyl-3-pentanol, which have been reported as good reductants in highvalent rhenium-catalyzed DODH reactions, ${ }^{[12,17-21]}$ only $14 \%$ and trace amounts of 1-octene were formed, respectively (entry 3 and 4). When using 3-pentanol, a small amount (4\%) of 2pentene was observed. Other secondary alcohols, such as 2-octanol and 4-octanol, were also investigated. When using 2-octanol as reductant and solvent, $88 \%$ of 1 -octene was formed from 1,2-octanediol, and 49\% (=n2-octene/n1,2-octanediol) of 2-octene was observed (entry 5). When 4 -octanol was used, only $20 \%$ of 1 -octene was formed, together with $4 \%$ (=n3-/4octene/n1,2-octanediol) of 3-/4-octene (entry 7). Besides, 1,2-octanediol itself could also be used as reductant; in this case $32 \%$ of 1 -octene was formed (entry 8 ). Based on these results, it was decided to stick with 3-octanol as the reductant and solvent in further investigations.

Table 5.2.5. $\mathrm{L}^{4} \mathrm{Re}(\mathrm{CO})_{3}$ catalyzed DODH of 1,2-octanediol using different alcohol reductants. ${ }^{\text {[a] }}$

\begin{tabular}{cccc}
\hline entry & secondary alcohol & yield $^{[\mathrm{b}]}$ & b.p. of solvent \\
\hline 1 & 1-butanol & n.d. ${ }^{[\mathrm{c}]}$ & $116-118^{\circ} \mathrm{C}$ \\
2 & 2-butanol & n.d. ${ }^{[\mathrm{c}]}$ & $98{ }^{\circ} \mathrm{C}$ \\
3 & 3-pentanol & $14 \%$ & $114-115^{\circ} \mathrm{C}$ \\
4 & 2,4-dimethyl-3-pentanol & trace & $139-140{ }^{\circ} \mathrm{C}$ \\
5 & 2-octanol & $88 \%$ & $177-182^{\circ} \mathrm{C}$ \\
6 & 3-octanol & $92 \%$ & $174-176{ }^{\circ} \mathrm{C}$ \\
7 & 4-octanol & $20 \%$ & $174-176^{\circ} \mathrm{C}$ \\
8 & none & $32 \%$ &
\end{tabular}

[a] Reaction conditions: 1,2-octanediol $(0.5 \mathrm{mmol}), \mathrm{L}^{4} \mathrm{Re}(\mathrm{CO})_{3}(0.01 \mathrm{mmol}, 2 \mathrm{~mol} \%)$, alcohol reductant/solvent $(5 \mathrm{~mL}), 180{ }^{\circ} \mathrm{C}$ (temperature of oil bath), 3h, air. [b] 1-Octene yield, determined by ${ }^{1} \mathrm{H}$ NMR using mesitylene $(0.5 \mathrm{mmol})$ as an internal standard. [c] n.d.= no 1-octene was detected. [d] All solvents were purchased from Sigma-Aldrich; boiling points are reported on the basis of the corresponding Safety Data Sheet.

\subsubsection{Substrates scope}

Following these optimization studies, the substrate scope using a variety of vicinal diols and polyols was investigated under optimized conditions, i.e., using $0.5 \mathrm{mmol}$ of substrate, $2 \mathrm{~mol} \%$ of $\mathrm{L}^{4} \mathrm{Re}(\mathrm{CO})_{3}, 5 \mathrm{~mL}$ of 3 -octanol, $180^{\circ} \mathrm{C}$, under air in a closed pressure tube (Table 5.2.6). The aliphatic vicinal diol 1,2-dodecanediol gave $93 \%$ of 1-dodecene. No olefin isomers of the 1dodecene product were detected, lending further credit to the notion that the formation of 2- 
octene and 3-octene results from alcohol dehydration, instead of 1-octene isomerization when using 3-octanol as the reductant. For the previously reported Cp'Re trioxo catalyzed DODH reactions, the formation of internal olefin isomers derived from the terminal olefin product were detected at reaction temperatures $\geq 135^{\circ} \mathrm{C}$, typically in $2-15 \%$ yield at $135^{\circ} \mathrm{C}$, and $4-29 \%$ yield at $180{ }^{\circ} \mathrm{C} \cdot{ }^{[13]}$ Accordingly, in situ activation of pre-catalyst $\mathrm{L}^{4} \mathrm{Re}(\mathrm{CO})_{3}$ does not provide access to a species active in olefin isomerization.

The aromatic vicinal diol 1-phenyl-1,2-ethanediol gave $83 \%$ yield of styrene at full conversion (entry 3). Interestingly, cis-1,2-cyclohexanediol gave 62\% yield of 1-cyclohexene under these reaction conditions. This cyclic vicinal diol is known as a quite challenging substrate for rhenium-catalyzed DODH reactions. For example, when using the $\mathrm{Cp}^{\mathrm{ttt}} \mathrm{Re}(\mathrm{CO})_{3}$ catalyst only $10 \%$ of 1 -cyclohexene forms at $21 \%$ substrate conversion. ${ }^{[22]}$

Inspired by these results, we moved to biomass-based substrates, such as 1,4-anhydroerythritol, glycerol, erythritol, and DL-threitol. When glycerol was used as substrate, $97 \%$ of allyl alcohol was formed (entry 5). The DODH activity of pre-catalyst $\mathrm{L}^{4} \mathrm{Re}(\mathrm{CO})_{3}$ for this substrate is competitive with respect to the activities that can be attained with high-valent rhenium trioxo catalysts. ${ }^{[21]}$ When erythritol and DL-threitol were used as substrate, $78 \%$ and $64 \%$ of $1,3-$ butadiene was formed, respectively (entry 7 and 8). On the other hand, 1,4-anhydroerythritol gave $80 \%$ of 2,5-dihydrofuran (entry 6). The latter observations suggest that the DODH of C4 tetraols using $\mathrm{L}^{4} \mathrm{Re}(\mathrm{CO})_{3}$ does not proceed via dehydrative cyclisation to form a cyclised diol as intermediate.

Given the interest in the catalytic formation of 1,3-butadiene from biomass, the activity and selectivity of pre-catalyst $\mathrm{L}^{4} \operatorname{Re}(\mathrm{CO})_{3}$ was compared to that of other catalysts reported in the field (Figure 5.2.4). The butadiene yield achieved with $\mathrm{L}^{4} \mathrm{Re}(\mathrm{CO})_{3}$ competes with the highest reported yields for this reaction using either $\mathrm{Cp}^{\text {tt }} \mathrm{ReO} \mathrm{O}_{3}$ or $\mathrm{MTO}$ as catalyst, i.e. compared to catalysts in which $\mathrm{Re}$ is already in a high-oxidation trioxo form from the start of the reaction. ${ }^{[18,21,22]}$ For catalysts included in this comparison that operate starting from a low oxidation state under oxidative conditions, $\mathrm{L}^{4} \operatorname{Re}(\mathrm{CO})_{3}$ gave a higher total yield compared to $\mathrm{BrRe}(\mathrm{CO})_{5}$. Among all these Re-systems, $\mathrm{L}^{4} \operatorname{Re}(\mathrm{CO})_{3}$ gave the highest 1,3-butadiene selectivity, i.e. $78 \%$ of 1,3 -butadiene yield and only $2 \%$ of 2,5-dihydrofuran byproduct, though the total yield of volatile products was not as high as for the $\mathrm{Cp}^{\mathrm{tt} R e O}$ and $\mathrm{MTO}$ catalysts. 
Table 5.2.6. $\mathrm{L}^{4} \mathrm{Re}(\mathrm{CO})_{3}$ catalyzed DODH of diols and polyols. ${ }^{[a]}$

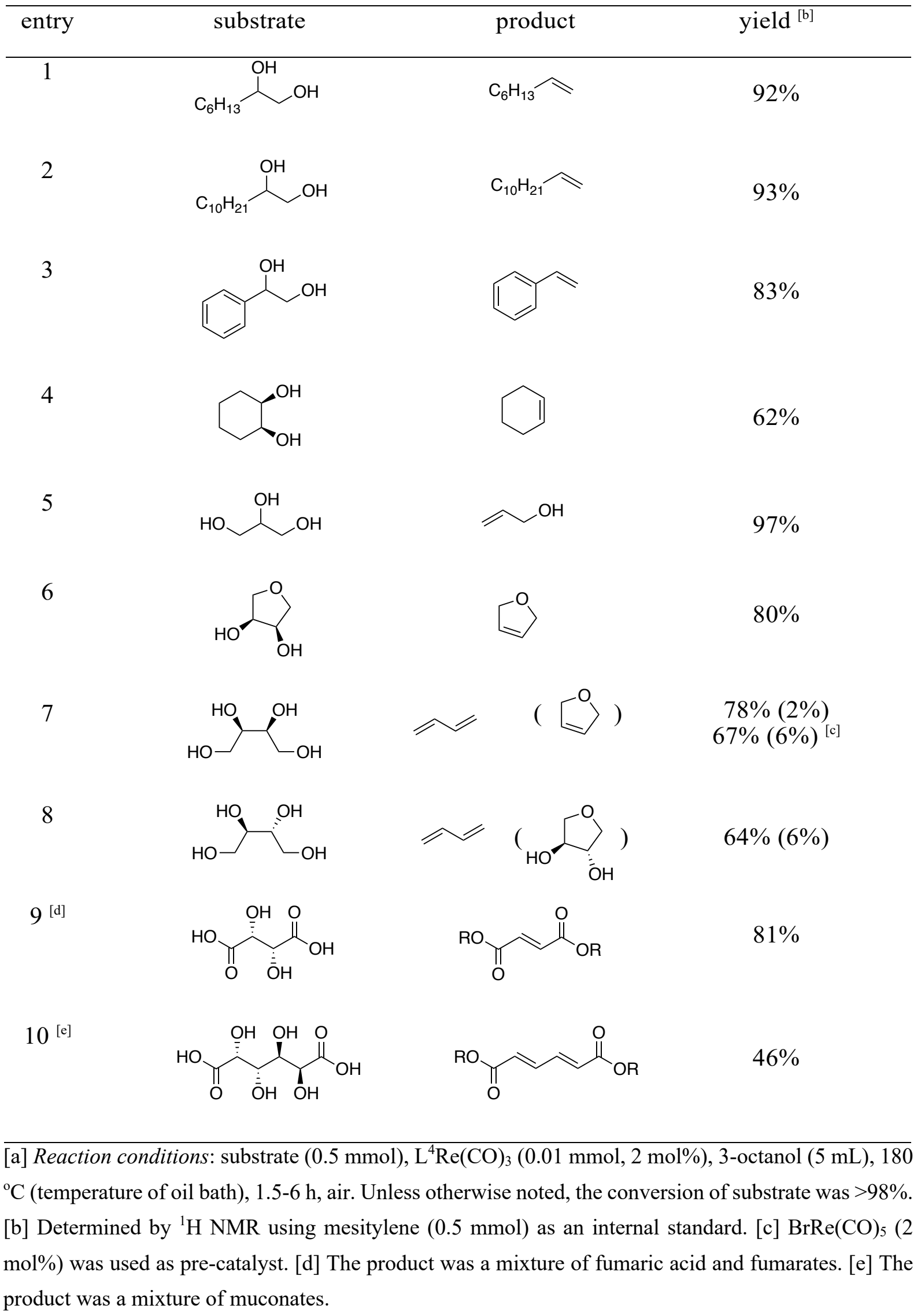


Next, two biomass-based acids, L-(+)-tartaric acid and mucic acid, were investigated using $\mathrm{L}^{4} \operatorname{Re}(\mathrm{CO})_{3}$. Since 3-octanol was also used as solvent, the deoxydehydration product of these two substrates was a mixture of acid and mono/di-octyl ester. L-(+)-tartaric acid gave $81 \%$ of fumaric acid and fumarates (entry 9), while mucic acid gave $46 \%$ of muconates. Remarkably, when using $\operatorname{Re}_{2}(\mathrm{CO})_{10}$ as pre-catalyst, no muconates were formed from mucic acid. ${ }^{[23]} \mathrm{Su}$ and Zhang claimed that this is probably due to the poor tolerance of $\operatorname{Re}_{2}(\mathrm{CO})_{10}$ to the carboxylic acid groups. Our results clearly indicate that once ligated by an N,N,O-type ligand the lowvalent Re center does not suffer from the presence of these functions groups. Although 3pentanol was not a very efficient reductant for the deoxydehydration of 1,2-octanediol, it provided a good overall activity in case of the deoxydehydration of L-(+)-tartaric acid; 83\% of a mixture of fumaric acid and fumarates was obtained at $155^{\circ} \mathrm{C}$ for $12 \mathrm{~h}$ (Figure 5.2.5). In previous work, L-(+)-tartaric acid was converted to $87 \%$ of fumarates while using $12 \mathrm{~mol} \%$ of $\mathrm{HReO} 4$ as catalyst, and $97 \%$ of fumarates were formed while using $5 \mathrm{~mol} \%$ of MTO as catalyst (Figure 5.2.5). ${ }^{[20,24]}$ In our system, the yield of fumaric acid and fumarates is slightly lower, albeit that a lower pre-catalyst loading of $2 \mathrm{~mol} \%$ is used.
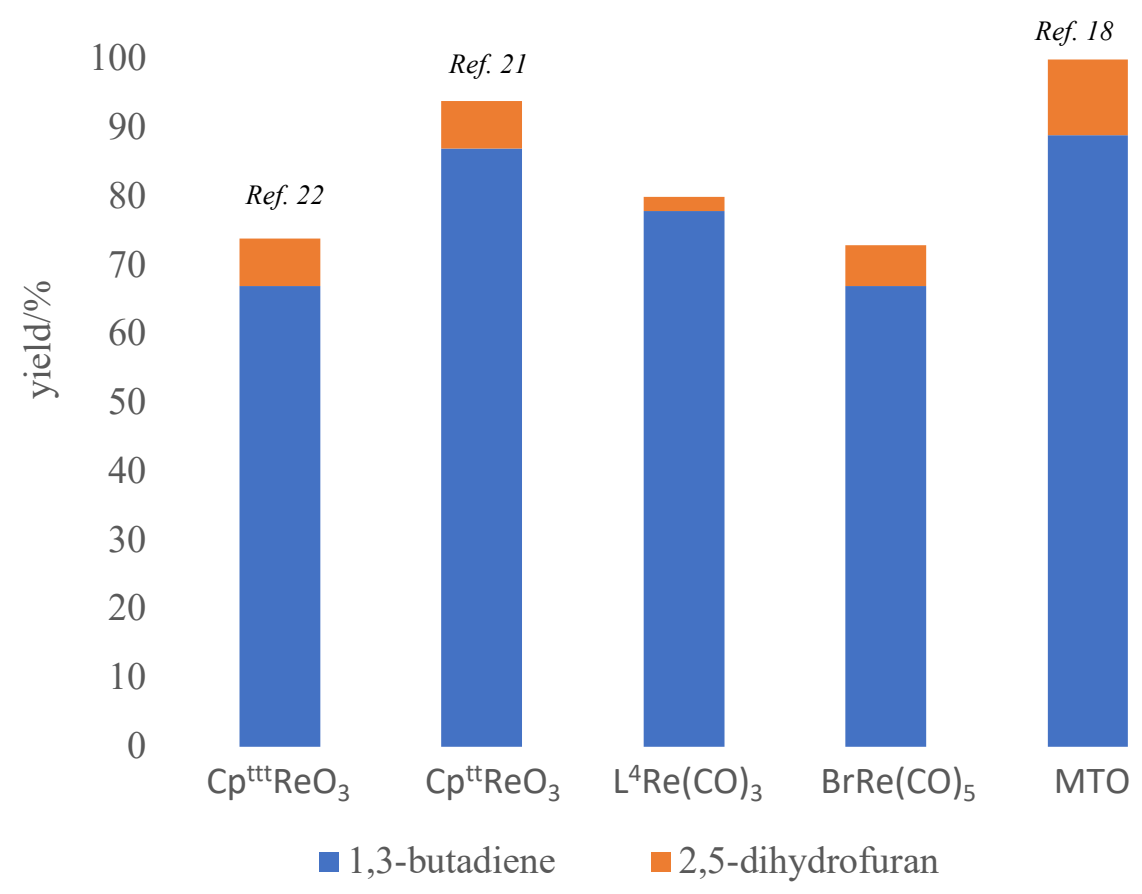

Figure 5.2.4 Comparison of DODH reactions of erythritol catalyzed/initiated by different Recomplexes. ${ }^{[18,21,22]}$ 
This work:<smiles>O=C(O)[C@H](O)[C@@H](O)C(=O)O</smiles>

$0.5 \mathrm{mmol}$<smiles>CCC(O)CC</smiles>

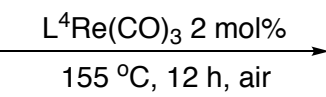

$5 \mathrm{~mL}$<smiles>CCC(CC)OC(=O)/C=C/C(=O)OC(CC)CCCCCCCCCCC(=O)OC(CC)CC</smiles>

Toste's work:<smiles>O=C(O)C(O)C(=O)O</smiles>

$0.3 \mathrm{mmol}$<smiles>OCC(O)C(O)CO</smiles>

$0.9 \mathrm{mmol}$ $\underset{\mathrm{HReO}_{4} 12 \text { mol\% to tartaric acid }}{\text { 2-methyl-1-butanol, } 170^{\circ} \mathrm{C}, 4 \mathrm{~h}, \mathrm{~N}_{2}}$<smiles>CCC(C)COC(=O)/C=C/C(=O)OCC(C)CC</smiles>

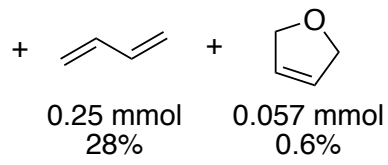

Zhang's work:

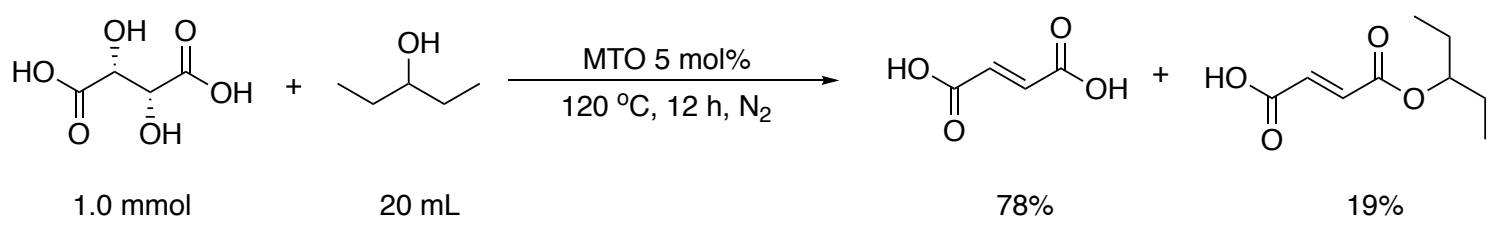

Figure 5.2.5 DODH of L-(+)-tartaric acid ${ }^{[20,24]}$

On basis of the results above, we have discovered a rhenium system which could be applied to the deoxydehydration of diols and polyols with quite good olefin yields. Sugars, which in a way can be labelled as complicated polyol substrates, are quite challenging substrates for Re-catalyzed DODH reactions. MTO has been reportedly used for the deoxydehydration of sugars, e.g., D-mannose, D-allose, D-glucose, and Dgalactose. 2-vinylfuran (2-VF) and furan were the main products in these reactions, with furan being the major product in most cases. ${ }^{[18]}$ For the $\mathrm{Cp}^{\text {tt }} \mathrm{ReO}_{3}$-catalyzed deoxydehydration of sugars, 2-vinylfuran and furan were also found to be the main products, but the product distribution was not the same as for MTO, ${ }^{[21]}$ which indicates that these systems might operate through a different active species. In a very recent report, Marrone, d'Alessandro and co-workers explored the deoxydehydration of glycerol using a series of rhenium sources (such as $\mathrm{MTO}, \mathrm{ReO}_{3}, \mathrm{Re}_{2} \mathrm{O}_{7}$, $\mathrm{IReO}_{2}\left(\mathrm{PPh}_{3}\right)_{2}, \mathrm{ReCl}_{5}$, and $\left.\mathrm{ReI}_{3}\right)$ as catalyst and secondary alcohols as reductant. ${ }^{[25]}$ For the latter reactions, an induction period was observed and a black solid separated from the reaction mixtures. When used in a next catalytic run, this black solid was found to be active In DODH without an induction period. The authors proposed that the black solid is the active species in these DODH reactions. Besides, they specifically analyse 
the MTO-catalyzed DODH and claim that MTO releases methane to form a $\mathrm{Re}^{\mathrm{VII}}$ alkoxide species with the help of a secondary alcohol at high temperature, and that the $\mathrm{Re}^{\mathrm{VII}}$ alkoxide species is the actual catalyst. Interestingly, the same authors also reported that $\operatorname{Re}_{2}(\mathrm{CO})_{10}$ is not active for the deoxydehydration of glycerol at $140{ }^{\circ} \mathrm{C}$ in air with 2,4-dimethyl-3-pentanol as reductant and solvent.

Table 5.2.7. DODH of sugars with different rhenium catalysts/pre-catalysts.

\begin{tabular}{|c|c|c|c|}
\hline sugar & {$[\mathrm{Re}](\mathrm{x} \mathrm{mol} \%)$} & total yield (2-VF:furan) & conditions \\
\hline \multirow[t]{6}{*}{ D-glucose } & MTO $(2.5)^{[18]}$ & $25 \%(1: 1.8)$ & 3-pentanol $(0.05 \mathrm{M})$ \\
\hline & & & $155^{\circ} \mathrm{C}, \mathrm{N}_{2}$ \\
\hline & $\mathrm{Cp}^{\mathrm{tt}} \mathrm{ReO}_{3}(2.0)^{[21]}$ & trace & 3-pentanol $(0.05 \mathrm{M})$ \\
\hline & & & $155^{\circ} \mathrm{C}, \mathrm{N}_{2}$ \\
\hline & $\mathrm{L}^{4} \operatorname{Re}(\mathrm{CO})_{3}(2.0)$ & $6 \%(1.8: 1)$ & 3-pentanol (0.1 M) \\
\hline & & & $155^{\circ} \mathrm{C}$, air \\
\hline \multirow[t]{6}{*}{ D-galactose } & $\operatorname{MTO}(2.5)^{[18]}$ & $32 \%(1: 3.0)$ & 3-pentanol $(0.05 \mathrm{M})$ \\
\hline & & & $155^{\circ} \mathrm{C}, \mathrm{N}_{2}$ \\
\hline & $\mathrm{Cp}^{\mathrm{tt}} \mathrm{ReO}_{3}(2.0)^{[21]}$ & $14 \%$ (no $2-V F)$ & 3-pentanol $(0.05 \mathrm{M})$ \\
\hline & & & $155^{\circ} \mathrm{C}, \mathrm{N}_{2}$ \\
\hline & $\mathrm{L}^{4} \operatorname{Re}(\mathrm{CO})_{3}(2.0)$ & $11 \%(2.0: 1)$ & 3-pentanol (0.1 M) \\
\hline & & & $155^{\circ} \mathrm{C}$, air \\
\hline \multirow[t]{6}{*}{ D-mannose } & $\operatorname{MTO}(2.5)^{[18]}$ & $30 \%(1: 2.3)$ & 3-pentanol $(0.05 \mathrm{M})$ \\
\hline & & & $155^{\circ} \mathrm{C}, \mathrm{N}_{2}$ \\
\hline & $\mathrm{Cp}^{\mathrm{tt}} \mathrm{ReO}_{3}(2.0)^{[21]}$ & $39 \%(2.3: 1)$ & 3-pentanol $(0.05 \mathrm{M})$ \\
\hline & & & $155^{\circ} \mathrm{C}, \mathrm{N}_{2}$ \\
\hline & $\mathrm{L}^{4} \operatorname{Re}(\mathrm{CO})_{3}(2.0)$ & $32 \%(1.5: 1)$ & 3-pentanol (0.1M) \\
\hline & & & $155^{\circ} \mathrm{C}$, air \\
\hline
\end{tabular}

Since in our current investigations, a secondary alcohol was also used as reductant, we were curious if similar Re-alkoxide active species would be formed and would lead to related product profiles in the DODH of sugar substrates. D-mannose, D-glucose, and D-galactose were then investigated using $\mathrm{L}^{4} \mathrm{Re}(\mathrm{CO})_{3}$ under optimized conditions (Table 5.2.7). Comparing the performance of $\mathrm{L}^{4} \mathrm{Re}(\mathrm{CO})_{3}$ to $\mathrm{MTO}$ and $\mathrm{Cp}^{\mathrm{tt}} \mathrm{ReO}_{3}$ clearly shows that for each sugar substrate the major product with $\mathrm{L}^{4} \mathrm{Re}(\mathrm{CO})_{3}$ is 2 -vinylfuran instead of furan. This observation may be taken as an indication that $\mathrm{L}^{4} \operatorname{Re}(\mathrm{CO})_{3}$ operates through a different active species compared to the Re-trioxo catalysts. In addition, no black solid was observed for the deoxydehydration of simple vicinal diols in our system. The highest total yield in furans for $\mathrm{L}^{4} \mathrm{Re}(\mathrm{CO})_{3}$ was achieved using D-mannose as 
substrate $(32 \%)$, which is quite similar to the MTO catalyst but somewhat lower than the $\mathrm{Cp}^{\mathrm{tt}} \mathrm{ReO}_{3}$ catalyst. For the other two sugars, the yields achieved with $\mathrm{L}^{4} \operatorname{Re}(\mathrm{CO})_{3}$ do not compete with those obtained with MTO.

\subsection{Conclusions}

A series of $\operatorname{LRe}(\mathrm{CO})_{3} \quad$ complexes $\quad(\mathrm{LH} \quad=\quad$ substituted 2-(((2(dimethylamino)ethyl)(methyl)amino)methyl)phenol) were investigated as pre-catalyst for the deoxydehydration of diols and polyols under aerobic conditions and using a secondary alcohol as reductant and solvent. The 2,4-di-tert-butyl-substituted complex $\mathrm{L}^{4} \mathrm{Re}(\mathrm{CO})_{3}$ was selected as the pre-catalyst for further investigation after initial catalytic screening of the series. Both aliphatic and aromatic vicinal diols, as well as biomass-derived glycerol and polyols can be converted using $\mathrm{L}^{4} \mathrm{Re}(\mathrm{CO})_{3}$ to the corresponding olefins with good yields. The application of sugar substrates to these reaction conditions leads to the preferential formation of 2-vinylfuran. This unusual product distribution indicates that the active species generated from $\mathrm{L}^{4} \mathrm{Re}(\mathrm{CO})_{3}$ could be different from the ones generated by Re-trioxo systems.

Compared to the Cp-based trioxo rhenium complexes previously reported by us, the new NNObased $\operatorname{Re}(\mathrm{CO})_{3}$ pre-catalysts are much more easy to handle. Not only are the NNO-ligands easy to prepare and modify, the low-yielding oxidation from $\operatorname{Re}(\mathrm{I})$ to $\operatorname{Re}(\mathrm{VII})$ during catalyst synthesis is avoided and the $(\mathrm{NNO}) \operatorname{Re}(\mathrm{CO})_{3}$ systems are air stable at room temperature while the $\mathrm{Cp}^{\prime} \mathrm{ReO}_{3}$ systems need to be stored at low temperature or under $\mathrm{N}_{2}$. In view of these considerations, the new NNO-based Re-tricarbonyl pre-catalysts are interesting alternatives for high-valent Re-trioxo systems in DODH chemistry.

\subsection{Experimental Section}

\subsubsection{General}

\section{Materials}

$\mathrm{PPh}_{3}$ was recrystallized from EtOH. Unless otherwise stated, all other chemicals were obtained commercially and used without further purification (Sigma Aldrich, Acros).

\subsubsection{Synthesis of $\operatorname{LRe}(\mathrm{CO})_{3}$}




\section{General information}

2-(((2-(dimethylamino)ethyl)(methyl)amino)methyl)phenol (HL $\left.{ }^{1}\right)$ was synthesized according to a known synthesize procedure. ${ }^{[14]}$ NMR spectra were recorded on a Varian VNMRS400 (400 $\mathrm{MHz})$ or Bruker $(600 \mathrm{MHz})$ at $298 \mathrm{~K}$. Infra-Red spectra were recorded using a Perkin-Elmer Spectrum One FT-IR spectrometer in the range of $650-4000 \mathrm{~cm}^{-1}$. Elemental analysis was done by MEDAC Ltd.

\section{Synthesis of $\mathrm{L}^{1} \operatorname{Re}(\mathrm{CO})_{3}$}

A solution of $\mathrm{HL}^{1}$ (363 mg, $1.74 \mathrm{mmol}, 1.0$ equiv.), $\operatorname{Re}(\mathrm{CO})_{5} \mathrm{Br}(708 \mathrm{mg}, 0.5 \mathrm{mmol}, 1.0$ equiv.) and $\mathrm{NaOAc}(1.427 \mathrm{~g}, 17.4 \mathrm{mmol}, 10$ equiv.) in toluene $(50 \mathrm{~mL})$ was refluxed for $3 \mathrm{~h}$ under argon atmosphere. The reaction mixture was treated with aq. $\mathrm{NH}_{4} \mathrm{Cl}$ and diluted with $\mathrm{CH}_{2} \mathrm{Cl}_{2}$. The organic layer was separated, dried over $\mathrm{Na}_{2} \mathrm{SO}_{4}$, and filtered. The solvent was removed under reduced pressure and the residue was purified by recrystallization $\left(\mathrm{Et}_{2} \mathrm{O} / \mathrm{MeCN}\right)$ to obtain $\mathrm{L}^{1} \mathrm{Re}(\mathrm{CO})_{3}$ as a blueish off-white solid $(697 \mathrm{mg}, 84 \%)$. Diffusion of $\mathrm{Et}_{2} \mathrm{O}$ into a MeCN solution at room temperature gave crystal of $\mathrm{L}^{1} \mathrm{Re}(\mathrm{CO})_{3}$ suitable for X-ray analysis.

${ }^{1} \mathrm{H}$ NMR (600 MHz), $\mathrm{CD}_{3} \mathrm{CN}(1.94 \mathrm{ppm}): \delta=7.10(\mathrm{ddd}, J=8.1,7.1,1.9 \mathrm{~Hz}, 1 \mathrm{H}), 6.94-6.90$ $(\mathrm{m}, 1 \mathrm{H}), 6.56(\mathrm{dd}, J=8.1,1.2 \mathrm{~Hz}, 1 \mathrm{H}), 6.48(\mathrm{td}, J=7.3,1.2 \mathrm{~Hz}, 1 \mathrm{H}), 4.06(\mathrm{~d}, J=13.5 \mathrm{~Hz}, 1 \mathrm{H})$, $3.72(\mathrm{~d}, J=13.5 \mathrm{~Hz}, 1 \mathrm{H}), 3.16(\mathrm{~s}, 3 \mathrm{H}), 3.11(\mathrm{~s}, 3 \mathrm{H}), 2.98(\mathrm{ddd}, J=11.6,5.9,2.6 \mathrm{~Hz}, 1 \mathrm{H}), 2.88$ $-2.72(\mathrm{~m}, 3 \mathrm{H}), 2.64$ (s, 3H). ${ }^{13} \mathrm{C}$ NMR (150 MHz), $\mathrm{CD}_{3} \mathrm{CN}$ (118.26 ppm): $\delta=198.36,198.02$, 197.07, 166.10, 131.07, 130.91, 123.95, 119.75, 115.62, 64.70, 62.51, 59.26, 57.52, 56.60, 50.34. Infrared $v(\mathrm{CO})\left(\mathrm{cm}^{-1}\right): 1877,1918,2014$. ESI-MS (in $\left.\mathrm{MeCN}\right)$ : calc. for $\left[\mathrm{C}_{15} \mathrm{H}_{19} \mathrm{~N}_{2} \mathrm{O}_{4} \mathrm{Re}+\mathrm{H}\right]^{+}:$479.1, found: 479.1. Elemental analysis calc. (\%) for $\mathrm{C}_{15} \mathrm{H}_{19} \mathrm{~N}_{2} \mathrm{O}_{4} \mathrm{Re}$ (477.53): C 37.73, H 4.01, N 5.86; found: C 37.38, H 3.79, N 5.86.

\section{Synthesis of $\mathrm{L}^{2} \operatorname{Re}(\mathrm{CO})_{3}$}

A mixture of $N, N, N$ '-trimethylethylenediamine (1.022 g, $10 \mathrm{mmol}), 2$-hydroxy-5methoxybenzaldehyde $(1.522 \mathrm{~g}, 10 \mathrm{mmol})$, and sodium triacetoxyborohydride $(3.179 \mathrm{~g}, 15$ $\mathrm{mmol})$, in 1,2-dichloroethane $(25 \mathrm{~mL})$ was stirred overnight under nitrogen. The reaction mixture was quenched by adding a saturated $\mathrm{NaHCO}_{3}$ solution. Dichloromethane was used to extract the mixture. The organic layer was dried with $\mathrm{MgSO}_{4}$ and the solvent was removed under vacuum to obtain a red-orange oil. The oil was further purified by column 
chromatography on silica gel with $\mathrm{CH}_{2} \mathrm{Cl}_{2} / \mathrm{MeOH}(20: 1)$ as the eluent. Removal of the solvent in vacuo gave $\mathrm{HL}^{2}$ as a red-orange oil $(1.260 \mathrm{~g}, 53 \%)$.

${ }^{1} \mathrm{H}$ NMR (400 MHz), $\mathrm{CD}_{3} \mathrm{CN}(1.94 \mathrm{ppm}): \delta=6.70(\mathrm{dd}, J=8.7,3.0 \mathrm{~Hz}, 1 \mathrm{H}), 6.66-6.60(\mathrm{~m}$, 2H), $3.69(\mathrm{~s}, 3 \mathrm{H}), 3.52(\mathrm{~s}, 2 \mathrm{H}), 2.47(\mathrm{td}, J=6.1,1.2 \mathrm{~Hz}, 4 \mathrm{H}), 2.20(\mathrm{~s}, 6 \mathrm{H}), 2.18(\mathrm{~s}, 3 \mathrm{H})$.

A solution of $\mathrm{HL}^{2}$ (119 mg, $0.5 \mathrm{mmol}, 1.0$ equiv.), $\mathrm{Re}(\mathrm{CO})_{5} \mathrm{Br}(203 \mathrm{mg}, 0.5 \mathrm{mmol}, 1.0$ equiv.) and $\mathrm{NaOAc}$ (410 mg, $5.0 \mathrm{mmol}, 10$ equiv.) in toluene $(15 \mathrm{~mL})$ was refluxed for $3 \mathrm{~h}$ under an argon atmosphere. The reaction mixture was treated with aq. $\mathrm{NH}_{4} \mathrm{Cl}$ and diluted with $\mathrm{CH}_{2} \mathrm{Cl}_{2}$. The organic layer was separated, dried over $\mathrm{Na}_{2} \mathrm{SO}_{4}$, and filtered. The solvent was removed under reduced pressure and the residue was purified by recrystallization $\left(\mathrm{Et}_{2} \mathrm{O} / \mathrm{MeCN}\right)$ to obtain $\mathrm{L}^{2} \operatorname{Re}(\mathrm{CO})_{3}$ as an off-white solid (190 $\left.\mathrm{mg}, 75 \%\right)$.

${ }^{1} \mathrm{H} \operatorname{NMR}(600 \mathrm{MHz}), \mathrm{CD}_{3} \mathrm{CN}(1.94 \mathrm{ppm}): \delta=6.72(\mathrm{dd}, J=8.7,3.2 \mathrm{~Hz}, 1 \mathrm{H}), 6.57(\mathrm{~d}, J=3.2$ Hz, 1H), 6.49 (d, $J=8.7 \mathrm{~Hz}, 1 \mathrm{H}), 3.89$ (d, $J=13.4 \mathrm{~Hz}, 1 \mathrm{H}), 3.72$ (d, $J=13.4 \mathrm{~Hz}, 1 \mathrm{H}), 3.67$ (s, $3 \mathrm{H}), 3.13(\mathrm{~s}, 3 \mathrm{H}), 3.11(\mathrm{~s}, 3 \mathrm{H}), 3.05-2.93(\mathrm{~m}, 1 \mathrm{H}), 2.92-2.81(\mathrm{~m}, 2 \mathrm{H}), 2.80-2.73(\mathrm{~m}, 1 \mathrm{H})$, 2.67 (s, 3H). ${ }^{13} \mathrm{C}$ NMR (150 MHz), $\mathrm{CD}_{3} \mathrm{CN}$ (118.26 ppm): $\delta=198.45,197.99,197.03,160.66$, $150.51,124.31,119.52,116.32,64.08,62.34,59.75,57.52,56.31,56.22,50.41$. Infrared $v$ (CO) $\left(\mathrm{cm}^{-1}\right)$ : 1859, 1886, 2007. ESI-MS (in MeCN): calc. for $\left[\mathrm{C}_{16} \mathrm{H}_{21} \mathrm{~N}_{2} \mathrm{O}_{5} \mathrm{Re}+\mathrm{H}\right]^{+}$: 509.1, found: 508.1. Elemental analysis calc. (\%) for $\mathrm{C}_{16} \mathrm{H}_{21} \mathrm{~N}_{2} \mathrm{O}_{5} \mathrm{Re}$ (507.56): C 37.86, H 4.17, N 5.52; found: C 38.15, H 4.27, N 5.44.

\section{Synthesis of $\mathrm{L}^{3} \operatorname{Re}(\mathrm{CO})_{3}$}

A mixture of $N, N, N$ '-trimethylethylenediamine (1.022 g, $10 \mathrm{mmol})$, 2-hydroxy-5nitrobenzaldehyde (1.671 g, $10 \mathrm{mmol})$, and sodium triacetoxyborohydride $(3.179 \mathrm{~g}, 15 \mathrm{mmol})$, in 1,2-dichloroethane $(25 \mathrm{~mL})$ was stirred overnight under nitrogen. The reaction mixture was quenched by adding a saturated $\mathrm{NaHCO}_{3}$ solution. Dichloromethane was used to extract the mixture. The organic layer was dried with $\mathrm{MgSO}_{4}$ and the solvent was removed under vacuum to obtain a bright yellow oil. The oil was further purified by column chromatography on silica gel with $\mathrm{CH}_{2} \mathrm{Cl}_{2} / \mathrm{MeOH}(10: 1)$ as the eluent. Removal of the solvent in vacuo gave $\mathrm{HL}^{3}$ as a yellow solid $(1.397 \mathrm{~g}, 55 \%)$.

${ }^{1} \mathrm{H}$ NMR (400 MHz), $\mathrm{CD}_{3} \mathrm{CN}(1.94 \mathrm{ppm}): \delta=7.99(\mathrm{dd}, J=9.0,3.0 \mathrm{~Hz}, 1 \mathrm{H}), 7.93(\mathrm{dt}, J=3.0$, $0.7 \mathrm{~Hz}, 1 \mathrm{H}), 6.59(\mathrm{~d}, J=9.1 \mathrm{~Hz}, 1 \mathrm{H}), 3.46(\mathrm{~s}, 2 \mathrm{H}), 2.81(\mathrm{dd}, J=6.7,5.7 \mathrm{~Hz}, 2 \mathrm{H}), 2.81(\mathrm{t}, J=$ 6.7, $5.7 \mathrm{~Hz}, 2 \mathrm{H}), 2.65(\mathrm{t}, J=6.1 \mathrm{~Hz}, 2 \mathrm{H}), 2.42(\mathrm{~s}, 6 \mathrm{H}), 2.20(\mathrm{~s}, 3 \mathrm{H})$. 
A solution of $\mathrm{HL}^{3}$ (127 mg, $0.5 \mathrm{mmol}, 1.0$ equiv.), $\mathrm{Re}(\mathrm{CO})_{5} \mathrm{Br}(203 \mathrm{mg}, 0.5 \mathrm{mmol}, 1.0$ equiv.) and $\mathrm{NaOAc}$ (410 mg, $5.0 \mathrm{mmol}, 10$ equiv.) in toluene $(15 \mathrm{~mL})$ was refluxed for $3 \mathrm{~h}$ under an argon atmosphere. The reaction mixture was treated with aq. $\mathrm{NH}_{4} \mathrm{Cl}$ and diluted with $\mathrm{CH}_{2} \mathrm{Cl}_{2}$. The organic layer was separated, dried over $\mathrm{Na}_{2} \mathrm{SO}_{4}$, and filtered. The solvent was removed under reduced pressure and the residue was purified by recrystallization $\left(\mathrm{Et}_{2} \mathrm{O} / \mathrm{MeCN}\right)$ to obtain $\mathrm{L}^{3} \mathrm{Re}(\mathrm{CO})_{3}$ as a yellow solid (190 mg, 73\%). Diffusion of $\mathrm{Et}_{2} \mathrm{O}$ into a $\mathrm{MeCN}$ solution at room temperature gave crystals of $\mathrm{L}^{3} \operatorname{Re}(\mathrm{CO})_{3}$ suitable for X-ray analysis.

${ }^{1} \mathrm{H}$ NMR (600 MHz), $\mathrm{CD}_{3} \mathrm{CN}(1.94 \mathrm{ppm}): \delta=8.02(\mathrm{dd}, J=9.1,3.0 \mathrm{~Hz}, 1 \mathrm{H}), 7.94(\mathrm{dd}, J=3.0$, $0.8 \mathrm{~Hz}, 1 \mathrm{H}), 6.60(\mathrm{~d}, J=9.1 \mathrm{~Hz}, 1 \mathrm{H}), 4.35(\mathrm{~d}, J=14.1 \mathrm{~Hz}, 1 \mathrm{H}), 3.78(\mathrm{~d}, J=14.1 \mathrm{~Hz}, 1 \mathrm{H}), 3.23$ (s, 3H), 3.13 (s, 3H), 2.98 (ddd, $J=13.8,8.3,3.5 \mathrm{~Hz}, 1 \mathrm{H}), 2.87$ (ddd, $J=13.7,8.3,3.5 \mathrm{~Hz}, 1 \mathrm{H})$, 2.73 (ddd, $J=13.8,6.8,3.5 \mathrm{~Hz}, 1 \mathrm{H}), 2.66$ (ddd, $J=13.7,6.8,3.5 \mathrm{~Hz}, 1 \mathrm{H}), 2.54(\mathrm{~s}, 3 \mathrm{H}) .{ }^{13} \mathrm{C}$ NMR (150 MHz), $\mathrm{CD}_{3} \mathrm{CN}$ (118.26 ppm): $\delta=198.19,194.84,170.79,136.73,135.12,128.44$, $127.45,123.24,120.39,76.07,65.04,62.80,58.34,57.74,57.32,50.10$. Infrared $v(C O)\left(\mathrm{cm}^{-}\right.$ $\left.{ }^{1}\right)$ : 1884, 1921, 2016. ESI-MS (in $\mathrm{MeCN}$ ): calc. for $\left[\mathrm{C}_{15} \mathrm{H}_{18} \mathrm{~N}_{3} \mathrm{O}_{6} \mathrm{Re}+\mathrm{H}+\mathrm{MeCN}\right]^{+}$: 565.1, found: 565.0. Elemental analysis calc. (\%) for $\mathrm{C}_{15} \mathrm{H}_{18} \mathrm{~N}_{3} \mathrm{O}_{6} \mathrm{Re}$ (522.53): C 34.48, H 3.47, N 8.04; found: C 43.11, H 3.48, N 7.95.

\section{Synthesis of $\mathrm{L}^{4} \operatorname{Re}(\mathrm{CO})_{3}$}

A mixture of $N, N, N$ '-trimethylethylenediamine (1.022 g, $10 \mathrm{mmol})$, 3,5-di-tert-butyl-2hydroxybenzaldehyde $(2.343 \mathrm{~g}, 10 \mathrm{mmol})$, and sodium triacetoxyborohydride $(3.179 \mathrm{~g}, 15$ $\mathrm{mmol})$, in 1,2-dichloroethane $(25 \mathrm{~mL})$ was stirred overnight under nitrogen. The reaction mixture was quenched by adding a saturated $\mathrm{NaHCO}_{3}$ solution. Dichloromethane was used to extract the mixture. The organic layer was dried with $\mathrm{MgSO}_{4}$ and the solvent was removed under vacuum to obtain a light-yellow oil. The oil was further purified by column chromatography on silica gel with $\mathrm{CH}_{2} \mathrm{Cl}_{2} / \mathrm{MeOH}(20: 1)$ as the eluent. Removal of the solvent in vacuo gave $\mathrm{HL}^{4}$ as a colorless solid $(1.873 \mathrm{~g}, 58 \%)$.

${ }^{1} \mathrm{H}$ NMR (400 MHz), $\mathrm{CD}_{3} \mathrm{CN}(1.94 \mathrm{ppm}): \delta=7.19(\mathrm{~d}, J=2.5 \mathrm{~Hz}, 1 \mathrm{H}), 6.97-6.82(\mathrm{~m}, 1 \mathrm{H})$, $3.63(\mathrm{~s}, 2 \mathrm{H}), 2.53(\mathrm{td}, J=6.4,1.1 \mathrm{~Hz}, 2 \mathrm{H}), 2.44(\mathrm{td}, J=6.4,1.1 \mathrm{~Hz}, 2 \mathrm{H}), 2.23(\mathrm{~s}, 3 \mathrm{H}), 2.16(\mathrm{~s}$, $6 \mathrm{H}), 1.38(\mathrm{~s}, 9 \mathrm{H}), 1.26(\mathrm{~s}, 9 \mathrm{H})$.

A solution of $\mathrm{HL}^{4}$ (225 mg, $0.7 \mathrm{mmol}, 1.0$ equiv.), $\mathrm{Re}(\mathrm{CO}){ }_{5} \mathrm{Br}$ (406 mg, $0.7 \mathrm{mmol}, 1.0$ equiv.) and $\mathrm{NaOAc}$ (574 mg, $7.0 \mathrm{mmol}, 10$ equiv.) in toluene $(21 \mathrm{~mL})$ was refluxed for $3 \mathrm{~h}$ under an argon atmosphere. The reaction mixture was treated with aq. $\mathrm{NH}_{4} \mathrm{Cl}$ and diluted with $\mathrm{CH}_{2} \mathrm{Cl}_{2}$. 
The organic layer was separated, dried over $\mathrm{Na}_{2} \mathrm{SO}_{4}$, and filtered. The solvent was removed under reduced pressure and the residue was purified by recrystallization ( $\mathrm{Et}_{2} \mathrm{O} /$ hexane) to obtain $\mathrm{L}^{4} \mathrm{Re}(\mathrm{CO})_{3}$ as an off-white solid (315 $\left.\mathrm{mg}, 76 \%\right)$. Recrystallization from $\mathrm{Et}_{2} \mathrm{O} /$ hexane $(1: 2)$ at $30{ }^{\circ} \mathrm{C}$ gave crystals of $\mathrm{L}^{4} \mathrm{Re}(\mathrm{CO})_{3}$ suitable for X-ray analysis.

${ }^{1} \mathrm{H}$ NMR (600 MHz), $\mathrm{CD}_{3} \mathrm{CN}(1.94 \mathrm{ppm}): \delta=7.20(\mathrm{~d}, J=2.6 \mathrm{~Hz}, 1 \mathrm{H}), 6.91(\mathrm{dd}, J=2.6,0.6$ $\mathrm{Hz}, 1 \mathrm{H}), 3.82(\mathrm{~d}, J=13.0 \mathrm{~Hz}, 1 \mathrm{H}), 3.29$ (d, $J=13.1 \mathrm{~Hz}, 1 \mathrm{H}), 3.21-3.14(\mathrm{~m}, 4 \mathrm{H}), 3.14-3.08$ (m, 1H), $3.08-2.97(\mathrm{~m}, 4 \mathrm{H}), 2.88(\mathrm{~s}, 3 \mathrm{H}), 2.82(\mathrm{ddd}, J=13.5,4.2,3.1 \mathrm{~Hz}, 1 \mathrm{H}), 1.43(\mathrm{~s}, 9 \mathrm{H})$, 1.26 (s, 9H). ${ }^{13} \mathrm{C}$ NMR (150 MHz), $\mathrm{CD}_{3} \mathrm{CN}$ (118.26 ppm): $\delta=198.90,197.55,196.68,166.78$, 137.73, 137.51, 126.37, 124.95, 124.05, 62.51, 61.63, 61.51, 57.28, 54.38, 51.22, 36.15, 34.11, 32.11, 30.50. Infrared $v(\mathrm{CO})\left(\mathrm{cm}^{-1}\right): 1851,1894,2010$. ESI-MS (in MeCN): calc. for $\left[\mathrm{C}_{23} \mathrm{H}_{35} \mathrm{~N}_{2} \mathrm{O}_{4} \mathrm{Re}+\mathrm{H}\right]^{+}:$591.2, found: 590.2. Elemental analysis calc. (\%) for $\mathrm{C}_{23} \mathrm{H}_{35} \mathrm{~N}_{2} \mathrm{O}_{4} \mathrm{Re}$ (589.75): C 46.84, H 5.98, N 4.75; found: C 46.94, H 5.75, N 4.80.

\section{Synthesis of $\mathrm{L}^{5} \operatorname{Re}(\mathrm{CO})_{3}$}

A mixture of $N, N, N^{\prime}$-trimethylethylenediamine (1.022 g, $\left.10 \mathrm{mmol}\right)$, 3,5-dichloro-2hydroxybenzaldehyde $(1.910 \mathrm{~g}, 10 \mathrm{mmol})$, and sodium triacetoxyborohydride $(3.179 \mathrm{~g}, 15$ $\mathrm{mmol})$, in 1,2-dichloroethane (25 mL) was stirred overnight under nitrogen. The reaction mixture was quenched by adding saturated $\mathrm{NaHCO}_{3}$ solution. Dichloromethane was used to extract the mixture. The organic layer was dried with $\mathrm{MgSO}_{4}$ and the solvent was removed under vacuum to obtain a light-yellow oil. The oil was further purified by column chromatography on silica gel with $\mathrm{CH}_{2} \mathrm{Cl}_{2} / \mathrm{MeOH}(20: 1)$ as the eluent. Removal of the solvent in vacuo gave $\mathrm{HL}^{5}$ as a yellow solid $(1.850 \mathrm{~g}, 67 \%)$.

${ }^{1} \mathrm{H}$ NMR (400 MHz), $\mathrm{CD}_{3} \mathrm{CN}(1.94 \mathrm{ppm}): \delta=7.28(\mathrm{dd}, J=2.6,0.5 \mathrm{~Hz}, 1 \mathrm{H}), 7.00(\mathrm{dt}, J=2.6$, $0.7 \mathrm{~Hz}, 1 \mathrm{H}), 3.52(\mathrm{~s}, 2 \mathrm{H}), 2.63-2.51(\mathrm{~m}, 4 \mathrm{H}), 2.25(\mathrm{~s}, 6 \mathrm{H}), 2.18(\mathrm{~s}, 3 \mathrm{H})$.

A solution of $\mathrm{HL}^{5}$ (55 mg, $0.2 \mathrm{mmol}, 1.0$ equiv.), $\mathrm{Re}(\mathrm{CO})_{5} \mathrm{Br}(81 \mathrm{mg}, 0.2 \mathrm{mmol}, 1.0$ equiv.) and $\mathrm{NaOAc}$ (164 mg, $2.0 \mathrm{mmol}, 10$ equiv.) in toluene $(6 \mathrm{~mL})$ was refluxed for $3 \mathrm{~h}$ under an argon atmosphere. The reaction mixture was treated with aq. $\mathrm{NH}_{4} \mathrm{Cl}$ and diluted with $\mathrm{CH}_{2} \mathrm{Cl}_{2}$. The organic layer was separated, dried over $\mathrm{Na}_{2} \mathrm{SO}_{4}$, and filtered. The solvent was removed under reduced pressure and the residue was purified by recrystallization $\left(\mathrm{DCM} / \mathrm{Et}_{2} \mathrm{O}\right)$ to obtain $\mathrm{L}^{5} \mathrm{Re}(\mathrm{CO})_{3}$ as a yellowish solid (86 mg, 79\%). 
${ }^{1} \mathrm{H} \mathrm{NMR}(600 \mathrm{MHz}), \mathrm{CD}_{3} \mathrm{CN}(1.94 \mathrm{ppm}): \delta=7.31(\mathrm{~d}, J=2.7 \mathrm{~Hz}, 1 \mathrm{H}), 6.97(\mathrm{~d}, J=2.7 \mathrm{~Hz}, 1 \mathrm{H})$, $3.90-3.73(\mathrm{~m}, 2 \mathrm{H}), 3.13(\mathrm{~s}, 6 \mathrm{H}), 3.00-2.93(\mathrm{~m}, 2 \mathrm{H}), 2.87(\mathrm{ddd}, J=13.3,8.1,5.0 \mathrm{~Hz}, 1 \mathrm{H})$, $2.77(\mathrm{dt}, J=13.9,4.4 \mathrm{~Hz}, 1 \mathrm{H}), 2.70(\mathrm{~s}, 3 \mathrm{H}) .{ }^{13} \mathrm{C} \mathrm{NMR}(150 \mathrm{MHz}), \mathrm{CD}_{3} \mathrm{CN}(118.26 \mathrm{ppm}): \delta$ $=197.43,161.14,129.91,129.27,127.52,124.42,118.56,63.39,62.28,60.05,57.46,56.75$, 51.02. Infrared $v(\mathrm{CO})\left(\mathrm{cm}^{-1}\right): 1855,1873,2007$. ESI-MS (in MeCN): calc. for $\left[\mathrm{C}_{15} \mathrm{H}_{17} \mathrm{Cl}_{2} \mathrm{~N}_{2} \mathrm{O}_{4} \mathrm{Re}+\mathrm{H}\right]^{+}$: 547.0, found: 547.0. Elemental analysis calc. (\%) for $\mathrm{C}_{15} \mathrm{H}_{17} \mathrm{Cl}_{2} \mathrm{~N}_{2} \mathrm{O}_{4} \mathrm{Re}$ (546.42): C 32.97, H 3.14, N 5.12; found: C 32.98, H 3.20, N 5.10.

\section{X-ray crystal structure determination of $\mathrm{L}^{1} \operatorname{Re}(\mathrm{CO})_{3}$}

$\mathrm{C}_{15} \mathrm{H}_{19} \mathrm{~N}_{2} \mathrm{O}_{4} \mathrm{Re}, \mathrm{FW}=477.52$, colorless needle, $0.53 \times 0.09 \times 0.07 \mathrm{~mm}^{3}$, monoclinic, $\mathrm{P} 2{ }_{1} / \mathrm{c}$ (no. 14), $\mathrm{a}=14.6069(6), \mathrm{b}=8.8710(4), \mathrm{c}=12.0927(8) \AA, \beta=90.801(3)^{\circ}, \mathrm{V}=1566.80(14) \AA^{3}, \mathrm{Z}$ $=4, \mathrm{D}_{\mathrm{x}}=2.024 \mathrm{~g} / \mathrm{cm}^{3}, \mu=7.78 \mathrm{~mm}^{-1}$. The diffraction experiment was performed on a Bruker Kappa ApexII diffractometer with sealed tube and Triumph monochromator $(\lambda=0.71073 \AA)$ at a temperature of $150(2) \mathrm{K}$ up to a resolution of $(\sin \theta / \lambda)_{\max }=0.65 \AA^{-1}$. The crystal appeared to be cracked, with a rotation angle of $3.0^{\circ}$ between the two crystal fragments. Consequently, two orientation matrices were used for the intensity integration with the Eval15 software ${ }^{[26]}$. A multi-scan absorption correction and scaling was performed with TWINABS ${ }^{[27]}$ (correction range $0.17-0.43)$. A total of 54428 reflections was measured, 3685 reflections were unique $\left(\mathrm{R}_{\text {int }}\right.$ $=0.050), 3281$ reflections were observed $[\mathrm{I}>2 \sigma(\mathrm{I})]$. The structure was solved with Patterson superposition methods using SHELXT ${ }^{[28]}$. Structure refinement was performed with SHELXL$2018^{[29]}$ on $\mathrm{F}^{2}$ of all reflections based on an HKLF-5 file ${ }^{[30]}$. Non-hydrogen atoms were refined freely with anisotropic displacement parameters. All hydrogen atoms were located in difference Fourier maps and refined with a riding model. 203 Parameters were refined with no restraints. R1/wR2 [I > 2 $\sigma(\mathrm{I})$ ]: 0.0354 / 0.0886. R1/wR2 [all refl.]: $0.0406 / 0.0913$. BASF for the two crystal fragments refined to zero. $\mathrm{S}=1.054$. Residual electron density between -3.15 and 3.40 $\mathrm{e} / \AA^{3}$ (in the proximity of the metal). Geometry calculations and checking for higher symmetry was performed with the PLATON program. ${ }^{[31]}$

\section{X-ray crystal structure determination of $\mathrm{L}^{3} \operatorname{Re}(\mathrm{CO})_{3}$}

$\mathrm{C}_{15} \mathrm{H}_{18} \mathrm{~N}_{3} \mathrm{O}_{6} \mathrm{Re}, \mathrm{Fw}=522.52$, yellow needle, $0.42 \times 0.09 \times 0.03 \mathrm{~mm}^{3}$, orthorhombic, Pbca (no. 61), $a=8.90063(16), b=11.9803(3), c=31.8099(7) \AA, V=3391.95(13) \AA^{3}, Z=8, D_{x}=2.046$ $\mathrm{g} / \mathrm{cm}^{3}, \mu=7.20 \mathrm{~mm}^{-1}$. The diffraction experiment was performed on a Bruker Kappa ApexII diffractometer with sealed tube and Triumph monochromator $(\lambda=0.71073 \AA)$ at a temperature of $150(2) \mathrm{K}$ up to a resolution of $(\sin \theta / \lambda)_{\max }=0.65 \AA^{-1}$. Intensity integration was performed 
with the Eval15 software ${ }^{[26]}$. A numerical absorption correction and scaling was performed with SADABS $^{[27]}$ (correction range 0.30-0.91). A total of 52093 reflections was measured, 3901 reflections were unique $\left(\mathrm{R}_{\text {int }}=0.069\right), 3027$ reflections were observed $[\mathrm{I}>2 \sigma(\mathrm{I})]$. The structure was solved with Patterson superposition methods using SHELXT ${ }^{[28]}$. Structure refinement was performed with SHELXL-2018 ${ }^{[29]}$ on $\mathrm{F}^{2}$ of all reflections. Non-hydrogen atoms were refined freely with anisotropic displacement parameters. All hydrogen atoms were introduced in calculated positions and refined with a riding model. 229 Parameters were refined with no restraints. R1/wR2 [I > 2 $\sigma(\mathrm{I})$ ]: $0.0229 / 0.0403 . \mathrm{R} 1 / \mathrm{wR} 2$ [all refl.]: $0.0402 / 0.0443 . \mathrm{S}=1.028$. Residual electron density between -0.64 and $1.14 \mathrm{e} / \AA^{3}$. Geometry calculations and checking for higher symmetry was performed with the PLATON program. ${ }^{[31]}$

\section{X-ray crystal structure determination of $\mathrm{L}^{4} \operatorname{Re}(\mathrm{CO})_{3}$}

$\mathrm{C}_{23} \mathrm{H}_{35} \mathrm{~N}_{2} \mathrm{O}_{4} \mathrm{Re}, \mathrm{Fw}=589.73$, colorless plate, $0.43 \times 0.20 \times 0.06 \mathrm{~mm}^{3}$, monoclinic, $\mathrm{C} 2 / \mathrm{c}$ (no. $15), a=23.9270(7), b=9.4928(3), c=22.1646(7) \AA, \beta=106.575(2)^{\circ}, V=4825.2(3) \AA^{3}, Z=$ $8, D_{\mathrm{x}}=1.624 \mathrm{~g} / \mathrm{cm}^{3}, \mu=5.07 \mathrm{~mm}^{-1}$. The diffraction experiment was performed on a Bruker Kappa ApexII diffractometer with sealed tube and Triumph monochromator $(\lambda=0.71073 \AA)$ at a temperature of $150(2) \mathrm{K}$ up to a resolution of $(\sin \theta / \lambda)_{\max }=0.65 \AA^{-1}$. Intensity integration was performed with the Eval15 software ${ }^{[26]}$. A numerical absorption correction and scaling was performed with $\mathrm{SADABS}^{[27]}$ (correction range 0.26-0.80). A total of 43450 reflections was measured, 5540 reflections were unique $\left(\mathrm{R}_{\text {int }}=0.084\right), 4228$ reflections were observed $[\mathrm{I}>2 \sigma(\mathrm{I})]$. The structure was solved with Patterson superposition methods using SHELXT ${ }^{[28]}$. Structure refinement was performed with SHELXL-2018 ${ }^{[29]}$ on $\mathrm{F}^{2}$ of all reflections. Non-hydrogen atoms were refined freely with anisotropic displacement parameters. All hydrogen atoms were introduced in calculated positions and refined with a riding model. 280 Parameters were refined

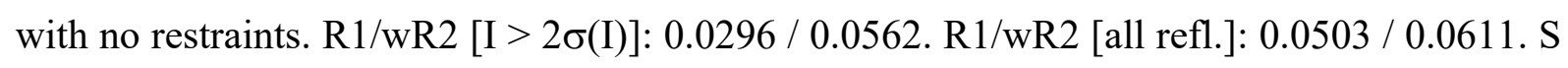
$=1.012$. Residual electron density between -0.60 and $1.16 \mathrm{e} / \AA^{3}$. Geometry calculations and checking for higher symmetry was performed with the PLATON program. ${ }^{[31]}$

CCDC 1978458-1978460 contain the supplementary crystallographic data for this paper. These data can be obtained free of charge from The Cambridge Crystallographic Data Centre via www.ccdc.cam.ac.uk/data_request/cif.

\subsubsection{General procedures for catalysis}




\section{General procedure for catalytic deoxydehydration using $\mathrm{PhCl}$ as solvent}

1,2-octanediol $(0.5 \mathrm{mmol}), \mathrm{L}^{1} \operatorname{Re}(\mathrm{CO})_{3}(0.01 \mathrm{mmol})$, reductant $(0.55 \mathrm{mmol})$, and mesitylene $(0.5 \mathrm{mmol})$ were dissolved in chlorobenzene $(5 \mathrm{~mL})$ and mixed well, the mixture was then transferred to a $25 \mathrm{~mL}$ thick-walled glass pressure tube (Ace) fitted with a Teflon screw-cap. Then, the closed reaction vessel was brought into a preheated silicone oil bath at $180^{\circ} \mathrm{C}$. After the reaction, aliquots of the reaction mixture were diluted with acetone (for both olefin and diol analysis). GC measurements were performed using a Perkin Elmer Autosystem XL Gas Chromatograph equipped with a Perkin Elmer Elite-17 column (Length: 30m, I.D.: $0.32 \mathrm{~mm}$, Film thickness: $0.50 \mu \mathrm{m}$ ), and with FID-detector. GC method: $40{ }^{\circ} \mathrm{C}, 5 \mathrm{~min} ; 3^{\circ} \mathrm{C} / \mathrm{min}$ to $55^{\circ} \mathrm{C}$; $20{ }^{\circ} \mathrm{C} / \mathrm{min}$ to $250{ }^{\circ} \mathrm{C} ; 250{ }^{\circ} \mathrm{C}, 10 \mathrm{~min}$. All olefinic products are known compounds and were calibrated against mesitylene for quantification.

\section{General procedure for catalytic deoxydehydration using alcohol as solvent}

Diols or polyols $(0.5 \mathrm{mmol}), \mathrm{LRe}(\mathrm{CO})_{3} / \mathrm{BrRe}(\mathrm{CO})_{5}(0.01 \mathrm{mmol})$ and mesitylene $(0.5 \mathrm{mmol})$ were dissolved in an alcohol $(5 \mathrm{~mL})$, the mixture was then transferred to a $25 \mathrm{~mL}$ thick-walled glass pressure tube (Ace) fitted with a Teflon screw-cap. The closed reaction vessel was brought into a preheated silicone oil bath at $155^{\circ} \mathrm{C}$ or $180^{\circ} \mathrm{C}$. The suspension became a homogeneous solution during heating. The amount of $\mathrm{O}_{2}$ present in the reaction set-up was calculated as follows: volume of gas phase $=$ total volume of reaction tube $(25 \mathrm{~mL})-$ total volume of reaction mixture $(5 \mathrm{~mL})=20 \mathrm{~mL}$. The percentage of $\mathrm{O} 2$ in air is apporx. $20 \%$; accordingly the volume of $\mathrm{O}_{2}$ would be $20 / 5=4 \mathrm{~mL}$. The amount of $\mathrm{O}_{2}$ would be $4 \mathrm{~mL} /(22.4 \mathrm{~mL} / \mathrm{mmol})=0.178 \mathrm{mmol}$. After the reaction, the reaction vessel was opened under ambient conditions and an aliquot $(\sim 0.1$ $\mathrm{mL})$ of the reaction mixture was taken, diluted with $\mathrm{CDCl}_{3}(\sim 0.4 \mathrm{~mL})$ and analyzed by ${ }^{1} \mathrm{H} \mathrm{NMR}$. Peaks of the olefin product were used to calculate the yield (listed below). ${ }^{1} \mathrm{H}$ NMR peak of internal standard (mesitylene) (400 MHz, $\mathrm{CDCl}_{3}$ ): $\delta 6.78$ (s, $3 \mathrm{H}$, used for calculation), 2.28 (s, $9 \mathrm{H})$.

\begin{tabular}{|l|l|l|l|}
\hline entry & product & structure & ${ }^{1} \mathrm{H} \mathrm{NMR}\left(\mathrm{CDCl}_{3}, 400 \mathrm{MHz}\right)$ \\
\hline 1 & 1 -octene & & $\delta 1.00-0.81(\mathrm{~m}, 3 \mathrm{H}), 1.50-$ \\
& & & $1.18(\mathrm{~m}, 8 \mathrm{H}), 2.11-1.98(\mathrm{~m}$, \\
& & $2 \mathrm{H}), 5.09-4.86(\mathrm{~m}, 2 \mathrm{H}), 5.82$ \\
& & $(\mathrm{ddt}, J=16.9,10.2,6.7 \mathrm{~Hz}$, \\
& & $1 \mathrm{H})$. \\
\hline
\end{tabular}




\begin{tabular}{|c|c|c|c|}
\hline 2 & 1-dodecene & $\curvearrowright /$ & $\begin{array}{l}\delta 0.77(\mathrm{t}, J=7.4 \mathrm{~Hz}, 1 \mathrm{H}), 2.03 \\
(\mathrm{dtt}, J=7.6,6.0,1.9 \mathrm{~Hz}, 2 \mathrm{H}), \\
4.91(\mathrm{ddt}, J=10.1,2.2,1.3 \mathrm{~Hz}, \\
1 \mathrm{H}), 4.98(\mathrm{dq}, J=17.1,1.8 \mathrm{~Hz}, \\
1 \mathrm{H}), 5.80(\mathrm{ddt}, J=16.9,10.2, \\
6.7 \mathrm{~Hz}, 1 \mathrm{H}),) \text {, other signals } \\
\text { overlapped with the signal of } \\
\text { the solvent. }\end{array}$ \\
\hline 3 & styrene & & $\begin{array}{l}\delta 5.22(\mathrm{dd}, J=10.9,0.9 \mathrm{~Hz}, \\
1 \mathrm{H}), 5.73(\mathrm{dd}, J=17.6,0.9 \mathrm{~Hz}, \\
1 \mathrm{H}), 6.70(\mathrm{dd}, J=17.6,10.9 \\
\mathrm{Hz}, 1 \mathrm{H}), 7.26-7.19(\mathrm{~m}, 1 \mathrm{H}), \\
7.34-7.27(\mathrm{~m}, 2 \mathrm{H}), 7.41- \\
7.36(\mathrm{~m}, 2 \mathrm{H}) .\end{array}$ \\
\hline 4 & cyclohexene & & $\begin{array}{l}\delta 1.98(\mathrm{tt}, J=3.9,2.0 \mathrm{~Hz}, 2 \mathrm{H}) \text {, } \\
5.65(\mathrm{t}, J=1.6 \mathrm{~Hz}, 2 \mathrm{H}) \text {, the } \\
\text { other two signals overlapped } \\
\text { with the signal of solvent. }\end{array}$ \\
\hline 5 & allyl alcohol & & $\begin{array}{l}\delta 4.10(\mathrm{~d}, J=5.1 \mathrm{~Hz}, 2 \mathrm{H}), 5.11 \\
(\mathrm{dd}, J=10.4,1.5 \mathrm{~Hz}, 1 \mathrm{H}), 5.25 \\
(\mathrm{dd}, J=17.2,1.7 \mathrm{~Hz}, 1 \mathrm{H}), 5.97 \\
(\mathrm{ddt}, J=17.0,10.2,5.1 \mathrm{~Hz}, \\
1 \mathrm{H}) .\end{array}$ \\
\hline 6 & 2,5-dihydrofuran & & $\delta 5.87(\mathrm{~s}, 2 \mathrm{H}), 4.62(\mathrm{~s}, 4 \mathrm{H})$ \\
\hline 7 & 1,3-butadiene & $\widehat{\gamma / 1}$ & $\begin{array}{l}\delta 5.14-5.02(\mathrm{~m}, 2 \mathrm{H}), 5.26- \\
5.15(\mathrm{~m}, 2 \mathrm{H}), 6.40-6.25(\mathrm{~m}, \\
2 \mathrm{H}) .\end{array}$ \\
\hline 8 & $\begin{array}{l}\text { 1,4-anhydrothreitol } \\
\text { (racemic) }\end{array}$ & HO" & $\begin{array}{l}\delta 4.02(\mathrm{dd}, 2 \mathrm{H}, J=12 \mathrm{~Hz}, 8 \\
\mathrm{Hz}), 4.15(\mathrm{~m}, 2 \mathrm{H}), 3.76(\mathrm{~d}, J= \\
10.0 \mathrm{~Hz}, 2 \mathrm{H})\end{array}$ \\
\hline
\end{tabular}




\begin{tabular}{|c|c|c|c|}
\hline 9 & $\begin{array}{l}\text { fumaric acid and } \\
\text { fumarates }\end{array}$ & $\prod_{0}$ & $\begin{array}{l}\text { Peaks at } 6.80,6.82 \text {, and } 6.84 \\
\text { ppm were observed. Because } \\
\text { of the overlap of acid, } \\
\text { monofumarate, } \\
\text { bisfumuarete signals, the total } \\
\text { value of these three was } \\
\text { counted as } 2 \mathrm{H} \text {. The aliphatic } \\
\text { signals overlapped with the } \\
\text { signal of the solvent. }\end{array}$ \\
\hline 10 & muconates & $\mathrm{HOOC} \leadsto \prod_{\mathrm{O}}^{\mathrm{O}} \mathrm{Y}_{\mathrm{Et}}^{\mathrm{C}_{5} \mathrm{H}_{11}}$ & $\begin{array}{l}\delta 6.41-6.09(\mathrm{~m}, 2 \mathrm{H}), 7.56- \\
7.19(\mathrm{~m}, 2 \mathrm{H}) . \text { The aliphatic } \\
\text { signals overlapped with the } \\
\text { signal of the solvent. }\end{array}$ \\
\hline 11 & furan & $\left|\|^{0}\right\rangle$ & $\delta 7.41(\mathrm{~s}, 2 \mathrm{H}), 6.36(\mathrm{~s}, 2 \mathrm{H})$ \\
\hline 12 & 2-vinylfuran & $|-\rangle$ & $\begin{array}{l}\delta 5.18(\mathrm{dd}, 1 \mathrm{H}, J=11.3,1.3 \\
\mathrm{Hz}), 5.69(\mathrm{dd}, 1 \mathrm{H}, J=17.5,1.3 \\
\mathrm{Hz}), 6.31-6.25(\mathrm{~m}, 1 \mathrm{H}), 6.39 \\
(\mathrm{dd}, 1 \mathrm{H}, J=3.3,1.9 \mathrm{~Hz}), 6.53 \\
(\mathrm{dd}, 1 \mathrm{H}, J=17.5,11.3 \mathrm{~Hz}), \\
7.40-7.34(\mathrm{~m}, 1 \mathrm{H})\end{array}$ \\
\hline
\end{tabular}

\subsection{References}

[1] P. Lanzafame, G. Centi, S. Perathoner, Chem. Soc. Rev. 2014, 43, 7562-7580.

[2] E. P. Ahern, P. Deane, T. Persson, O. Brian, Renew. Energy 2015, 78, 648-656.

[3] D. M. Alonso, J. Q. Bond, J. A. Dumesic, Green Chem. 2010, 12, 1493-1513.

[4] A. Corma Canos, S. Iborra, A. Velty, Chem. Rev. 2007, 107, 2411-2502.

[5] T. A. Bender, J. A. Dabrowski, M. R. Gagné, Nat. Rev. Chem. 2018, 2, 35-46.

[6] M. Schlaf, Dalt. Trans. 2006, 4645-4653.

[7] L. L. Adduci, M. P. McLaughlin, T. A. Bender, J. J. Becker, M. R. Gagné, Angew. Chem. Int. Ed. 2014, 53, 1646-1649.

[8] T. J. Korstanje, E. F. De Waard, J. T. B. H. Jastrzebski, R. J. M. K. Gebbink, ACS Catal. 2012, 2, 2173-2181.

[9] S. Raju, M. E. Moret, R. J. M. Klein Gebbink, ACS Catal. 2015, 5, 281-300.

[10] J. R. Dethlefsen, P. Fristrup, ChemSusChem 2015, 8, 767-775. 
[11] L. J. Donnelly, S. P. Thomas, J. B. Love, Chem. Asian J. 2019, 14, 3782-3790.

[12] E. Arceo, J. A. Ellman, R. G. Bergman, J. Am. Chem. Soc. 2010, 132, 11408-11409.

[13] S. Raju, C. A. M. R. Van Slagmaat, J. Li, M. Lutz, J. T. B. H. Jastrzebski, M. E. Moret, R. J. M. Klein Gebbink, Organometallics 2016, 35, 2178-2187.

[14] D. G. Lonnon, S. B. Colbran, D. C. Craig, Eur. J. Inorg. Chem. 2006, 2006, 1190-1197.

[15] M. Toganoh, N. Harada, H. Furuta, Polyhedron 2013, 52, 1153-1158.

[16] C. Hansch, A. Leo, R. W. Taft, Chem. Rev. 1991, 91, 165-195.

[17] J. Yi, S. Liu, M. M. Abu-Omar, ChemSusChem 2012, 5, 1401-1404.

[18] M. Shiramizu, F. D. Toste, Angew. Chemie.Int. Ed. 2012, 51, 8082-8086.

[19] C. Boucher-Jacobs, K. M. Nicholas, ChemSusChem 2013, 6, 597-599.

[20] M. Shiramizu, F. D. Toste, Angew. Chemie. Int. Ed. 2013, 52, 12905-12909.

[21] J. Li, M. Lutz, M. Otte, R. J. M. Klein Gebbink, ChemCatChem 2018, 10, 4755-4760.

[22] S. Raju, J. T. B. H. Jastrzebski, M. Lutz, R. J. M. Klein Gebbink, ChemSusChem 2013, 6, 1673-1680.

[23] X. Li, D. Wu, T. Lu, G. Yi, H. Su, Y. Zhang, Angew. Chemie - Int. Ed. 2014, 53, 4200-4204.

[24] X. Li, Y. Zhang, ChemSusChem 2016, 9, 2774-2778.

[25] M. Lupacchini, A. Mascitti, V. Canale, L. Tonucci, E. Colacino, M. Passacantando, A. Marrone, N. Alessandro, Catal. Sci. Technol. 2019, 9, 3005-3296.

[26] A. M. M. Schreurs, X. Xian, L. M. J. Kroon-Batenburg. J. Appl. Cryst. 2010. 43, 70-82.

[27] G. M. Sheldrick (2014). TWINABS. Universität Göttingen, Germany.

[28] G. M. Sheldrick. Acta Cryst. 2015. A71, 3-8.

[29] G. M. Sheldrick. Acta Cryst. 2015. C71, 3-8.

[30] R. Herbst-Irmer, G. M. Sheldrick. Acta Cryst. 1998. B54, 443-449.

[31] A. L. Spek. Acta Cryst. 2009. D65, 148-155. 


\section{Summary}

Because of the depletion of fossil fuel resources as well as their gradual increase in cost, the development of new supply chains for the chemical industry that rely on renewable feedstocks, such as biomass, is highly required. These biomass-derived feedstocks are typically highoxygen content and over-functionalized, which makes their application quite challenging. In order to address this problem, different reduction strategies, e.g., hydrodeoxygenation, hydrogenolysis, decarbonylation, decarboxylation, or direct deoxygenation, are currently investigated. Deoxydehydration, which combines deoxygenation and dehydration, reduces two vicinal hydroxyl groups in a diol or polyol to the correspoding olefin, offering an effcient way to realize biomass conversion and upgrading. Metal complexes, in particular rhenium, molybdenum, and vanadium complexes, have been reported as catalysts for deoxydehydration (DODH) of diols and biomass derived polyols.

Chapter 1 of this thesis provides a general description of homogeneous transition metalcatalyzed DODH reactions of diols and polyols. Catalytic deoxydehydration systems using high valent rhenium complexes, i.e., Cp-based trioxo-rhenium complexes, methyltrioxorhenium, perrhenates, and perrhenic acid, as catalysts are summarized in the first section of this chapter. Triphenylphosphine $\left(\mathrm{PPh}_{3}\right)$, secondary alcohols, sulfites, hydroaromatic reductants, and element reductants are widely applied as sacrificial reducing agents for these DODH systems. High to excellent olefin yields and substrate conversions can be obtained by these Re-catalyzed DODH systems when diols are used as substrates. For biomass-derived polyol substrates, moderate to high olefin yields can be achieved. In addition, mechanistic studies based on experimental observations or explored by density functional theory (DFT) calculations are also described in this section. Three fundamental steps are typically involved in the catalytic cycle, that is, the reduction of a $\mathrm{Re}=\mathrm{O}$ motif, the condensation of the diol and a $\mathrm{Re}=\mathrm{O}$ moiety forming a Re-diolate, and olefin extrusion from the Re-diolate. The order of $\mathrm{Re}=\mathrm{O}$ reduction and diol condensation mainly depends on the combination of catalyst, reductant, and substrate. Except for high valent rhenium catalysts, low valent rhenium pre-catalysts are also descried. In the second section of this chapter, molybdenum-based catalysts are described. Unlike the rheniumbased catalysts, only a limited number of Mo-based DODH catalysts have been investigated. Moderate olefin yields are typically obtained in these Mo-catalyzed DODH systems, due to side reactions, such as diol dehydration and oxidative $\mathrm{C}-\mathrm{C}$ bond cleavage of diols. Last but not 
the least, catalytic DODH systems using vanadium complexes as catalysts and their mechanistic studies based on DFT calculations are documented in the third and last section of the introduction chapter. Overall, this chapter shows the development of homogeneous transition metal-catalyzed deoxydehydration systems as well as the corresponding mechanistic studies.

In Chapter 2, the Cp-based trioxo-rhenium complex $\mathrm{Cp}^{\text {tt }} \mathrm{ReO}_{3} \quad\left(\mathrm{Cp}^{\text {tt }}=1,3\right.$-di-tertbutylcyclopentadienyl) is investigated as catalyst for the DODH of diols and polyols. Initial reactions were performed with $2 \mathrm{~mol} \% \mathrm{Cp}^{\mathrm{tt}} \mathrm{ReO}_{3}$ at $135^{\circ} \mathrm{C}$ in chlorobenzene and 1.1 equiv. of a sacrificial reducing agent under an inert nitrogen atmosphere. Both the $\mathrm{PPh}_{3}$ and 3-octanol reductants give high olefin yields. Considering that the chlorobenzene solvent is neither green nor good at dissolving polar biomass-derivatives, 3-octanol was then chosen as the solvent and reducing agent in subsequent $\mathrm{DODH}$ reactions with $\mathrm{Cp}^{\mathrm{tt}} \mathrm{ReO}_{3} . \mathrm{Cp}^{\mathrm{tt}} \mathrm{ReO}_{3}$ not only initiates the catalytic conversion of a variety of vicinal diols into olefins at high yields, but also exhibits an excellent DODH activity for biomass-derived polyols. Specifically, when using $\mathrm{Cp}^{\mathrm{tt}} \mathrm{ReO}_{3}$ as catalyst, mucic acid gives $75 \%$ of muconates at $91 \%$ conversion (Scheme 1, a) and glycerol is almost quantitively converted to allyl alcohol. Besides, the loading of $\mathrm{Cp}^{\mathrm{tt}} \mathrm{ReO} \mathrm{O}_{3}$ can be reduced to $0.1 \mathrm{~mol} \%$ to achieve a turn-over number as high as 900 per Re in the DODH of glycerol, indicating a rather stable active species (Scheme 1, b).

a.
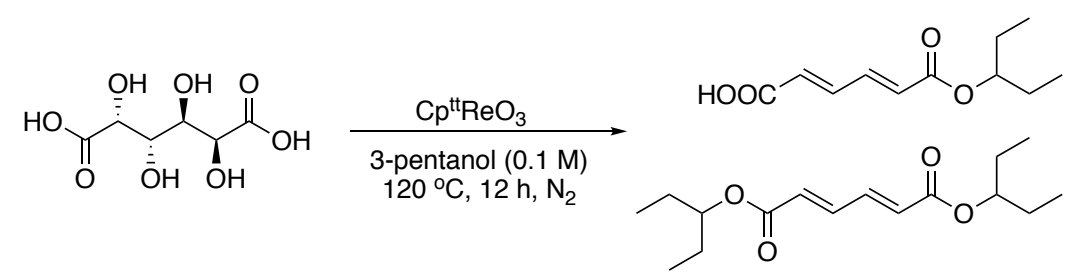

b. yield: $75 \%$, conversion: $91 \%$

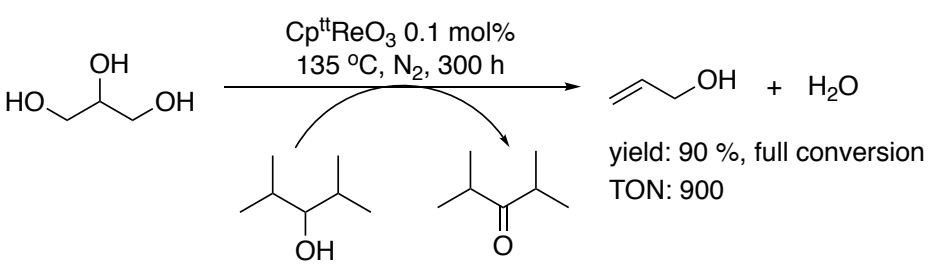

Scheme 1. $\mathrm{Cp}^{\mathrm{tt}} \mathrm{ReO}_{3}$-catalyzed DODH of biomass-derived polyols.

Time course profile experiments have shown ligand dissociation during DODH reactions with different substituted $\mathrm{Cp}^{\prime} \mathrm{ReO}_{3}$ complexes $\left(\mathrm{Cp}^{\prime}=\right.$ substituted $\mathrm{Cp}$ ligand) including $\mathrm{Cp}^{\mathrm{tt}} \mathrm{ReO}_{3}$. In addition, ligand dissociation seems to be related to (initial) catalytic activity. These observations raise questions on the nature of the active species in DODH catalysis, on the role of the Cp' ligand in catalysis, and in a more general sense on the relation between the Cp' ligand structure and the stability of the corresponding $\mathrm{Cp}^{\prime} \mathrm{ReO}_{3}$ complexes. Comparison with 
perrhenate salts seems to rule out a simple and purely inorganic active species in DODH catalysis using $\mathrm{Cp}^{\prime} \mathrm{ReO}_{3}$ complexes.

In Chapter 3, two new tetradentate $\mathrm{N}_{2} \mathrm{Py}_{2}$ ligand supported $\mathrm{ReO}_{2}^{+}$complexes, cis$\left[(\mathrm{BPMEN}) \mathrm{ReO}_{2}\right] \mathrm{PF}_{6}$ and $c i s-\left[\left(\mathrm{B}^{\mathrm{mdm}} \mathrm{PMEN}\right) \mathrm{ReO}_{2}\right] \mathrm{PF}_{6}$, are synthesized and characterized (Scheme 2). Along with the complexes cis-[( S,S-BPBP) $\left.\mathrm{ReO}_{2}\right] \mathrm{PF}_{6}$ and trans-[(Py) $\left.\mathrm{ReO}_{2}\right] \mathrm{PF}_{6}$, these N-donor ligand-supported dioxo-rhenium complexes were investigated as catalyst for the DODH of 1,2-octanediol using $\mathrm{PPh}_{3}$ as reductant and $\mathrm{PhCl}$ as solvent. Quantitative 1-octene yields can be obtained with all the complexes. However, kinetic studies showed an induction period for the $\left[\left(\mathrm{N}_{2} \mathrm{Py}_{2}\right) \mathrm{ReO}_{2}\right]^{+}$catalyzed reaction, while no induction period was observed with trans-[( $\left.\left.\mathrm{Py}_{4}\right) \mathrm{ReO}_{2}\right] \mathrm{PF}_{6}$; in the latter case the reaction is done within $15 \mathrm{~min}$ when a $10 \mathrm{~mol} \%$ catalyst loading is applied. ESI-MS measurements then showed the presence of protonated $\mathrm{N}_{2} \mathrm{Py}_{2}$ ligand and $\mathrm{ReO}_{4}^{-}$in a DODH reaction mixture of $c$ is-[(BPMEN) $\left.\mathrm{ReO}_{2}\right] \mathrm{PF}_{6}$, suggesting that the perrhenate anion is the active species in $\left[\left(\mathrm{N}_{2} \mathrm{Py}_{2}\right) \mathrm{ReO}_{2}\right]^{+}$catalyzed DODH reactions. Under the same reaction conditions, a much shorter induction period was observed when using pyridinium perrhenate as catalyst. Yet, the reaction rate of this catalyst is slower than the one of trans-[(Py4) $\left.\mathrm{ReO}_{2}\right] \mathrm{PF}_{6}$, which in turn suggests the involvement of another active species.

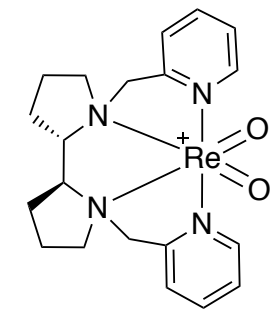

cis-[(S,S-BPBP)ReO $]^{+}$

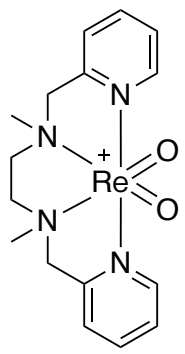

cis-[(BPMEN)ReO $]^{+}$cis- $\left[\left(\mathrm{B}^{\mathrm{mdm}} \mathrm{PMEN}\right) \mathrm{ReO}_{2}\right]^{+}$
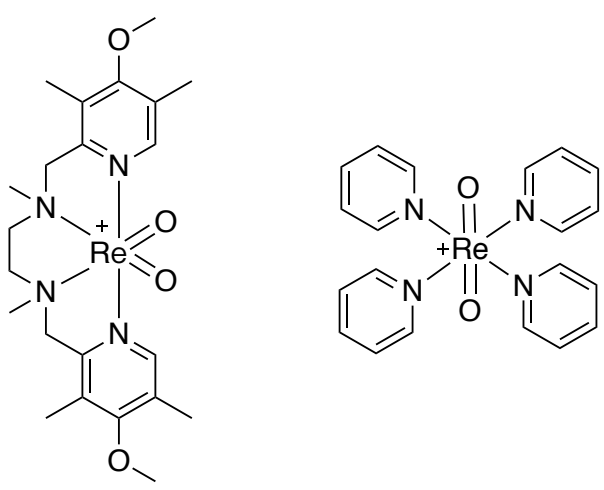

trans-[(Py $\left.) \mathrm{ReO}_{2}\right]^{+}$

Scheme 2. Tetradentate $\mathrm{N}_{2} \mathrm{Py}_{2}$ and monodentate pyridine supported $\mathrm{ReO}_{2}{ }^{+}$complexes.

Treating cis-[(BPMEN) $\left.\mathrm{ReO}_{2}\right] \mathrm{BPh}_{4}$ with an excess amount of water regenerates a rhenium species without coordinated $\mathrm{N}_{2} \mathrm{Py}_{2}$ ligand. The rhenium-based product of this reaction shows catalytic activity in the DODH of 1,2-octanediol and shows a much shorter induction period than the originating Re-complex. A similar reaction rate and final 1-octene yield are obtained for these two DODH reaction, indicating that the pristine cis-[(BPMEN) $\left.\mathrm{ReO}_{2}\right] \mathrm{BPh}_{4}$ complex and its "water-treated" product form the same active species. Based on IR analysis, it is proposed that a rhenium-oxide/hydroxide oligomer is formed in DODH reactions catalyzed by $\mathrm{N}_{2} \mathrm{Py}_{2}$ ligand supported $\mathrm{ReO}_{2}{ }^{+}$complexes, induced by $\mathrm{N}_{2} \mathrm{Py}_{2}$ ligand dissociation. The 
remarkably high catalytic activity of trans- $\left[\left(\mathrm{Py}_{4}\right) \mathrm{ReO}_{2}\right] \mathrm{PF}_{6}$ can, accordingly, be explained by the more facile dissociation of monodentate pyridine ligands. The substrate scope of trans$\left[\left(\mathrm{Py}_{4}\right) \mathrm{ReO}_{2}\right] \mathrm{PF}_{6}$ was then investigated for the DODH of diols and biomass-derived polyols, showing the versatility of this rather simple pre-catalyst.

The scarcity and high cost of rhenium asks for the availability of alternative catalysts based on less expensive metals, such as Mo and V. In Chapter 4, $\left[\mathrm{Cp}^{*} \mathrm{MoO}_{2}\right]_{2} \mathrm{O}$ is explored as catalyst for the DODH of diols. Initially, molybdenum sources, such as $\left[\mathrm{Cp}^{*} \mathrm{MoO}_{2}\right]_{2} \mathrm{O},\left[\mathrm{Cp}^{\mathrm{tt}} \mathrm{MoO}_{2}\right]_{2} \mathrm{O}$, $\mathrm{NBu}_{4}\left[\mathrm{Cp}^{*} \mathrm{MoO}_{3}\right],\left(\mathrm{Me}_{3} \mathrm{tacn}\right) \mathrm{MoO}_{3}, \mathrm{MoO}_{2}(\mathrm{acac})_{2}$, and $\left(\mathrm{NH}_{4}\right)_{6} \mathrm{Mo}_{7} \mathrm{O}_{24} \cdot 4 \mathrm{H}_{2} \mathrm{O}$, were investigated for the DODH of 1,2-octanediol using $\mathrm{PPh}_{3}$ as reductant, and anisole as solvent at $200{ }^{\circ} \mathrm{C}$ for $15 \mathrm{~h}$ under $\mathrm{N}_{2}$. Among these, the highest 1-octene yield is obtained using $\left[\mathrm{Cp}^{*} \mathrm{MoO}_{2}\right]_{2} \mathrm{O}$. Screening of the reductant, solvent, and reaction temperature then led to optimized reaction conditions involving $4 \mathrm{~mol} \%\left[\mathrm{Cp}^{*} \mathrm{MoO}_{2}\right]_{2} \mathrm{O}$ as catalyst (based on Mo), 1.1 equiv. $\mathrm{PPh}_{3}$ as reductant, and anisole $(0.1 \mathrm{M})$ as a benign solvent at $200{ }^{\circ} \mathrm{C}$ for $15 \mathrm{~h}$ under $\mathrm{N}_{2}$. The olefin product selectivity using these conditions is only $55 \%$ because of the side reactions occurring in this reaction system, i.e., dehydration and oxidative cleavage of the substrate. The carbonyl compounds formed in these side reactions can further react with the diol substrate to generate ketals causing further substrate consumption. The $\left[\mathrm{Cp}^{*} \mathrm{MoO}_{2}\right]_{2} \mathrm{O}$ catalyst is able to convert both linear and cyclic aliphatic diols into the corresponding olefins, albeit with moderate product yields ranging from 22 to $56 \%$. Attempts to extend the substrate scope to aromatic diols lead to $47 \%$ of styrene formation when starting from 1-phenyl-1,2-ethanediol, but gave benzaldehyde as the only detectable product in case of 1,2-diphenylethane-1,2-diol.

Mechanistic studies have detected $\left[\mathrm{Cp}^{*} \mathrm{MoO}_{2}\right]_{2}$ as one of the reduction products arising from $\left[\mathrm{Cp}^{*} \mathrm{MoO}_{2}\right]_{2} \mathrm{O}$. While $\left[\mathrm{Cp}^{*} \mathrm{MoO}_{2}\right]_{2}$ was found to engage in a stoichiometric condensation reaction with a diol substrate and the subsequent olefin extrusion step, the catalytic activity of $\left[\mathrm{Cp}^{*} \mathrm{MoO}_{2}\right]_{2}$ is much lower than that of $\left[\mathrm{Cp}^{*} \mathrm{MoO}_{2}\right]_{2} \mathrm{O}$. Along with the observation of zeroorder reaction kinetics and of a second reduction product $\mathbf{X}$ arising from $\left[\mathrm{Cp}^{*} \mathrm{MoO}_{2}\right]_{2} \mathrm{O}$, an alternative reaction pathway was proposed in which $\left[\mathrm{Cp}^{*} \mathrm{MoO}_{2}\right]_{2}$ is an off-cycle species and the unidentified reduction product is involved in catalytic turn-over (Scheme 3). 


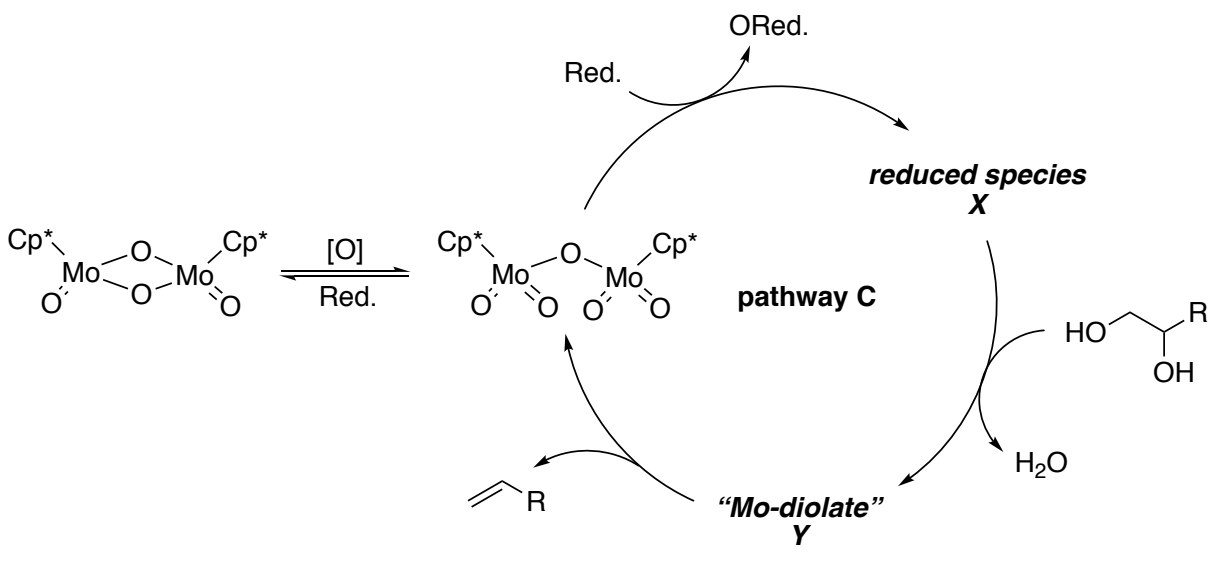

Scheme 3 Proposed catalytic cycle of $\left[\mathrm{Cp}^{*} \mathrm{MoO}_{2}\right]_{2} \mathrm{O}$-catalyzed DODH reactions involving $\left[\mathrm{Cp}^{*} \mathrm{MoO}_{2}\right]_{2}$ is an off-cycle species.

Finally, in Chapter 5 a series of $\mathrm{LRe}(\mathrm{CO})_{3}$ complexes $\quad(\mathrm{LH}=$ substituted 2-(((2(dimethylamino)ethyl)(methyl)amino)methyl)phenol) are synthesized and characterized (Scheme 4). Structural characterization of complexes $\mathrm{L}^{1} \mathrm{Re}(\mathrm{CO})_{3}, \mathrm{~L}^{3} \mathrm{Re}(\mathrm{CO})_{3}$, and $\mathrm{L}^{4} \mathrm{Re}(\mathrm{CO})_{3}$ by single crystal X-Ray analysis shows the overall octahedral geometry of these complexes with the tripodal N,N,O-ligand coordinated to rhenium in a facial manner.

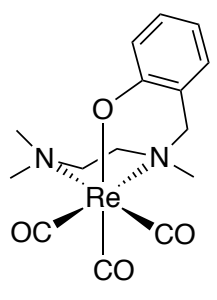

$\mathrm{L}^{1} \operatorname{Re}(\mathrm{CO})_{3}$

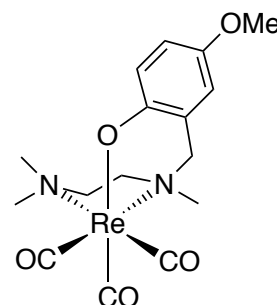

$\mathrm{L}^{2} \operatorname{Re}(\mathrm{CO})_{3}$

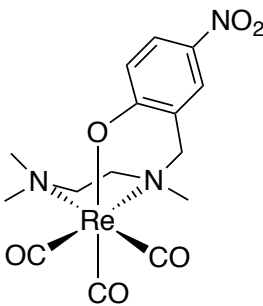

$\mathrm{L}^{3} \mathrm{Re}(\mathrm{CO})_{3}$

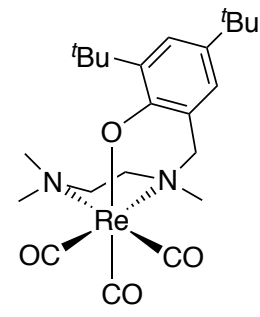

$\mathrm{L}^{4} \mathrm{Re}(\mathrm{CO})_{3}$

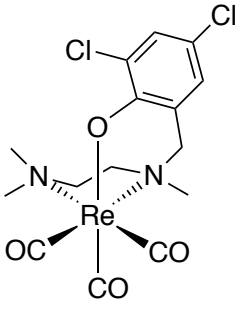

$\mathrm{L}^{5} \operatorname{Re}(\mathrm{CO})_{3}$

Scheme 4. (NNO)tricarbonylrhenium complexes in chapter 5.

These low valent $\mathrm{LRe}(\mathrm{CO})_{3}$ complexes were tested in DODH catalysis under aerobic conditions, assuming that the complexes would be oxidized in situ to the corresponding high-valent Retrioxo complexes. Using 3-octanol as both reductant and solvent, all five complexes are active as DODH pre-catalysts and among these the di-tert-butyl-substituted complex $\mathrm{L}^{4} \mathrm{Re}(\mathrm{CO})_{3}$ shows the highest catalytic activity. A substrate screening using $\mathrm{L}^{4} \operatorname{Re}(\mathrm{CO})_{3}$ showed that it is active in the DODH of both aliphatic and aromatic vicinal diols, as well as biomass-derived glycerol and polyols to provide the corresponding olefins in good yields. The application of $\mathrm{L}^{4} \operatorname{Re}(\mathrm{CO})_{3}$ to sugar substrates leads to the preferential formation of 2-vinylfuran, instead of the usual non-substituted furan product. This unusual product distribution indicates that the active 
species generated from $\mathrm{L}^{4} \mathrm{Re}(\mathrm{CO})_{3}$ could be different from the ones generated by Re-trioxo systems.

Compared to the $\mathrm{Cp}$-based trioxo rhenium complexes previously reported by us, the new NNObased $\operatorname{Re}(\mathrm{CO})_{3}$ pre-catalysts are much more easy to handle. Not only are the NNO-ligands easy to prepare and modify, the low-yielding oxidation from $\operatorname{Re}(\mathrm{I})$ to $\operatorname{Re}(\mathrm{VII})$ of the (pre)catalyst is avoided and the $\mathrm{LRe}(\mathrm{CO})_{3}$ systems are air stable at room temperature, while the $\mathrm{Cp}^{\prime} \mathrm{ReO}_{3}$ systems need to be stored at low temperature or under $\mathrm{N}_{2}$. In view of these considerations, these new NNO-based Re-tricarbonyl (pre)catalysts are interesting alternatives for high-valent Retrioxo systems in DODH chemistry.

In conclusion, this thesis describes several different catalytic systems for the catalytic deoxydehydration of diols and polyols, with the aim to either discover new (pre)catalyst for DODH catalysis or to investigate catalyst evolution under catalytic conditions. 


\section{Samenvatting}

Vanwege de uitputting en de daarmee gepaard gaande geleidelijke stijging van de kostprijs van fossiele grondstoffen is de ontwikkeling van nieuwe toeleveringsketens voor de chemische industrie, gebaseerd op hernieuwbare grondstoffen zoals biomassa, van groot belang. Deze van biomassa afgeleide grondstoffen hebben doorgaans een hoog zuurstofgehalte en bevatten veel functionele groepen in vergelijking met fossiele grondstoffen, wat hun toepassing behoorlijk uitdagend maakt. Om dit probleem aan te pakken worden verschillende reductiestrategieën onderzocht, waaronder hydrodeoxygenering, hydrogenolyse, decarbonylering, decarboxylering of directe deoxygenering. Deoxydehydratatie (DODH) reacties, die deoxygenatie en dehydratatie combineren, reduceren twee vicinale hydroxylgroepen in een diol of polyol tot het corresponderende olefine, wat een efficiënte manier is om biomassaconversie en -opwaardering te realiseren. DODH-reacties van zowel diolen als van biomassa afgeleide polyolen kunnen gekatalyseerd worden door metaalcomplexen gebaseerd op renium, molybdeen en vanadium.

Hoofdstuk 1 van dit proefschrift geeft een algemene beschrijving van homogene, overgangsmetaal-gekatalyseerde DODH-reacties van diolen en polyolen. DODH-katalysatoren gebaseerd op hoog-valente renium-complexen, d.w.z. cyclopentadienyltrioxo-reniumcomplexen, methyltrioxorenium, perrenaten en perrenium zuur, zijn samengevat in het eerste deel van dit hoofdstuk. In het algemeen worden trifenylfosfine $\left(\mathrm{PPh}_{3}\right)$, secundaire alcoholen, sulfieten, hydroaromatische reductiemiddelen en elementaire reductiemiddelen toegepast als reductiemiddelen in combinatie met deze katalysatoren. Hoge tot uitstekende olefineopbrengsten en substraatconversies kunnen worden verkregen met deze Re-gebaseerde DODHkatalysatoren wanneer vicinale diolen als substraat gebruikt worden. Met biomassa-afgeleide polyolsubstraten worden redelijke tot hoge olefine-opbrengsten bereikt. Daarnaast beschrijft dit deel ook mechanistische studies aan deze katalysatoren op basis van experimentele waarnemingen en dichtheidsfunctionaaltheorie (DFT)-berekeningen. Drie fundamentele stappen zijn typisch betrokken bij de katalytische cyclus: de reductie van een $\mathrm{Re}=\mathrm{O}$-motief, de condensatie van het diol en een $\mathrm{Re}=\mathrm{O}$-restgroep waarbij een $\mathrm{Re}$-diolaat gevormd wordt, en een olefine-extrusie stap vanuit het Re-diolaat. De volgorde van de $\mathrm{Re}=\mathrm{O}$-reductie en diolcondensatie hangt voornamelijk af van de combinatie van katalysator, reductiemiddel en substraat. Behalve hoog-valente reniumkatalysatoren worden ook laag-valente renium prekatalysatoren beschreven. In het tweede deel van dit hoofdstuk worden katalysatoren op basis van molybdeen beschreven. In tegenstelling tot de op renium-gebaseerde katalysatoren is 
slechts een beperkt aantal op Mo-gebaseerde DODH-katalysatoren onderzocht. Redelijke olefine-opbrengsten worden typisch verkregen met deze Mo-katalysatoren als gevolg van nevenreacties, zoals dehydratatie van diolen en oxidatieve $\mathrm{C}-\mathrm{C}$-splitsing van diolen. Tenslotte zijn katalytische DODH-katalysatoren gebaseerd op vanadium en studies op basis van DFTberekeningen naar het mechanisme van deze V-katalysatoren beschreven in het derde en laatste deel van het inleidende hoofdstuk. Samenvattend toont dit hoofdstuk de ontwikkeling van homogene overgangsmetaal-gekatalyseerde DODH-reacties en de bijbehorende mechanistische studies.

In Hoofdstuk 2 wordt het trioxo-reniumcomplex $\mathrm{Cp}^{\text {tt }} \mathrm{ReO}_{3} \quad\left(\mathrm{Cp}^{\text {tt }}=1,3\right.$-di-tertbutylcyclopentadienyl) onderzocht als katalysator voor de DODH van diolen en polyolen. De eerste reacties werden uitgevoerd met $2 \mathrm{~mol} \% \mathrm{Cp}^{\mathrm{tt}} \mathrm{ReO}_{3}$ bij $135{ }^{\circ} \mathrm{C}$ in chloorbenzeen en 1.1 equiv. van een reductiemiddel onder een inerte stikstofatmosfeer. Zowel de reductiemiddelen $\mathrm{PPh}_{3}$ als 3-octanol geven hoge olefine-opbrengsten. Aangezien het oplosmiddel chloorbenzeen noch groen noch goed is in het oplossen van polaire biomassa-derivaten, werd vervolgens gekozen voor 3-octanol als oplosmiddel en reductiemiddel in daaropvolgende DODH-reacties met $\mathrm{Cp}^{\mathrm{tt}} \mathrm{ReO}_{3}$. $\mathrm{Cp}^{\mathrm{tt}} \mathrm{ReO}_{3}$ initieert niet alleen de katalytische omzetting van verschillende vicinale diolen in olefinen met hoge opbrengsten, maar vertoont ook een uitstekende DODHactiviteit voor uit biomassa afgeleide polyolen. M.b.v. $\mathrm{Cp}^{\mathrm{tt}} \mathrm{ReO}_{3}$ als katalysator kan galactaarzuur, ook bekend als slijmzuur, omgezet worden in $75 \%$ muconzure esters bij een conversie van 91\% (Schema 1, a) en wordt glycerol bijna kwantitatief omgezet in allylalcohol. Bovendien kan de belading van $\mathrm{Cp}^{\text {tt }} \mathrm{ReO}_{3}$ worden verlaagd tot 0.1 mol\% om een omzettingsgetal van wel 900 per Re in de DODH van glycerol te bereiken, wat wijst op een vrij stabiele katalysator (Schema 1, b).

a.
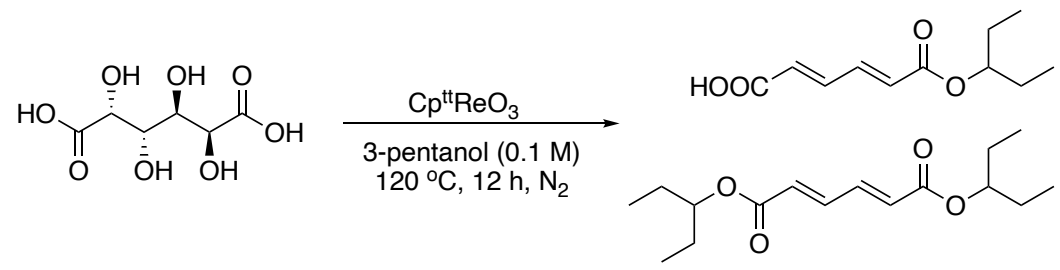

b. opbrengst: $75 \%$, conversie: $91 \%$

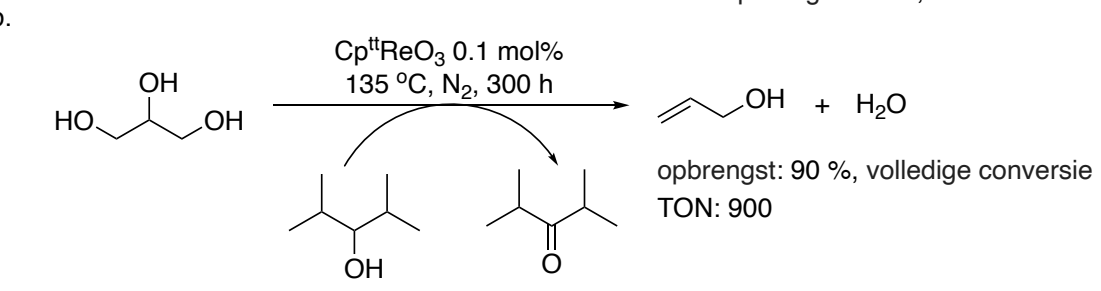

Schema 1. $\mathrm{Cp}^{\text {tt }} \mathrm{ReO}_{3}$-gekatalyseerde DODH van biomassa-afgeleide polyolen. 
Kinetische experimenten wezen vervolgens op ligand-dissociatie tijdens DODH-reacties met verschillende gesubstitueerde $\mathrm{Cp}^{\prime} \mathrm{ReO}_{3}$-complexen $\left(\mathrm{Cp}{ }^{\prime}=\right.$ gesubstitueerd $\mathrm{Cp}$-ligand $)$, waaronder $\mathrm{Cp}^{\text {tt }} \mathrm{ReO}_{3}$. Daarnaast lijkt ligand-dissociatie gerelateerd te zijn aan de (initiële) katalytische activiteit. Deze waarnemingen werpen vragen op over de aard van de actieve katalysator in DODH-reacties, over de rol van het Cp'-ligand in de katalyse, en in meer algemene zin over de relatie tussen de Cp'-ligandstructuur en de stabiliteit van de overeenkomstige $\mathrm{Cp}^{\prime} \mathrm{ReO}_{3}$ complexen. Een vergelijking met perrenaatzouten lijkt een eenvoudige en puur anorganische katalysatorvorm in DODH-katalyse met $\mathrm{Cp}^{\prime} \mathrm{ReO}_{3}$ complexen uit te sluiten.

In Hoofdstuk 3 worden twee nieuwe $\mathrm{ReO}_{2}{ }^{+}$-complexen gebaseerd op tetradentate $\mathrm{N}_{2} \mathrm{Py}_{2}$ liganden, $\quad c i s-\left[\left(\mathrm{BPMEN}^{\mathrm{R}} \mathrm{ReO}_{2}\right] \mathrm{PF}_{6}\right.$ en $\quad c i s-\left[\left(\mathrm{B}^{\mathrm{mdm}} \mathrm{PMEN}\right) \mathrm{ReO}_{2}\right] \mathrm{PF}_{6}$ gesynthetiseerd en gekarakteriseerd (Schema 2). Samen met de complexen cis-[(S,S-BPBP) $\left.\mathrm{ReO}_{2}\right] \mathrm{PF}_{6}$ en trans$\left[\left(\mathrm{Py}_{4}\right) \mathrm{ReO}_{2}\right] \mathrm{PF}_{6}$, zijn deze N-donor-gebaseerde dioxo-renium complexen onderzocht als katalysator voor de $\mathrm{DODH}$ van 1,2 -octaandiol met $\mathrm{PPh}_{3}$ als reductiemiddel en $\mathrm{PhCl}$ als oplosmiddel. Met alle complexen werden kwantitatieve opbrengsten van 1-octeen verkregen. Kinetische experimenten lieten echter een inductieperiode zien voor de $\left[\left(\mathrm{N}_{2} \mathrm{Py}_{2}\right) \mathrm{ReO}_{2}\right]^{+}-$ gekatalyseerde reacties, terwijl er geen inductieperiode werd waargenomen met trans$\left[\left(\mathrm{Py}_{4}\right) \mathrm{ReO}_{2}\right] \mathrm{PF}_{6}$; in het laatste geval is de reactie binnen $15 \mathrm{~min}$. compleet wanneer een katalysatorbelading van $10 \mathrm{~mol} \%$ wordt toegepast. ESI-MS metingen toonden vervolgens de aanwezigheid van geprotoneerd $\mathrm{N}_{2} \mathrm{Py}_{2}$-ligand en $\mathrm{ReO}_{4}{ }^{-}$aan in een DODH-reactiemengsel van cis-[(BPMEN) $\left.\mathrm{ReO}_{2}\right] \mathrm{PF}_{6}$, wat suggereert dat het perrenaat anion de actieve katalysator is in $\left[\left(\mathrm{N}_{2} \mathrm{Py}_{2}\right) \mathrm{ReO}_{2}\right]^{+}$gekatalyseerde DODH reacties. Onder dezelfde reactieomstandigheden werd een veel kortere inductieperiode waargenomen bij gebruik van pyridinium perrenaat als katalysator. Toch is de reactiesnelheid van deze katalysator langzamer dan die van trans$\left[\left(\mathrm{Py}_{4}\right) \mathrm{ReO}_{2}\right] \mathrm{PF}_{6}$, wat de betrokkenheid van een andere actieve katalysator suggereert.

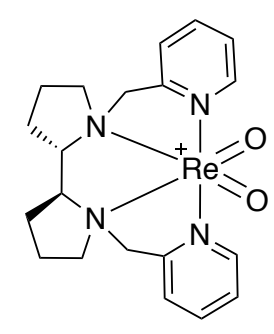

cis-[(S,S-BPBP)ReO $]^{+}$

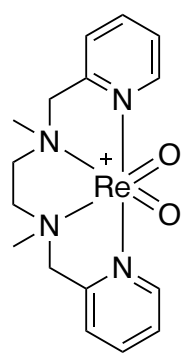

cis-[(BPMEN)ReO $]^{+}$

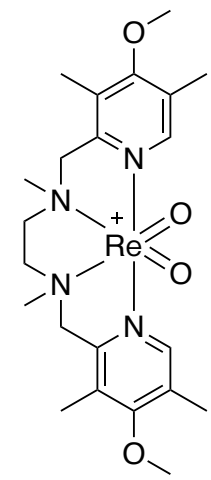

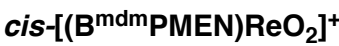

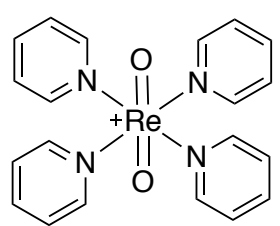

trans- $\left[\left(\mathrm{Py}_{4}\right) \mathrm{ReO}_{2}\right]^{+}$

Schema 2. $\mathrm{ReO}_{2}{ }^{+}$complexen gebaseerd op tetradentate $\mathrm{N}_{2} \mathrm{Py}_{2}$ en monodentate pyridine liganden. 
Behandeling van cis-[(BPMEN) $\left.\mathrm{ReO}_{2}\right] \mathrm{BPh}_{4}$ met een overmaat aan water regenereert een reniumproduct zonder gecoördineerd $\mathrm{N}_{2} \mathrm{Py}_{2}$-ligand. Het op renium gebaseerde product van deze reactie vertoont katalytische activiteit in de DODH van 1,2-octaandiol en vertoont een veel kortere inductieperiode dan het oorspronkelijke Re-complex. Een vergelijkbare reactiesnelheid en 1-octeen opbrengst worden verkregen voor deze twee DODH-reacties, wat aangeeft dat het oorspronkelijke cis-[(BPMEN) $\left.\mathrm{ReO}_{2}\right] \mathrm{BPh}_{4}$-complex en diens "met water behandelde" product tot dezelfde actieve katalysatorvorm leiden. Op basis van IR-analyse wordt voorgesteld dat een reniumoxide/hydroxide-oligomeer wordt gevormd in DODHreacties die worden gekatalyseerd door de $\mathrm{N}_{2} \mathrm{Py}_{2}-\mathrm{ReO}_{2}{ }^{+}$-complexen, geïnduceerd door $\mathrm{N}_{2} \mathrm{Py}_{2}-$ ligand-dissociatie. De opmerkelijk hoge katalytische activiteit van trans- $\left[\left(\mathrm{Py}_{4}\right) \mathrm{ReO}_{2}\right] \mathrm{PF}_{6} \mathrm{kan}$ zodoende worden verklaard door de eenvoudigere dissociatie van monodentate pyridineliganden. De katalytische DODH-activiteit van trans-[( $\left.\left.\mathrm{Py}_{4}\right) \mathrm{ReO}_{2}\right] \mathrm{PF}_{6}$ werd vervolgens onderzocht voor een serie diolen en van biomassa afgeleide polyolen, wat de veelzijdigheid van deze vrij eenvoudige prekatalysator aantoonde.

De schaarste en hoge kostprijs van renium vragen om de beschikbaarheid van alternatieve katalysatoren op basis van goedkopere metalen, zoals Mo en V. In Hoofdstuk 4 wordt $\left[\mathrm{Cp}^{*} \mathrm{MoO}_{2}\right]_{2} \mathrm{O}$ onderzocht als katalysator voor de DODH van diolen. Aanvankelijk werden molybdeenverbindingen, zoals $\left[\mathrm{Cp}^{*} \mathrm{MoO}_{2}\right]_{2} \mathrm{O},\left[\mathrm{Cp}^{\mathrm{tt}} \mathrm{MoO}_{2}\right]_{2} \mathrm{O}, \mathrm{NBu}_{4}\left[\mathrm{Cp}^{*} \mathrm{MoO}_{3}\right],\left(\mathrm{Me}_{3} \operatorname{tacn}\right)$ $\mathrm{MoO}_{3}, \mathrm{MoO}_{2}(\mathrm{acac})_{2}$ en $\left(\mathrm{NH}_{4}\right)_{6} \mathrm{Mo}_{7} \mathrm{O}_{24} \cdot 4 \mathrm{H}_{2} \mathrm{O}$ onderzocht voor de DODH van 1,2-octaandiol met $\mathrm{PPh}_{3}$ als reductiemiddel en anisol als oplosmiddel bij $200{ }^{\circ} \mathrm{C}$ gedurende 15 uur onder $\mathrm{N}_{2}$. Hierbij werd de hoogste opbrengst aan 1-octeen verkregen met $\left[\mathrm{Cp}^{*} \mathrm{MoO}_{2}\right]_{2} \mathrm{O}$. Screening van het reductiemiddel, oplosmiddel en reactietemperatuur leidde vervolgens tot geoptimaliseerde reactieomstandigheden waarbij $4 \mathrm{~mol} \% \quad\left[\mathrm{Cp}^{*} \mathrm{MoO}_{2}\right]_{2} \mathrm{O}$ als katalysator gebruikt wordt (gebaseerd op Mo), 1.1 equiv. $\mathrm{PPh}_{3}$ als reductiemiddel en anisol $(0.1 \mathrm{M})$ als een milieuvriendelijk oplosmiddel bij $200 \quad{ }^{\circ} \mathrm{C}$ gedurende 15 uur onder $\mathrm{N}_{2}$. De olefine productselectiviteit onder deze omstandigheden is slechts $55 \%$ vanwege de nevenreacties die optreden in dit reactiesysteem, d.w.z. dehydratatie en oxidatieve splitsing van het substraat. De carbonylverbindingen die bij deze nevenreacties worden gevormd kunnen verder reageren met het diolsubstraat om ketalen te genereren, leidend tot een niet-productieve substraatomzetting. De $\left[\mathrm{Cp}^{*} \mathrm{MoO}_{2}\right]_{2} \mathrm{O}$-katalysator kan zowel lineaire als cyclische alifatische diolen omzetten in de overeenkomstige olefinen, zij het met matige tot redelijke productopbrengsten van 22 tot $56 \%$. Pogingen om het substraatbereik uit te breiden tot aromatische diolen leidden tot $47 \%$ styreenvorming uitgaande van 1-fenyl-1,2-ethaandiol, maar leverden benzaldehyde op als het enige detecteerbare product in het geval van 1,2-difenylethaan-1,2- diol. 
In mechanistische studies werd $\left[\mathrm{Cp}^{*} \mathrm{MoO}_{2}\right]_{2}$ gedetecteerd als een van de reductieproducten die gevormd worden vanuit $\left[\mathrm{Cp}^{*} \mathrm{MoO}_{2}\right]_{2} \mathrm{O}$. Hoewel $\left[\mathrm{Cp}^{*} \mathrm{MoO}_{2}\right]_{2}$ in staat is een stoichiometrische condensatiereactie met een diolsubstraat en de daaropvolgende olefine-extrusiestap uit te voeren, is de katalytische activiteit van $\left[\mathrm{Cp}^{*} \mathrm{MoO}_{2}\right]_{2}$ veel lager dan die van $\left[\mathrm{Cp}^{*} \mathrm{MoO}_{2}\right]_{2} \mathrm{O}$. Naast de observatie van de nulde-orde reactiekinetiek en van een tweede reductieproduct $\mathbf{X}$ dat voortkomt uit $\left[\mathrm{Cp}^{*} \mathrm{MoO}_{2}\right]_{2} \mathrm{O}$, werd een alternatief mechanisme voor de DODH-reactie met $\left[\mathrm{Cp}^{*} \mathrm{MoO}_{2}\right]_{2} \mathrm{O}$ voorgesteld waarin $\left[\mathrm{Cp}^{*} \mathrm{MoO}_{2}\right]_{2}$ zich buiten de katalytische cyclus bevindt en het niet-geïdentificeerde reductieproduct betrokken is bij de katalytische omzetting (Schema 3).

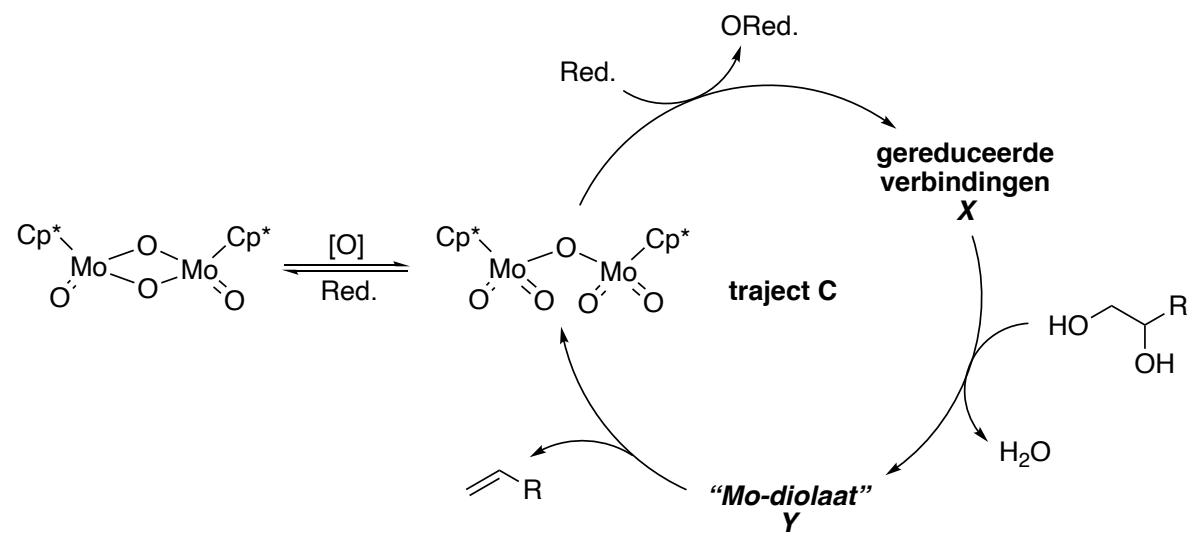

Schema 3 De voorgestelde katalytische cyclus van $\left[\mathrm{Cp}^{*} \mathrm{MoO}_{2}\right]_{2} \mathrm{O}$-gekatalyseerde DODH-reacties, waarbij $\left[\mathrm{Cp}^{*} \mathrm{MoO}_{2}\right]_{2}$ niet betrokken is in de cyclus.

Tenslotte wordt in Hoofdstuk 5 een reeks LRe(CO) $)_{3}$-complexen $(\mathrm{LH}=$ gesubstitueerde 2-(( (2(dimethylamino)ethyl)(methyl)amino)methyl)fenol) gesynthetiseerd en gekarakteriseerd (Schema 4). Structurele karakterisering van de complexen $\mathrm{L}^{1} \operatorname{Re}(\mathrm{CO})_{3}, \mathrm{~L}^{3} \operatorname{Re}(\mathrm{CO})_{3}$ en $\mathrm{L}^{4} \mathrm{Re}(\mathrm{CO})_{3}$ door röntgenanalyse toont de algehele octaëdrische geometrie van deze complexen met het tripodale $\mathrm{N}, \mathrm{N}, \mathrm{O}-$ ligand gecoördineerd aan renium op een faciale manier.

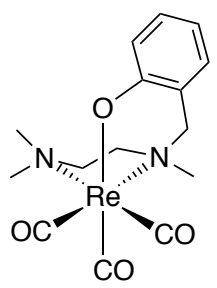

$\mathrm{L}^{1} \mathrm{Re}(\mathrm{CO})_{3}$

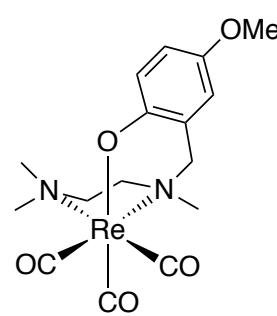

$\mathrm{L}^{2} \operatorname{Re}(\mathrm{CO})_{3}$

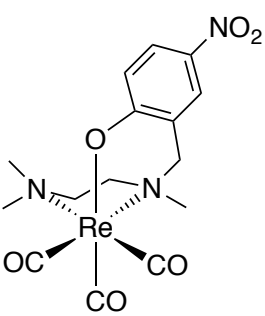

$\mathrm{L}^{3} \operatorname{Re}(\mathrm{CO})_{3}$

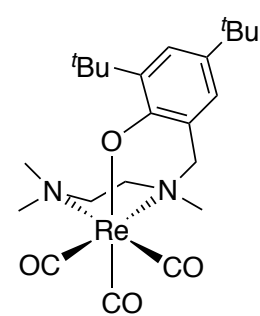

$\mathrm{L}^{4} \mathrm{Re}(\mathrm{CO})_{3}$

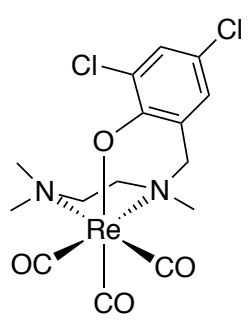

$\mathrm{L}^{5} \operatorname{Re}(\mathrm{CO})_{3}$

Schema 4. (NNO)tricarbonylrenium complexen beschreven in hoofdstuk 5. 
Deze laag-valente $\operatorname{LRe}(\mathrm{CO})_{3}$-complexen werden getest in DODH-katalyse onder aërobe omstandigheden, ervan uitgaande dat de complexen in situ zouden worden geoxideerd tot de overeenkomstige hoog-valente Re-trioxo-complexen. Gebruikmakend van 3-octanol als reductiemiddel en oplosmiddel, zijn alle vijf complexen actief als DODH-prekatalysator en van deze complexen vertoont het di-tert-butylgesubstitueerde complex $\mathrm{L}^{4} \mathrm{Re}(\mathrm{CO})_{3}$ de hoogste katalytische activiteit. Een substraatonderzoek met $\mathrm{L}^{4} \mathrm{Re}(\mathrm{CO})_{3}$ toonde aan dat het actief is in de DODH van zowel alifatische als aromatische vicinale diolen, evenals van glycerol en van biomassa afgeleide polyolen om de overeenkomstige olefinen met goede opbrengsten te verkrijgen. De toepassing van $\mathrm{L}^{4} \operatorname{Re}(\mathrm{CO})_{3}$ op suikersubstraten leidt tot de preferentiële vorming van 2-vinylfuraan, in plaats van het gebruikelijke niet-gesubstitueerde furaanproduct. Deze ongebruikelijke productverdeling geeft aan dat de actieve katalysator die wordt gegenereerd uit $\mathrm{L}^{4} \mathrm{Re}(\mathrm{CO})_{3}$ anders is dan de katalysatoren die worden gegenereerd door Re-trioxo-systemen.

Vergeleken met de Cp-gebaseerde trioxo-reniumcomplexen die eerder door ons zijn gerapporteerd, zijn de nieuwe $(\mathrm{NNO}) \operatorname{Re}(\mathrm{CO})_{3}$-prekatalysatoren veel gemakkelijker te hanteren. Niet alleen zijn de NNO-liganden gemakkelijk te synthetiseren en te modificeren, de synthesestap met de laagste opbrengst, nl. de oxidatie van het $\mathrm{Re}(\mathrm{I})$-carbonylcomplex naar het $\operatorname{Re}(\mathrm{VII})$-trioxocomplex, wordt vermeden. Daarnaast zijn de $\mathrm{LRe}(\mathrm{CO})_{3}$-systemen luchtstabiel bij kamertemperatuur, terwijl de $\mathrm{Cp}^{\prime} \mathrm{ReO}_{3}$-systemen moeten worden bewaard bij lage temperatuur of onder $\mathrm{N}_{2}$. Gezien deze overwegingen zijn deze nieuwe, op NNO-ligandengebaseerde Re-tricarbonyl (pre)katalysatoren interessante alternatieven voor de hoog-valente Re-trioxo-systemen in DODH-katalyse.

Concluderend beschrijft dit proefschrift verschillende katalytische systemen voor de katalytische deoxydehydratatie van diolen en polyolen, met als doel ofwel een nieuwe (pre)katalysator voor DODH-katalyse te ontdekken of om de katalysator-evolutie onder katalytische omstandigheden te onderzoeken. 


\section{Acknowledgements}

After four and half year of study, it's a great moment for me to look back at my $\mathrm{PhD}$ life in Utrecht and it's my honor to convey my sincere acknowledgements and respects to those people who have given me great help and contributions during this period.

First and foremost, I would like to give my sincere appreciation and gratitude to my promotor, prof. dr. Klein Gebbink. Dear Bert, thank you for giving me this opportunity to perform my $\mathrm{PhD}$ study in the OCC group at Utrecht; for helping me preparing the application of CSC scholarship; for providing me encouragement and support when I came up with my own research ideas, through which way I have been trained as an independent junior scientist; for enlightening me when I got lost during the research process; for offering me input and comments patiently while I was writing my thesis, making the stories of the thesis more readable and logical; for taking care of my personal life in The Netherlands, extending my contract to help me go through the hard period caused by the coronavirus. I benefitted a lot from our meetings and discussions as you shared your experience and knowledges from the field of chemistry with me, and gave me guidance towards the right direction of my project. All in all, thank you so much for all your support of my project and life in Utrecht.

Matthias, as my daily supervisor for the first year of my $\mathrm{PhD}$ project, your input was of great help for me to get familiar with the group and the lab. I greatly appreciate your contributions to my first project, that is the work of Chapter 2, and the contributions to the preparation and correlations of my first publication. I wish you all the best in your life!

Marc-Etienne, your wide knowledge in chemistry and critical thinking of my project helped me a lot, your nice suggestions during group meetings and work discussions were very useful. I greatly appreciated your help on my $\mathrm{PhD}$ project. Pieter, you joined the group at a later stage of my project, thank you very much for being a reading committee member of my thesis. Danny, your passion for chemistry and instant discovery of the problems are inspiring, thank you for your useful suggestions during group meetings and work discussions.

Additionally, I have received a lot of help and support from the OCC group during my $\mathrm{PhD}$ project. Johann, you are the expert of NMR measurements, thank you so much for your support 
on NMR measurements. Besides, you also gave me a lot of help related to computer issues, which I appreciate a lot. Jord and Thomas, thank you for ordering the chemicals and keeping the group running regularly. Besides, Thomas, thank you for organizing the Friday borrels, it's really a good way to refresh our brain; although I am not a big fan of beer. Henk, thank you for your help with ESI-MS measurements and GC instructions. Milka, your help in preparing visa and residential issues were essential at the beginning of my study in the Netherlands. Thank you for all your contributions. Silvia, thank you for setting the meetings in the group.

Except the colleagues from the OCC group, I would like to thank my collaborator, Dr. Martin Lutz. Thank you for analyzing the crystal structures for me, for preparing the experimental sections of my thesis, for your discussions and input for the X-ray structural analysis parts.

I was fortunate to have several motivated bachelor and master students joining my project. Arthur, Errikos, Jasper and Sofie, you dedicated to the work of chapter 4, working with some molybdenum chemistry, helping me making the very beautiful bright-yellow crystals. I am so happy that three of you continued your bachelor project in the OCC group. Arthur and Errikos, you also did your master project in the OCC group, nice choice! Jan, you continued the molybdenum project, not only doing some complexations, but also applying the complexes in catalysis. Thank you, Arthur, Errikos, Jasper, Sofie and Jan, for your essential studies as of chapter 4, I appreciate all your contributions! Rohald, you have joined the project on 'tuck-in' ligand synthesis and complexation with rhenium. Although you were not able to obtain the final ligand, it was still a good experience that you have tried some different chemistry. Elena, you were my only master student. You were trying to make the functionalized $\mathrm{Cp}$ ligand, which would then be used to realize catalyst immobilization. You are a hard-working student and good at making plans, I wish you all the best for your future!

Now it's time to thank all my awesome colleagues in OCC. I was so lucky to have you as my colleagues during my $\mathrm{PhD}$ project in Utrecht. I enjoyed the working conditions you have built up, as well as the after-working atmosphere. You are not only my colleagues, but also my friends! I have learnt a lot from you, for both science and life.

To the former OCC members: Jianming, you picked me up at the airport when I arrived in The Netherlands, and helped me a lot to get used to living here. In terms of science, we always discussed projects together although I did reduction while you were good at oxidation. I appreciate to all of your contributions to both my work and life here. I wish you all the best for your current work in Shenzhen and your future career! Pradip, you were always willing to help 
me with your wide knowledge of chemistry. Thank you very much for all of your help. I wish you all the best for your current work in Hamburg and your future career! Suresh, you have introduced me to the project of $\mathrm{Cp}$-based trioxo-rhenium catalyzed DODH at the beginning of my $\mathrm{PhD}$ study, thank you very much for training me how to use the glovebox and showing me how to perform the essential reactions of my project. I wish you all the best for your career. Alessio, you are a very humorous Italian guy, always trying to hide my Panda, and offering "your educations" to me. You have done very nice nickel chemistry, I wish you all the best for your career in Switzerland! Emma, thank you for telling me the rules of the lab and reminding me of small things related to safety issues. Léon, thank you for helping me with the lab work and also showing me how to prepare the scientific report for the $\mathrm{B} \& \mathrm{O}$ meeting in my first year. Bas, thank you for sharing your experiences in the lab when we worked in the same lab aisle. Adri, thank you for encouraging me during my first year when I was trying to get used to the English-speaking conditions, and telling me "don't be nervous" before work discussion. For the rest, Dide, Richard, Peter, Sipeng, Marco, Valeria, Massi, thank you all for your help during my $\mathrm{PhD}$ study.

To current OCC members: Emily, my paranymph, we have been together to Do! Days and we have memories of duck faces in front of tulip fields. You are always willing of helping people of the OCC group, you have a lot of duties for taking care of equipment in the lab and also organizing group events. At the very end of my thesis writing, we sometime had a short chat in the office, it's really a good way for me to release the stress, I appreciate all your contributions to both my research project and my life in Utrecht a lot. You will be the next one who will defend her thesis, good luck with your defense in advance. I wish you all the best for the rest of your $\mathrm{PhD}$ project. Eduard, my paranymph, we have been in the same office area for more than three and half years and we always discussed our projects with each other when we were facing problems in our projects. Thank you for sharing your nice oxidation chemistry with me and giving me nice suggestions. I wish you all the best for the rest of your $\mathrm{PhD}$ project. Pamela, my dear Italian friend, you always gave me hugs when I needed support and were willing to give me suggestions when I asked for help. I have very nice memories with you for both being roommates at NCCC and my last King's Day borrel. Many thanks for being my colleague and my friend, I wish you all the best for the rest of your PhD project. Maria, thank you for your Mexican gifts and also the Tequila for King's Day borrel. Jacco, thank you for your kindness and for writing the Dutch summary of this thesis. Pablo, thank you for bringing a gift for my panda and thank you for helping me taking care of the still systems. Fanshi and Fuqiang, thank you for helping me doing the house moving. For the rest, Cody, Roel, Jochem, Charl, Martine, Serhii, Carolien, Sander, Razvan, Wirawan, Tharun, Agneev, thank you all for your help 
in the lab and hope you all will enjoy the rest of your time in the OCC group!

I was lucky to meet many other people outside the group, I would like to thank all the Chinese friends in Utrecht: Yanna and Donglong, we arrived in The Netherlands almost the same time, we were the only three Chinese PhD students that year in the David de Wied building. Massive thanks for supporting me when I felt depressed, for sharing experiences of living in Utrecht and for traveling with me during holidays, we have a lot of impressive memories from this four and half years. I wish you two all the best for your future! Yanyan, many thanks to you for being my friend during the past two years, to help me doing the house moving, to share interesting things with me. I hope you will enjoy the rest of your time in Utrecht and wish you all the best for your PhD project! Lifeng and Minglong, thank you for preparing amazing Chinese dishes and organizing events to make life in Utrecht more colorful. Ying, Lemeng, Huiru, my previous flatmates, thank you all for your help when we lived together. Jie Z., my temporary neighbor, thank you for taking care of me when I was sick. Jie G., thank you for sharing your experience of living in The Netherlands when I just arrive here. For the rest, Wenjing, Haili, Jie S., Xin, Hao, Guangyun, Xianke, Dushen, Xuan, Zeshi, Xiangjie, thank you all for your help when I was in Utrecht, I wish you all the best for your future!

Last but not the least, I would like to give my immense thanks to my family. 最后, 我要把我 最忠心的感谢献给我的家人, 我的妈妈和我的爸爸, 谢谢你们的养育之恩, 谢谢你们 这些年对我的支持、理解和包容。儿行千里母担忧, 我感到非常愧疚这些年非但没能 尽孝左右, 还总是让你们担心我在外的安危。这篇论文是我远渡重洋学习的结果, 也 是我献给你们的礼物。 


\section{About the Author}

The author of this thesis was born on October 12, 1989, in Nantong City, Jiangsu Province, China. She grew up, and received primary and secondary education in the same city. After graduating from high school in 2008, she started to study biology at South China University of Technology, her major was biology engineering. After four- years of study, she obtained her BSc degree in 2012. Later on, she started her MSc program in chemistry engineering at University of Chinese Academy of Sciences, under the supervision of dr. Q. Zhu. The title of her MSc thesis was "Application of Functionalized Isocyanide in Palladium-Catalyzed Synthesis of $N$-Heterocycles". She obtained her MSc degree in 2015. From October in that same year, she moved to The Netherlands and started as a PhD student in the Organic Chemistry and Catalysis group at Utrecht University, under the supervision of prof. dr. R. J. M. Klein Gebbink. Her project was financially supported by the China Scholarship Council (CSC) Scholarship and the most important results of this project are presented in this thesis. Parts of this thesis have been presented at national and international conferences including the Netherlands' Catalysis and Chemistry Conference (NCCC), the Dutch chemistry conference CHAINS, the 22 ${ }^{\text {nd }}$ EuCheMS International Organometallic Conference (EuCOMC-22, 2017, Amsterdam, The Netherlands), the $21^{\text {st }}$ International Symposium on Homogeneous Catalysis (ISHC-21, 2018, Amsterdam, The Netherlands), and the $17^{\text {th }}$ Ferrocene Colloquium (2019, Rostock, Germany). 


\section{List of Publications}

Synthesis of Cyclopentadienyl-Based Trioxo-rhenium Complexes and Their Use as Deoxydehydration Catalysts

S. Raju, C. A. M. R. van Slagmaat, J. Li, M. Lutz, J. T. B. H. Jastrzebski, M.-E. Moret and R. J. M. Klein Gebbink. Organometallics, 2015, 35, 2178.

A C $\mathrm{p}^{\mathrm{tt}}$-Based Trioxo-Rhenium Catalyst for the Deoxydehydration of Diols and Polyols.

J. Li, M. Lutz, M. Otte, and R. J. M. Klein Gebbink. ChemCatChem., 2018, 10, 4755. (Chapter 2)

N,N,O-coordinated Tricarbonylrhenium Pre-catalysts for the Aerobic Deoxydehydration of Diols and Polyols

J. Li, M. Lutz, and R. J. M. Klein Gebbink. Catal. Sci. Technol. 2020, DOI: 10.1039/d0cy00618a

A Cp-based Molybdenum Catalyst for the Deoxydehydration of Biomass-derived Diols

J. Li, M. Lutz, and R. J. M. Klein Gebbink. in preparation. (Chapter 4)

N-Donor Ligand Supported " $\mathrm{ReO}_{2}{ }^{+}$": A Pre-Catalyst for the Deoxydehydration of Diols and Polyols

J. Li, M. Lutz, and R. J. M. Klein Gebbink. in preparation. (Chapter 3) 